

\title{
Iraqi Journal of Medical Sciences
}

\author{
Editorial Director \\ Professor ALAA G. HUSSIEN FICMS \\ Editor in-Chief \\ Professor WASEEM F. Al-TAMEEMI CABMS
}

\section{Editorial Secertary}

Lecturer MAJID H. AHMED PhD

\section{Executive Editorial Board}

$\begin{array}{ll}\text { Professor } & \text { HASAN A. AL-HAMADANI FICMS } \\ \text { Professor } & \text { HAIDER S. KADHIM PhD } \\ \text { Professor } & \text { ABDUL-KAREEM M. ALI CABP } \\ \text { Professor } & \text { HAYDER J. MOBARAK PhD } \\ \text { Professor } & \text { RAYAH S. BABAN PhD } \\ \text { Professor } & \text { WASAN I. AL-SAADI FICMS } \\ \text { Professor } & \text { AHMED R. ABU-RGHIF PhD } \\ \text { Assistant Professor } & \text { ATHEER J. AL-SAFFAR FICMS } \\ \text { Assistant Professor } & \text { TAQI S. ATIYAH FICMS } \\ \text { Assistant Professor } & \text { AHMAD S. ABDUL-AMEER PhD } \\ \text { Assistant Professor } & \text { ALI F. AL-HASHIMI PhD } \\ \text { Assistant Professor } & \text { BAN J. QASIM PhD }\end{array}$

Linguistic Editor

Lecturer NAWFAL K. SALIH CABS

Managing Editor

Lecturer KASIM SH. AL-MAYAH PhD

Secretary

Miss. ESRAA' S. NAJI

Mrs. ZAINAB A. HAMOODI 


\section{Editorial Board Members}

ABDULL HUSSEIN M. AL HADI , PhD

Emeriretus professor

(Health Cure Administration)

AHMED N.AL NIAMI ,MD

Asst. Professor

(Gynecologic Oncology)

ANAM R .AL SALIHI, PhD

Emeriretus Professor

(Anatomy)

BASSEM YAMOUT,MD

Professor

(Neurology)

FAIZ TUMA ,MD

Asst.Professor

(Surgery, Medical Education)

FARQAD B. HAMDAN ,PhD

Professor

(Neurophysiology)

GEORGY F. ARAJ ,PhD

Professor

(Microbiology)

GERAD M. GARDNER, MD

Asst. Professor

(Dermatology, Pathology)

IMAD M. AL ANI , PhD

Professor

(Histology, cell Biology)

LOAI A. A. AL SHAMAONY, PhD

Professor

(Biochimestry)

MARK R. WICK , MD

Professor

(Pathology)

MOHAMMED H. QARI, FRCPA

Professor

(Clinical Hematology)

Mohammed S. HAMEED , MRCP

Professor

(Clinical Hematology)

SALMAN M. MROUEH, MD

Professor

(Pediatric)

SHEREIN S. GHALB ,PhD

Professor

(Forensic Medicine, Clinical Toxicology)

TAHSEEN I . AL-SALEEM ,MD

Professor

(Pathology, Hematopathology)

TAREK . A. EL DIASTY ,PhD

Professor

(Radiology)
AL Nahrrain university, IRAQ

E.mail: ahalhadi@yahoo.com

University of Wisconsin ,USA

E.mail: alniaimi@ wisc.edu

AL Nahrain University, IRAQ

E.mail: anamalsalihi2015@yahoo.com

AUB, LEBANON

E.mail:yamoutba@idm.net.lb

Oklahoma university, US

E.mail: faiz-tuma@ouhsc.edu

AL Nahrain university, IRAQ

E.mail: farqadbhamdan@colmed-alnahrain.edu.iq

AUB,LEBANON

E.mail: garaj@aub.edu.lb

University of Arkansas, USA

E.mail:JMGardnerMD@gmail.com

International Islamic university, MALYSIA

E.mail: imad_alani@yahoo.com

Misr University ,EGYPT

E.mail: loaialshamaony@yahoo.com

Virgina University, USA

E.mail: Mrw9c@virginia.edu

King Abdul aziz University, SA

E.mail : drqari200@gmail.com

University Hospitals of north Midlands, LONDON

E.mail: mohammed.hameed@uhnm.nhs.uk

AUB, LEBANON

E.mail: smroueh@aub.edu.lb

Beni sueif university, EGYPT

E.mail:shr2002eg@yahoo.com

Fox chase cancer center, USA

Mansoura university, EGYPT

E.mail: teldiasty@hotmail.com 


\title{
Iraqi Journal of Medical Sciences
}

\author{
Atims and 8 cope
}

Iraqi Journal of Medical Sciences is published by College of Medicine, Al-Nahrain University. It is a quarterly multidisciplinary medical journal. High quality papers written in English, dealing with aspects of clinical, academic or investigative medicine or research will be welcomed. Emphasis is placed on matters relating to medicine in Iraq in particular and the Middle East in general, though articles are welcomed from anywhere in the world.

Iraqi Journal of Medical Sciences publishes original articles, case reports, and letters to the editor, editorials, investigative medicine, and review articles.

All articles published represent the opinions of the authors and do not reflect the policy of Iraqi Journal of Medical Sciences. All rights are reserved to Iraqi Journal of Medical Sciences. No part of the journal may be reproduced or transmitted in any form or by any means, electronic or mechanical, including photocopying, recording, or via any storage or retrieval system, without written permission from the journal.

\section{Mission of Iraqi JMS}

\section{Mission and Vision}

To establish rapid review processes aiming to puplish scientific papers that help to augment knowledge and highlight discoveries in the field of medical sciences

to be a world wide forum in assisting the distribution of medical reasearches to career readers

Vision of Iraqi JMS

To be pioneer national medical Journal interesting in increasing the understanding of diseases and treatment.

All correspondence and subscription information requests should be addressed to:

The Editor of Iraqi Journal of Medical Sciences

College of Medicine

Baghdad, Iraq

Tel. + 9647717516090

P.O.Box 70044, Kadhimiya, Baghdad, Iraq.

E-mail: iraqijms@colmed-alnahrain.edu.iq

http://www.iraqijms.net 


\title{
Iraqi JMS FORMAT
}

\author{
INSTRUCTION TO AUTHORS
}

Iraqi Journal of Medical Sciences (Iraqi JMS) is a periodic, peer-reviewed journal published quarterly by College of Medicine, Al-Nahrain University. Iraqi JMS publishes manuscripts in all fields of health and medicine written in English.

Types of Contributions: Original articles, review articles, case studies, editorials, medical education, history of medicine, ethics, practical points, medical quiz, conferences, meetings and letters to the Editor.

\section{Manuscripts:}

- Submission of a manuscript implies that is not being considered for publication anywhere.

- The author should provide the following:

A. A document officially state that the current work was carried out at the site, which provides the certification. The document should be signed by the highest authorized member at that location.

B. Document stated clearly that his current work is in agreement with the medical ethics provided either from the local ethical committee in the place where he did his work or from the Ministry of Health, Department of Training and Improving skill - Research and Educational facilities, the approval has to be stated separetly in the method section.

C. Publication fees are 80,000 IDs in addition to 20,000 IDs for checking of plagiarism. Other extra fees will be taken for extra pages (6000 dinars for each additional page (more than six pages) and up to 24000 IDs only).

- Manuscripts submitted to Iraqi JMS are subject to editorial evaluation and revision by three referees after being checked electronically for any plagiarism.

- The format of IJMS complies with the uniform requirements for manuscripts submitted to Biomedical Journals, published by the International Committee of Medical Journals Editors (ICMJE) (Vancouver, British Colombia, 1979) and its last update in October 2001, available on the web site www.icmje.org.

- Manuscript should be typewritten font size 14 , double spaced on size A4 $(29.5 \times 21 \mathrm{~cm})$ paper with wide margins and line- numbered. Page should be numbered consecutively. One original and three photocopies including figures, tables, and photographs should be submitted. Begin each of following sections on separate page in the following sequence: Title page, abstract and keywords, text, acknowledgments, references, tables, and legends for illustration.

- Manuscript and figures will not be returned to the authors whether the editorial decision is to accept, revise or reject.

- Manuscripts must be accompanied by a covering paper signed by all authors that the paper has not been published in and will not be submitted to any other journal if accepted in Iraqi JMS. 
- The title page should contain (a) title of the manuscript, (b) names of each author (first name, middle initial and family name) including highest academic degree, (c) official academic and/or clinical title and affiliation (d) name and address of the institution where the work was done (e) name and address (E-mail if available) of the author to whom correspondence should be sent.

- Authors can also submit the scientific publication through the official Iraqi JMS web site at (http://submit.Iraqijms.com/). Users must register when accessing the Iraqi JMS online submission system for the first time, by clicking on "Register." Three steps are involved in obtaining a personal account.

Abstract: Manuscript should include an abstract of not more than 250 words. Structured abstract typed on a separate sheet and consist of background, objective, method, results, and conclusion.

Keywords: Three to ten keywords should be provided on the same page as the abstract in English. As far as possible, be selected from the National Library of Medicine, Medical Subject Headings.

Manuscript format: It should be divided into the following parts: introduction, methods, results and discussion.

References: All references should be listed in consecutive numerical order by English numerical, in the order of citation in the text and each reference must be followed with its DOI link. Once a reference is cited all subsequent citations should be to the original number.

\section{Examples}

1. Standard Journal Article: use et al when the number of authors exceeds 3.

Halliwell B, Gutteridge JMC. Oxygen toxicity, Oxygen radicals, transition metals and disease. Biochem J. 1984; 219: 1-14.

2. Books: Mann JI, Pyorala K, and Teuscher A. Diabetes in epidemiological perspective. London: Churchill Livingstone; 1983. p. 1-5.

3. Chapter in book: Phillips SJ, and Whisnant JP. Hypertension and strock. In: Laragh JH, and Brenner BM. editors. Hypertension: Pathophysiology, diagnosis, and management. $2^{\text {nd }}$ ed. NewYork: Raven Press; 1995. p. 465-78.

\section{- How to find DOI for the references of your submitted article to Iraqi Lournal of Medical Sciences (IIMS)}

1. First, click on this link http://www.crossref.org/guestquery/

2. Go to "search on article title"

3. Fill in the author name and the title of the reference

4. Copy and paste the found DOI (if any: as some references have no DOI) to the end of each reference in the reference list in your article to be submitted to IJMS.

That's it!!

Tables: Each table should be typed on a separate page double-spaced, including all headings, number all tables with Arabic numerals and include a short title. Vertical lines between columns are to be avoided. 
Figures: All figures must be suitable for reproduction without being retouched or redrawn. Photographs must be supplied as glossy black and white prints. The top of the figures should be indicated clearly.

Legends: Captions for figures must be typed; double spaced, and must not appear on the figure.

Acknowledgments: Collate acknowledgments in a separate section at the end of the article before the references and do not, therefore, include them on the title page, as a footnote to the title or otherwise. List here those individuals who provided help during the research (e.g., providing language help, writing assistance or proof reading the article, etc.).

Conflict of interest: All authors must disclose any financial and personal relationships with other people or organisations that could inappropriately influence (bias) their work. Example of potential conflicts of interest include employment, consultancies, stock ownership, honoraria, paid expert testimony, patent applications/registrations, and grants or other funding. See also http://www.elsevier.com/conflictsofinterest .

Please complete and upload the conflict of interest and author declaration form with your manuscript.

Author contributions: Each author is required to declare his or her individual contribution to the article: all authors must have materially participated in the research and $\backslash$ or article preparation, so roles for all authors should be described. The statement that all authors have approved the final author's article should be true and included article in the disclosure.

Role of the funding source: You are requested to identify who provided financial support for the conduct of the research andlor preparation of the article and to briefly describe the role of the sponsor (s), if any, in study design; in the collection, analysis and interpretation of data; in the writing of the report; and in the decision to submit the article for publication. If the funding source (s) had no such involvement then this should be stated.

List of abbreviation: Any abbreviations used should be listed after the abstract and defined at first use in the main body of the article. Use only widely accepted and conventional abbreviations. Avoid abbreviations in the title and abstract.

Proof Reading will be done by the secretarial office of the journal. The principal author will receive a copy of the journal. The authors are responsible for accuracy of all statements, data, and references included in the manuscript.

- After the manuscript has been accepted for publication, authors are required to supply the final version of the manuscript on CD in MS word version 6 or later. 


\title{
Iraqi Journal of Medical Sciences
}

\author{
A Medical Journal Encompassing All Medical Specializations \\ Issued Quarterly
}

CONTENTS

\section{Editorial}

1. CERVICAL CANCER SCREENING IN DEVELOPING COUNTRIES

Ban J. Qasim

ARTICLES

2.TECHNICAL ERRORS IN USING INHALERS AMONG PATIENTS WITH ASTHMA OR COPD IN IRAQ

Hasanain G. Khudhair, Haidar A.N. Abood, Ali M. Al-Mousawi, Sajjad J. Al-Hatab, Ibrahim A. Al-Obaidi, Ali A.K. Abutiheen

3.IMMUNOHISTOCHEMICAL MALONDIALDEHYDE ANTIBODIES CHANGES OF THE ADULT MICE TESTES AFFECTED BY PRENATAL MANGANESE CHLORIDE EXPOSURE

Hayder J. Mubarak, Nameer F. Gaeab, Hussein A. Jarullah

4.DUCTECTASIA OF THE BREAST; AN EXPERIENCE WITH HADFIELD OPERATION (RADICAL EXCISION OF THE SUBAREOLAR DUCT SYSTEM)

Taqi S. Atiyah

5.COMPARISON OF TWO VIRUS CONCENTRATION METHODS FOR ENTERIC VIRUSES DETECTION IN MOROCCAN WASTEWATER AND TREATED EFFLUENT

Hasna A. Amdiouni, Leena Maunula, Arwa M. Al-Shuwaikh, Jalal Nourlil

6.ASSESSMENT OF SERUM ZINC LEVEL IN PATIENTS WITH POLYCYSTIC OVARY SYNDROME

Iqbal G. Farhood

7.LOCALIZATION OF TIGHT JUNCTIONS BETWEEN TANYCYTE-LIKE CELLS OF THE SULCUS MEDIANUS ORGANUM IN RAT BRAIN

Fadhil H. Ahmed, Muthanna A. Al-Kaabi, Sarmad E. Al-Marsoummi, Hayder A. AlAubaidy

8.ISOLATION, IDENTIFICATION AND DETERMINATION OF ANTIFUNGAL SENSITIVITY OF FUNGI ISOLATED FROM A SAMPLE OF PATIENTS WITH RHINOSINUSITIS IN BAGHDAD CITY

Israa A. Ali

9.KNOWLEDGE, ATTITUDE AND PRACTICE OF MOTHERS TOWARDS TYPHOID FEVER DISEASE

Taha N. Sadeq, Rasha K. Jabar

10.THE ROLE OF ESTROGEN AND PROGESTERONE ON VAGINAL CYTOLOGY DURING PROLIFERATIVE AND SECRETARY PHASES OF MENSTRUAL CYCLE IN WOMEN WITH POLYCYSTIC OVARIAN SYNDROME

Huda R. Kareem, Haider A. Jaafer, Zainab H. Hashim 


\title{
Iraqi Journal of Medical Sciences
}

\author{
A Medical Journal Encompassing All Medical Specializations \\ Issued Quarterly
}

CONTENTS

11.THE SEROPOSITIVITY OF PARVOVIRUS B19 AMONG KIDNEY TRANSPLANT RECIPIENTS

Zainab A. Hlail, Ahmed S. Abdulamir, Ali J.H. Al-Saedi

88-93

12.FREQUENCY OF HUMAN CYTOMEGALOVIRUS AND HUMAN HERPESVIRUS-1 ANTIGENS IN PRODUCT OF CONCEPTUS TISSUES OF PREGNANT WOMEN WITH SPONTANEOUS ABORTION

Areej A. Hussein, Sawsan T. Salman, Basim M. Khashman

13.SUCCESSFUL TRIAL OF LABOR AFTER PRIMARY AND REPEATED CESAREAN SECTIONS: A CASE REPORT

Yosra T. Jarjees 
Published by Al-Nahrain College of Medicine P-ISSN 1681-6579

E-ISSN 2224-4719

Email: iraqijms@colmed-alnahrain.edu.iq

http://www.colmed-alnahrain.edu.iq

http://www.iraqijms.net

\title{
Cervical Cancer Screening in Developing Countries
}

\author{
Ban J. Qasim PhD \\ Dept. of Pathology and Forensic Medicine, College of Medicine, Al-Nahrain University, Baghdad, Iraq
}

\begin{abstract}
Cervical cancer (CC) represents the most common cancer among women in developing countries. Present confirmation suggests that human papillomavirus (HPV) testing is more efficient than cytology for CC screening. Even if implementing a high-quality cytology programme in these countries is probable, it would only be fairly effective. This is because the presently used Pap test misses approximately $50 \%$ of high-grade precursor lesions and cancers with a single screening.

Several screening alternatives have been planned for areas with incomplete resources. Amid these, visual inspection with acetic acid (VIA) includes the application to the cervix of $5 \%$ diluted acetic acid (vinegar), making the dysplastic epithelium turn white (acetowhitening). Screening with HPV testing and VIA have been verified to be effective and potentially cost-effective in low-resource settings, allowing for fewer follow-up visits (e.g., screen-and-treat approaches) and, in the case of HPV testing, automated processing of laboratory specimens that reduces resource and quality control necessities
\end{abstract}

Keywords Cervical cancer, screening, cytology, human papillomavirus testing, visual inspection with acetic acid Citation Ban J. Qasim. Cervical cancer screening in developing countries. Iraqi JMS. 2017; Vol. 15(1): 1-3. doi: 10.22578/JMMS.15.1.1

List of abbreviation: $C C=$ Cervical cancer, $\mathrm{HPV}=$ human papillomavirus, VIA = Visual inspection with acetic acid

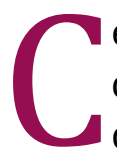
ervical cancer (CC) represents the most common cancer among women in developing countries, principally because of the failure either to start or continue successful cervical-cancer screening programs. This potentially preventable and curable cancer continues to cause high mortality among relatively young women living in low-resource countries (1). The main obstacles inbuilt to these countries are poverty and a deficient healthcare infrastructures and trained practitioners. With the availability of novel technologies, researchers have attempted to discover new strategies that are modified to low- and middle-income countries to encourage early diagnosis of cervical pathology. Present confirmation suggests that human papillomavirus (HPV) testing is more efficient than cytology for CC screening (2).

The implementation of health care measures to prevent cervical cancer reflects the priority of women (especially middle aged women) in a society, as well as the civilization and progress of a country. However, this measure has not been employed by developing countries, and the goal to screen $\mathrm{CC}$ for middle aged women has not been realized. This is probably attributed to the imbalance of health care resources in developing countries; limited medical resources are used in a small population (3).

Even though new studies hold up the possible promise of an effective vaccine against selected high-risk types of HPV, the vaccine is not up till now commercially accessible $(4,5)$. Given that first-generation vaccines will target 
young adolescents, it will require several decades to settle on the effect of these vaccines on the rate of death from cervical cancer. As current vaccines target only two types of oncogenic HPV, a combination of screening and vaccination will most likely be necessary. Thus, appropriate accomplishment of a cost-effective screening plan for use in developing countries is chiefly critical ${ }^{(6)}$.

A cytology-based (Pap test) screening program requires repeat testing and visits to recognize women who require treatment. In addition, a cytopathologist, a colposcopy specialist and a pathologist should also be concerned. To promise the success of a screening program, training and ongoing education are vital (7). Preceding knowledge has shown no decline in the incidence and/or mortality of CC and this is perhaps because of low-quality cytology smears ${ }^{(8)}$. Furthermore, even if implementing a high-quality cytology program in these countries is probable, it would only be fairly effective. This is because the presently used Pap test misses approximately $50 \%$ of highgrade precursor lesions and cancers with a single screening. As well, in low-resource settings, women would probably only be screened once or twice in their lifetime $(2,9)$.

Several screening alternatives have been planned for areas with incomplete resources. amid these, visual inspection with acetic acid (VIA) includes the application to the cervix of $5 \%$ diluted acetic acid (vinegar), making the dysplastic epithelium turn white (acetowhitening). The key advantages of this technique are that unlike conventional cytology, it is of little cost, uncomplicated to carry out and does not need specialized laboratory. The outcomes of the test are obtained more or less without delay facilitating same-day screen and management. However, VIA is controversial because of concerns over its reproducibility and accuracy ${ }^{(10)}$.

HPV testing presently has restricted use in lowincome countries. It demands laboratory infrastructure, skilled technicians, and storage services. Still, HPV testing provides a reproducible profile of women who are at high risk of developing precancerous or cancerous lesions. When used unaccompanied, or in combination with VIA, HPV DNA testing has shown great promise ${ }^{(11)}$.

Screening with HPV testing and VIA have been verified to be effective (12-14) and potentially cost-effective (6) in low-resource settings, allowing for fewer follow-up visits (e.g., screenand-treat approaches) and, in the case of HPV testing, automated processing of laboratory specimens that reduces resource and quality control necessities (15). Besides, the World Health Organization has newly recommended the use of HPV testing or VIA for cervical cancer screening in those regions and countries that have not previously established a successful, high-coverage Pap-based program (16).

Management options differ for women who test positive for HPV. In low resource settings where colposcopy and biopsy may not be on hand, conducting VIA after a positive HPV test can help decide if precancerous lesions are present on the cervix and if cryotherapy treatment is fitting. In some settings, even if the woman does not have a visibly noticeable lesion, cryotherapy has been performed on the whole cervical transformation zone particularly if the woman is unlikely to come back for follow-up care ${ }^{(17)}$.

\section{References}

1. Wright TC Jr, Kuhn L. Alternative approaches to cervical cancer screening for developing countries. Best Pract Res Clin Obstet Gynaecol. 2012; 26: 197208. doi: 10.1016/j.bpobgyn.2011.11.004.

2. Catarino R, Petignat $P$, Dongui $G$, et al. Cervical cancer screening in developing countries at a crossroad: Emerging technologies and policy choices. World J Clin Oncol. 2015; 6: 281-90. doi: 10.5306/wjco.v6.i6.281.

3. Qiao YL. Perspective of cervical cancer prevention and control in developing countries and areas. Chin J Cancer. 2010; 29: 1-3.

4. Koutsky LA, Ault KA, Wheeler CM, et al. A controlled trial of a human papillomavirus type 16 vaccine. $\mathrm{N}$ Engl J Med. 2002; 347: 1645-51. doi: 10.1056/NEJMoa020586.

5. Harper DM, Franco EL, Wheeler C, et al. Efficacy of a bivalent $L 1$ virus-like particle vaccine in prevention of infection with human papillomavirus type 16 and 18 
in young women: a randomised control trial. Lancet. 2004; 364: 1757-65. doi: 10.1016/S01406736(04)17398-4.

6. Goldie SJ, Gaffikin L, Goldhaber-Fiebert JD, et al. Cost-effectiveness of cervical-cancer screening in five developing countries. N Engl J Med. 2005; 353: 215868. DOI: 10.1056/NEJMsa044278.

7. Denny L, Quinn M, Sankaranarayanan R. Chapter 8: Screening for cervical cancer in developing countries. Vaccine. 2006; 24 Suppl 3: S3/71-S3/77. doi: 10.1016/j.vaccine.2006.05.121.

8. Sankaranarayanan R, Budukh AM, Rajkumar R. Effective screening programmes for cervical cancer in low- and middle-income developing countries. Bull World Health Organ. 2001; 79: 954-62.

9. Cuzick J, Clavel C, Petry KU, et al. Overview of the European and North American studies on HPV testing in primary cervical cancer screening. Int J Cancer. 2006; 119: 1095-101. doi: 10.1002/ijc. 21955.

10. Alec $M$, Vassilakos $P$. Cervical cancer information. Available at cervical cancer in developing countries. website: $\quad$ http://www.gfmer.ch/ccdc/cervicalcancer.htm. Accessed at 2/3/2017.

11. Elit L, Jimenez W, McAlpine J, et al. Cervical cancer prevention in low-resource settings. J Obstet Gynaecol Can. 2011; 33(3): 272-9.

12. Sankaranarayanan R, Esmy PO, Rajkumar R, et al. Effect of visual screening on cervical cancer incidence and mortality in Tamil Nadu, India: a clusterrandomised trial. Lancet 2007; 370: 398-406. doi: 10.1016/S0140-6736(07)61195-7.

13. Shastri SS, Mittra I, Mishra GA, et al. Effect of VIA screening by primary health workers: randomized controlled study in Mumbai, India. J Natl Cancer Inst 2014; 106: dju009. doi: 10.1093/jnci/dju009.

14. Sankaranarayanan R, Nene BM, Shastri SS, et al. HPV screening for cervical cancer in rural India. N Engl J Med. 2009; 360: 1385-94. doi: 10.1056/NEJMoa0808516.

15. Campos NG, Sharma M, Clark A, et al. Resources required for cervical cancer prevention in low- and middle-income countries. PLoS One. 2016; 11(10): e0164000. doi: 10.1371/journal.pone. 0164000.

16. World Health Organization. WHO guidelines for screening and treatment of precancerous lesions for cervical cancer prevention. Geneva: World Health Organization, 2013.

17. Denny L, Kuhn L, De Souza M, et al. Screen-and-treat approaches for cervical cancer prevention in lowresource settings: a randomized controlled trial. JAMA. 2005; 294: 2173-81. doi: 10.1001/jama.294.17.2173

\section{E-mail: dr.banqasim@yahoo.com}




\title{
Iraqi JMS
}

Published by Al-Nahrain College of Medicine P-ISSN 1681-6579

E-ISSN 2224-4719

Email: iraqijms@colmed-alnahrain.edu.iq

http://www.colmed-alnahrain.edu.iq

http://www.iraqijms.net

\section{Technical Errors in Using Inhalers among Patients with Asthma or COPD in Iraq}

\author{
Hasanain G. Khudhair ${ }^{1} B S c$ (MedSci), Haidar A.N. Abood ${ }^{2}$ PhD, Ali M. Al-Mousawi ${ }^{1} M^{2} S c$, Sajjad J. \\ Al-Hatab ${ }^{1}$ BSC (MedSCi), Ibrahim A. Al-Obaidi ${ }^{1}$ BSC (MedSci), Ali A.K. Abutiheen ${ }^{3}$ FIBMS FM
}

${ }^{1}$ Dept. of Family and Community Medicine, ${ }^{2}$ Dept. of Pharmacology, College of Medicine/Karbala University, Iraq

\begin{abstract}
Background Inhaler is a device holding a medicine taking by breathing (inhalation). It is estimated that about 25 billion dollars spent for inhalers annually, 5-7 billion dollars are wasted because of inhaler misuse.

Objective To evaluate inhaler use technique among Iraqi asthmatic and chronic obstructive pulmonary diseases (COPD) patients and identify the technical mistakes in using inhalers.

Methods The study protocol consisted of interview session to answer the study questionnaire and assessment session to estimate the performance of using inhaler in three cities in the middle of Iraq during the interval between $1^{\text {st }}$ of August and $20^{\text {th }}$ of September 2015. Chi-square test and trend chi-square test were used for univariate association between potential determinants and correctness of inhalation technique. Relevant determinants were entered into a multivariate logistic regression model.

Results A total of 364 patients participated in this study, $39.6 \%$ of patients were using their inhalers inadequately. Patients using turbuhaler, older patients ( $>60$ years old) and patients with low level of education or shorter duration of use were significantly associated with more inhaler use mistakes.

Conclusion This study showed that substantial proportion of patients with asthma or COPD using their inhaler inadequately. The worse performance was among patients using turbuhaler and best among those using disckus inhaler.

Keywords Inhaler administration, asthma, COPD, pMDI, turbuhaler, disckus inhaler

Citation Hasanain G. Khudhair, Haidar A.N. Abood, Ali M. Al-Mousawi, Sajjad J. Al-Hatab, Ibrahim A. AlObaidi, Ali A.K. Abutiheen. Technical errors in using inhalers among patients with asthma or COPD in Iraq. Iraqi JMS. 2017; Vol. 15(1): 4-12. doi: 10.22578/IJMS.15.1.2
\end{abstract}

List of abbreviation: COPD = Chronic obstructive pulmonary diseases, $\mathrm{DPI}=$ Dry powder inhalers, $\mathrm{pMDI}=$ pressurized metered-dose inhaler, SPSS = Statistical package for the social science

\section{Introduction}

$\mathrm{M}$ ore than 300 million people, worldwide have asthma with 250000 deaths each year, while chronic obstructive pulmonary diseases (COPD) affects 210 million people ${ }^{(1)}$. In Iraq, nearly 230000 asthmatics visited primary health care centers and asthmatic patients formed 16.4 per 1000 hospital outpatient visitors in $2013^{(2)}$.
Inhaled therapy, introduced into clinical use 60 years ago, is a fundamental route of drug administration in modern management of asthma, and it might be difficult to think of a time when asthma was managed without (1). Inhalers are also very important in the management of COPD, which makes inhaled drugs the cornerstone in the treatment of these diseases ${ }^{(1,3)}$. The inhaler is next to pills, the most common medication for asthma in the world, but the main problem is the incorrect use of inhaler devices, which may 
have a major influence on the therapeutic efficiency of used drug ${ }^{(3,4)}$. Mistakes in inhaler use have been reported to occur in up to $85 \%$ of patients ${ }^{(3)}$. The most frequently used inhaler for treatment of asthma and COPD are the metered-dose inhaler (MDI) and dry powder inhalers (DPI) like turbuhaler and disckus inhaler ${ }^{(5,6)}$.

MDI have many advantages and disadvantages. MDI are usually small in size, portable, compact, convenient, relatively low cost, multidose capability, quick delivery, and their contents are protected from contamination by pathogens (7). The disadvantages of MDIs include: drug delivery is highly dependent on inhaler use technique and misuse could result in a suboptimal (even zero) lung deposition as most of the dose is deposited in the oropharynx, failure to shake, have fixed drug concentration, and adverse reactions to propellants (7). For DPI, a primary advantage is the need for coordination of actuation with inspiration, which depends on patient's inspiratory flow, while the main disadvantage is the time needed to load a dose for each use. For these reasons, large number of different types of inhalers were manufactured and introduced in the market ${ }^{(7)}$. The type of inhaler is an important determinant of mistakes in inhaler use and these were significantly more with users of the MDI use ${ }^{(3,8-10)}$.

It is worth to mention that inhaler use technique is considered as dealing with a simple device, so it is often neglected in the general medical textbooks and literature (11). A review of medical textbooks used in the education of physicians revealed that only two out of 40 books included a simple list of steps for proper pressurized metered-dose inhaler (pMDI) use ${ }^{(12)}$. As a result, $39-67 \%$ of nurses, doctors, and respiratory therapists were reported to be unable to adequately describe or perform critical steps for using inhalers ${ }^{(4)}$. This might be the reason behind the finding that between $28 \%$ and $68 \%$ of patients do not use $\mathrm{pMDI}$ or DPI well enough to benefit from the prescribed medication ${ }^{(4)}$.
The incorrect use of inhalers may lead to uncontrolled asthma and increased costs due to increased utilization for medication resulting from inefficient drug use ${ }^{(6)}$. It is estimated that out of 25 billion dollars spent for inhalers annually in the United States, 5-7 billion dollars were wasted because of inhaler misuse ${ }^{(4)}$.

In a recent study in Palestine, among 149 asthmatic patients showed that only $37.6 \%$ used inhalant properly and significant differences were found between types of inhaler device. Large number of published research had documented significant differences between different types of inhalers $(8,9)$. Additionally, significant relationship was found between correct score of handling inhaler device and educational level (10). Similar significant differences were reported by many other studies. Training the patients and improving patient education about inhaler use technique could reduce these wasted resources and improve the effect of treatment (4,13-15). All these issues make inhaler use evaluation and patient education, fundamental needed steps in respiratory diseases treatment with inhalation drugs ${ }^{(13,14)}$.

The objective of this study was to evaluate inhaler use technique among Iraqi asthmatic and COPD patients and to identify the technical mistakes in using inhalers.

\section{Methods}

A cross sectional study conducted among asthmatic and COPD patients in the Medical City/Baghdad, Imam Hussein Medical City/Karbala and the Center of Asthma and Allergy/ Babylon between $1^{\text {st }}$ of August and $20^{\text {th }}$ of September 2015. A total of 364 outpatients (172 males and 192 females) were involved in the study. The study aimed to determine the main mistakes in inhaler use technique for the three main types of inhalers used (pMDls, turbuhaler and diskus) ${ }^{(10)}$. The common investigated predictors of these technical mistakes were type of inhaler device and patient characteristics (gender, age, level of education and duration of disease). Inclusion 
criteria: All patients with asthma or COPD using pMDI, turbuhaler or diskus inhaler who accepted to participate in the study. While exclusion criteria were: patients using other type of inhalers or those using additional spacer device beside the inhaler; patients below 6 year of age (because they need spacer devices); patient in acute attack of asthma or COPD (because they may have mistaken due to confusion). The study included two sessions for each participant: interview session to answer the study questionnaire and assessment session to evaluate his or her performance in using the inhaler. The interview session included information about the following four sections:

1. Demographic questions: age, gender, level of education, occupation and residency.
2. History of the present disease: type of the disease and its duration (asthma or COPD).

3. Inhaler use: Type of inhaler and the duration of inhaler use.

4. Who give the patients instructions to using their inhalers?

Assessment session included the demonstration of inhaler use according to standard steps for each inhaler type, ability to declared whether the inhaler contain drug and reading expiry date of the inhaler. The steps list was derived from the medication leaflet and from previous studies (16), (Table 1). The practical assessment followed standardized steps checking which was followed strictly, as the interviewers were trained before conducting the study.

Table 1: Standard steps for each inhaler type as included in the form of assessment

\begin{tabular}{|c|c|c|c|}
\hline Steps & pMDI inhaler & Diskus inhaler & Turbuhaler \\
\hline 1 & Removing dust cap & Removing the dust cap & Removing dust cap \\
\hline 2 & Shaking inhaler well & Loads inhaler with one dose & Loads inhaler with one dose \\
\hline 3 & Exhaling before use & Exhaling before use & Exhaling before use \\
\hline 4 & $\begin{array}{l}\text { Inhaling through inhaler and } \\
\text { releases a dose }\end{array}$ & $\begin{array}{c}\text { Places mouthpiece in mouth } \\
\text { and closes lips } \\
\text { around it }\end{array}$ & $\begin{array}{c}\text { Places mouthpiece in mouth } \\
\text { and closes lips } \\
\text { around it }\end{array}$ \\
\hline 5 & $\begin{array}{l}\text { Removing inhaler and holds } \\
\text { breath }\end{array}$ & $\begin{array}{l}\text { Inhaling forcefully and } \\
\text { deeply }\end{array}$ & $\begin{array}{l}\text { Inhaling forcefully and } \\
\text { deeply }\end{array}$ \\
\hline 6 & Observe that no leak & $\begin{array}{l}\text { Removing inhaler and holds } \\
\text { breath }\end{array}$ & $\begin{array}{l}\text { Removing inhaler and holds } \\
\text { breath }\end{array}$ \\
\hline 7 & Wash mouth* & Wash mouth* & Wash mouth* \\
\hline 8 & Replacing dust cap & Closing dust cap & Replacing dust cap \\
\hline
\end{tabular}

* If the inhaler contains corticosteroids

\section{Scoring system}

A Likert scale was followed in the assessment of each step according to its importance in the treatment as reported in many similar studies (4), and a final score was calculated accordingly. The steps of inhaler use were divided into:

1. Essential step that is critical to ensure the drug delivery to the lung and mistake in this step cause failure in the treatment. These steps included "inhaling properly through inhaler with active the canister to releases the dose and" Observe that no leak ", for pMDI inhaler; and "loads inhaler with one dose" and "inhaling forcefully and deeply" for both diskus and turbuhaler inhalers. This type of classifying the steps into essential and minor steps was followed in many published studies (8-10). Each step was assessed by the interviewer and then a score was given consisting of three grades, 0 : if the patient did not conduct the process 
at all, 2: if the step was done partially and 4: if the step was properly done.

2. Minor step that have minor effect on drug delivery, which included shaking inhaler well before use, exhaling gently as much as comfortable, removing inhaler, holds breath and wash mouth for steroid containing inhalers. Here scoring was similar to the essential steps but a lower score was given consisting of three grades, 0 : if the patient did not conduct the process at all, 1 : if the step was done partially and 2: if the step was properly done.

3. Routine steps included other steps not affecting drug delivery and these were not scored.

The total score for each patient was found by summation of the scores got for all the steps. A range of 11-14 was considered as 'Adequate' while a score of 10 or less was categorized as 'Inadequate score'. The data was entered into a database using the Statistical Package for Social Science (SPSS) version 22. Chi-square test was used for bivariate associations between inhaler use performance and potential determinants. Relevant determinants were entered into a multivariate logistic regression model and correlation analysis. Effect sizes were expressed in odds ratios (OR) with their $95 \%$ confidence intervals $(95 \% \mathrm{Cls})$. Moreover, inhalation technique errors were examined for three inhalers and all were assessed at a significance level of $<0.05$.

\section{Results}

A total of 364 patients, 172 male (47.3\%) and 192 female patients (52.7\%) participated in this study. The age ranged between 11 and 78 year with a mean of $47.8 \pm 14.6$ year. The majority of patients had asthma (332 patient, 91.2\%) and the remaining had COPD (32 patient, 8.8\%).

About two thirds (220 patients, 60.4\%) got an adequate score of performance in the assessment session indicating acceptable inhaler use (Table 2). A highly significant difference in performance was observed between the different types of inhaler used. The best performance was observed among patients using disckus inhaler, where $88.2 \%$ of the patients got adequate score while the lowest proportion was among patients using turbuhaler (48.5\%), while pMDI was in the middle (72.5\%, Figure 1 and Table 2).

\section{Adequate $\mathbf{\text { Inadequate }}$}

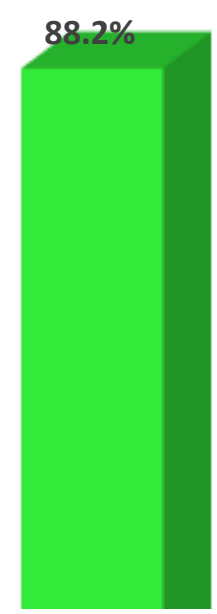

Figure 1. Inhaler use performance by type of inhaler among 364 Iraqi patients. 
The most common errors among patients using pMDI inhaler were missing exhalation before use (36.6\%) and missing to shake the inhaler before use $(21.5 \%)$. Among patients using turbuhaler and diskus inhaler, the most common errors were missing mouth washing after use (51\%) and (29.4), respectively. Other common missed steps for turbuhaler patients were failure to load inhaler with one dose properly $(49.5 \%$ - both partial done and not do at all-) and not exhaling before use (44.8\%, Table 3).

Table 2. The distribution of patient's inhaler use performance according to inhaler type, disease, demographic characteristics and duration of disease among 364 Iraqi patients

\begin{tabular}{|c|c|c|c|c|c|}
\hline Variable & Categories & $\begin{array}{c}\text { Adequate } \\
\text { No. (\%) }\end{array}$ & $\begin{array}{c}\text { Inadequate } \\
\text { No. (\%) }\end{array}$ & $x^{2}$ & Significance \\
\hline \multirow{3}{*}{ Inhaler type } & pMDI & $111(72.5 \%)$ & $42(27.5 \%)$ & \multirow{3}{*}{26.533} & \multirow{3}{*}{$<0.001$} \\
\hline & Turbuhaler & 94 (48.5\%) & $100(51.5 \%)$ & & \\
\hline & Diskus inhaler & $15(88.2 \%)$ & $2(11.8 \%)$ & & \\
\hline \multirow{2}{*}{ Disease } & Asthma & 199 (59.9\%) & $133(40.1 \%)$ & \multirow{2}{*}{0.395} & \multirow{2}{*}{0.530} \\
\hline & COBD & $21(65.6 \%)$ & $11(34.4 \%)$ & & \\
\hline \multirow{2}{*}{ Gender } & Male & 105 (61.0\%) & 67 (39.0\%) & \multirow{2}{*}{0.050} & \multirow{2}{*}{0.823} \\
\hline & Female & 115 (59.9\%) & $77(40.1 \%)$ & & \\
\hline \multirow{2}{*}{ Residency } & Urban & $196(60.1 \%)$ & $130(39.9)$ & \multirow{2}{*}{0.131} & \multirow{2}{*}{0.717} \\
\hline & Rural & $24(63.2 \%)$ & $14(36.8 \%)$ & & \\
\hline \multirow{6}{*}{ Age group (year) } & $21-30$ & $25(65.8 \%)$ & $13(34.2 \%)$ & \multirow{6}{*}{3.43} & \multirow{6}{*}{$0.047^{*}$} \\
\hline & $31-39$ & $31(56.4 \%)$ & $24(43.6 \%)$ & & \\
\hline & $40-49$ & $64(66.6 \%)$ & $32(33.3 \%)$ & & \\
\hline & $50-59$ & $51(68 \%)$ & $24(32 \%)$ & & \\
\hline & $60-69$ & 40 (54.8\%) & $33(45.2 \%)$ & & \\
\hline & $70-80$ & $9(33.3 \%)$ & $18(66.3 \%)$ & & \\
\hline \multirow{5}{*}{ Educational level } & Illiterates & $48(44.9 \%)$ & 59 (55.1\%) & \multirow{5}{*}{21.11} & \multirow{5}{*}{$<0.001^{*}$} \\
\hline & Primary school & $67(60.4 \%)$ & $44(39.6 \%)$ & & \\
\hline & Intermediate school & $33(61.1 \%)$ & $21(38.9 \%)$ & & \\
\hline & Secondary school & $31(77.5 \%)$ & $9(22.5 \%)$ & & \\
\hline & College graduates & $41(78.8 \%)$ & $11(21.2 \%)$ & & \\
\hline \multirow{3}{*}{ Duration of disease } & $<1$ year & $18(50.0 \%)$ & $18(50.0 \%)$ & \multirow{3}{*}{2.71} & \multirow{3}{*}{$<0.001^{*}$} \\
\hline & $1-20$ year & $154(60.2 \%)$ & 102 (39.8\%) & & \\
\hline & $>20$ year & $48(66.7 \%)$ & $24(33.3 \%)$ & & \\
\hline \multicolumn{2}{|c|}{ Total } & $220(60.4 \%)$ & $144(39.6 \%)$ & & \\
\hline
\end{tabular}

* Trend chi square test (trend chi-square test) used for ordinal variables

Patients with COPD did better than patients with asthma in inhaler use performance $(65.6 \%$ and $59.9 \%$, respectively) but the difference was not significant. There was slight non-significant difference in adequate score between patients living in rural and urban areas $163.2 \%$ and $60.1 \%$, respectively, Table 2 ).
Negative significant association was found between performance score and age distribution ( $r=-0.132, p=0.012$ ). The highest proportion of patients with adequate score was among those aged $50-59$ year (68\%), while the lowest (33.3\%) was among those aged 71-80 year and the difference was significant (table 
2). Additionally, a highly significant positive association was found between performance score and patient educational level $(r=0.254$, $p<0.001)$. The highest proportion of adequate scores was among patient having education level 4 (college graduates, $78.8 \%$ ), while the least (44.9\%) was among patients having education level 0 (illiterates, Table 2 ).

There was no gender difference in performance although males showed better performance (Table 2). A positive significant association was found between performance score and duration of disease $(r=0.1162$, $p=0.028)$. The best performance was among patients having the disease for $>20$ years $(66.7 \%)$, while the least was among patients having the disease for less than 1 year (50\%) (Table 2).

The majority of patients (84.3\%) reported that they were able to decide whether inhaler contain drug or is empty, whilst, more than one-half of the patients (56.6\%) reported that they read the expiry date. Regarded the instructor for using inhaler, the majority (85.4\%) learned using inhaler by their treating physician and most of the patients (76.9\%) declared that they prefer being taught by their treating physician.

Table 3. The distribution inhaler use performance assessment by type of inhaler type among 364 Iraqi patients

\begin{tabular}{ccccc}
\hline $\begin{array}{c}\text { Inhaler } \\
\text { type }\end{array}$ & Steps of inhaler use & $\begin{array}{c}\text { Done properly } \\
\text { No. (\%) }\end{array}$ & $\begin{array}{c}\text { Done partially } \\
\text { No. (\%) }\end{array}$ & $\begin{array}{c}\text { Not done } \\
\text { No. (\%) }\end{array}$ \\
\hline \multirow{2}{*}{ pMDI } & $\begin{array}{c}\text { Shaking inhaler well } \\
\text { Exhaling before use } \\
\text { Removing inhaler and } \\
\text { holds breath }\end{array}$ & $\begin{array}{c}115(75.2 \%) \\
92(60.1 \%)\end{array}$ & $\begin{array}{c}5(3.3 \%) \\
5(3.3 \%)\end{array}$ & $\begin{array}{c}33(21.5 \%) \\
56(36.6 \%)\end{array}$ \\
\hline \multirow{2}{*}{ Turbuhaler } & $\begin{array}{c}\text { Loads inhaler with one } \\
\text { dose }\end{array}$ & $98(50.5 \%)$ & $93(48 \%)$ & $3(1.5 \%)$ \\
& $\begin{array}{c}\text { Exhaling before use } \\
\text { Wash mouth }\end{array}$ & $102(52.6 \%)$ & $5(2.6 \%)$ & $87(44.8 \%)$ \\
Diskus & $95(49 \%)$ & $0(0 \%)$ & $99(51 \%) \mathrm{s}$ \\
inhaler & $\begin{array}{c}\text { Exhaling before use } \\
\text { Removing inhaler and } \\
\text { holds breath }\end{array}$ & $13(76.5 \%)$ & $0(0 \%)$ & $4(23.5 \%)$ \\
& Wash mouth & $14(82.4 \%)$ & $0(0 \%)$ & $3(17.6 \%)$ \\
\hline
\end{tabular}

A multivariate regression model for inhaler use performance was built including all variables and the results showed that the significant predictors for performance were: Educational level (odds ratio $=0.60$ ); the duration of disease (odds ratio $=0.69$ ) and Inhaler type (odds ratio= 1.71) while governorate where the study was conducted (odds ratio $=0.78$ ) (Table 4). The goodness of fit for the model was acceptable (0.750) (Table 4).

\section{Discussion}

Inadequate use of inhalers is a significant problem for both asthma and COPD management because it may result in diminished therapeutic effect, resulting in poor control of symptoms and thereby insufficient disease management ${ }^{(3,16)}$. In Iraq, a previous published study tried to explore inhaler use technique mistakes among 150 asthmatic patients in Baghdad reported that two-third (66\%) of participant used inhaler incorrectly (17). However, the study did not observe the patients using inhaler, but depend on selfadministered questionnaire. A study in the Netherland reported that about one quarter (24.2\%) of the asthmatic and COPD patients $(\mathrm{N}=558)$ made at least one essential mistake in their inhalation technique ${ }^{(8)}$. 
Table 4. Inhaler use performance logistic regression model with predictors results among 364 Iraqi patients

\begin{tabular}{ccc}
\hline Variable & $\begin{array}{c}\text { Odd ratio and 95\% } \\
\text { confidence interval }\end{array}$ & Significance \\
\hline $\begin{array}{c}\text { Medical department (Governorate) Ref. category: } \\
\text { Kerbala governorate } \\
\begin{array}{c}\text { Inhaler type } \\
\text { Ref. category: Ventolin inhaler }\end{array}\end{array}$ & $0.78(0.58-1.04)$ & 0.082 \\
$\begin{array}{ccc}1.71(1.34-2.17) \\
\text { Duration of disease Ref. category: one year or less } \\
\text { Educational level Ref. category: Illiterate patients }\end{array}$ & $0.69(0.59-0.82)$ & $<0.001$ \\
\hline
\end{tabular}

The scoring system used in this study was better than assessment in a previous study conducted in Baghdad (17), where only selfadministered questionnaire with no assessment of inhaler use was tried. Scoring is thought to be better than the scoring system reported in the study in the Netherland (8), where one or more negative scores on preparation or breathing maneuvers indicated incorrect technique while the Likert scale scoring used in the present study allowed a quantitative assessment rather than only 'all or none' scoring indicating presence or absence of the step.

In the present study, patients having asthma were much more than those having COPD because one of the study premises was a specialized center for asthmatics. Additional reason might be related to wide range of participants' age as COPD is not common among Youngers.

The present study showed that about two fifths of the patients (39.6\%) were using the inhaler inadequately, which was similar to the findings in Jordon (43\%) reported by Khassawneh and his colleague in $2008{ }^{(9)}$. A lower prevalence (24.2\%) was reported in a study in by Hesselink and his colleague in the Netherland in $2001{ }^{(8)}$, and the reason might be related to methodology as the measurement checklist used in this study included only essential steps in inhaler use technique ${ }^{(8)}$. However, variation in the results is common and is accepted and was estimated to be between $4 \%$ and $94 \%$ in a systematic literature review by Lavorini and his colleague in $2008^{(3,8,9)}$. The wide range in the prevalence of incorrect technique reported may largely be explained by differences in scoring systems $(3,10)$. Significant large difference between the different types of inhalers was expected because of the difference in the techniques and the date of introduction in the market ${ }^{(3,6,8,8)}$. DPI available since the 1970s, have been developed to make inhalation simpler compared with pMDIs, without the need to coordinate inhalation and actuation, this should be made DPIs easier to use ${ }^{(3)}$. However, Turbuhaler got the highest percentage of inadequate use (52\%) in the present study. A possible explanation might be related to the free distribution of Turbuhaler inhaler in the visited hospitals, leading to possible increased patients neglect to learn instruction use. Additionally, in some studies, it was also observed that many doctors and staff teach the patients incorrectly regarding the loading inhaler with one dose ${ }^{(9,10)}$, a finding reported by other studies ${ }^{(18,19)}$. Next possible reason might be due to the fact that pMDI inhaler was available long before Turbuhaler and this is supported by high percentage of adequate grade among patients using inhaler for longer duration in the present study.

The majority (85.4\%) of patients in the present study was taught to use inhaler by their treating physician and this was similar to those reported in other studies ${ }^{(10)}$, but this was not a source for significant improvement in performance which was reported by the study in Palestine ${ }^{(10)}$.

The three most frequent missed steps were mouth wash after use, exhalation before use 
and shaking inhaler before use (table 3). Poor training by medical staff might be an additional reason for these common mistakes $(18,19)$. Additional reasons behind these common mistakes might be related patients neglect or they consider these not important steps. Besides, the low educational level of the participants where about two thirds (59.9\%, table 2) were illiterate or primary school graduates might be a contributing factor. The increasing in the adequate performance of using inhalers with increase in education level may due to access to information on the internet and other sources and easy to understanding the correct instruction.

The highest inadequate grade (66.6\%) was among those aged 71-80 years old and also about one half of the patients in the 61-70 years group do inadequately and a similar finding was reported by the study in Baghdad (17), This might be related to their medical problem such as arthritis, weakness or impaired dexterity or vision and needs further study.

The positive significant correlation between the duration of disease and the total score of the patient can contributed to the experience of the patients over the time and was reported in some reviewed studies $(3,8,9)$.

The highest percentage of patients not know expiratory date it might because large proportion of patients in the present study were illiterate or at low level of education, similar results was reported by the study in Baghdad (17).

The COPD patients and patients living in rural area did better than other patients in this study but the difference was not significant and this might be due to small number of COPD and rural patients, so these findings need to be explored further in future studies.

The multivariate regression model findings demonstrated that inhaler type and medical premises were the significant predictors of mistakes in inhaler use. Rootmensen and his colleagues ${ }^{(15)}$, reported that inhaler type was a significant predictor of mistakes (OR between 1.5 and 25.7).

Conclusion: Our study showed that substantial proportion of patients with asthma or COPD using their inhaler inadequately. Adequate performance was more in patients of younger age groups and high level of education. The worse performance was among patients using turbuhaler and best among those using disckus inhaler.

Recommendation: Education system about their inhalers should be introduced alongside with regular assessment of patient with asthma and COPD. Special attention should be paid for elderly patients using tubuhaler and pMDI.

\section{Acknowledgments}

First, we would like to thank all patients that participated and cooperated with us in the study. In addition, we thank medical staff of Baghdad Medical City/Baghdad, Imam Hussein Medical City/Karbala and Center of Asthma and Allergy/ Babylon for her help in our study. Thanks also extend to administration of College of Medicine/Karbala University for their support.

\section{Author contribution}

Abood: study design, questionnaire preparation and training of interviewer. AlMousawi: literature review. Al-Mousawi and Abutiheen: preparation of the questionnaire, statistical analysis and interpretation. Khudhair, AL-Khatab and AL-Obaidi: data collection (interview and practical assessment). Khudhair: data entry to the SPSS program, interpretation and preparing the article.

All authors were involved in final approval of the version to be published as group.

\section{Conflict of interest}

Authors declare no conflict of interest.

\section{Funding}

There was no funding source for this research.

\section{References}

1. Crompton G. A brief history of inhaled asthma therapy over the last fifty years. Prim Care Resp J. 2006; 15(6): 326-31. doi: 10.1016/j.pcrj.2006.09.002.

2. Ministry of Health, Republic of Iraq, Annual Report. Baghdad, Iraq: 2014.

3. Lavorini F, Magnan A, Christophe Dubus JC, et al. Effect of incorrect use of dry powder inhalers on management of patients with asthma and COPD. 
Resp Med. 2008; 102(4): 593-604. doi: 10.1016/j.rmed.2007.11.003.

4. Fink J, Rubin B. Problems with inhaler use: A call for improved clinician and patient education. Resp Care. 2005; 50(10): 1360-74.

5. Castro-Rodriguez JA, Custovic A, Ducharme FM. Treatment of asthma in young children: Evidencebased recommendations. Asthma Res Pract. 2016; 2: 5. doi: 10.1186/s40733-016-0020-z.

6. Price $D$, Bosnic-Anticevich $S$, Briggs $A$, et al. Inhaler competence in asthma: Common errors, barriers to use and recommended solutions. Resp Med. 2013; 107(1): 37-46. doi: 10.1016/j.rmed.2012.09.017.

7. Hess DR. Aerosol delivery devices in the treatment of asthma. Respiratory Care. 2008; 53(6): 699-723.

8. Hesselink $A E$, Penninx BWJH, Wijnhoven $\mathrm{HAH}$ et al. Determinants of an incorrect inhalation technique in patients with asthma or COPD. Scandinavian J Prim Health Care. 2001; 19(4): 255-60. doi: 10.1080/02813430152706792.

9. Khassawneh B, Al-Ali M, Alzoubi K, et al. Handling of inhaler devices in actual pulmonary practice: Metered-dose inhaler versus dry powder inhalers. Respiratory Care. 2008; 53(3): 324-8.

10. Salah OAF. Assessing appropriate use of Inhaler devices among asthmatic patients. MSc thesis. AnNajah National University, Nablus, Palestine; 2013.

11. Hanania N, Wittman R, Kesten $S$, et al. Medical personnel's knowledge of and ability to use inhaling devices. Metered-dose inhalers, spacing chambers, and breath-actuated dry powder inhalers. Chest. 1994; 105(1): 111-6.

12. Hashmi A, Soomro JA, Memon A, et al. Incorrect inhaler technique compromising quality of life of Asthmatic patients. Journal of Medicine. JOM. 2012; 13(1). doi: 10.3329/jom.v13i1.7980.
13. Onyedum C, Desalu O, Nwosu N, et al. Evaluation of inhaler techniques among asthma patients seen in Nigeria: An observational cross sectional study. Ann Med Health Sci Res. Medknow. 2014; 4(1): 67. doi: 10.4103/2141-9248.126617.

14. Verver S, Poelman $M$, Bögels $A$, et al. Effects of instruction by practice assistants on inhaler technique and respiratory symptoms of patients. A controlled randomized videotaped intervention study. Fam Pract. 1996; 13(1): 35-40. doi: 10.1093/fampra/13.1.35.

15. Rootmensen GN, van Keimpema ARJ, Jansen HM, et al. Predictors of incorrect inhalation technique in patients with asthma or COPD: A study using a validated videotaped scoring method. J Aerosol Med Pulm Drug Deliv. 2010; 23(5): 323-8. doi: 10.1089/jamp.2009.0785.

16. World Health Organization Regional Office for Europe. Pharmacy-based asthma services: Protocols and guidelines. 1998.

17. Mahdi S, Mohammed A, Alani W. Assessment of inhaler misuse in asthmatic patients. J Fac Med Baghdad. 2014; 56(2): 205-10.

18. Crompton G. Problems patients have using pressurized aerosol inhalers. Eur J Resp Dis Suppl. 1982; 119: 101-4.

19. Newman S, Busse W. Evolution of dry powder inhaler design, formulation, and performance. Resp Med. 2002; 96(5): 293-304. doi: 10.1053/rmed.2001.1276.

Correspondence to Hasanain G. Khudhair E-mail: hasanain.ghaleb@gmail.com Received 15 ${ }^{\text {th }}$ Jun. 2016 Accepted 15 th Jan. 2017 
Published by Al-Nahrain College of Medicine P-ISSN 1681-6579

E-ISSN 2224-4719

Email: iraqijms@colmed-alnahrain.edu.iq http://www.colmed-alnahrain.edu.iq http://www.iraqijms.net

\title{
Immunohistochemical Malondialdehyde Antibodies Changes of the Adult Mice Testes Affected by Prenatal Manganese Chloride Exposure
}

\author{
Hayder J. Mubarak ${ }^{1} P h D$, Nameer F. Gaeab ${ }^{2}$ MSc, Hussein A. Jarullah ${ }^{1} P h D$ \\ ${ }^{1}$ Dept. of Human Anatomy, College of Medicine, Al-Nahrain University, Baghdad, Iraq, ${ }^{2}$ Dept. of Human Anatomy, \\ College of Medicine, Diala University, Iraq
}

\begin{abstract}
Background The harmful effect of manganese chloride on postnatal spermatogenesis was evidently concluded in previous experimental researches, however, the molecular changes related to this effect of manganese chloride needs further elaboration.

Objective To investigate the toxic effect of prenatal manganese chloride exposure on adult mice testes using malondialdehyde (MDA) antibodies as an immunohistochemical marker.

Methods In this study, 30 pregnant mice were divided into control and experimental groups. The experimental animals were given $0.1 \mathrm{ml}$ of manganese chloride solution $(8000 \mathrm{mg} / \mathrm{Liter}$ concentration) orally during the first 17 days of pregnancy. The control group of pregnant mice was given $0.1 \mathrm{ml}$ of distilled water orally rather than the solution of manganese chloride. Paraffin sections of the offspring mice testes were stained for general histological features and for antiMDA immunohistochemical evaluation. The Aperio Image Scope v.9 software was used to evaluate the immunohistochemical reaction.

Results Sections of testes from mice of the experimental group showed distorted morphology and organization of the stages of sperm development with distorted histological criteria of the interstitial tissue. Results from mice testes revealed statistically significant variability of antimalondialdehyde (MDA) immunohistochemical expression in the experimental group compared to that of the control group.

Conclusion Manganese chloride induced lipid peroxidation as part of its toxic effect. This lipid peroxidation caused cellular injury leading to apoptosis and autophagy.

Keywords Testes, development, manganese chloride, mice, toxicity, immnuohistochemistry, apoptosis

Citation Hayder J. Mubarak, Nameer F. Gaeab, Hussein A. Jarullah. Immunohistochemical malondialdehyde antibodies changes of the adult mice testes affected by prenatal manganese chloride exposure. Iraqi JMS. 2017; Vol. 15(1): 13-19. doi: 10.22578/IJMS.15.1.3
\end{abstract}

List of abbreviation: MDA = Malondialdehyde

\section{Introduction}

The reproductive toxicity of manganese had been proved to affect the testes.

The exposure to manganese affected the levels of malondialdehyde (MDA) in the testicular tissue and increased the number of apoptotic cells, and caused obvious histopathological changes in the testes (1). Among these heavy metals, the normal testicular functions depend on zinc, manganese, and selenium (2).

Manganese is the second of the most common ten metals on the surface of earth; it forms more than hundred compounds ${ }^{(3)}$. Manganese is important in the metabolism of 
carbohydrates, lipids, and proteins, and it acts as a co-factor for many enzymes (4).

Manganese chloride $\left(\mathrm{MnCl}_{2}\right)$ is a solid substance that is soluble in water forming an acidic solution ( $\mathrm{pH} 4){ }^{(5)}$. Manganese is absorbed in the intestine (6), and it is not metabolized inside the boby ${ }^{(7)}$. Manganese is excreted with feces, bile, milk, sweat, and urine (8).

MDA is a natural material formed in all mammalian cells as a product of lipid peroxidation. MDA is a highly reactive byproduct of polyunsaturated fatty acid peroxidation and arachidonic acid metabolism, it can combine with many functional groups on proteins, lipoproteins, and DNA ${ }^{(9)}$.

The toxicity of manganese was reported to be mainly affected the central nervous system, mainly the hypothalamus ${ }^{(10)}$. Also, the toxicity of manganese was suggested to affect the gastric mucosa (11), and affected the hemoglobin synthesis (12), and affecting testicular development ${ }^{(13)}$.

The aim of this study is to investigate the effect of exposure to $\mathrm{MnCl}_{2}$ sub-lethal dose during prenatal development of the mice testes using MDA antibody as an immunohistochemical marker.

\section{Methods}

In this study 30 healthy pregnant female adult Swiss albino mice (Mus musculus) were used, these mice were approximately 6 weeks of age and weighing 20-25 g. The animals were taken from the animal house of the High Institute for Infertility Diagnosis and Assisted Reproductive Technologies / Al-Nahrain University. These animals were maintained under uniform conditions of natural photoperiod (12 hours light/dark cycle), and temperature $\left(24-32{ }^{\circ} \mathrm{C}\right)$. The animals had free access to standard diet and water.

Detection of the vaginal plug was used as an indication of fertilization and pregnancy. The animals were divided into two groups with 15 mice in each group; the control group and the experimental group. The control group of pregnant female mice was given $0.1 \mathrm{ml}$ of distilled water orally.

The experimental group was given a sub-lethal dose of $8000 \mathrm{mg} / \mathrm{L} \mathrm{MgCl}_{2}$ solution (13). This solution was administered orally to the pregnant mice through oro-gastric intubation (polyethylene catheter fitted to a $1 \mathrm{ml}$ hypodermic syringe). The amount of $\mathrm{MgCl}_{2}$ solution given each time was $0.1 \mathrm{ml}(0.8 \mathrm{mg}$ ) every morning at 24 hours' intervals during the first 17 days of pregnancy.

After birth, the offspring received breast feeding from their mothers for three weeks. Then after, 30 male mice from the offspring were isolated in special cages and grown to reach the 6 weeks of age in the same animal house. The adult male offspring was sacrificed by cervical dislocation and scrotal incisions were done to obtain the testes.

Testicular tissues were processed for paraffin sectioning for histological examination according to the routine methodology ${ }^{(14)}$.

Paraffin sections of the testicular tissue were used for immunohistochemical staining. The MDA antibodies were provided from Abcam (code no. ab6463). They are rabbit polyclonal antibodies containing small molecules of synthetic malondialdehyde conjugated to bovine serum albumin. The immunohistochemistry detection kit is called Expose Mouse and Rabbit Specific HRP/DAB Detection IHC Kit from Abcam (code no. ab80436).

Aperio Image Scope version 9 software was used for the evaluation of MDA antibodies immunohistochemical reaction. This image analysis software involves counting the number of strong positive pixels to evaluate the immunohistochemical stain. The list of positive pixel count algorithm includes parameters obtained from the application of this software to quantify the amount of a specific stain present in a scanned slide image. These parameters when first selected have been pre-configured for brown color quantification. Pixels which are stained, but do not fall into the positive-color specification, are considered 
negative stained pixels. Analysis of variance (ANOVA) has been used for statistical Results

All female mice treated with the $\mathrm{MgCl}_{2}$ completed their pregnancy successfully.

Histological changes of the testes in the control group:

The examination of the mice testicular sections from the control group showed normal histology with normal arrangement of evaluation of the mean values of MDA immuno-histochemical reactivity.

spermatogenic cells; these cells were arranged in a radial pattern from the outer basement membrane to the lumen of seminiferous tubules (Figure 1). The cells of these tubules were bound together in a chain like configuration.

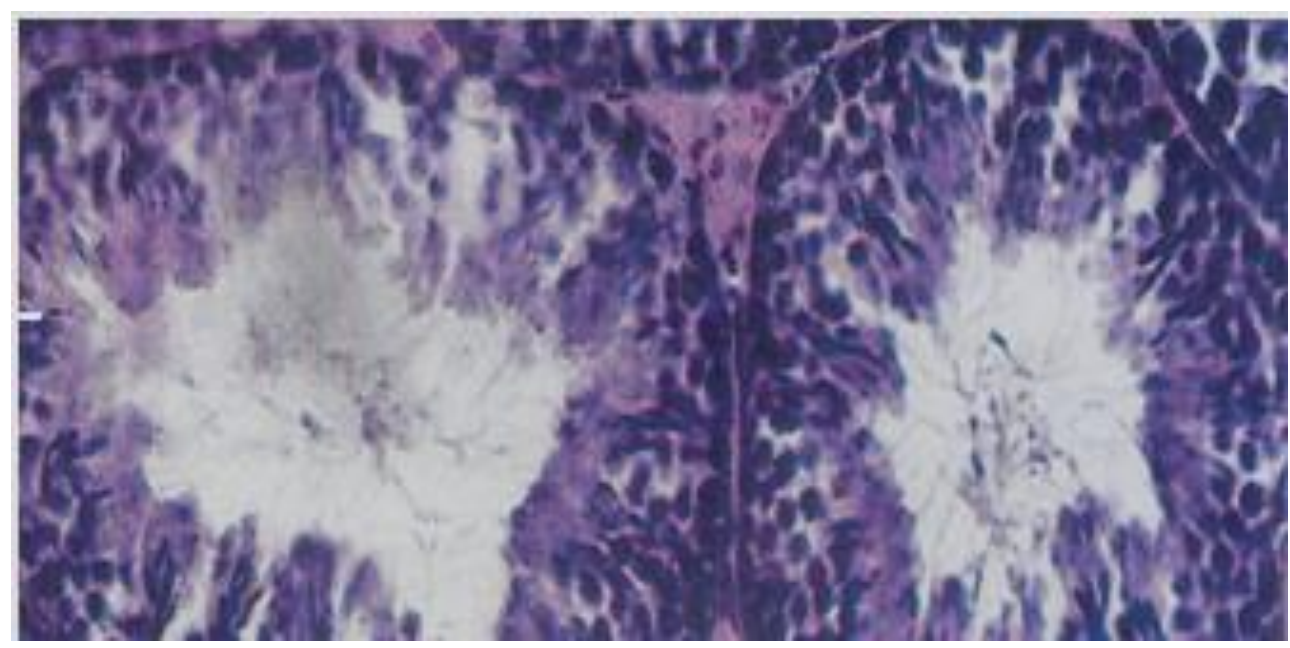

Figure 1. Mice testicular paraffin sections from the control group stained by hematoxylin and eosin showing normal testicular histology (X400)

Histological changes of the testes in the experimental group:

Testicular sections of the mice from the experimental group showed wide intercelluar spaces between the cells of the seminiferous tube compared to the control group. The nuclei of these germinal epithelial cells in the experimental group were more condensed, and the fully developed spermatozoa were less in number at the luminal part of the tubules.

The seminiferous tubules of the treated group exhibited distorted morphology and organization of the chain like serial stages of sperm development (Figure 2).
Anti-MDA immunohistochemical changes in the testes of the experimental groups (Figures 3 \& 4):

The evaluation of the counted mean values of MDA immuno-histochemical reactivity obtained by the application of the Aperio Image Scope software in the testicular tissue of mice in the experimental group revealed statistically significant variability compared to those of the control group $(p<0.001)$. The counting of the mean value of the number of strong positive pixels was higher in the experimental group (2700.174 \pm 325.35$)$, compared to that of the control group (2060 \pm 325.35$)$. 


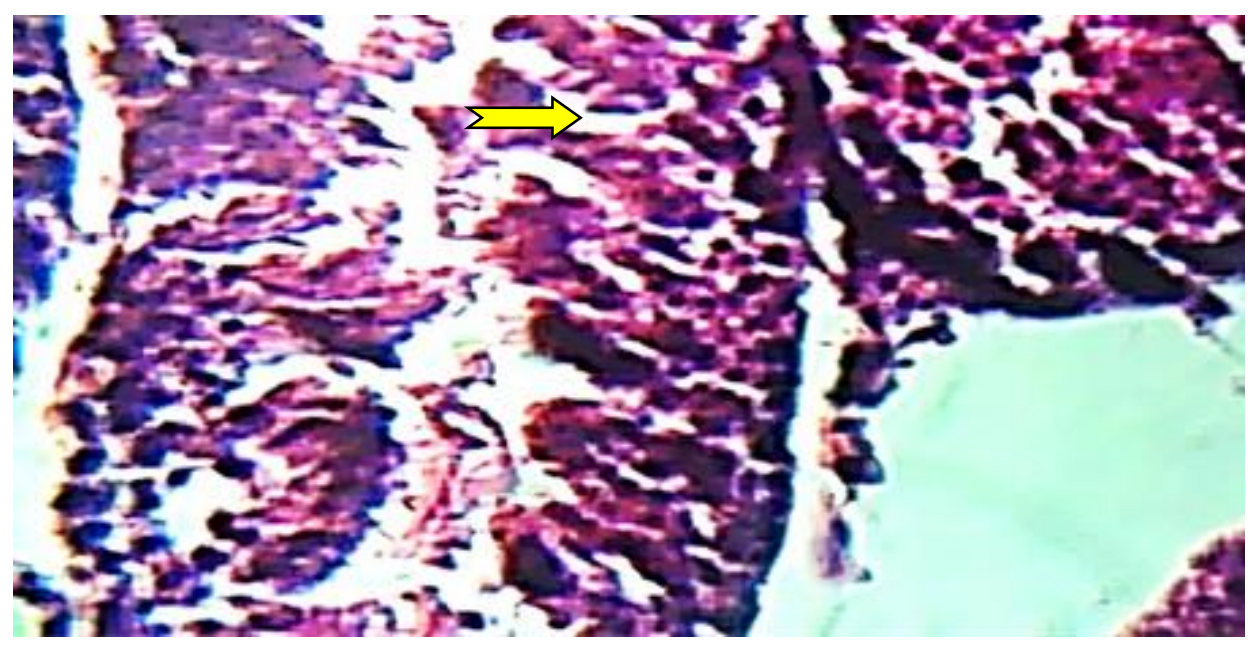

Figure 2. Mice testicular paraffin sections from the experimental group stained by hematoxylin and eosin showing tissue clefts (arrow) with distortion of spermatogenetic cells chain (X400)

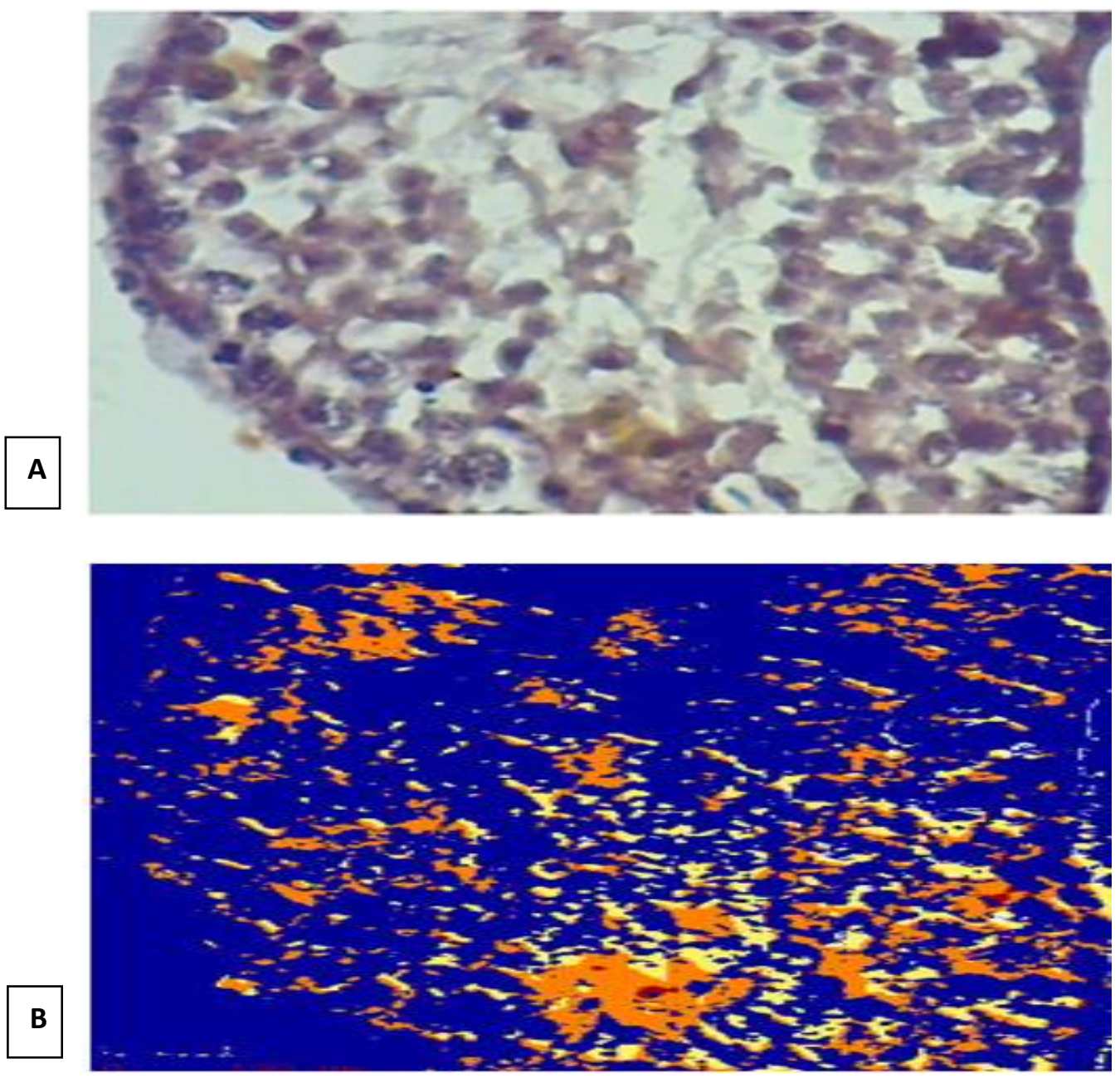

Figure 3. (A) Anti-MDA immunohistochemial changes in the mouse testis from the control group (400X). (B) The snap shoot as analyzed by Aperio Positive Pixel Count Algorithm software. The positive brown color appeared red in color in the markup image of the Aprio image scope software 



Figure 4. (A) Anti-MDA immunohistochemial changes in the mouse testis from the experimental group (X400). (B) The snap shoot as analyzed by Aperio Positive Pixel Count Algorithm software. The positive brown color appeared red in color in the markup image of the Aprio image scope software

\section{Discussion}

The harmful effect of $\mathrm{MgCl}_{2}$ on postnatal spermatogenesis was evidently concluded in previous experimental researches ${ }^{(13)}$.

Manganese compounds proved to decrease testicular weight and to produce necrosis of the seminiferous tubules after oral administration to adult experimental animals (13).

In support to the results of this study, it was reported that manganese compounds produce delay in postnatal sexual maturation in male mice associated with histological changes in the testes including congestion and seminiferous tubular necrosis $(15,16)$. The postnatal toxicity of manganese on testicular tissue was not investigated in this study as the doses of manganese chloride were administered only during the first 17 days of pregnancy.

The destructive effect of manganese compounds was suggested to be related to the substantial damage of the luteinizing hormone (LH) receptors on the surface of the Leydig cells resulting in loss of the function of testosterone secretion by these cells (17). Testosterone has significant effect in stimulating Sertoli cells to 
produce androgen binding protein which maintains the process of spermatogenesis ${ }^{(18)}$. Anti-MDA immunohistochemical reactivity shown in our results proved that $\mathrm{MgCl}_{2}$ induced lipid peroxidation. The lipid peroxidation after cellular injury leads to apoptosis and autophagy. The cellular membranes, because of their high lipid content, are especially susceptible to damage because lipid peroxidation reactions can alter the structure and function of critical membrane lipids leading to cell injury and cell death ${ }^{(19)}$.

This study concluded that prenatal oral administration of $\mathrm{MgCl}_{2}$ produces postnatal necrosis of the germinal epithelium in the seminiferous tubules. Anti-MDA immunohistochemical reactivity proved the role of lipid peroxidation leading to apoptosis.

\section{Acknowledgments}

Regard and gratefulness should be presented to the staff members Department of Human Anatomy at the College of Medicine Al-Nahrain University for their assistance and cooperation.

\section{Author contribution}

Fathel: performing the laboratory research work. Dr. Jarullah: performing production of the results. Dr. Mubarak: performing the interpretation of the results.

\section{Conflict of interest}

The author discloses no any financial and personal relationships with other people or organizations that inappropriately influence (bias) our work.

\section{Funding}

The research working funding was provided by the authors.

\section{References}

1. Liu XF, Zhang LM, Guan HN, et al. Effects of oxidative stress on apoptosis in manganese-induced testicular toxicity in cocks. Food Chem Toxicol. 2013. 60: 16876. doi: 10.1016/j.fct.2013.07.058.

2. Anderson MB, Pedigo NG, Katz RP et al. Histopathology of the testes from mice chronically treated with Cobalt. Reprod Toxicol. 1992. 7: 41-50.
3. Stokinger HE. The metals. In: Patty's Industrial hygiene and toxicology. Vol. 2A. 1st ed. New York: John Wiley and Sons. 1981. p. 1749-69.

4. Keen CL, Lonnerdal B, Hurley LS. Manganese. In: Biochemistry of the essential ultratrace elements. New York: Frieden; $1984 . \quad$ p. 89-132. doi: 10.1007/978-1-4684-4775-0_5

5. Ponnapakkam PT, Bailey KS, Graves KA, et al. Assessment of male reproductive system in the mice following oral manganese exposure. Reprod Toxicol. 2003. 17(5): 547-51. doi: 10.1016/S08906238(03)00101-1

6. Schwartz R, Apgar BJ, Wein EM. Apparent absorption and retension of $\mathrm{Ca}, \mathrm{Mg}, \mathrm{Mn}$, and $\mathrm{Zn}$ from a diet containing bran. Am J Clin Nutr. 1986. 43: 444-5.

7. Orten JM, Neuhaus OW. Human biochemistry. $9^{\text {th }}$ ed. St. Louis: Mosby company; 1975. p. 546-7.

8. Roels HA. Assessment of permissible exposure level to manganese in workers exposed to manganese dioxide dust. British J Ind Med. 1992. 49: 25-34. doi: 10.1136/oem.49.1.25

9. Del RD, Stewart AJ, Pellegrini N. A review of recent studies on malondialdehyde as toxic molecule and biological marker of oxidative stress. Nutr Metab Cardiovasc Dis. 2005. 15(4): 316-28. doi: 10.1016/j.numecd.2005.05.003

10. Deskin R, Bursian SJ, Edens FW. Neurochemical alterations induced by manganese chloride in neonatal rats. Neurotoxicology. 1980. 2: 65-73.

11. Chandra SV, Imam Z. Manganese induced histochemical and histological alterations in gastrointestinal mucosa of guinea pigs. Acta Pharmacol et Biochem. 1973. 4: 16-26. doi: 10.1111/j.1600-0773.1973.tb01546.x

12. Hurley L, Keen CL. Trace elements in human and animal nutrition. $5^{\text {th }}$ ed. Vol. 1. New York: Academic Press; 1987. p. 185-223. doi: 10.1016/B978-0-08092468-7.50010-7

13. Murthy RC, Srivastava RS, Gupta SK, et al. Manganese induced testicular changes in monkey. Exp Path. 1980.18: 240-4.

14. Bancroft JD, Stevens A. Theory and practice of histological techniques. $2^{\text {nd }}$ ed. Edinburgh: Churchill Livingstone; 1982. p. 109-22.

15. Laskey JW, Rehnberg JF, Hein JF, et al. Effect of chronic manganese exposure on selected reproductive parameters in rat. J Toxicol Environ Health. 1982; 9: 677-87. doi: $10.1080 / 15287398209530195$

16. Gray LE, Laskey JW. Multivariation analysis of the effect of manganese on the reproductive physiology and behavior of the male house mouse. J Toxicol Environ Health. 1980; 6: 861-7.

17. Jing $C$, Juan LF, Zong CZ. The inhibitory effects of manganese on steroidogenesis in rat primary Leydig cells by disrupting steroidogenic acute regulatory (StAR) protein expression. Toxicology. 2003; 187(23): 139-48.

18. Akinolye A, Abatan K, Alaka O; et al. Histopathological studies on the effect of 
calotropisprocera on the male reproductive organs of Wistar rat. African J Biomed Res. 2002; 5: 57-61.

19. Kiang JG, Fukumoto R, Gorbunov NV. Lipid peroxidation after ionizing irradiation leads to apoptosis and autophagy. In: Catala A. (ed.) Biochemistry, genetics and molecular biology "lipid peroxidation". USA: InTech; 2012. 63-70. doi: $10.5772 / 48189$

Correspondence to Dr. Hayder J. Mubarak

E-mail: hayder_67_67@yahoo.com

Received $18^{\text {th }}$ Nov. 2015

Accepted 20th Dec. 2016 
Published by Al-Nahrain College of Medicine P-ISSN 1681-6579

E-ISSN 2224-4719

Email: iraqijms@colmed-alnahrain.edu.iq http://www.colmed-alnahrain.edu.iq http://www.iraqijms.net

\title{
Ductectasia of the Breast; an Experience with Hadfield Operation (Radical Excision of the Subareolar Duct System)
}

\author{
Taqi S. Atiyah FICMS \\ Dept. of Surgery, College of Medicine/Al-Nahrain University, Baghdad, Iraq
}

\begin{abstract}
Background
\end{abstract}

Objective

Methods

Results

Conclusion

Keywords

Citation

Ductectasia of the breast is a benign condition. It is characterized by dilatation of the mammary ducts, which is often associated with periductal inflammation. Recurrent sepsis is often resistant to non-operative management. Furthermore, it can be very difficult to exclude malignancy.

To evaluate the significance of Hadfield operation (radical excision of major mammary ducts) in treatment of ductectasia and in detecting coexistent early carcinoma of the breast that cannot be visualized by ultrasound and mammography.

A Prospective study in Al-Imamein Al-Kadhimein Medical City for female patients with ductectasia of the breast over the period from April 2007 to April 2015. Ultrasound was done for all patients to prove the diagnosis and to exclude any suspicious mass. Mammography was done for patients above 40 years old. Patients with breast mass diagnosed clinically or by investigations were excluded from the study. Patients were divided into two groups according to the type of treatment; (Group A) patients were treated conservatively by antibiotics and analgesia, and (Group B) patients were treated surgically by radical excision of the major mammary ducts (Hadfield operation). Follow up of all patients for at least one year.

Over eight years of the study, the total number was 720 female patients, their age ranges from $21-$ 55 years with mean age ( $33 \pm 48$ year). Group A includes 614 ( $85.28 \%)$ patients, all of them were still complains of nipple discharge and not cured. Group B includes 106 (14.72\%) patients all of them were cured from nipple discharge. One patient in Group B accidentally found to have ductal carcinoma in situ of the breast which was not visualized by preoperative ultrasound or by mammography.

Conservative management of ductectasia of the breast does not relief symptoms of nipple discharge, while surgical excision of major mammary ducts relief symptoms of nipple discharge. Coexistence of breast carcinoma in situ (which was not appeared by preoperative ultrasound and mammography of the breast) in specimen of excised mammary ducts is an interested finding.

Ductectasia of the breast; Hadfield operation; early breast carcinoma

Taqi S. Atiyah. Ductectasia of the breast; an experience with hadfield operation (radical excision of the subareolar duct system). Iraqi JMS. 2017; Vol. 15(1): 20-26. doi: 10.22578/IJMS.15.1.4

\section{Introduction}

$\mathrm{D}$ uctectasia of the breast is a benign condition associated with periareolar sepsis (periductal mastitis). It is characterized by dilation of major ducts in the subareolar region. The ducts contain eosinophilic granular secretions and foamy histiocytes ${ }^{(1)}$. Ductectasia affects primarily middle-aged to elderly women but can occasionally occur in children (2). Nipple discharge is the third most common reason for presentation to a breast clinic (3). In cases of ductectasia, the dilated lactiferous ducts are filled with a stagnant brown or green secretion which may discharge. These fluids then set up an irritant reaction in surrounding tissue 
leading to periductal mastitis or even abscess and fistula formation. Sometimes the discharge may be blood stained (4).

An alternative theory suggests that periductal inflammation is the primary condition and, indeed, anaerobic bacterial infection is found in some cases. Nipple discharge (of any color), a subareolar mass, abscess, mammary duct fistula and/or nipple retraction are the most common symptoms. Conservative management of ductectasia is by antibiotic, the most appropriate agents being co-amoxiclav or flucloxacillin and metronidazole. Fibrosis eventually develops, which may cause slit-like nipple retraction. In some cases, a chronic indurated mass forms beneath the areola, which mimics a carcinoma. Recurrent sepsis is often resistant to non-operative intervention. Persistent or recurrent cases of ductectasia are managed with surgical excision of the ducts below the nipple. A focused excision is preferable, as there are lower rates of seroma formation, nipple numbness and nipple inversion (5).

Furthermore, it can be very difficult to exclude malignancy and ultrasound of the breast and mammography may still miss a small proportion of cases of carcinoma of the breast. A mammogram should be performed whenever complicated, malignant and uncommon forms of mastitis are suspected (6). The aim of the study was to evaluate the methods of the management of patients with ductectasia of the breast

\section{Methods}

After ethical approval of the study by Institution Review Board in the College of Medicine, Al-Nahrain University, a prospective cross sectional study performed in Al-Imamein Al-Kadhimein Medical City, Breast Consultation Clinic, for female patients complained of nipple discharge and non-cyclical mastalgia (and were diagnosed as ductectasia of the breast by ultrasound) over the period from April 2007April 2015.
Exclusion criteria include; patients with palpable breast mass, or had radiological mass by ultrasound or mammography, patients with bloody nipple discharge, and patients with coexistent breast carcinoma; all those patients were excluded from the study because they were already managed by the protocol of breast mass, or bloody nipple discharge.

Inclusion criteria include patients presented with non-cyclic mastalgia and nipple discharge (other than bloody discharge) and were proved to have ductectasia of the breast by ultrasound; with no other detectable breast diseases by clinical examination or radiological investigations.

Proper history and physical examination was done for every patient. Patients were presented with non-cyclic mastalgia with nipple discharge of different colors (brown or greenish discharge). Ultrasound of the breast was done for all patients to prove the diagnosis and to exclude any suspicious mass or other disease of the breast. Mammography was done for older patients for the same reason. Nipple discharge of all patients was sent for cytology to exclude malignancy and for culture and sensitively to choose appropriate antibiotics.

Patients were divided into two groups according to the type of treatment; (Group A) patients were treated conservatively by antibiotics, analgesia, reassurance and follow up; and (Group B) patients were treated surgically by radical excision of the subareolar duct system (Hadfield Operation) after explaining for them the procedure, its possible complications, and written consent was taken from them; all the ducts under the nipple and areola are excised and it is, therefore, obviously not advised if future breastfeeding is anticipated; the excised major mammary ducts were sent for histopathological examination.

One patient with incidental finding of ductal carcinoma in situ (which is not shown by preoperative ultrasound or preoperative mammography and was an accidental histopathological result) was submitted to simple mastectomy. 
All the patients were followed up for at least one year and were monitored for, nipple discharge, non-cyclic mastalgia, and complications of surgery for those patients who underwent surgery.

\section{Results}

Over eight years, the total number was 720 female patients; their age ranges from 21-55 years with mean age ( $33 \pm 48$ year). (Group A) patients, who were treated conservatively by antibiotics and analgesia, include 614 (85.28\%) patients. (Group B) patients who were treated by surgical excision of the major mammary ducts (Hadfield operation) include 106(14.72\%) patients. Figure (1) shows the number of patients treated conservatively versus operative treatment (Hadfield operation). Cytological examination of the nipple discharge was negative for malignancy in all patients.

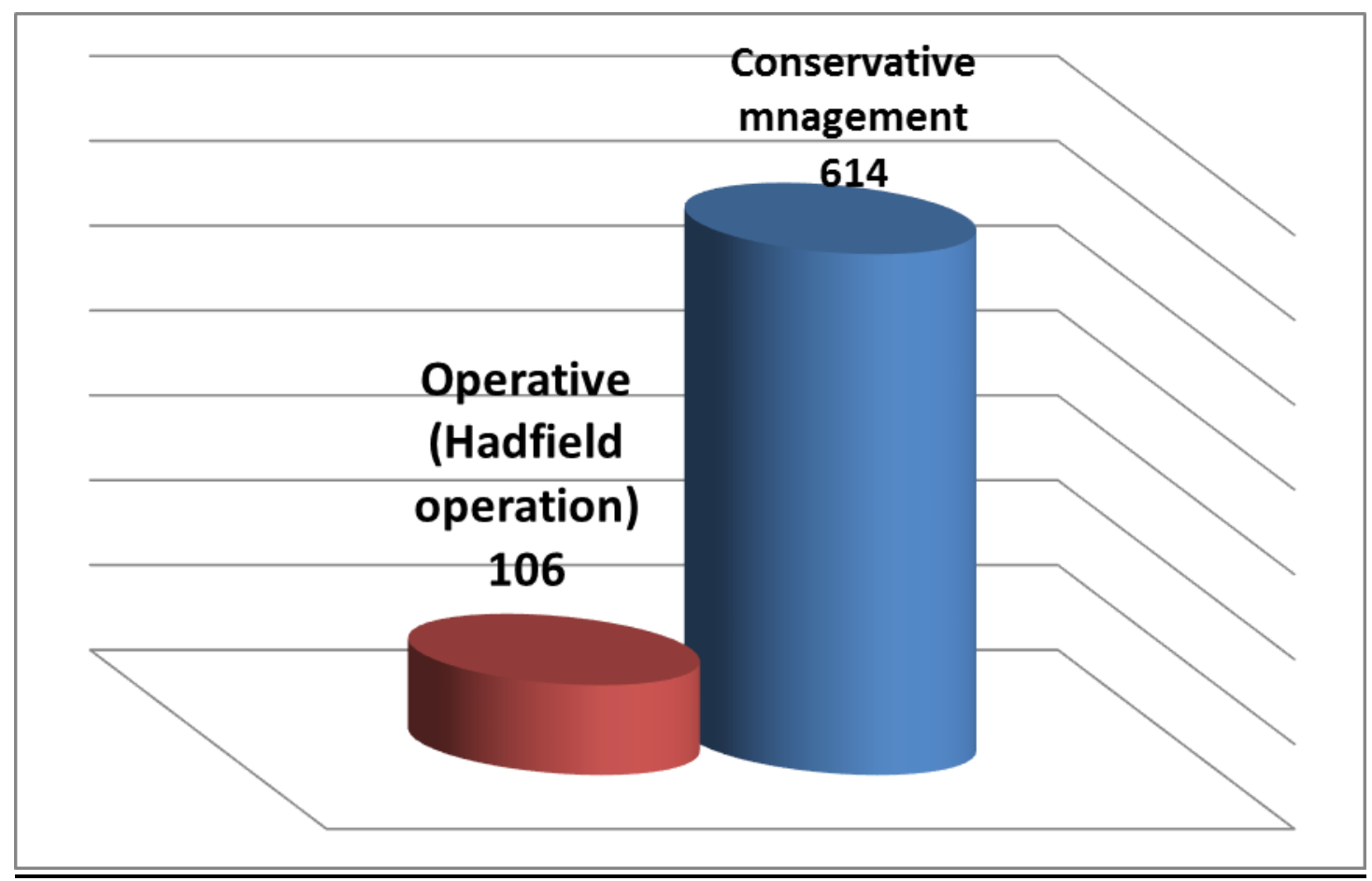

Figure 1. The number of patients treated conservatively versus operative treatment (Hadfield operation)

Operative findings of patients who underwent surgery shows dilatation of major mammary ducts in all patients in addition to that, some patients had other findings; 6 (5.66\%) patients had breast abscess that cause destruction of more than half of the breast tissue (due to neglected ductectasia); 4 (3.77\%) patients had toothpaste like material that involve the whole breast tissue even its periphery (thickened secretions that involve the minor ducts). One (0.94\%) patient unexpectedly found that her histopathological examination was ductal carcinoma in situ, which was not appeared preoperatively (she had no palpable mass on clinical examination and her preoperative investigations was normal ultrasound and normal mammography), simple mastectomy was done for this patient after receiving her histopathological result. Table (1) shows the unexpected operative findings in addition to dilated major mammary ducts.

Follow up of all patients for at least one year shows that Group A patients still complain of nipple discharge and breast discomfort in spite of treatment with antibiotics and analgesia. While Group B patients who were treated by 
surgical excision of major mammary ducts (Hadfield operation); 106 (100\%) patients got complete relief of nipple discharge which is significant $(P<0.05)$; and 95 (89.62\%) patients had got complete relief of their pain and discomfort of the breast and had no complications which is also significant $(\mathrm{P}<$ $0.05)$; while 11 (10.38\%) patients still have, but mild discomfort of the breast. Table (2) shows symptoms of patients after one year follow up.

Table 1. Additional Operative findings apart from dilated major mammary ducts

\begin{tabular}{lc}
\hline Additional operative findings (other than ductectasia) & $\begin{array}{c}\text { No. of patients } \\
\text { (\%) }\end{array}$ \\
\hline $\begin{array}{l}\text { Toothpaste like material that involve the whole breast } \\
\text { Breast abscess that cause destruction of more than half of the } \\
\text { breast tissue }\end{array}$ & $4(3.77 \%)$ \\
$\begin{array}{l}\text { Coexistent carcinoma in situ that was not visualized preoperatively } \\
\text { (normal U/S and mammography preoperatively) }\end{array}$ & $1(5.66 \%)$ \\
\hline
\end{tabular}

Table 2. Symptoms of patients after one year follow up; conservative treatment versus surgical treatment

\begin{tabular}{cccccc}
\hline \multirow{2}{*}{ Symptoms } & \multicolumn{2}{c}{ Conservative treatment } & \multicolumn{2}{c}{$\begin{array}{c}\text { Surgical treatment } \\
\text { (Hadfield operation) }\end{array}$} & Significance \\
\cline { 2 - 5 } & $\begin{array}{c}\text { After } \\
\text { treatment }\end{array}$ & $\begin{array}{c}\text { Before } \\
\text { treatment }\end{array}$ & $\begin{array}{c}\text { After } \\
\text { treatment }\end{array}$ & $\begin{array}{c}\text { Before } \\
\text { treatment }\end{array}$ & level \\
\hline $\begin{array}{c}\text { Nipple } \\
\text { discharge } \\
\begin{array}{c}\text { Pain and } \\
\text { discomfort }\end{array}\end{array}$ & 614 & $614(100 \%)$ & 106 & None & $\mathrm{P}<0.05$ \\
\hline
\end{tabular}

Complications of surgery were, 11 (10.38\%) patients had experienced altered nipple sensation and paraesthesia; 5 (4.71\%) patients had mild deformity of the nipple. Table (3) shows the complications of surgery.

Table 3. Complication of surgery (Hadfield operation)

\begin{tabular}{cc}
\hline Complications of Surgery & No. of patients (\%) \\
\hline Altered nipple sensation and paraesthesia & $11(10.38 \%)$ \\
Deformity of the nipple & $5(4.71 \%)$ \\
\hline
\end{tabular}

\section{Discussion}

Nipple discharge is the third most common reason for presentation to a breast clinic (3). Conservative management of patients with ductectasia of the breast with antibiotics does not cure the condition, and the patients were still complaining of nipple discharge and non- cyclic mastalgia. Ductectasia for prolonged time may lead to advanced destruction of the breast tissue by sepsis.

Surgical excision of major mammary ducts (Hadfield operation) relief the patient's symptoms of nipple discharge $(P<0.05)$, and non-cyclic mastalgia. In the cohort of patients 
operated upon; Hadfield operation was safe, simple and without serious complications other than occasional cases of altered nipple sensation, and deformity of the nipple.

Unfortunately, one patient's histopathological report was carcinoma in situ, which was not shown by clinical examination or by radiological examination (ultrasound and mammography). This patient was submitted to simple mastectomy.

Ultrasound of the breast remains operator dependent. Normal mammogram does not exclude the presence of carcinoma. Early breast carcinoma may not present as a welldefined mass that can be detected by radiological examination. In total, 5 per cent of breast cancers are missed by population-based mammographic screening programs, even in retrospect such carcinomas are not apparent (7).

For these reasons, and when breastfeeding is not anticipated, patients who were bothered by nipple discharge, may get benefit by surgical excision of major lactiferous ducts (Hadfield operation) because, beside they get rid of nipple discharge and relief their symptoms without long term courses of antibiotics; there may be a coexistent carcinoma in situ which had not been detected by triple assessment of the breast and so get proper early management and prevent serious events if delayed; as it was found in one (0.94\%) of the patients with ductectasia in this study who had normal preoperative ultrasound and mammography of the breast and treated surgically by excision of the major mammary ducts (Hadfield operation) and incidentally found to have ductal carcinoma in situ, for which simple mastectomy was performed.

Ductal imaging by ductography is helpful in detecting ductal carcinoma of the breast but it is non-specific ${ }^{(8)}$. Ductography has a highpositive predictive value in the diagnosis of intra ductal lesions, papilloma and carcinoma; however, it has a low sensitivity and is painful (3).
Breast ductoscopy is an evolving technology. However, further studies are required to define its role more clearly, as there are still limitations in clinical practice (8-14). Magnetic resonance imaging (MRI) may play an adjunctive role, aiding in the differentiation of benign ductal abnormalities from malignant ones (15-18).

Although not a routine practice in the United Kingdom; a number of techniques have been used to determine the cause of nipple discharge, beyond the triple assessment. Nipple discharge cytology has a low sensitivity for the detection of breast cancer (19) and is unlikely to alter the management of patients with nipple discharge ${ }^{(20)}$.

Hadfield's procedure and microdochectomy are the most common techniques for the surgical treatment of patients with nipple discharge. Both techniques enable histopathological diagnosis and treatment of symptoms. Recognized side effects of these procedures include nipple deformity, necrosis, and periareolar anesthesia in some cases $(20 \%)$ (2123).

There are many advanced studies and investigations for early detection of breast carcinoma, but all the investigations carry a certain percentage of false negative results in detecting early breast carcinoma, even advanced investigations like MR imaging with different contrast materials are not $100 \%$ accurate in excluding early breast carcinoma (23-32) and this support the advice of this study treating older patients with ductectasia (when breastfeeding is not anticipated) by surgical excision of the major lactiferous ducts (Hadfield operation), in trial to find coexistent ductal carcinoma in situ that may not be detected by mammography nor by ultrasound study of the breast.

This study concluded that conservative management of ductectasia of the breast by antibiotics does not relief symptoms. When breastfeeding is not anticipated, patients who were bothered by nipple discharge due to ductectasia may get benefit by surgical excision 
of major lactiferous ducts (Hadfield operation) to relief their symptoms and to detect any coexistent carcinoma in situ which had not been detected by mammography and ultrasound.

\section{Acknowledgments}

None.

\section{Conflict of interest}

None.

\section{Funding}

Self-funding.

\section{References}

1. Guray $M$, Sahin $A A$. Benign breast diseases: classification, diagnosis, and management. Oncologist. 2006; 11(5) :435-49. doi: 10.1634/theoncologist.11-5-435.

2. McHoney M, Munro F, Mackinlay G. Mammary duct ectasia in children: report of a short series and review of the literature. Early Hum Dev. 2011; 87(8): 527-30. doi: 10.1016/j.earlhumdev.2011.04.005.

3. Goksel HA, Yagmurdur MC, Demirhan B, et al. Management strategies for patients with nipple discharge. Langenbecks Archiv Surg. 2005; 390(1): 52-8.

4. Hussain AN, Policarpio C, Vincent MT. Evaluating nipple discharge. Obstet Gynecol Surv. 2006; 61(4): 278-83.

5. Zervoudis $S$, latrakis $G$, Economides $P$, et al. Nipple discharge screening. Women's Health (Lond). 2010; 6(1): 135-51. doi: 10.2217/whe.09.81.

6. Kamal RM, Hamed ST, Salem DS. Classification of inflammatory breast disorders and step by step diagnosis. Breast J. 2009; 15(4): 367-80. doi: 10.1111/j.1524-4741.2009.00740.x.

7. Morakkabati-Spitz N, Leutner C, Schild H, et al. Diagnostic usefulness of segmental and linear enhancement in dynamic breast MRI. Eur Radiol. 2005; 15(9): 2010-7.

8. Hou MF, Tsai KB, Ou-Yang F, et al. Is a one-step operation for breast cancer patients presenting nipple discharge without palpable mass feasible? Breast. 2002; 11: 402-7.

9. Louie LD, Crowe JP, Dawson AE, et al. Identification of breast cancer in patients with pathologic nipple discharge: does ductoscopy predict malignancy? Am J Surg. 2006; 192(4): 530-3.

10. Escobar PF, Crowe JP, Matsunaga T, et al. The clinical applications of mammary ductoscopy. Am J Surg. 2006; 191(2): 211-5.

11. Dooley WC. Routine operative breast endoscopy for bloody nipple discharge. Ann Surg Oncol. 2002; 9(9): 920-3.
12. Denewer A, El-Etribi $K, \mathrm{Nada} N$, et al. The role and limitations of mammary ductoscope in management of pathologic nipple discharge. Breast J. 2008; 14(5): 442-9. doi: 10.1111/j.1524-4741.2008.00620.x.

13. Simpson JS, Connolly EM, Leong WL, et al. Mammary ductoscopy in the evaluation and treatment of pathologic nipple discharge: a Canadian experience. Can J Surg. 2009; 52(6): E245-8.

14. Kamali S, Bender O, Aydin MT, et al. Ductoscopy in the evaluation and management of nipple discharge. Ann Surg Oncol. 2010; 17(3): 778-83.

15. Dooley WC. Breast ductoscopy and the evolution of the intraductal approach to breast cancer. Breast. 2009; 15, supplement 1: S90-4. doi: 10.1111/j.15244741.2009.00799.x.

16. Hirose M, Otsuki N, Hayano D, et al. Multi-volume fusion imaging of $M R$ ductography and $M R$ mammography for patients with nipple discharge. Magn Reson Med Sci. 2006; 5(2): 105-12.

17. Tokuda Y, Kuriyama K, Nakamoto A, et al. Evaluation of suspicious nipple discharge by magnetic resonance mammography based on breast imaging reporting and data system magnetic resonance imaging descriptors. J Comput Assist Tomogr. 2009; 33(1): 5862. doi: 10.1097/RCT.0b013e3181671ad2.

18. Lorenzon M, Zuiani C, Linda A, et al. Magnetic resonance imaging in patients with nipple discharge: should we recommend it? Eur Radiol. 2011 May;21(5):899-907. doi: 10.1007/s00330-010-2009$y$.

19. Ballesio L, Maggi C, Savelli S, et al. Role of breast magnetic resonance imaging (MRI) in patients with unilateral nipple discharge: preliminary study. Radiol Med. 2008; 113(2): 249-64. doi: 10.1007/s11547008-0245-x.

20. Cabioglu N, Hunt KK, Singletary SE, et al. Surgical decision making and factors determining a diagnosis of breast carcinoma in women presenting with nipple discharge. J Am Coll Surg. 2003; 196(3): 354-64.

21. Tamaki $Y$, Akashi-Tanaka $S$, Ishida $T$, et al. 3D imaging of intraductal spread of breast cancer and its clinical application for navigation surgery. Breast Cancer. 2002; 9: 289-95.

22. Dixon JM. ABC of breast diseases. $4^{\text {th }}$ ed. UK: WileyBlackwell, BMJ Books. 1994.

23. Orel SG, Schnall. MR imaging of the breast for the detection, diagnosis, and staging of breast cancer. Radiology. 2001; 220(1): 13-30.

24. Morris EA. Review of breast MRI: indications and limitations. In: Miller WT, Berg WA. (eds.) Seminars in roentgenology. Vol. 36. Breast imaging. Philadelphia: Saunders, 2001: p. 226-37.

25. Satake H, Shimamoto K, Sawaki A, et al. Role of ultrasonography in the detection of intraductal spread of breast cancer: correlation with pathologic findings, mammography and MR imaging. Eur Radiol. 2000; 10: 1726-32.

26. Uematsu T, Sano M, Homma $K$, et al. Comparison between high-resolution helical CT and pathology in breast examination. Acta Radiol. 2002; 43: 385-90. 
27. Nakahara H, Namba K, Fukami A, et al. Threedimensional MR imaging of mammographically detected suspicious microcalcifications. Breast Cancer. 2001; 8: 116-24.

28. Lindfors KK, Boone JM, Nelson TR, et al. Dedicated breast CT: initial clinical experience. Radiology. 2008; 246 (3): 725-33.

29. Newell D, Nie K, Chen JH, et al. Selection of diagnostic features on breast MRI to differentiate between malignant and benign lesions using computer-aided diagnosis: differences in lesions presenting as mass and non-mass like enhancement. Eur Radiol. 2010; 20(4): 771-81.

30. Chen SC, Carton AK, Albert M, et al. Initial clinical experience with contrast-enhanced digital breast tomosynthesis. Acad Radiol. 2007; 14(2): 229-38.
31. Perrone A, Lo Mele L, Sassi S, et al. MDCT of the breast. AJR Am J Roentgenol. 2008; 190(6): 1644-51. doi: 10.2214/AJR.07.3145.

32. Zhao $H, X u R$, Ouyang $Q$, et al. Contrast-enhanced ultrasound is helpful in the differentiation of malignant and benign breast lesions. Eur J Radiol. 2010; 73(2): 288-93. doi: 10.1016/j.ejrad.2009.05.043.

\section{E-mail: taqi.atyia@yahoo.com Received 4 ${ }^{\text {th }}$ Apr. 2016 Accepted 3 $3^{\text {rd }}$ Jan. 2017}




\title{
Iraqi JMS
}

Published by Al-Nahrain College of Medicine P-ISSN 1681-6579 E-ISSN 2224-4719

Email: iraqijms@colmed-alnahrain.edu.iq http://www.colmed-alnahrain.edu.iq http://www.iraqijms.net

\section{Comparison of Two Virus Concentration Methods for Enteric Viruses Detection in Moroccan Wastewater and Treated Effluent}

\author{
Hasna A. Amdiouni ${ }^{1,2} P h D$, Leena Maunula ${ }^{3} P h D$, Arwa M. Al-Shuwaikh ${ }^{4} P h D$, Jalal Nourlil ${ }^{1} M D$ \\ ${ }^{1}$ Medical Virology and BSL3 Laboratory, Institut Pasteur du Maroc. Casablanca, Morocco, ${ }^{2}$ Laboratory of Physiology \\ and Molecular Genetics, Faculty of Sciences, Aîn chock, University Hassan II, Casablanca, Morocco, ${ }^{3}$ Dept. of Food \\ Hygiene and Environmental Health, Faculty of Veterinary Medicine, University of Helsinki, Helsinki, Finland, ${ }^{4}$ Dept. of \\ Microbiology, College of Medicine, Al-Nahrain University, Baghdad, Iraq
}

\begin{abstract}
Background The effluents of wastewater treatment plants may contain infectious human viruses representing a major public health issue. Wastewater must be analyzed for viruses' detection using easy and rapid protocol.

Objective To compare between two viral concentration methods used for detection of enteric viruses in wastewater and treated effluent. Then assess the presence of viral genomes by cell culture and polymerase chain reaction (PCR).

Methods Fifty samples of wastewater were collected from two wastewater treatment plants during one year survey (January-December 2009) in order to compare two virus concentration methods; the polyethylene glycol (PEG) precipitation and the two-phase separation method, advised by the World Health Organization guidelines. Then assess the presence of viral genomes of human enteroviruses (EV), human adenoviruses (HAdV), hepatitis $A$ and $E$ viruses (HAV and HEV), human noroviruses (HuNoV), human rotaviruses (RV) and human astroviruses (HAstV) by cell culture and PCR technique.

Results This study, using three statistical tests, showed that there was no significant difference between the two concentration methods: the PEG precipitation and the two-phase separation ( $P>0.05)$.

Conclusion Considering this study with protocol time, cost and simplicity. The PEG precipitation seems to be an alternative method of the two-phase separation method.

Keywords Wastewater, enteric-virus, concentration methods, PCR, cell culture, Morocco

Citation Hasna A. Amdiouni, Leena Maunula, Arwa M. Al-Shuwaikh, Jalal Nourlil. Comparison of two virus concentration methods for enteric viruses detection in Moroccan wastewater and treated effluent. Iraqi JMS. 2017; Vol. 15(1): 27-38. doi: 10.22578/IJMS.15.1.5
\end{abstract}

List of abbreviation: PEG = polyethylene glycol, EV = Human enteroviruses, HAdV = Human adenoviruses, HAV = Hepatitis A, HEV = Hepatitis $E$ viruses, HuNoV = Human noroviruses, RV = Human rotaviruses, $\mathrm{HAstV}=$ Human astroviruses

\section{Introduction}

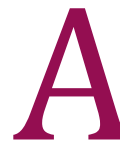
wide variety of pathogenic organisms pass through municipal wastewater treatment systems, including viruses ${ }^{(1)}$. The enteric viruses found in human feces belong to more than 140 types ${ }^{(2)}$. According to public health data, those types can colonize the gastrointestinal tracts and cause a wide variety of illnesses, inducing variable epidemiological features and some water-related diseases (3). EV, HAV, HEV, HAdV, HuNoV, RV and HAstV have been detected in raw wastewater and treated effluent in different studies ${ }^{(4-9)}$. 
There are several studies, which have demonstrated the advantage of environmental surveillance as an additional tool to determine the epidemiology of different viruses circulating in a given community $(10,11)$. The availability of improved detection techniques, combined with an increased awareness of gastroenteritis-causing viral pathogens, has also led to the establishment of surveillance systems in various countries (12). While a number of techniques have been developed and refined, it has been proven difficult to achieve the detection of all relevant virus types over the spectrum of water quality matrices that exist in nature and human-constructed facilities (13). The detection of viruses in wastewater, especially at low concentrations, is a major challenge. Because relatively few viral particles are present in wastewater samples, it is necessary to concentrate the viruses in a large volume of water, commonly from 13 to $21 \mathrm{ml}(14,15)$. Hence, many virus concentration methods have been developed: the two-phase separation (16), methods using an electronegative filter (17), polyethylene glycol (PEG) precipitation ${ }^{(18,19)}$, the ultracentrifugation (4) and methods using an electropositive filter (20). Furthermore, two virus concentration methods from wastewater are advised by the WHO for environmental poliovirus surveillance (21). The first one uses bags with sorbent macroporous glass to trap viruses and the second uses the two-phase separation, which is applied in this study. Regarding the comparison of virus concentration methods in water, several studies have been conducted using polymerase chain reaction (PCR) and cell culture ${ }^{(13,22)}$.

In the present study, a one-year survey (January - December 2009) was conducted in order to compare two virus concentration methods, the PEG precipitation and the twophase separation using three statistical tests, to analyze the correlation between the cell culture and PCR for both EV and HAdV and to assess the presence of viral genomes of $E V$, HAV, HEV, HAdV, HuNoV, RV and HAstV by each method. Furthermore, the presence of infectious EV and HAdV in raw wastewater and treated effluent was also evaluated.

\section{Methods}

\section{Sample collection}

From January to December 2009, fifty samples (25 raw wastewater and 25 treated effluents) were collected monthly from two wastewater treatment plants (WWTPs): Zone 1 (Z1) and Zone 2 (Z2). The plants are officially registered as secondary treatment plants by lagooning and located at $70 \mathrm{~km}$ from Casablanca. All 50 samples were collected in plastic bottles during sampling and delivered to the laboratory for immediate concentration.

\section{Concentration methods}

The wastewater samples were concentrated using two methods. The first one "PEG precipitation" was carried out as described elsewhere ${ }^{(18)}$ with modifications. Five hundred milliliters of sample were clarified by centrifugation ( $30 \mathrm{~min}, 1000 \mathrm{~g}$ ) and the pellet was resuspended in $10 \mathrm{ml}$ of the supernatant. The remaining portion of supernatant was saved. Chloroform was added to the resuspended sample to a concentration of $10 \%$ ( $\mathrm{v} / \mathrm{v}$, Sigma, USA) and mixed, and the mixture was centrifuged again ( $5 \mathrm{~min}, 1000 \mathrm{~g}$ ). The first and second supernatants were combined. The volume was measured and the $\mathrm{pH}$ was adjusted to (7.5). The PEG- $\mathrm{NaCl}$ technique as described by ${ }^{(23)}$ was used with modification. The combined supernatants were supplemented with $\mathrm{NaCl}$ and PEG until a final concentration of $2.2 \%$ (w) $\mathrm{NaCl}$ (Sigma, St Louis, USA) and 7\% (w) PEG 6000 (Fluka, Steinheim, Germany) was obtained. The mixture was stirred $4 \mathrm{~h}$ at $4{ }^{\circ} \mathrm{C}$ and then centrifuged for $2 \mathrm{~h}$ at $2000 \mathrm{~g}$ at $4{ }^{\circ} \mathrm{C}$. Supernatant was discarded and the pellet was suspended in $5 \mathrm{ml}$ of phosphate buffer saline (PBS).

In the second method "two-phase separation" $(16,21), 500 \mathrm{ml}$ of sample was centrifuged for (10 $\mathrm{min}$ at $1000 \mathrm{~g}$ ). The pellet was stored and the $\mathrm{pH}$ of the supernatant was adjusted to neutral 
$\mathrm{pH}$ (7-7.5). The supernatant was mixed with $39.5 \mathrm{ml}$ of $22 \%$ dextran (Sigma Aldrich, St Louis, USA), $287 \mathrm{ml}$ of 29 \% PEG 6000 (Fluka, Steinheim, Germany), and $35 \mathrm{ml}$ of $(5 \mathrm{~N}) \mathrm{NaCl}$ (Sigma, St Louis, USA) and kept in constant agitation for $1 \mathrm{~h}$ at $4{ }^{\circ} \mathrm{C}$ using a magnetic stirrer. After overnight incubation at $4{ }^{\circ} \mathrm{C}$ in a separation funnel, the entire lower layer and the interphase were collected. The pellet from the first centrifugation was resuspended in this concentrate and the suspension was extracted with $20 \%$ volume of chloroform by shaking vigorously, followed by centrifugation for ( 5 $\min$ at $1000 \mathrm{~g})$. The supernatant $(10 \mathrm{ml})$ was recovered and decontaminated by antibiotic (e.g., penicillin $G$ and streptomycin to final concentrations of $100 \mathrm{IU} / \mathrm{ml}$ and $100 \mathrm{~g} / \mathrm{ml}$, respectively).

\section{Detection of EV and HAdV by cell culture}

Two cell lines, human rhabdomyosarcoma tumour tissue (RD) and laryngeal carcinoma cells (Hep2), were used for inoculation. Cells were cultivated in minimum essential medium (MEM; Gibco) supplemented with $2 \%$ fetal bovine serum (FBS), penicillin and streptomycin, then incubated at $37{ }^{\circ} \mathrm{C}$ with $5 \%$ $\mathrm{CO}_{2}$ for 5 days. For cell culture infection, cells were grown in 24-well microplates. The water concentrates were filtered through a $0.22 \mu \mathrm{m}$ pore-size membrane filter, and $100 \mu \mathrm{l}$ of filtered water samples was inoculated in duplicate wells. Virus replication was monitored daily under the microscope up to 7 days. All cultures with or without cytopathic effect (CPE) were frozen and thawed up to three times to release the virus, the debris was removed by centrifugation at $1500 \times$ g for 20 $\min$ and virus suspensions were stored at -80 ${ }^{\circ} \mathrm{C}$ until further processing. Echovirus 7 (EV-7) and adenovirus C5 (HAdV-C5) used as positive controls were obtained from patient fecal samples and maintained in Institut Pasteur du Maroc Medical Virology and BSL3 Laboratory Casablanca Morocco. Titers of EV-7 and HAdV5 were 107 and 106 TCID50 per $100 \mu \mathrm{l}$, respectively, determined by $50 \%$ tissue culture infective dose (TCID50).

\section{Detection of EV, HAV, HEV, RV, HuNoV GI, HuNoV GII and HAstV by PCR}

All PCR done on cell culture supernatant even if the cells are not specific for viruses because The use of integrated cell culture/PCR (ICCPCR) helps to dilute the PCR inhibitors present in environmental samples and allows the in vitro amplification of the virus on different cellular systems as reported by Reynolds, 2004 (24).

Nucleic acid extraction: The High Pure Viral Nucleic Acid Kit (Roche, California, USA) was used to extract the DNA and RNA from the samples according to manufacturer's instructions. DNA and RNA extracts obtained were performed on $200 \mu \mathrm{l}$ of sample concentrate and eluted in $50 \mu$ l.

Positive controls: HAV type IB and RV type G9P (2) were obtained from patient fecal samples and maintained in Institut Pasteur du Maroc Medical Virology and BSL3 Laboratory. HEV type G3 was kindly provided by Dr. Leena Maunula from the Faculty of Veterinary Medicine, university of Helsinki, Finland. HAstV- 1 and NoV GII.4 were kindly provided by Dr. Nicole Gregoricus from the Calicivirus Laboratory, CDC, Atlanta, GA. These virus samples were used as positive controls during molecular detection. All virus stocks were stored at $-80^{\circ} \mathrm{C}$ until use.

PCR for adenovirus detection: Polymerase chain reaction for HAdV was performed following the protocol of Casas et al., 2005 (25). The primers for the first round of $P C R$ were ADHEX1F (5'-CAACACCTAYGASTACATGAA-3') and ADHEX1R (5'-KATGGGGTARAGCATGTT-3'), yielding an amplicon of $473 \mathrm{bp}$, and the primers for the second round of $P C R$ were ADHEX2F (5'-CCCITTYAACCACCACCG-3') and ADHEX2R (5'-ACATCCTTBCKGAAGTTCCA-3') with a resulting amplicon of $168 \mathrm{bp}$. Seven microlitres of sample was used in $50 \mu \mathrm{l}$ reaction mixture containing $1 \mathrm{X}$ PCR buffer, $2 \mathrm{mmol}$ I-I 1 $\mathrm{MgCl}_{2}, 200$ Imol I-I deoxynucleoside 
triphosphate (dNTP), $0.5 \mu \mathrm{mol}$ l-I concentration of each primer and $1.5 \mathrm{U}$ of Taq DNA polymerase (Invitrogen, London, UK). The PCR cycles for the first round and nested PCR were $94^{\circ} \mathrm{C}$ for $5 \mathrm{~min}$, followed by 35 cycles of $94^{\circ} \mathrm{C}$ for $30 \mathrm{~s}, 50{ }^{\circ} \mathrm{C}$ for $30 \mathrm{~s}$ and $72{ }^{\circ} \mathrm{C}$ for $30 \mathrm{~s}$; and a final extension at $72{ }^{\circ} \mathrm{C}$ for $7 \mathrm{~min}$. PCR products were resolved by electrophoresis on $2 \%$ agarose gel.

Reverse transcription PCR (RT-PCR) for EV, HAV, HEV, RV, HuNoV and HAstV detection: For RT-PCR reaction, cDNA synthesis was performed following the protocol of Amdiouni et al., $2012^{(26)}$ : a pd (N) 6 random primer and 5 $\mu l$ of RNA were mixed, heated at $70^{\circ} \mathrm{C}$ for $5 \mathrm{~min}$ and quickly chilled on ice. $200 \mu \mathrm{mol} \mathrm{I}-1$ of dNTP, $20 \mathrm{U}$ of RNAsin, $20 \mathrm{U}$ of reverse transcriptase (MMLV) and $5 \mu \mathrm{l}$ of $5 \mathrm{X}$ buffer MMLV were added in the tubes and incubated at $37^{\circ} \mathrm{C}$ for $60 \mathrm{~min}$ and $94^{\circ} \mathrm{C}$ for $5 \mathrm{~min}$.

For PCR reaction of all retrieved enteric viruses, $5 \mu \mathrm{l}$ of cDNA was used as template for PCR amplification carried out in a final volume of 50 $\mu l$ that included: $5 \mu$ of $10 X$ PCR buffer, 200 $\mu \mathrm{mol} \mathrm{I}-1$ of each dNTP, 2 mmol I-1 MgCl2, $1.5 \mathrm{U}$ of Taq DNA polymerase, $0.3 \mathrm{Imol} \mathrm{I}-1$ of each primers. The thermocycler profile was $5 \mathrm{~min}$ at $94{ }^{\circ} \mathrm{C}$ followed by 35 cycles of 20 s at $94{ }^{\circ} \mathrm{C}$, 30s at $\mathrm{Tm}$ and $30 \mathrm{~s}$ at $72{ }^{\circ} \mathrm{C}$; and a final extension of $10 \mathrm{~min}$ at $72{ }^{\circ} \mathrm{C}$. The $\mathrm{PCR}$ products were analyzed on ethidium bromide ( $\mathrm{EtBr})$-stained agarose gels. The $\mathrm{Tm}$ and primers used are listed in table 1.

\section{Statistical analysis}

All statistical analyses were carried out with GraphPad Prism software version 6.03 using binary variables (presence or absence) of independent groups, except the analysis results of the presence of infectious EV and HAdV in raw wastewater and treated effluent was calculated using the Excel program. The comparison of the ability of the two virus concentration methods to concentrate infectious EV and HAdV was carried out by Fischer exact test, the correlation between the cell culture and PCR was determined by chi- squared (X2) test and the assessment of the viral genome by method was performed by student test (t-test). Differences were considered significant if $\mathrm{P}<0.05$.

\section{Results}

\section{Presence of infectious EV and HAdV by cell culture}

To detect both infectious and non-infectious HAdV and EV on the Hep2 and RD monolayer, all cultures with or without CPE were analysed by PCR (Fig. 1). The results obtained by cell culture infection showed that $12 \%(6 / 50)$ of samples induced positive CPE for culturable EV on the RD cell line and 10\% (5/50) of samples on the Hep2 cell line using the PEG precipitation method and $8 \%(4 / 50)$ and $2 \%$ $(1 / 50)$ of samples were positive on the RD and Hep2 cell lines respectively using the two phase separation method. HAdV was detected on the RD and Hep2 cell lines, in $8 \%(4 / 50)$ and $12 \%$ $(6 / 50)$ of samples, using the PEG precipitation method, and in $6 \%(3 / 50)$ and $12 \%(6 / 50)$ of samples using the two phase separation, respectively (Fig. 2). However, the difference between the two methods was statistically not significant for the EV and HAdV concentration ( $n=50, P=0.24$ and $P=0.74$, respectively, Fisher exact test).

\section{Correlation between the cell culture and PCR}

Among the fifty wastewater samples analyzed for EV and HAdV, 26\% (13/50) and 30\% (15/50) samples were positive by PCR, whereas $22 \%$ $(11 / 50)$ and $20 \%(10 / 50)$ were positive for the cell culture, respectively using the PEG precipitation method. However, the results of the two-phase separation method showed that $22 \%(11 / 50)$ and $26 \%(13 / 50)$ of samples were positive by PCR for EV and HAdV, while $10 \%$ $(5 / 50)$ and $18 \%(9 / 50)$ were positive by cell culture, respectively (Fig. 3 and 4). This study found that there is no correlation between the detection of infectious EV and HAdV and viral genomes, for both methods: the PEG precipitation and the two phase separation ( $n=$ $50, P=0.34 \& P=0.74$, respectively, $X 2$ test). 
Table 1. Primers used for the various RT-PCR

\begin{tabular}{|c|c|c|c|c|c|}
\hline Virus & Sequence & Region & $\begin{array}{l}\mathrm{Tm} \\
\left({ }^{\circ} \mathrm{C}\right)\end{array}$ & $\begin{array}{l}\text { Amplicon } \\
\text { (pb) }\end{array}$ & References \\
\hline \multirow{2}{*}{ EV } & $\begin{array}{c}292 \\
\text { (MIGCIGYIGARACNGG) }\end{array}$ & \multirow{2}{*}{ VP1 } & \multirow{2}{*}{45} & \multirow{2}{*}{340 appr } & \multirow{2}{*}{$\begin{array}{l}\text { Obertse et al. } \\
\quad 2003 \text { (27) }\end{array}$} \\
\hline & $\begin{array}{c}222 \\
\text { (CICCIGGIGGIAYRWACAT) }\end{array}$ & & & & \\
\hline \multirow{2}{*}{ HAV } & $\begin{array}{c}\text { HAVU2167 } \\
\text { (GTTTTGCTCCTCTTTACCATGCTATG) }\end{array}$ & \multirow{2}{*}{ VP3-VP1 } & \multirow{2}{*}{54} & \multirow{2}{*}{247} & \multirow{2}{*}{$\begin{array}{l}\text { Hot et al. } \\
2003^{(28)}\end{array}$} \\
\hline & $\begin{array}{c}\text { HAVL2413 } \\
\text { (GGAAATGTCTCAGGTACTTTCTTTG) }\end{array}$ & & & & \\
\hline \multirow{2}{*}{ HEV } & $\begin{array}{c}\text { ConsORF2-s1 } \\
\text { (GACAGAATTRATTTCGTCGGCTGG) }\end{array}$ & \multirow{2}{*}{ ORF2 } & \multirow{2}{*}{54} & \multirow{2}{*}{197} & \multirow{2}{*}{$\begin{array}{l}\text { Wang et al. } 1999 \\
\text { (29) }\end{array}$} \\
\hline & $\begin{array}{c}\text { ConsORF2-a1 } \\
\text { (CTTGTTCRTGYTGGTTRTCATAATC) }\end{array}$ & & & & \\
\hline \multirow{4}{*}{ RV } & $\begin{array}{c}\text { ROT2U23 } \\
\text { (GCTTTAAAARMGAGAATTTCCGT) }\end{array}$ & \multirow{2}{*}{ VP7 } & \multirow{2}{*}{58} & \multirow{2}{*}{376 appr } & \multirow{2}{*}{$\begin{array}{l}\text { Hot et al. } \\
2003^{(28)}\end{array}$} \\
\hline & $\begin{array}{c}\text { ROT376L23 } \\
\text { (TAAACWGAWCCWGTYGGCCAWCC) }\end{array}$ & & & & \\
\hline & $\begin{array}{c}\text { VP4-F } \\
\text { (TATGCTCCAGTNAATTGG) }\end{array}$ & \multirow{2}{*}{ VP4 } & \multirow{2}{*}{50} & \multirow{2}{*}{663 appr } & \multirow{2}{*}{$\begin{array}{l}\text { Simmonds et al. } \\
2008^{(30)}\end{array}$} \\
\hline & $\begin{array}{c}\text { VP4-R } \\
\text { (ATTGCATTTCTTTCCATAATG) }\end{array}$ & & & & \\
\hline \multirow{2}{*}{$\begin{array}{c}\text { HuNoV } \\
\text { GI }\end{array}$} & $\begin{array}{c}\text { G1SKF } \\
\text { (CTGCCCGAATTYGTAAATGA ) }\end{array}$ & \multirow{2}{*}{ VP1 } & \multirow{2}{*}{50} & \multirow{2}{*}{330} & \multirow{4}{*}{$\begin{array}{l}\text { Kojima et al. } \\
2002 \text { (31) }\end{array}$} \\
\hline & $\begin{array}{c}\text { G1SKR } \\
\text { (CCAACCCARCCATTRTACA) }\end{array}$ & & & & \\
\hline \multirow{2}{*}{$\begin{array}{l}\text { HuNoV } \\
\text { GII }\end{array}$} & $\begin{array}{c}\text { G2SKF } \\
\text { (CNTGGGAGGGCGATCGCAA) }\end{array}$ & \multirow{2}{*}{ VP1 } & \multirow{2}{*}{50} & \multirow{2}{*}{344} & \\
\hline & $\begin{array}{c}\text { G2SKR } \\
\text { (CCRCCNGCATRHCCRTTRTACAT) }\end{array}$ & & & & \\
\hline \multirow{2}{*}{ HAstV } & $\begin{array}{c}\text { Mon269 } \\
\text { (CAACTCAGGAAACAGGGTGT) }\end{array}$ & \multirow{2}{*}{ ORF2 } & \multirow{2}{*}{50} & \multirow{2}{*}{449} & \multirow{2}{*}{$\begin{array}{l}\text { Matias et al. } \\
2007 \text { (32) }\end{array}$} \\
\hline & $\begin{array}{c}\text { Mon270 } \\
\text { (TCAGATGCATTGTCATTGGT ) }\end{array}$ & & & & \\
\hline
\end{tabular}

\section{Assessment of the viral genome by PCR}

The viral genome was detected by PCR from cell supernatant in $28 \%, 30 \%, 4 \%, 10 \%, 2 \%, 6 \%$ and $2 \%$ of samples for EV, HAdV, HAV, HEV, RV, HuNoV GII and HAstV respectively, for PEG precipitation method, while $20 \%, 26 \%, 8 \%, 0 \%$, $10 \%, 4 \%$ and $2 \%$ were positive by PCR for EV,
HAdV, HAV, HEV, RV, HuNoV GII and HAstV, respectively using the two phase-separation. No sample was found positive for HuNoV GI for both methods. The difference between the two methods was not statistically significant to detect viral genome ( $n=50, P=0.5$, t-test) (Fig. 5). 

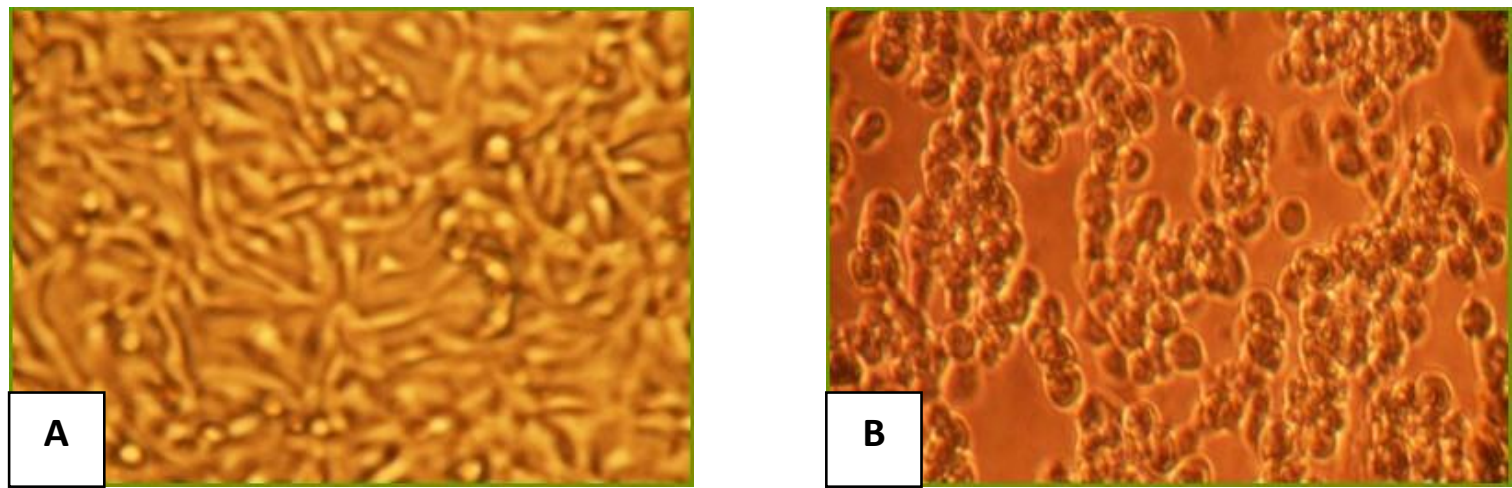

Figure 1. Typical cytopathic effect on the Hep-2 cell line infected by the propagation of the Enterovirus. (A) Normal Hep-2 cell line, (B) Enterviruses infected Hep-2 cell line showed rounding of the cells, shrinkage and detachment of surface
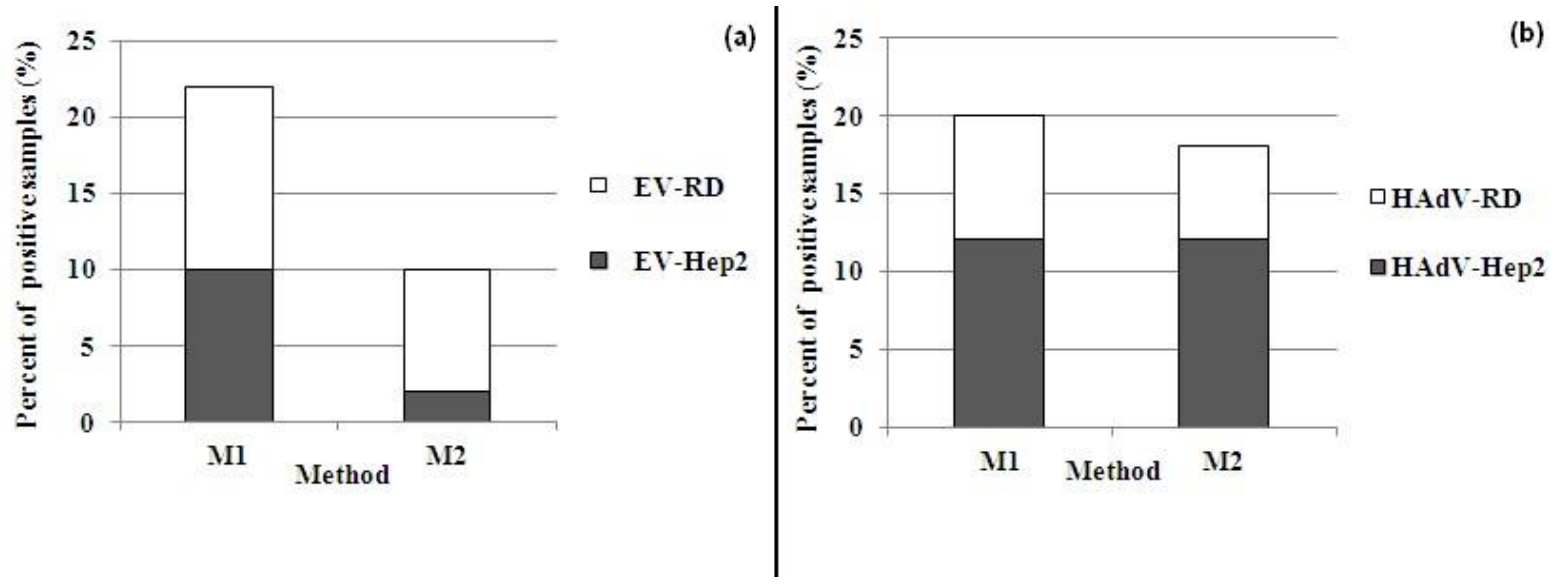

Figure 2. Comparison of infectious EV (a) and HAdV (b) using the PEG precipitation method and the two phase separation method with cell culture CPE. M1. PEG precipitation. M2. Two phaseseparation
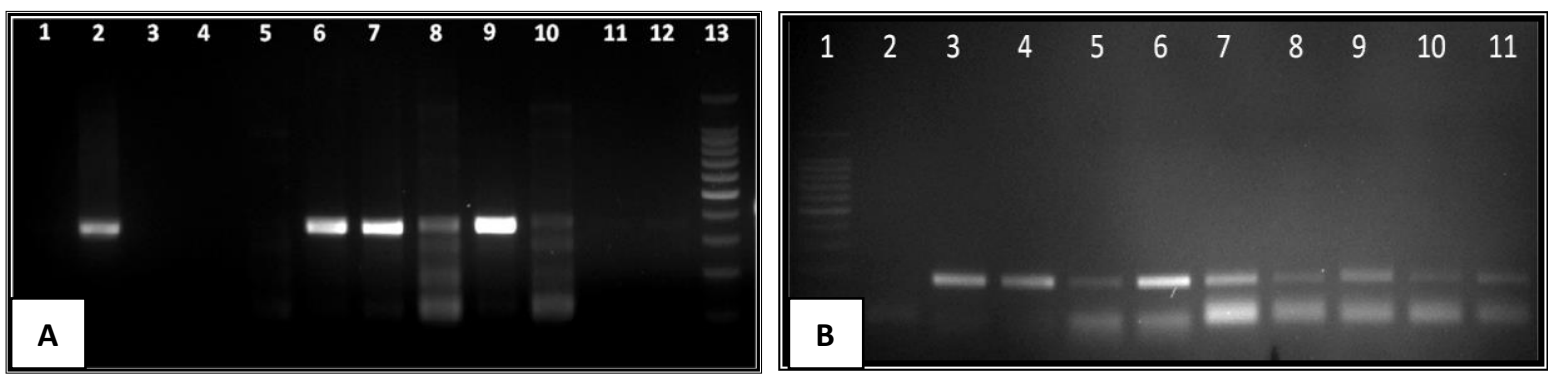

Figure 3. A: PCR of EV detection. Line 1: Negative control. Line 2: Positive control. Lines 3, 4, 5, 8, 10, 11, 12: Negative samples. Lines 6, 7, 9: Positive samples. Line 13: 100 pb ladder. B: PCR of HAdV detection. Line 1: 100 pb ladder. Line 2: Negative control. Line 3: Positive control. Lines 3 to 11: Positive samples 


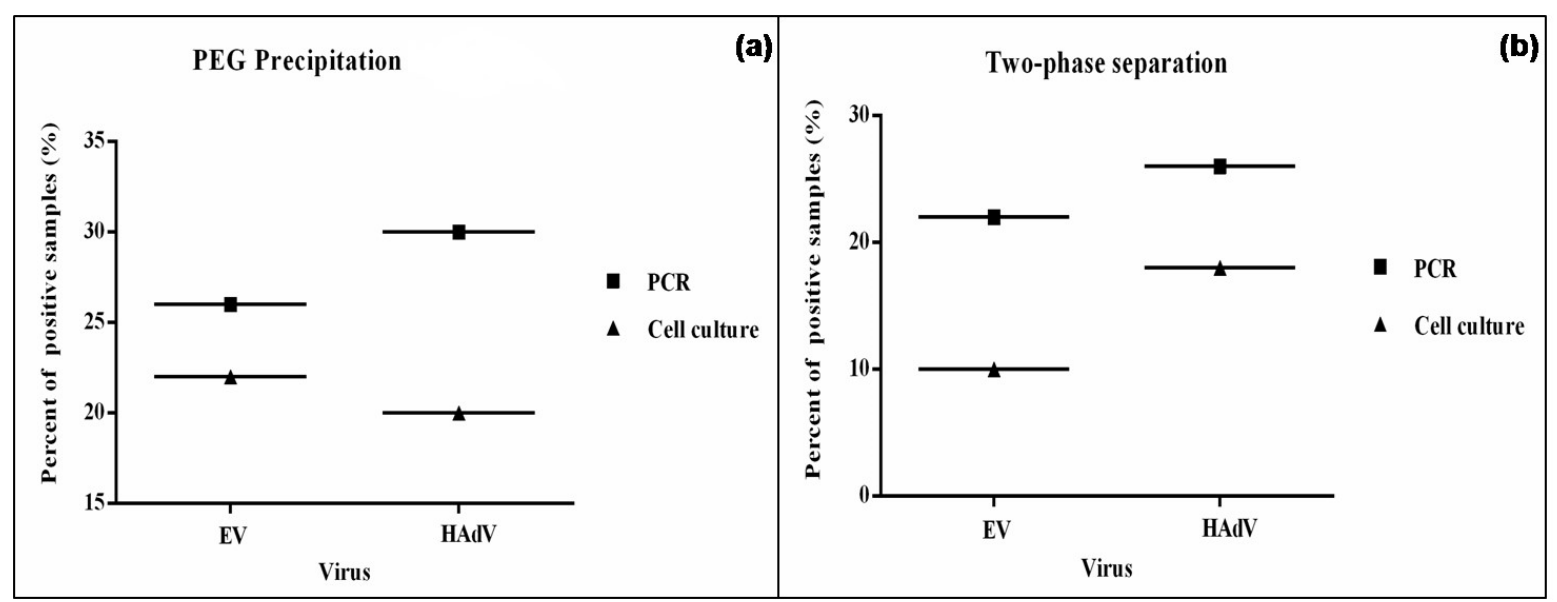

Figure 4. Comparison of the correlation between cell culture and PCR

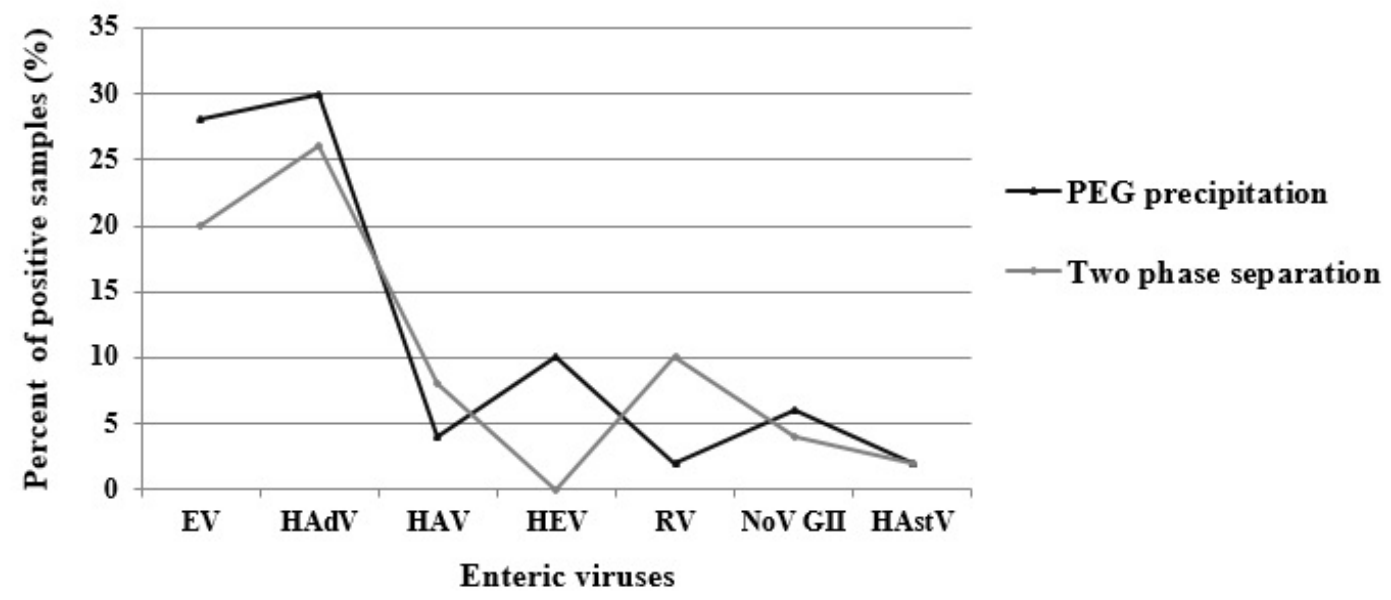

Figure 5. Comparison of PCR positive samples for the PEG precipitation and the two phase separation methods

Presence of infectious EV and HAdV in raw wastewater and treated effluent

By combining the cell culture results of EV and HAdV for both methods. In the Z1, HAdV were found in $31 \%(4 / 13)$ and $38.5 \%(5 / 13)$ of positive raw wastewater and treated effluent samples, respectively. While, the EV were detected in $46.5 \%(6 / 13)$ and $8 \%(1 / 13)$ of raw wastewater and treated effluent samples, respectively. HAdV were the most infectious viruses detected in treated effluents of this zone. The reverse results were found in the $\mathbf{Z Z}$. Indeed, infectious EV were more common in treated effluent than wastewater with $42 \%$ $(5 / 12)$ and $25 \%(3 / 12)$ positive samples respectively, while HAdV were found in $33 \%$ $(4 / 12)$ and $8.5 \%(1 / 12)$ of raw wastewater and treated effluent (Fig. 6).

\section{Discussion}

Presence of infectious EV and HAdV by cell culture

The obtained results showed that Hep2 cells were more suitable for adenovirus detection as reported in previous study ${ }^{(22)}$. The use of both cell lines was useful for us to isolate the most of HAdV and EV in samples. Current virus concentration methods are founded on cell culture to detect infectious enteric viruses that can grow on lines selected from host cells. 
There are a number of cellular systems in which different viruses found in aquatic environments are likely to multiply, causing a specific cytopathic effect.

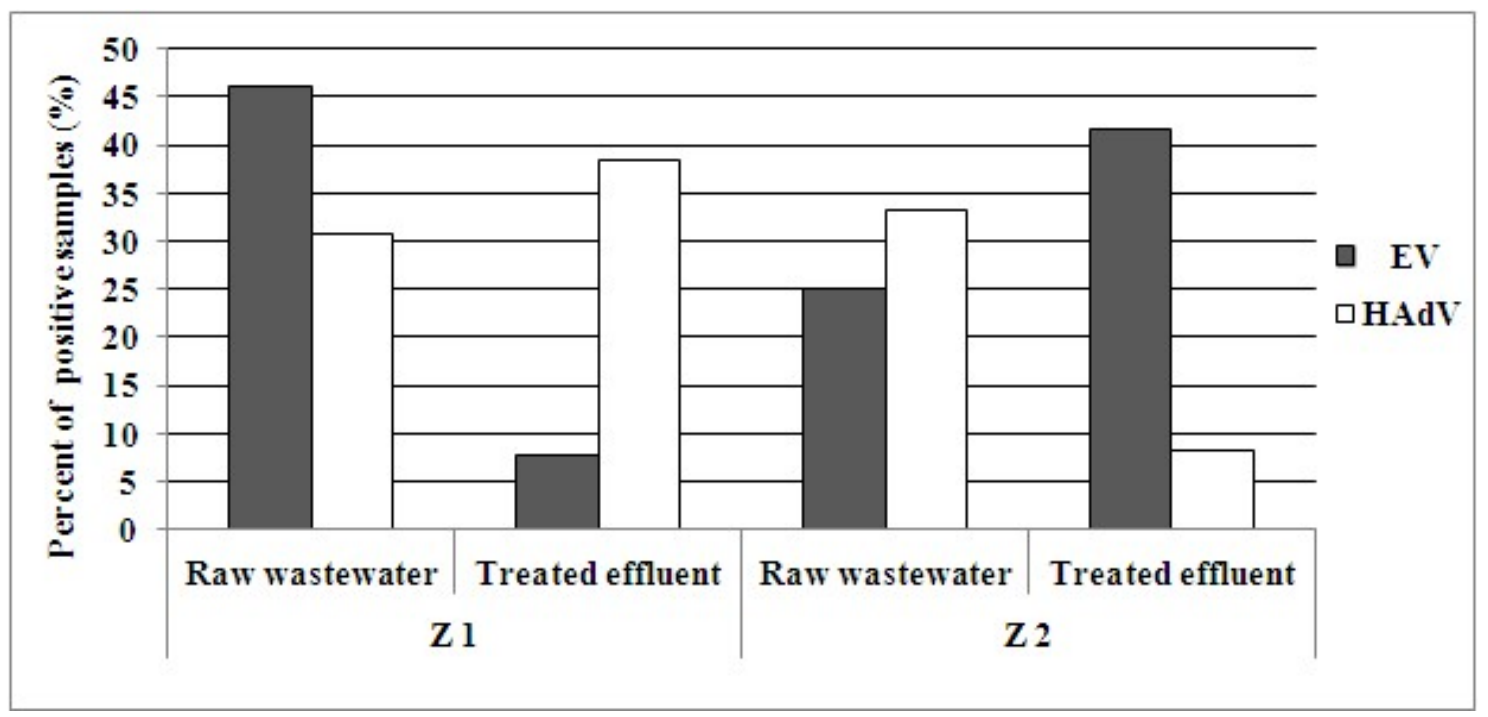

Figure 6. Comparison of the presence of infectious EV and HAdV in the two studied zones

The cell culture sensitivity can be increased by a combination of different cell lines for virus surveillance in water ${ }^{(33)}$. However, to detect a wide range of infectious HAdV and EV. Several cell lines were used: Hep 2 and BGM (34), RD and $L 20 B{ }^{(35)}$ and Vero ${ }^{(36)}$.

Taking into account the difficulty to detect all infectious enteric viruses, virological surveillance of water could be based on the detection of virological indicator for the presence of human enteric viruses. Indeed, EV and HAdV have been proposed and used as indicators of viral contamination or treatment efficiency, because they are relatively easy to grow in cell cultures because of their presence at higher rates than other enteric viruses $(21,37,38,39)$. The difference between the two methods to concentrate infectious EV and HAdV was not significant, which explains that the two methods were able to concentrate EV and HAdV similarly. Rodriguez et al., $2008{ }^{(40)}$ showed that the organic flocculation method, could also concentrate infectious EV and HAdV similarly using the PLC/PRF/5 and BGM cells, while Schlindwein et al., $201{ }^{(41)}$ were able to detect a higher rate of HAdV grown on three cell lines: FRhK- 4 cells (derived from monkey kidney epithelial cells), A549 (basal epithelial cells of the human alveolar carcinoma) and Hep-2 than PV on Vero cells (derived fibroblast African green monkey kidney cells), using the electronegative membrane-elution. The use of cell culture followed by PCR helps to dilute the PCR inhibitors present in environmental samples and allows the in vitro amplification of viruses in different cell systems ${ }^{(24)}$.

\section{Correlation between the cell culture (CC) and PCR}

The results of cell culture and PCR are different and depend on the state of the viral particle. To explain the simultaneously negative and positive results of the CC and PCR, This could be due to that during the transport and treatment of wastewater, some viral particles undergo alterations that reduce their infectivity in vitro which decrease the positive samples by CC (22). The inactivation of viruses could be caused by virus contact with wastewater treatment lagoons sides or natural inactivation by sunshine (26). To increase the sensitivity of the cell culture, the ICC-PCR has been widely 
used for the detection of EV, HAdV, HAstV and HAV from environmental samples ${ }^{(36,42)}$.

The correlation between cell culture and PCR has been reported previously in different studies while a Tunisian study showed that there is no correlation between the cell culture and PCR of HEV in raw sewage using the adsorption-elution ( $\mathrm{n}=26$ technical, $\mathrm{P}=0.077$, $\chi 2$ test ) ${ }^{(36)}$. Hewitt et al., $2011{ }^{(43)}$ detected HAdV in $90 \%(27 / 30)$ samples of raw sewage by PCR while $80 \%$ (24/30) were positive by cell culture, and EV in 100\% (30/30) and 60\% $(18 / 30)$ by PCR and cell culture, respectively, using the beef extract extraction - precipitation with PEG. All the results highlight a significant increase in sensitivity of detection of pathogenic viruses in relation to the only technique CC. In fact, the ICC-PCR is a perfectly interesting technique for enteric viruses that do not cause CPE in cell lines ${ }^{(44)}$. PCR can recover defective or non-culturable strains of virus particles but it is sensitive for the inhibitors which are present in the environmental samples.

\section{Assessment of the viral genome by PCR}

The results correlate with those obtained in our previous study, in which we have detected more HAdV than HEV using the PEG precipitation method (26). The same results were obtained by Kokkinos et al., $2010^{(4)}$ when the ultracentrifugation method was used, with $40 \%(10 / 25)$ rate of $\mathrm{EV}$ and $\mathrm{HAdV}$, and $4 \%$ $(1 / 25)$ of HAV. Using the same method, Kokkinos et al., 2011 (2) detected HAdV in $45.8 \%(22 / 48)$ of samples, followed by $8.3 \%$ (4/48) for HAV, 6.3\% (3/48) for HuNoV, with none of HEV. A Tunisian study detected a prevalence of RV with $32 \%(80 / 250)$ of wastewater samples, followed by $\mathrm{HuNoV}$ in $4.4 \%(11 / 250)$ and one HAdV (45).

Hugues et al., $1993{ }^{(46)}$ showed that according to the technique used to concentrate the EV in treated wastewater (adsorption-elution on glass wool or glass powder), $94 \%$ or $46 \%$ of samples were found positive. Until now, there are no technical consensus protocols for the extraction and amplification of viral genomes. However, the PCR is the only technique used to isolate all enteric viruses in all types of environmental samples.

\section{Presence of infectious EV and HAdV in raw wastewater and treated effluent}

Many studies of HAdV and EV in wastewater were conducted previously. In previous study (26), we have seen a decrease in infectious viruses in treated effluent for EV and HAdV in $11.5 \%(1 / 9)$ and $22.5 \%$ (2/9), respectively. Otherwise, Hewitt et al., $2011^{(43)}$ reported that the rate of positive treated effluents samples from activated sludge WWTP has decreased to half for HAdV and quarterback for EV. The efficiency of wastewater treatment by lagooning fluctuates enormously (from 0 to 99.9\%) and depends particularly on the duration of the treatment ${ }^{(47)}$.

The impact of temperature on the inactivation of enteric viruses has been widely reported with a different survival. In this study, the temperature for both studied WWTPs ranged from 24.5 to $25^{\circ} \mathrm{C}$ for waste water and from 23 to $24.9{ }^{\circ} \mathrm{C}$ for treated effluent. In the same temperature, the differences in virus survival were observed between the PV and HAdV where PV was the most sensitive and HAdV the most resistant Enriquez et al., 1995 (48). Actually, the temperature parameter is difficult to setting because it may have a role in some chemical reactions ${ }^{(49)}$.

The comparison between the presence of infectious EV and HAdV in sewage and treated effluent provides us with information about their presence in both sewage and treated effluent. It can be suggested that EV and HAdV could be very interesting indicators of viral contamination as reported previously by several studies in different countries. Some of them advised $\mathrm{EV}{ }^{(37,50)}$ and others advised HAdV (38,51).

Current study results are in agreement with those obtained in previous study when the same methods were compared using Echovirus 7 as a model of enteroviruses (22). 
This follow-up study confirms that, considering the protocol time, the cost and the no significant difference between the two methods, the PEG precipitation seems to be an alternative method of the two-phase separation method.

\section{Acknowledgments}

Thanks for Dr. Nozha Cohen and Dr. Kaoutar Hajjami for their assistance in wastewater samples collection.

\section{Author contributions:}

All authors contributed to this manuscript. Prof. Amdiouni performed the laboratory work, implementation and progress of this study, Dr. Al-Shuwaikh interpreted and arranged drafting of this paper, Dr. Maunula and Dr. Nouril supervise, conception and design of study.

\section{Conflict of interest}

There is no conflict of interest.

\section{Funding}

This study was funded by the Medical Virology \& BSL3 Laboratory, Institut Pasteur du Maroc, Casablanca, Morocco.

\section{References}

1. Sinclair RG, Choi $C Y$, Riley $M R$, et al. Pathogen surveillance through monitoring of sewer systems. Adv Appl Microbiol. 2008; 65: 249-69. doi: 10.1016/S0065-2164(08)00609-6.

2. Kokkinos PA, Ziros PG, Mpalasopoulou A, et. al. Molecular detection of multiple viral targets in untreated urban sewage from Greece. Virol J. 2011; 8: 195. doi: 10.1186/1743-422X-8-195.

3. World Health Organization (WHO). Waterborne zoonoses: identification, causes and control. London: World Health Organization; 2001 p. 1-528. Available from:

http://www.who.int/water_sanitation_health/diseas es/zoonoses.pdf

4. Kokkinos K, Filippidou S, Karlou K, et al. Molecular typing of enteroviruses, adenoviruses, and hepatitis A viruses in untreated and treated sewage of a biological treatment plant in Greece. Food Environ Virol. 2010; 2(2): 89-96. doi: 10.1007/s12560-0109036-3.

5. Fumian TM, Vieira CB, Leite JP, et al. Assessment of burden of virus agents in an urban sewage treatment plant in Rio de Janeiro, Brazil. J Water Health. 2013; 11(1): 110-9. doi: 10.2166/wh.2012.123.
6. Masclaux FG, Hotz P, Friedli D, et al. High occurrence of hepatitis $E$ virus in samples from wastewater treatment plants in Switzerland and comparison with other enteric viruses. Water Res. 2013; 47(14): 51019. doi: 10.1016/j.watres.2013.05.050.

7. Momou KJ, Akoua-Koffi C, Dosso M. Detection of enteroviruses in water samples from Yopougon, Côte d'Ivoire by cell culture and polymerase chain reaction. Food Environ Virol. 2014; 6 (1): 23-30. doi: 10.1007/s12560-013-9130-4.

8. Tonani KA, Padula J, Juliao FC, et al. Persistence of giardia, cryptosporidium, rotavirus and adenovirus in treated sewage in São Paulo State, Brazil. J Parasitol. 2013; 99(6): 1144-7. doi: 10.1645/12-121.1.

9. Han TH, Kim SC, Kim ST, et al. Detection of norovirus genogroup IV, klassevirus, and pepper mild mottle virus in sewage samples in South Korea. Archives of Virology. 2014; 159 (3): 457-63. doi: 10.1007/s00705013-1848-7.

10. Pinto RM, Alegre $D$, Dominguez $A$, et al. Hepatitis $A$ virus in urban sewage from two Mediterranean countries. Epidemiol Infect. 2007; 135: 270-3. doi: 10.1017/S0950268806006753.

11. La Rosa G, Pourshaban $M$, laconelli $M$, et. al. Detection of genogroup IV noroviruses in environmental and clinical samples and partial sequencing through rapid amplification of cDNA ends. Arch Virol. 2008; 53(11): 2077-83. doi: 10.1007/s00705-008-0241-4.

12. Bosch A, Guix S, Sano D, et. al. New tools for the study and direct surveillance of viral pathogens in water. Curr Opin Biotechnol. 2008. 19 (3): 295-301. doi: 10.1016/j.copbio.2008.04.006.

13. Ikner LA, Gerba CP, Bright KR. Concentration and recovery of viruses from water: a comprehensive review. Food Environ Virol. 2012. 4 (2): 41-67. doi: 10.1007/s12560-012-9080-2.

14. Myrmel M, Berg EM, Grinde B, et al. Enteric viruses in inlet and outlet samples from sewage treatment plants. J Water Health. 2006; 4(2): 197-209.

15. Kamel AH, Ali MA, El-Nady HG, et al. Evidence of the co-circulation of enteric viruses in sewage and in the population of greater Cairo. J Appl Microbiol. 2010; 108: 1620-9. doi: 10.1111/j.1365-2672.2009.04562.x.

16. Hovi T, Stenvik M, Partanen $H$, et al. Poliovirus surveillance by examining sewage specimens: quantitative recovery of virus after introduction into sewerage at remote upstream location. Epidemiol Infect. 2001; 127: 101-6. doi: $10.1017 /$ S0950268801005787.

17. Haramoto E, Katayama H, Oguma K, et. al. Recovery of naked viral genomes in water by virus concentration methods. J Virol Methods. 2007; 142: 169-73. doi: 10.1016/j.jviromet.2007.01.024.

18. Meleg E, Jakab F, Kocsis B, et al. Human astroviruses in raw sewage samples in Hungary. J Appl Microbiol. 2006; 101: 1123-9. doi: 10.1111/j.13652672.2006.02997.x.

19. Melegh B, Szucs G. Detection and quantification of group $\mathrm{C}$ rotaviruses in communal sewage. Appl 
Environ Microbiol. 2008; 74: 3394-9. doi: 10.1128/AEM.02895-07.

20. Lee H, Kim M, Paik SY, et al. Evaluation of electropositive filtration for recovering norovirus in water. J Water Health. 2011; 9: 27-36. doi: 10.2166/wh.2010.190.

21. World Health Organization (WHO). Guidelines for environmental surveillance of poliovirus circulation. Geneva: World Health Organization; 2003 p. 1-28. Available from: http://apps.who.int/iris/bitstream/10665/67854/1/ WHO_V-B_03.03_eng.pdf.

22. Amdiouni H, Maunula L, Hajjami K, et al. Recovery comparison of two virus concentration methods from wastewater using cell culture and real-time PCR. Curr Microbiol. 2012; 65(4): 432-7. doi: 10.1007/s00284012-0174-8.

23. Minor PD. Growth, assay and purification of picornaviruses. In: Mahy BWJ. (ed.) Virology: A practical approach. Oxford, Washington: IRL Press; 1985. p. 25-41.

24. Reynolds KA. Integrated cell culture / PCR for detection of enteric viruses in environmental samples. Methods Mol Biol. 2004; 268: 69-78. doi: 10.1385/1-59259-766-1:069.

25. Casas I, Avellon A, Mosquera M, et al. Molecular identification of adenoviruses in clinical samples by analyzing a partial hexon genomic region. J Clin Microbiol. 2005. 43: 6176-82. doi: 10.1128/JCM.43.12.6176-6182.2005.

26. Amdiouni H, Faouzi A, Fariat N. Detection and molecular identification of human adenoviruses and enteroviruses in wastewater from Morocco. Lett Appl Microbiol. 2012. 54(4): 359-66. doi: 10.1111/j.1472765X.2012.03220.x.

27. Oberste MS, Nix WA, Maher K. Improved molecular identification of enteroviruses by RTPCR and amplicon sequencing. J Clin Virol. 2003. 26: 375-7.

28. Hot D, Legeay $O$, Jacques J, et al. Detection of somatic phages, infectious enteroviruses and enterovirus genomes as indicators of human enteric viral pollution in surface water. Water Research. 2003. 37: 4703-10. doi: 10.1016/S00431354(03)00439-1.

29. Wang $Y$, Ling R, Erker JC, et al. A divergent genotype of hepatitis $E$ virus in Chinese patients with acute hepatitis. J. Gen Virol. 1999; 80 (1): 169-77. doi: 10.1099/0022-1317-80-1-169.

30. Simmonds MK, Armah G, Asmah R, et al. New oligonucleotide primers for P-typing of rotavirus strains: Strategies for typing previously untypeable strains. Clin Virol. 2008. 42 (4): 368-73. doi: 10.1016/j.jcv.2008.02.011.

31. Kojima S, Kageyama T, Fukushi S, et al. Genogroupspecific PCR primers for detection of Norwalk-like viruses. J Virol Methods. 2002; 100(1-2): 107-14. doi: 10.1016/S0166-0934(01)00404-9.

32. Matias V, Carvalho-Costa FA, Heinemann MB, et al. Genotypes and molecular epidemiology of human astroviruses in hospitalized children with acute gastroenteritis in Rio de Janeiro. Brazil J Med Virol. 2007; 79(7): 939-44. doi: 10.1002/jmv.20814.

33. Sedmak G, Bina D, Macdonald J, et al. Nine-year study of the occurrence of culturable viruses in source water for two drinking water treatment plants and the influent and effluent of a waste water treatment plant in Milwaukee, Wisconsin (August 1994 through July 2003). Appl Environ Microbiol. 2005; 71: 1042-50. doi: 10.1128/AEM.71.2.10421050.2005.

34. Puig $M$, Jofre J, Lucena $F$, et al. Detection of adenoviruses and enteroviruses in polluted waters by nested PCR amplification. Appl Environ Microbiol. 1994; 60: 2963-70.

35. World Health Organization (WHO). Polio laboratory manual. Geneva: World Health Organization; 2004 p. 1-166. Available from: http://apps.who.int/iris/bitstream/10665/68762/1/ WHO_IVB_04.10.pdf.

36. Sdiri $\bar{K}$, Khelifi $H$, Belghith $K$, et al. Comparison of cell culture and RT-PCR for the detection of enterovirus in sewage and shellfish. Pathologie Biologie. 2006. 54: 280-4. doi: 10.1016/j.patbio.2005.12.001.

37. Hovi T. Surveillance of poliovirus. Biologicals. 2006; 34: 123-6. doi: 10.1016/j.biologicals.2006.02.009.

38. Silva DH, García-Zapata MTA, Anunciação CE. Why the use of adenoviruses as water quality virologic marker? Food Environ Virol. 2011; 3(3-4): 138-40. doi: 10.1007/s12560-011-9069-2.

39. United States Environmental Protection Agency (USEPA). Guidelines for water reuse. Washington: US Environmental Protection Agency; 2004 p. 1-28. Available from: http://www.waterboards.ca.gov/water_issues/progr ams/grants_loans/water_recycling/docs/econ_tskfrc e/14.pdf.

40. Rodriguez RA, Gundy PM, Gerba CP. Comparison of $\mathrm{BGM}$ and PLC/PRC/5 cell lines for total culturable viral assay of treated sewage. Appl Environ Microbiol. 2008; 74: 2583-7. doi: 10.1128/AEM.00626-07.

41. Schlindwein $A D$, Rigotto $C$, Simões $C M$, et al. Detection of enteric viruses in sewage sludge and treated wastewater effluent. Water Sci Technol. 2010; 61 (2): 537-44. doi: 10.2166/wst.2010.845.

42. Chapron CD, Ballester NA, Fontaine JH, et al. Detection of astroviruses, enteroviruses, and adenovirus type 40 and 41 in surface waters collected and evaluated by the information Collection rule and an integrated cell culture-nested PCR procedure. Appl Environ Microbiol. 2000; 66: 2520-5. doi: 10.1128/AEM.66.6.2520-2525.2000.

43. Hewitt J, Leonard M, Greening GE. Influence of wastewater treatment process and the population size on human virus profiles in wastewater. Water Res. 2011; 45(18): 6267-76. doi: 10.1016/j.watres.2011.09.029.

44. Vivier JC, Ehlers MM, Grabow WO. Detection of enteroviruses in treated drinking water. Water Res. 2004; 38 (11): 2699-705. doi: 10.1016/S00431354(01)00433-x. 
45. Sdiri-Loulizi K, Hassine M, Aouni Z. Detection and molecular characterization of enteric viruses in environmental samples in Monastir, Tunisia between January 2003 and April.2007 J Appl Microbiol. 2010; 109(3): 1093-104. doi: 10.1111/j.13652672.2010.04772.x.

46. Hugues B, Andre M, Plantat JL. Comparison of glass wool and glass powder methods for concentration of viruses from treated waters. Zentralbl Hyg Umweltmed. 1993; 193: 440-9.

47. Hurst CJ. Fate of viruses during wastewater sludge treatment processes. Crit. Rev Env Control. 1989; 18: 317-43. doi: 10.1080/10643388909388352.

48. Enriquez C, Hurst CJ, Gerba CP. Survival of the enteric Adenovirus 40 and 41 in Tap Sea and wastewater. Water Res. 1995; 29: 2548-53.

49. Beaudeau $P$, Tousset $N$, Lefèvre $A$, et al. Disparition des Escherichia coli dans les rivières normandes, rapprot de l'agence de l'eau Seine-Normandie. 1998; 92.

50. Hovi T, Shulman LM, van der Avoort $H$, et al. Role of environmental poliovirus surveillance in global polio eradication and beyond. Epidemiol Infect. 2012; 140(1): 1-13. doi: 10.1017/S095026881000316X.

51. Tong $\mathrm{HI}$, Lu Y. Effective detection of human adenovirus in Hawaiian waters using enhanced PCR methods. Virol J. 2011; 8: 57. doi: 10.1186/1743422X-8-57.

\footnotetext{
Correspondence to Prof. Hasna A. Amdiouni

E-mail: hasna.amdiouni@gmail.com, hasna.amdiouni@yahoo.fr

Received $6^{\text {th }}$ Oct. 2016

Accepted 15 th Jan. 2017
} 
Published by Al-Nahrain College of Medicine P-ISSN 1681-6579

E-ISSN 2224-4719

Email: iraqijms@colmed-alnahrain.edu.iq http://www.colmed-alnahrain.edu.iq http://www.iraqijms.net

\title{
Assessment of Serum Zinc Level in Patients with Polycystic Ovary Syndrome
}

\author{
lqbal G. Farhood FICMS (D\&V) \\ Section of Dermatology \& Venereology, Dept. of Medicine, College of Medicine, Al-Nahrain University, Baghdad, Iraq
}

\begin{abstract}
Background

Objective

Methods
\end{abstract}

Results

Conclusion

Keywords

Citation

Polycystic ovary syndrome (PCOS) is the most common endocrine-metabolic disorder affecting women of reproductive age characterized by multiple hormonal imbalances, reflecting on a clinical presentation dominated by manifestations of hyperandrogenism, which generate short and long term consequences on female health. Skin is a major target for androgen activity, several hyperandrogenemia-triggered dermatologic alterations can be seen in PCOS, most commonly hirsutism, androgenic alopecia, acne, seborrhea, onycholysis, and onychorrhexis. Zinc is one of the most important trace elements required as a catalytic, structural, and regulatory ion for the activities of more than 300 enzymes, proteins, and transcriptional factors. Zinc insufficiency in the female can lead to complications such as impaired synthesis/secretion of follicular stimulating hormone (FSH) and luteinizing hormone (LH), abnormal ovarian development.

To assess serum zinc level in patients with PCOS.

A case-controlled study was conducted in Al-Imamein Al-Kadhemein Medical City from the period of March to June 2016. Eighty females were enrolled in this study; their age ranged from 20 to 32 years. They were divided into 4 groups: Group I: Twenty patients with PCOS with body mass index (BMI) ranged from 30.0-40.0. Group II: Twenty normal healthy control obese ladies with BMI ranged from 30.0-40.0. Group III: Twenty patients with polycystic ovary syndrome with BMI ranged from 18.5-29.9. Group IV: Twenty females as a healthy control non-obese ladies with BMI ranged from 18.5-29.9.

Serum zinc level was significantly decreased in obese PCO group than in non-obese PCO group. Serum prolactin (PRL) level and LH levels were elevated in PCO group which was highly significant. There was negative correlation between serum zinc level and BMI in PCO patients. Also, negative correlation was observed between serum zinc level and serum PRL level in non-obese PCO patients. Serum zinc level reduced in obese PCOS than in non-obese PCO.

Serum zinc level, polycystic ovary syndrome

Iqbal G. Farhood. Assessment of serum zinc level in patients with polycystic ovary syndrome. Iraqi JMS. 2017; Vol. 15(1): 39-47. doi: 10.22578/JJMS.15.1.6

List of abbreviation: $\mathrm{BMI}=$ Body mass index, $\mathrm{FSH}=$ Follicle stimulating hormone, IR = Insulin resistance, $\mathrm{LH}=$ Luteinizing hormone, $\mathrm{PCOS}=$ Polycystic ovary syndrome, $\mathrm{PRL}=$ Prolactin

\section{Introduction}

$\mathrm{P}$ olycystic ovary syndrome (PCOS) is the most common endocrine-metabolic disorder affecting women of reproductive age characterized by multiple hormonal imbalances, reflecting on a clinical presentation dominated by manifestations of hyperandrogenism, which generate short and long term consequences on female health ${ }^{(1)}$.

It is a common endocrinopathy affecting $6-10 \%$ of reproductive aged women (2), with a prevalence ranging from $5-10 \%$ in the general 
population and almost $30 \%$ among obese women ${ }^{(3)}$.

It is multi-factorial, with complex genetic and endocrine disorder; this heterogeneity seems to be modulated by multiple factors, such as prenatal androgen exposure, nutritional status in the uterus, genetic factors, as well as ethnicity, insulin resistance of puberty and/or exaggerated adrenarche and changes in body weight. Environmental factors, such as obesity, appear to exacerbate the underlying genetic predisposition. It is characterized by menstrual disturbances, clinical and biochemical manifestations of hyperandrogenism, ovulatory dysfunction and polycystic ovaries (4).

PCOS is associated with an approximately 7fold increased risk of type 2 diabetes mellitus (5). Insulin resistance (IR) and pancreatic $\beta$ cell dysfunction are major risk factors for the development of type 2 diabetes mellitus. Defects in insulin action and insulin secretion are critical determinants in the pathogenesis of glucose intolerance in PCOS and both are influenced by genetic and environmental factors ${ }^{(6)}$.

PCOS is manifested by abdominal obesity, insulin resistance, dyslipidemia, and endothelial dysfunction. Central adiposity appears to play an important role in the metabolic phenotype through the production of various adipocyte-derived cytokines and proteins known as adipokines (7). Furthermore, PCOS has been described as a state of chronic low-grade inflammation mainly characterized by a modest rise in serum C-reactive protein compared to the weight matched controls (8).

Because skin is a major target for androgen activity, several hyperandrogenemia-triggered dermatologic alterations can be seen in PCOS, most commonly hirsutism, androgenic alopecia, and acne and also seborrhea, onycholysis, and onychorrhexis (9).

Hirsutism: is defined as the presence of excessive terminal hair in areas of the body that are androgen dependent and usually hairless or with limited hair growth such as the face, chest, areolas, abdomen, and upper thighs ${ }^{(10)}$. Although hyperandrogenemia is the trigger for hirsutism, the rate of hair growth is not proportional to the degree of hyperandrogenism ${ }^{(11)}$.

Acne and Seborrhea: Sebaceous glands are also androgen-dependent structures, with adipocytes being highly sensitive to androgen signaling, which is exacerbated in PCOS, leading to the development of acne and seborrhea (12). Androgenic Alopecia: is a disorder in which, hair is miniaturized, due to an increased telogen:anagen ratio "with telogen hair being at mitotical rest and anagen hair being mitotically active" and associated to genetic susceptibility related to increased $5 \alpha$-reductase activity in the hair follicle. This increased enzymatic activity would favor the local conversion of testosterone into dihydrotestosterone, a more powerful androgen (13).

The diagnosis of PCOS is based on the Rotterdam criteria ${ }^{(14)}$ with women satisfying at least two of the following three criteria:

1) oligomenorrhea/oligoovulation

2) clinical or biochemical hyperandrogenism

3)polycystic ovaries on ultrasound examination.

Zinc is one of the most important trace elements required as a catalytic, structural, and regulatory ion for the activities of more than 300 enzymes, proteins, and transcriptional factors ${ }^{(15)}$. Therefore, zinc is a key element in many homeostatic responses of the body, including oxidative stress and in many biological functions, including immune efficiency (16). Zinc keeps hormone like estrogen, progesterone and testosterone levels stable throughout the entire menstrual cycle. Zinc is reported to be necessary for DNA replication, RNA polymerases, protein synthesis and various metabolic processes. The cell replication, protein synthesis and growth processes etc. are reported to be to some extent dependent upon zinc (17).

It is known that the adult human body have about $1-3 \mathrm{~g}$ of zinc, and about $0.1 \%$ of which is replenished daily ${ }^{(18)}$. 
Zinc insufficiency in the female can lead to complications such as impaired synthesis/secretion of follicle stimulating hormone (FSH) and luteinizing hormone (LH), abnormal ovarian development, estrous cycle disruption, frequent abortion, extended gestation period, teratogenicity, stillbirths, complexity in parturition, pre-eclampsia, toxemia and inferior infant birth weights ${ }^{(19)}$.

Oocytes have shown to express most of the zinc transporters, metallothioneins and metal regulatory transcription factor which may point out a significant role for zinc, in particular with potential linkage toward genome stability during early embryonic development (20).

This study aimed to assess serum zinc level in patients with PCOS.

\section{Methods}

A case-controlled study was conducted in AlImamein Al-Kadhemein Medical City from the period of March to June 2016. Eighty females were enrolled in this study; their age ranged from 20 to 32 years.

Blood samples were obtained from all subjects for serum zinc, serum prolactin (PRL), serum $\mathrm{FSH}$ and serum LH assessments. All subjects had pelvic ultrasonography and body mass index (BMI) measurements.

Exclusion criteria were: chronic or acute medical illnesses, pregnancy, hypothyroidism, and current or previous (within last 2 months) use of any medications known to affect inflammation, anti-diabetic and anti-obesity drugs, insulin or vitamin and mineral supplements.

The subjects were divided into 4 groups:

Group I: Twenty patients with PCOS with BMI ranged from 30.0-40.0

Group II: Twenty normal healthy control obese ladies with BMI ranged from 30.0-40.0

Group III: Twenty patients with PCOS with BMI ranged from 18.5-29.9.

Group IV: Twenty non-obese ladies as a healthy control with BMI ranged from 18.529.9.

\section{Results \\ PCO group vs control group}

Table 1 shows no significant differences in age and in BMI between PCO patients and control group. Serum PRL level was significantly higher in PCO group $(15.07 \pm 8.42)$ than in the control group $(9.19 \pm 2.2)$ with $\mathrm{P}$ value $=0.0001$. Also, serum LH level was significantly higher in PCO group (6.48 \pm 4.36$)$ than in control group $(4.57 \pm 1.8)$ with $P$ value $=0.0123$. There were no significant differences in serum FSH level and serum Zinc level between PCO patients and control group in this study.

Table 1. Comparison between PCO group and control group by unpaired t-test

\begin{tabular}{cccc}
\hline Parameters & $\begin{array}{c}\text { PCO } \\
\mathbf{N}=\mathbf{4 0} \\
\text { Mean } \pm \text { SD }\end{array}$ & $\begin{array}{c}\text { Control } \\
\mathbf{N}=\mathbf{4 0} \\
\text { Mean } \pm \text { SD }\end{array}$ & P value \\
\hline Age $(\mathrm{yr})$ & $25.48 \pm 3.56$ & $25.18 \pm 3.1$ & 0.6889 \\
BMI $\left(\mathrm{kg} / \mathrm{m}^{2}\right)$ & $28.34 \pm 7.17$ & $28.28 \pm 8.33$ & 0.9725 \\
S. PRL $(\mathrm{IU} / \mathrm{ml})$ & $15.07 \pm 8.42$ & $9.19 \pm 2.2$ & 0.0001 \\
S. FSH $(\mathrm{IU} / \mathrm{ml})$ & $4.76 \pm 1.48$ & $4.89 \pm 1.3$ & 0.6689 \\
S. $\mathrm{LH}(\mathrm{IU} / \mathrm{ml})$ & $6.48 \pm 4.36$ & $4.57 \pm 1.8$ & 0.0123 \\
S. Zinc $(\mu \mathrm{g} / \mathrm{dl})$ & $75.31 \pm 33.91$ & $83.8 \pm 10.11$ & 0.1330 \\
\hline
\end{tabular}

\section{Obese PCO group vs obese control group}

There were no significant differences in age and in BMI between obese PCO patients and obese control group in this study. Serum PRL level was significantly higher in obese PCO group (19.57 \pm 9.28$)$ than in obese control group 
(9.54 \pm 2.11$)$ with $P$ value $<0.0001$. Serum $\mathrm{LH}$ level was significantly higher in obese PCO group $(9.84 \pm 3.81)$ than in obese control group $(5.83 \pm 1.63)$ with $P$ value $=0.0001$. Serum zinc level was significantly decreased in obese PCO group $(65.68 \pm 31.28)$ than in obese control group $(82.56 \pm 9.84)$ with $\mathrm{P}$ value $=0.0269$. There was no significant difference in serum FSH level between obese PCO patients and obese control group in this study, (Table 2).

Table 2. Comparison between obese PCO and obese control group by unpaired t-test

\begin{tabular}{cccc}
\hline Parameters & $\begin{array}{c}\text { Obese PCO } \\
\mathbf{N = 2 0} \\
\text { Mean } \pm \text { SD }\end{array}$ & $\begin{array}{c}\text { Obese Control } \\
\mathbf{N = 2 0} \\
\text { Mean } \pm \text { SD }\end{array}$ & P value \\
\hline Age $(\mathrm{yr})$ & $25.6 \pm 3.68$ & $25.55 \pm 3.05$ & 0.9629 \\
BMI $\left(\mathrm{kg} / \mathrm{m}^{2}\right)$ & $35.06 \pm 2.11$ & $35.79 \pm 3.52$ & 0.4711 \\
S. PRL $(\mathrm{IU} / \mathrm{ml})$ & $19.57 \pm 9.28$ & $9.54 \pm 2.11$ & $<0.0001$ \\
S. FSH $(\mathrm{IU} / \mathrm{ml})$ & $4.33 \pm 1.76$ & $4.78 \pm 1.57$ & 0.3971 \\
S. LH $(\mathrm{IU} / \mathrm{ml})$ & $9.84 \pm 3.81$ & $5.83 \pm 1.63$ & 0.0001 \\
S. Zinc $(\mu \mathrm{g} / \mathrm{dl})$ & $65.68 \pm 31.28$ & $82.56 \pm 9.84$ & 0.0269 \\
\hline
\end{tabular}

Non-obese PCO group vs non-obese control group:

There were no significant differences in age, $\mathrm{BMI}$, serum PRL level, serum FSH level, serum
LH level and serum zinc level between nonobese PCOS patients and non-obese control group in this study (Table 3 ).

Table 3. Comparison between non-obese control group and non-obese PCO group by unpaired ttest

\begin{tabular}{cccc}
\hline Parameters & $\begin{array}{c}\text { Non-obese PCO } \\
\mathbf{N = 2 0} \\
\text { Mean } \pm \text { SD }\end{array}$ & $\begin{array}{c}\text { Non-obese Control } \\
\mathbf{N = 2 0} \\
\text { Mean } \pm \text { SD }\end{array}$ & P value \\
\hline Age $(\mathrm{yr})$ & $25.35 \pm 3.53$ & $24.8 \pm 3.19$ & 0.608 \\
BMI $\left(\mathrm{kg} / \mathrm{m}^{2}\right)$ & $21.63 \pm 1.72$ & $20.78 \pm 3.41$ & 0.3288 \\
S. PRL $(\mathrm{IU} / \mathrm{ml})$ & $10.56 \pm 4.08$ & $8.84 \pm 2.28$ & 0.1083 \\
S. FSH $(\mathrm{IU} / \mathrm{ml})$ & $5.18 \pm 1.02$ & $5.0 \pm 1.01$ & 0.5726 \\
S. LH $(\mathrm{IU} / \mathrm{ml})$ & $3.12 \pm 0.86$ & $3.31 \pm 0.82$ & 0.4819 \\
S. Zinc $(\mu \mathrm{g} / \mathrm{dl})$ & $84.94 \pm 34.46$ & $85.05 \pm 10.48$ & 0.9892 \\
\hline
\end{tabular}

Obese control group and non-obese control group

There were no significant differences in age, serum PRL level, serum FSH level and serum zinc level between obese control and nonobese control group in our study. Serum LH level was highly significantly increased in obese control group $(5.83 \pm 1.63)$ than in non-obese control group $(3.31 \pm 0.82)$ with $\mathrm{P}$ value $<0.0001$ as shown in table (4).

Obese PCO group and non-obese PCO group
Table (5) reveals no significant differences in age, serum FSH level and serum zinc level between obese PCO and non-obese PCO groups in this study. Serum PRL level was significant increase in obese PCO group $(19.57 \pm 9.28)$ than in non-obese PCO group $(10.56 \pm 4.08)$ with $P$ value $=0.0003$. Serum $\mathrm{LH}$ level was significantly higher in obese PCO group (9.84 \pm 3.81$)$ than in non-obese PCO group $(3.12 \pm 0.86)$ with $P$ value $<0.0001$. 
Table 4. Comparison between obese control group and non-obese control group by unpaired ttest

\begin{tabular}{|c|c|c|c|}
\hline Parameters & $\begin{array}{c}\text { Obese Control } \\
\qquad \begin{array}{c}\mathrm{N}=\mathbf{2 0} \\
\text { Mean } \pm S D\end{array} \\
\end{array}$ & $\begin{array}{c}\text { Non-obese Control } \\
\mathrm{N}=\mathbf{2 0} \\
\text { Mean } \pm \text { SD }\end{array}$ & $P$ value \\
\hline Age (yr) & $25.55 \pm 3.05$ & $24.8 \pm 3.19$ & 0.452 \\
\hline $\mathrm{BMI}\left(\mathrm{kg} / \mathrm{m}^{2}\right)$ & $35.79 \pm 3.52$ & $20.78 \pm 3.41$ & $<0.0001$ \\
\hline S. PRL (IU/ml) & $9.54 \pm 2.11$ & $8.84 \pm 2.28$ & 0.3199 \\
\hline S. FSH (IU/ml) & $4.78 \pm 1.57$ & $5.0 \pm 1.01$ & 0.597 \\
\hline S. LH (IU/ml) & $5.83 \pm 1.63$ & $3.31 \pm 0.82$ & $<0.0001$ \\
\hline S. Zinc $(\mu \mathrm{g} / \mathrm{dl})$ & $82.56 \pm 9.84$ & $85.05 \pm 10.48$ & 0.4432 \\
\hline
\end{tabular}

Table 5. Comparison between obese PCO group and non-obese PCO group by unpaired t-test

\begin{tabular}{cccc}
\hline Parameters & $\begin{array}{c}\text { Obese PCO } \\
\mathbf{N = 2 0} \\
\text { Mean } \pm \text { SD }\end{array}$ & $\begin{array}{c}\text { Non-obese PCO } \\
\mathbf{N = 2 0} \\
\text { Mean } \pm \text { SD }\end{array}$ & P value \\
\hline Age $(\mathrm{yr})$ & $25.6 \pm 3.68$ & $25.35 \pm 3.53$ & 0.8275 \\
BMI $\left(\mathrm{kg} / \mathrm{m}^{2}\right)$ & $35.06 \pm 2.11$ & $21.63 \pm 1.72$ & $<0.0001$ \\
S. PRL $(\mathrm{IU} / \mathrm{ml})$ & $19.57 \pm 9.28$ & $10.56 \pm 4.08$ & 0.0003 \\
S. FSH $(\mathrm{IU} / \mathrm{ml})$ & $4.33 \pm 1.76$ & $5.18 \pm 1.02$ & 0.0673 \\
S. LH $(\mathrm{IU} / \mathrm{ml})$ & $9.84 \pm 3.81$ & $3.12 \pm 0.86$ & $<0.0001$ \\
S. Zinc $(\mu \mathrm{g} / \mathrm{dl})$ & $65.68 \pm 31.28$ & $84.94 \pm 34.46$ & 0.072 \\
\hline
\end{tabular}

Serum zinc level in the four study groups

Serum zinc level was lowest in obese PCO group in comparison with non-obese PCO, obese control and non-obese groups as shown in figure (1).

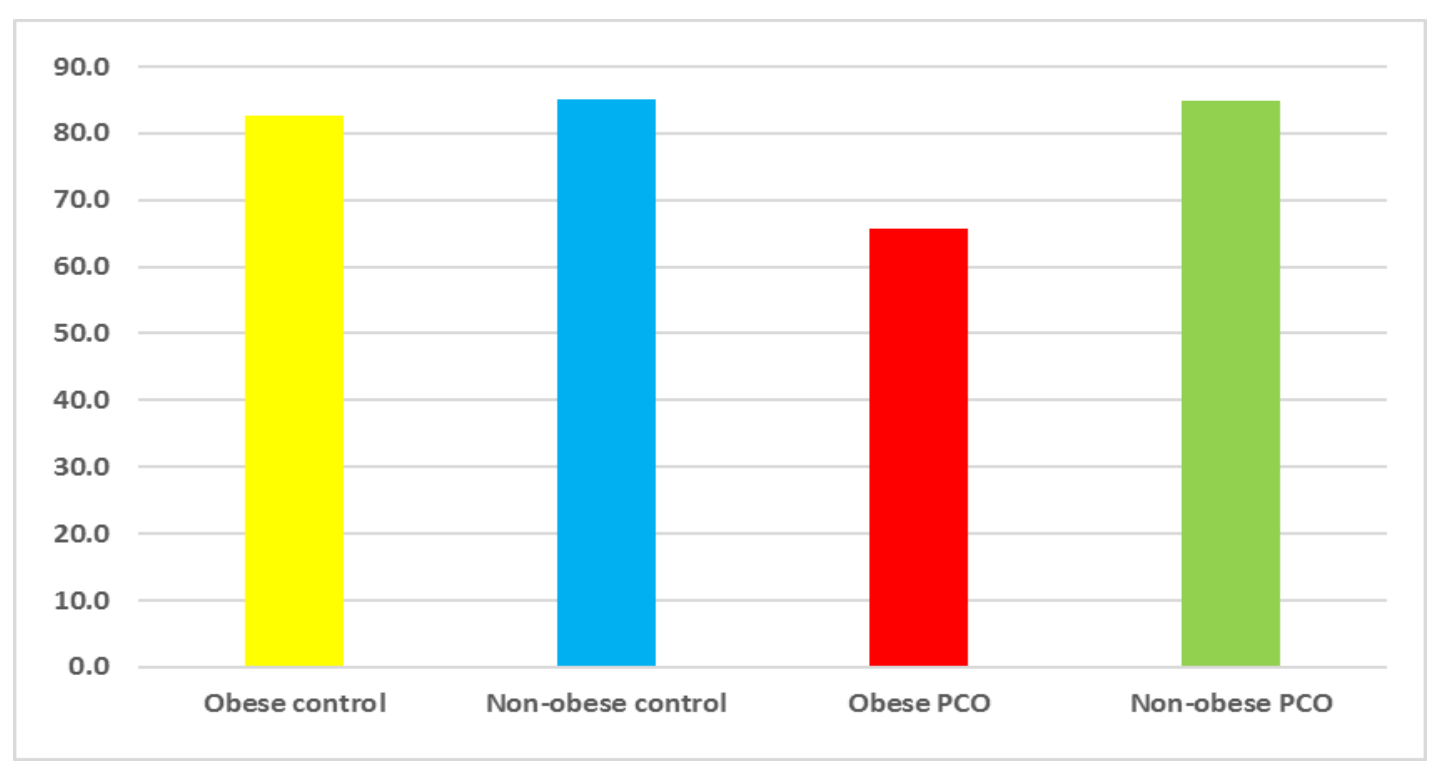

Figure 1. Level of serum zinc in four study groups 
Correlation of serum zinc with other parameters in the four study groups

There was significant negative correlation between serum zinc level and serum PRL level in obese PCO patients. While in non-obese PCO patients, there was significant negative correlation between serum zinc level with BMI and serum PRL as shown in table (6).

Table 6. Correlation of serum zinc with other parameters in the four study groups

\begin{tabular}{|c|c|c|c|c|c|c|c|c|}
\hline \multirow[t]{2}{*}{ Parameters } & \multicolumn{2}{|c|}{$\begin{array}{l}\text { Obese Control } \\
\qquad N=20\end{array}$} & \multicolumn{2}{|c|}{$\begin{array}{c}\text { Non-obese Control } \\
\qquad N=20\end{array}$} & \multicolumn{2}{|c|}{$\begin{array}{c}\text { Obese PCO } \\
\mathbf{N}=\mathbf{2 0}\end{array}$} & \multicolumn{2}{|c|}{$\begin{array}{c}\text { Non-obese PCO } \\
\mathrm{N}=\mathbf{2 0}\end{array}$} \\
\hline & $r$ & $\mathbf{P}$ & $r$ & $\mathbf{P}$ & $r$ & $\mathbf{P}$ & $\mathbf{R}$ & $\mathbf{P}$ \\
\hline Age (yr) & -0.236 & 0.316 & -0.066 & 0.783 & -0.094 & 0.695 & -0.297 & 0.204 \\
\hline BMI $\left(\mathrm{kg} / \mathrm{m}^{2}\right)$ & -0.196 & 0.408 & -0.048 & 0.842 & -0.558 & 0.010 & -0.646 & 0.002 \\
\hline S. PRL (IU/ml) & 0.032 & 0.895 & -0.176 & 0.457 & -0.097 & 0.684 & -0.539 & 0.014 \\
\hline S. FSH (IU/ml) & 0.239 & 0.311 & 0.226 & 0.337 & -0.021 & 0.928 & -0.223 & 0.345 \\
\hline S. LH (IU/ml) & 0.326 & 0.161 & -0.337 & 0.146 & 0.179 & 0.449 & -0.080 & 0.736 \\
\hline
\end{tabular}

Correlation of serum zinc with other parameters in control and PCO groups

There was significant negative correlation between serum zinc level with BMI and serum
PRL level in PCO patients, which was not significant in control group as shown in table (7).

Table 7. Correlation of serum zinc with other parameters in control and PCO groups

\begin{tabular}{ccccc}
\hline & \multicolumn{3}{c}{ Control } \\
N=40 & & \multicolumn{3}{c}{ PCO } \\
Narameters & $\mathbf{r}$ & $\mathbf{P}$ & $\mathbf{r}$ & $\mathbf{P}$ \\
\hline Age $(\mathrm{yr})$ & -0.160 & 0.325 & -0.199 & 0.217 \\
BMI $\left(\mathrm{kg} / \mathrm{m}^{2}\right)$ & -0.172 & 0.289 & -0.445 & 0.004 \\
S. PRL $(\mathrm{IU} / \mathrm{ml})$ & 0.098 & 0.547 & -0.334 & 0.035 \\
S. FSH $(\mathrm{IU} / \mathrm{ml})$ & 0.235 & 0.145 & -0.003 & 0.984 \\
S. LH $(\mathrm{IU} / \mathrm{ml})$ & -0.026 & 0.875 & -0.162 & 0.318 \\
\hline
\end{tabular}

\section{Discussion}

Polycystic ovary syndrome is the most common endocrine-metabolic disorder. It can be defined as a combination of hyperandrogenism (hirsutism and acne) and anovulation (oligomenorrhea, infertility, and dysfunctional uterine bleeding) with polycystic ovaries ${ }^{(1)}$.

Serum PRL level was significantly higher in PCO group than in control group with $P$ value < 0.0001 , which is consistent with other study (21). This increased PRL level may augment adrenal androgen secretion by the inhibition of 3-betahydroxysteroid dehydrogenase activity or, less often, through selective action on the sulfation of DHEA in adrenal or extra-adrenal sites. However, PRL inhibits FSH-induced ovarian aromatase, leading to intraovarian hyperandrogenemia ${ }^{(22)}$. Serum LH level was significantly increased in PCO group than in control group with $P$ value $<0.01$, which is consistent with other study ${ }^{(23)}$.

Serum PRL level and serum LH level in obese PCO group were highly significantly increased compared to obese control group with $\mathrm{P}$ value $<0.0001$ in which, they were consistent with other study ${ }^{(24)}$. It can be explained due to abnormality of the hypothalamic-pituitary ovarian or adrenal axis has been implicated in PCOS. Disturbance in gonadotrophin releasing hormone $(\mathrm{GnRH})$ results in the relative increase 
in LH to FSH release, abnormal feedback mechanism by ovarian estrogen is blamed to play role in this discriminated increase in $\mathrm{LH}$ release ${ }^{(25)}$.

Serum zinc level was significantly decreased in obese PCO group than in obese control group with $P$ value $<0.02$, which is different from other study which showed no significant difference between patients group and control group with respect to serum zinc levels $(P>$ $0.05)^{(26)}$.

One of the possible mechanisms of zinc relationship to PCOS other than insulin signaling system defects may be its effect on oxidative stress, zinc is a potent antioxidant and its deficiency causes increased oxidative damage in multiple organs, including the heart (27).

Oxidative stress induces infertility in women through a variety of mechanisms. Excess reactive oxygen species (ROS) in the follicle may overwhelm follicular fluid antioxidant defense and directly damage oocytes. The DNA of oocytes and spermatozoa may be damaged, leading to defective fertilization when the peritoneal cavity microenvironment is plagued with severe oxidative stress. Even when fertilization is achieved, oxidative stressinduced apoptosis may result in embryo fragmentation, implantation failure, abortion, impaired placentation, and congenital abnormalities ${ }^{(28)}$.

Excess ROS may hinder the endometrium, which normally functions to support the embryo and its development (29). Oxidative stress may induce luteal regression and insufficient luteal hormonal support for the continuation of a pregnancy ${ }^{(30)}$.

Non-obese PCO patients without insulin resistance also have been reported to have elevated total oxidant and antioxidant status. Verit et al. demonstrated that total antioxidant status in these types of PCO patients was correlated with raised LH levels and free androgen and dehydroepiandrosterone (DHEAS) levels (31).
There was significant negative correlation between serum zinc level and BMI in PCO patients. It has been found that BMI and PRL are all inversely associated with arsenic, cadmium, copper, lead, manganese, molybdenum, and $\mathrm{Zn} \mathrm{(32).} \mathrm{Obese} \mathrm{individuals}$ have lower blood concentrations of some vitamins and minerals compared to non-obese individuals ${ }^{(33)}$. Also, it has been observed that zinc concentration is directly associated with serum leptin concentration (34). So leptin resistance that occurred in obesity might have resulted from zinc deficiency in which, zinc may either directly affect leptin gene expression or indirectly cause leptin production by increasing glucose use of the fatty tissue. Also, there was significant negative correlation between serum zinc level and serum PRL level in non-obese PCO patients. This had been shown in a wide number of in vitro studies in which, an inverse relationship between zinc and PRL. Zinc interferes physiologically and pharmacologically in the synthesis, storage, release and peripheral action of PRL. Interaction with calcium-channels, calciumcalmodulin complex, adenylate cyclase, secretory granules, membrane stabilization and membrane receptors are some of proposed mechanisms of Zinc involvement in PRL secretion, as was reviewed by Brando-Neto et al (35).

It is concluded that serum zinc level reduced in obese PCO than in non-obese PCO. The level of serum zinc is negatively correlated with BMI and serum PRL level.

\section{Acknowledgments}

Great thanks to Dr. Batool H. Al-Musawi for her unlimited help in collection of patients. Also my thanks to Dr. Majid H. Ahmed for his effort in doing statistics.

\section{Conflict of interest}

There is no conflict of interest.

Funding

Self-funding. 


\section{References}

1. Christensen SB, Black MH, Smith $\mathrm{N}$, et al. Prevalence of polycystic ovary syndrome in adolescents. Fertil Steril. 2013, 100(2), 470-7. doi: 10.1016/j.fertnstert.2013.04.001.

2. Hwang KR, Choi YM, Kim JJ, et al. Effects of insulinsensitizing agents and insulin resistance in women with polycystic ovary syndrome. Clin Exp Reprod Med 2013, 40(2): 100-5. doi: 10.5653/cerm.2013.40.2.100.

3. Alvarez-Blasco F, Botella-Carretero JI, San Millan JL, et al. Prevalence and characteristics of the polycystic ovary syndrome in overweight and obese women, Arch Intern Med. 2006; 166, 2081-6. doi: 10.1001/archinte.166.19.2081.

4. Witchel S. Puberty and polycystic ovary syndrome. Mol Cel Endocrinol. 2006; 254-255: 146-53. doi: 10.1016/j.mce.2006.04.028.

5. Jakubowski L. Genetic aspects of polycystic ovary syndrome. Endokrynol Pol. 2005; 56, 285-93.

6. Carmina E. Cardiovascular risk \& events in polycystic ovary syndrome. Climacteric. 2009; 12(Suppl 1): 22-5. doi: 10.1080/13697130903003842.

7. Pasquali R, Gambineri A, Pagotto U. The impact of obesity on reproduction in women with polycystic ovary syndrome. BJOG 2006; 113: 1148-59. doi: 10.1111/j.1471-0528.2006.00990.x.

8. Diamanti-Kandarakis $\mathrm{E}$, Paterakis $\mathrm{T}$, Alexandraki K, et al. Indices of low-grade chronic inflammation in polycystic ovary syndrome and the beneficial effect of metformin. Hum Reprod. 2006; 21: 1426-31. doi: 10.1093/humrep/del003.

9. Essah PA, Wickham III EP, Nunley JR, et al. Dermatology of androgen-related disorders. Clin Dermatol. 2006; 24(4): 289-98. doi: 10.1016/j.clindermatol.2006.04.004.

10. Redmond GP, Bergfeld WF. Diagnostic approach to androgen disorders in women: acne, hirsutism, and alopecia. Cleveland Clin J Med. 1990; 57(5): 423-7. doi: 10.3949/ccjm.57.5.423.

11. Escobar-Morreale HF, Carmina E, Dewailly D, et al. Epidemiology, diagnosis and management of hirsutism: a consensus statement by the androgen excess and polycystic ovary syndrome society. Hum Reprod Update. 2012; 18(2): 146-70. doi: 10.1093/humupd/dmr042.

12. Zouboulis CC. Acne and sebaceous gland function. Clin Dermatol. 2004; 22(5): 360-6. doi: 10.1016/j.clindermatol.2004.03.004.

13. Price VH. Androgenetic alopecia in women. J Invest Dermatol Symp Proc. 2003; 8(1): 24-7. doi: 10.1046/j.1523-1747.2003.12168.x.

14. Rotterdam ESHRE/ASRM-Sponsored PCOS Consensus Workshop Group. Revised 2003 consensus on diagnostic criteria and long-term health risks related to polycystic ovary syndrome (PCOS). Hum Reprod 2004; 19: 41-7. doi: https://doi.org/10.1093/humrep/deh098.

15. Prasad AS. Zinc: mechanisms of host defense. J Nutr. 2007; 137(5): 1345-9.
16. Rink L, Kirchner $\mathrm{H}$. Zinc-altered immune function and cytokine production. J Nutr. 2000; 130: 1407S-11S.

17. Environmental Health Criteria (EHC). Zinc. IPCS INCHEM. 2001; 221. Available at: http://www.inchem.org/documents/ehc/ehc/ehc221 .htm

18. Maret W, Sandstead $\mathrm{HH}$. Zinc requirements and the risks and benefits of zinc supplementation. J Trace Elem Med Biol. 2006; 20: 3-18. doi: 10.1016/j.jtemb.2006.01.006.

19. Bedwal RS, Bahuguna A. Zinc, copper and selenium in reproduction. Experientia. 1994; 50: 626-40. doi: 10.1007/BF01952862.

20. Ménézo $Y$, Pluntz L, Chouteau J, et al. Zinc concentrations in serum and follicular fluid during ovarian stimulation and expression of $\mathrm{Zn} 2 \pm$ transporters in human oocytes and cumulus cells. Reprod Biomed Online. 2011; 22: 647-52. doi: 10.1016/j.rbmo.2011.03.015.

21.Zandi S, Farajzadeh S, Safari H. Prevalence of polycystic ovary syndrome in women with acne: hormone profiles and clinical findings. J Pakistan Ass Dermatol. 2010; 20: 194-8.

22. Roy George K, Malini NA. The prevalence and etiology of polycystic ovarian syndrome (PCOS) as a cause of female infertility in central Travancore. The Bioscan. 2014; 9(1): 1-6.

23. Anlakash $\mathrm{AH}$. Polycystic ovarian syndrome-the correlation between $\mathrm{LH} / \mathrm{FSH}$ ratio and disease manifestation. Middle East Fertil Soc J. 2007; 12(1): 35-40.

24. Richard SL, Ricardo A. Androgen excess disorders. Danforth's obstetrics and gynecology. 8th ed. Philadelphia: Lippincott Williams \& Wilkins; 2003. p. 663-72.

25. McKenna TJ. Pathogenesis and treatment of polycystic ovary syndrome. N Engl J Med. 1988; 318: 558-62. doi: 10.1056/NEJM198803033180906.

26. Sohrabvand F, Shirazi $M$, Shariat $M$, et al. Serum zinc level in infertile women with and without polycystic ovary syndrome: a comparative study. Tehran Univ Med J. 2013; 71(3): 157-63.

27. Guler I. Zinc and homocysteine levels in polycystic ovarian syndrome patients with insulin resistance. Biol Trace Elem Res. 2014; 158(3): 297-304. doi: 10.1007/s12011-014-9941-7.

28. Agarwal A, Said TM, Bedaiwy MA, et al. Oxidative stress in an assisted reproductive techniques' setting. Fertil Steril 2006; 86(3): 503-12. doi: 10.1016/j.fertnstert.2006.02.088.

29. Iborra A, Palacio JR, Martinez P. Oxidative stress and autoimmune response in the infertile woman. Chem Immunol Allergy. 2005; 88: 150-62. doi: 10.1159/000087832.

30. Agarwal A, Allamaneni S. Role of free radicals in female reproductive diseases and assisted reproduction. Reprod Biomed. 2004; 9(3): 338-47. doi: 10.1016/S1472-6483(10)62151-7.

31. Verit FF, Erel O. Oxidative stress in nonobese women with polycystic ovary syndrome: correlations with 
endocrine and screening parameters. Gynecol Obstet Invest. 2008; 65(4): 233-9. doi: 10.1159/000113046.

32. Meeker JD, Rossano MG, Protas B, et al. Multiple metals predict prolactin and thyrotropin (TSH) levels in men. Environ Res. 2009; 109(7): 869-73. doi: 10.1016/j.envres.2009.06.004.

33. Singh RB, Beegom R, Rastogi SS, et al. Association of low plasma concentrations of antioxidant vitamins, magnesium and zinc with high body fat per cent measured by bioelectrical impedance analysis in Indian men. Magnes Res. 1998, 11(1): 3-10.

34. Mantzoros CS, Prasad AS, Beck FW, et al. Zinc may regulate serum leptin concentrations in humans. J
Am Coll Nutr. 1998, 17(3): 270-5. doi: 10.1080/07315724.1998.10718758.

35. Brando-Neto J, Mduriera G, Mendonca BB, et al. Endocrine interaction between and zinc and prolactin. An interpretive review. Biol Trace Elem Res. 1995; 49: 139-49. doi: 10.1007/BF02788963.

\section{E-mail: driqbalderma30@gmail.com Received 4 ${ }^{\text {th }}$ Oct. 2016 Accepted 10 $0^{\text {th }}$ Jan. 2017}


Published by Al-Nahrain College of Medicine P-ISSN 1681-6579

E-ISSN 2224-4719

Email: iraqijms@colmed-alnahrain.edu.iq http://www.colmed-alnahrain.edu.iq http://www.iraqijms.net

\title{
Localization of Tight Junctions between Tanycyte-Like Cells of the Sulcus Medianus Organum in Rat Brain
}

\author{
Fadhil H. Ahmed ${ }^{1}$ BVM\&S, Muthanna A. Al-Kaabi ${ }^{1} P h D$, Sarmad E. Al-Marsoummi ${ }^{1}$ MSc, Hayder \\ A. Al-Aubaidy ${ }^{2} P h D$
}

${ }^{1}$ Dept. of Human Anatomy, College of Medicine, Al-Nahrain University, Baghdad, Iraq, School of Medicine, Faculty of Health, University of Tasmania, Australia

\begin{abstract}
Background Tanycytes are highly specialized ependymal cells (ECs) that line the regions of circumventricular organs (CVOs) where the blood-brain barrier is absent. These cells show tight junctions (TJs) that form a blood-cerebrospinal fluid barrier at the regions of these organs, thus modulating the transport mechanisms between the cerebrospinal fluid and the brain capillaries.

Objective To investigate the presence of TJs between ECs of the sulcus medianus organ (SMO) in the floor of the $4^{\text {th }}$ ventricle in comparison to the region of the median eminence (ME) of the hypothalamus, a known CVO in the brain.

Methods Ten adult male rats (Rattus Norvegicus Albinus) aged 3-6 months were used to study the general histological morphology of ECs at the SMO and ME regions by $\mathrm{H}$. and E. stain, and to explore the immunofluorescence labelling of these cells for TJs using anti-ZO1 FITC.

Results The ECs were arranged in 2-3 layers in the depth of the median sulcus (MS) at the SMO region as seen with $\mathrm{H}$. and E. stain. Immunofluorescent labelling with anti-ZO1 FITC revealed the presence of TJs between ECS of the SMO in a way similar to that reported between tanycytes of the ME.

Conclusion The SMO contained tanycytes or tanycyte-like cells that exhibited TJ complexes. This unique cell population added a strong evidence for the presence of a CVO in the rostral part of the MS to link CVOs on both sides of the cerebral aqueduct.

Keywords Tanycytes, circumventricular organs, sulcus medianus organum, tight junctions

Citation Fadhil H. Ahmed, Muthanna A. Al-Kaabi, Sarmad E. Al-Marsoummi, Hayder A. Al-Aubaidy. Localization of tight junctions between tanycyte-like cells of the sulcus medianus organum in rat brain. Iraqi JMS. 2017; Vol. 15(1): 48-63. doi: 10.22578/IJMS.15.1.7
\end{abstract}

List of abbreviation: $A P=$ Area postrema, $B B B=$ Blood-brain barrier, BCSFB = Blood-CSF barrier, CNS = Central nervous system, CSF $=$ Cerebrospinal fluid, $\mathrm{CVOS}=$ Circumventricular organs, $\mathrm{ECS}=$ Ependymal cells, $\mathrm{ME}=$ Median eminence, $\mathrm{MS}=$ Median sulcus, $\mathrm{NH}=$ Neurohypophysis, OVLT = Vascular organ of the lamina terminalis, $\mathrm{Pi}=$ Pineal gland, $\mathrm{SCO}=$ Subcommissural organ, $\mathrm{SFO}=$ Subfornical organ, $\mathrm{SMO}=$ Sulcus medianus organum, $\mathrm{TJ} \mathrm{s}=$ Tight junctions, $\mathrm{ZO} 1=$ Zonula occludens-1

\section{Introduction}

$\mathrm{n}$ the rat brain, neuroepithelial cells form ependymal cells (ECs) before day 10 of embryonic development and start to proliferate after the neural plate formation (1). Altman and Bayer ${ }^{(2,3)}$ observed that ependyma was first formed on day 16 of embryonic development but reported that it was not completed in some regions until the second postnatal week. In addition, the bulk of common ECs within the cerebral ventricles form on embryonic days 16-18, however, the specialized tanycytic epithelium is generated mainly postnatally.

Horstmann ${ }^{(4)}$ was the first to describe that the elongated bipolar ependymal cells lining the infundibular recess of the $3^{\text {rd }}$ ventricle had their proximal pole in the ventricular wall and 
the distal pole contacting the pituitary portal vessels. Because of their shape, Horstmann called these cells "tanycytes" (Greek tanus, "elongated"). Tanycytes that line the $3^{\text {rd }}$ ventricle do not comprise a homogenous cell population; four different types of tanycytes have been described based on their location, morphology, cytochemistry, ultrastructure, and function ${ }^{(5)}$. Tanycytes have been reported on the floor of the $4^{\text {th }}$ ventricle as well as on the walls and floor of the $3^{\text {rd }}$ ventricle, but few data are available regarding tanycytes of the cerebral aqueduct ${ }^{(6)}$.

Circumventricular organs (CVOs) are small structures bordering the median ventricular cavities in the brain which share common morphological and endocrine-like characteristics that distinguish them from other parts of the nervous system. Some of their unique features are cellular contacts with two fluid compartments, blood and cerebrospinal fluid (CSF), in addition to neural connections with strategic brain nuclei to form circuits for communications throughout the neural pathways ${ }^{(7)}$. These specialized areas are points of integration between the blood, the brain parenchyma, and the CSF ${ }^{(8)}$.

Most of the brain's CVOs (median eminence (ME), neurohypophysis (NH), vascular organ of the lamina terminalis (OVLT), subfornical organ (SFO), pineal gland $(\mathrm{Pi})$, subcommissural organ (SCO), are located at various positions in the wall of the $3^{\text {rd }}$ ventricle, while the area postrema (AP) is situated in the wall of the $4^{\text {th }}$ ventricle ${ }^{(9)}$.

The most fascinating part of the vascular morphology in CVOs is the capillary vessels having fenestrated endothelial cells in all CVOs aside from the SCO ${ }^{(10)}$. Thus, the blood-brain barrier (BBB) is lacking in all except one: the SCO and, unlike many regions of the brain, there can be bidirectional movement of polar particles between the blood and the neural environments of the CVOs. Nevertheless, there are variations in the barrier properties of each of the CVOs, with the ME and AP expressing less proteins related to endothelial tight junctions than SFO, OVLT and SCO (11-13), thus allowing more access of circulating polar particles into and out of the interstitium. The mammalian CVOs subdivided into two groups. One group, comprised of the SCO and choroid plexus, is characterized by modified or vascularized ECs. The second group, comprised of the SFO, OVLT, NH, ME, Pi, and AP, is characterized by subependymal elements, which differ from the ECs. This second group has been further categorized into sensory (SFO, OVLT, and $A P$ ) and secretory CVOs (NH, ME, and $\mathrm{Pi}$ ) (7).

In CVOs where exchange between the specialized neurons and the blood needs to be maintained (neuropeptide secretion to blood; chemosensitivity to monitor blood composition), the capillary endothelium is permeable, but these regions do not form a 'leak' across the BBB, by virtue of tight junctions between specialized ECs in CVOs, and between the processes of tanycytes and astrocytes glia that isolate the CVOs from brain parenchyma (14).

The specialized ECs (tanycytes) of these brain areas, are connected by tight junctions (TJs) between their apices, near their ventricular surface. The hemal milieu of the perivascular spaces and the CSF-milieu of the ventricle are here distinctly separated by the apical TJs of the tanycytes ${ }^{(15)}$.

The TJs protein zonula occludens-1 (ZO1) is expressed by ECs as opposed to fenestrated endothelial cells, suggesting that the barrier has been shifted from the vascular to the ventricular side. Therefore, blood-CSF barrier (BCSFB) is composed of the choroid plexus epithelial cells (ependyma) while the endothelial BBB is composed of the highly specialized central nervous system (CNS) microvascular endothelial cells. These barriers prevent paracellular diffusion of destructive elements into the CNS by presence of highly complex TJs of the BCSFB and BBB, which maintain brain homeostasis ${ }^{(16,17)}$.

Collins ${ }^{(18)}$ in 1989 was the first to describe a CVO in the region of the median sulcus (MS) of 
the $4^{\text {th }}$ ventricle in the rabbit where she designated it as the sulcus medianus organum (SMO). Since then, little attention was paid for the investigation of this organ. The ECs cells in this region are predominantly nonciliated. The apical surface of each cell has characteristic microvillous projections with pinocytotic vesicles. The cell body is elongated, with basal process. The general morphology of the cells is similar to tanycytes found in other CVOs. However, no immunohistochemical studies were done on the SMO to demonstrate TJs complexes between ECs of this region to add an evidence for the existence of a CVO in the rostral part of the MS.

This work targets the immunohistochemical proof for the presence of tanycytes or tanycyte-like cells in the region of the SMO. General histological staining and fluorescence immunohistochemical labelling were used to achieve this goal.

\section{Methods}

\section{Animals and tissue preparation}

A sample of 10 adult male rats (Rattus Norvegicus Albinus) aged 3-6 months were taken from the animal house of the High Institute for Infertility Diagnosis and Assisted Reproductive Technologies - Al-Nahrain University during the years 2015-2016 on basis of being apparently active and healthy, with $300 \pm 50$ g body weight. Animals were kept on fresh trefoil diet for 2 weeks prior to dissection. Animals were euthanized with chloroform impregnated cotton wool in an air tight chamber for 5 minutes. Then, skull dissection was done to deliver the brain into and fixed in $10 \%$ neutral buffer formalin (NBF) (Fisher scientific $\left.^{\otimes}\right)$ for 36 hours in preparation for dissection into two parts under dissecting lens, one part contained the $\mathrm{ME}$ and the other part included the cerebellum, $4^{\text {th }}$ ventricle and SMO.

Standard processing procedures were performed with Analar ${ }^{\circledR}$ materials and $5 \mu \mathrm{m}$ thickness section were cut from the regions of the SMO and ME with a Richert-Jung ${ }^{\circledR}, 2030$ MOT Biocut microtome.
Hematoxylin and Eosin (H. \& E.) staining

Harris modified hematoxylin (Riedel-de Haen ${ }^{\circledR}$ ) and Eosin-Y (Fisher scientific ${ }^{\circledR}$ ) were prepared according to Suvarna et al. ${ }^{(19)}$.

\section{Immunohistochemical staining:}

\section{Antigen retrieval}

Hydrated slides were processed for antigen retrieval as follows: Slide were put in a Coplin jar containing sodium citrate buffer (antigen retrieval solution) which was prepared according to Shi et al. (20):

- Solution A: (10.505 g) of Citric acid monohydrate dissolve in $500 \mathrm{ml}$ of distilled water (0.1 M)

- Solution B: (14.704 g) of Sodium citrate dissolve in $500 \mathrm{ml}$ of distilled water (0.1 M)

Mix $9 \mathrm{~mL}$ of solution $\mathrm{A}+41 \mathrm{~mL}$ of solution $\mathrm{B}$. Then the Coplin jar was transferred to an autoclave $\left(120^{\circ} \mathrm{C}, 1.2 \mathrm{Bar}\right)$ for 30 minutes and left to cool down to room temperature for 20 minutes. Slides were washed in running tap water for 5 minutes, distilled water for 5 minutes, Tris buffer-Tween 20 for 5 minutes and finally rinsed 3 time with Tris buffer.

\section{Antibody labelling}

Tissue sections were then "ringed" using wax pen, rinsed 3 times in Tris buffer and incubated in a humid chamber with the primary antibodies for 2 hours at room temperature $\left(25^{\circ} \mathrm{C}\right)$. The primary antibodies were diluted (1:100) in Tris buffer. Rabbit anti-Zo1 primary antibodies were pre-conjugated with FITC (Biorbyte ${ }^{\circledR}$ ) where they needed no further labelling procedure.

\section{Controls}

Negative control was prepared by staining sections from the regions of SMO and $M E$, in addition to kidney sections in the same staining producer except for the omission of the primary antibody.

Positive control was prepared by using kidney sections stained with anti-ZO1 antibodies in the same producer. 


\section{Examination of slides}

Examination of slides stained with H\&E was done under light microscope (Richert-Jung ${ }^{\circledR}$ Polivar) with $4 \mathrm{X}, 10 \mathrm{X}$ and $40 \mathrm{X}$ objective lenses and photographed with Nikon $\mathrm{D} 3000^{\circledR}$ digital camera.

Those slides labelled with (anti-ZO1-FITC) were examined with fluorescent microscope (AXIOZEISS $\left.{ }^{\circledR}\right)$. Two UV filters were used: FITC filter (519 nm), and DAPI filter (435 nm) for bright green, and blue fluorescence, respectively.

\section{Ethical statement}

All applicable international, national, and/or institutional guidelines for the care and use of animals were followed. All procedures performed in studies involving animals were in accordance with the ethical standards of the institution or practice at which the studies were conducted.

\section{Results}

General morphology with H. \& E. staining Median eminence

The ME, located at the ventral side of the $3^{\text {rd }}$ ventricle, was lined with a single layer of ECs similar to those lining the cerebral ventricles elsewhere. The nuclei of these cells stained blue-violate in color while their cytoplasm stained pink. No specific features could be identified with H. \& E. staining to mark these ECs as tanycytes (figures 1 and 2).

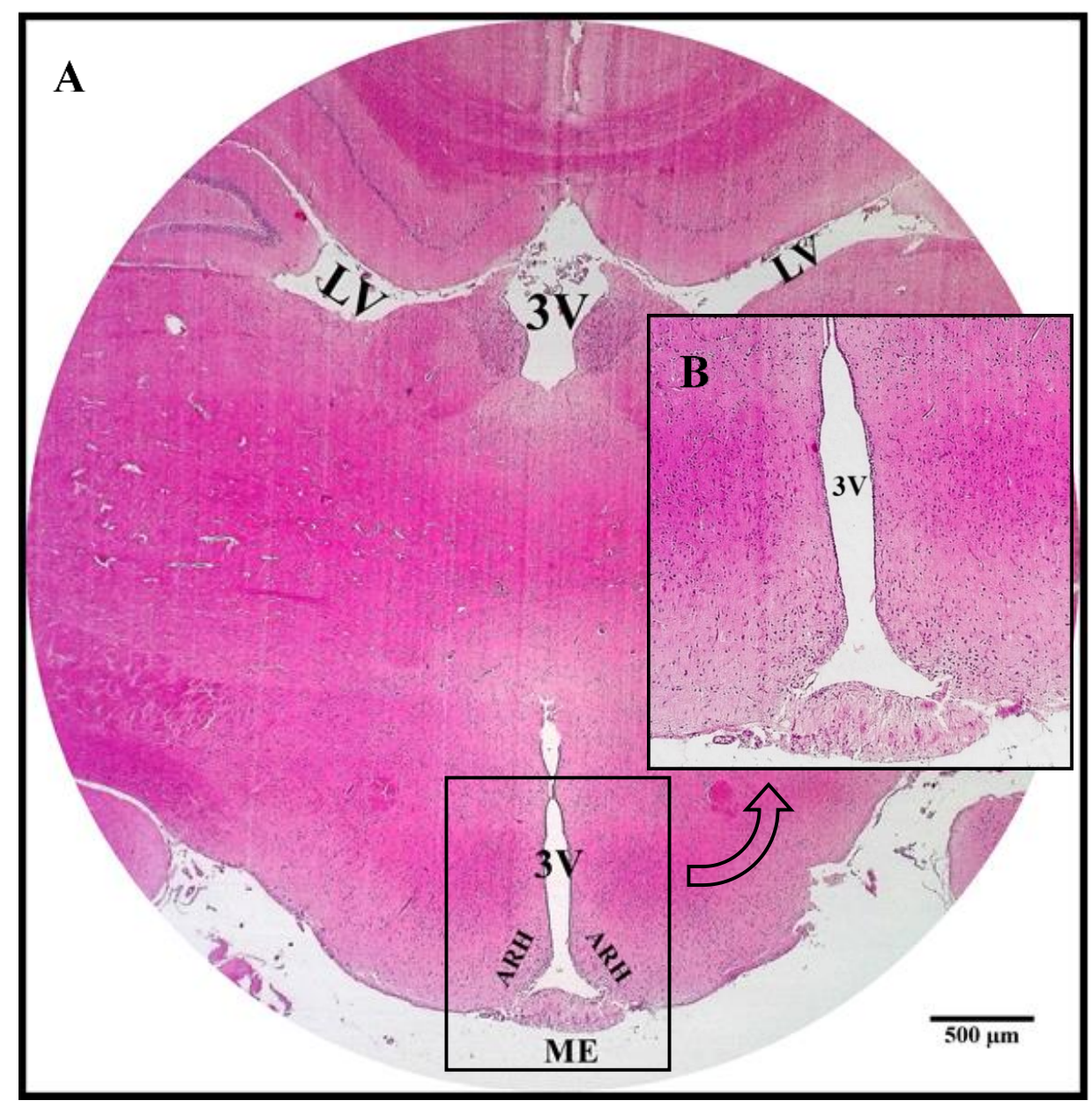

Figure 1. ME lining of ependymal cells in rat. Coronal sections. H. \& E. stain. (A) 40X. (B) 100X. $3 V: 3^{\text {rd }}$ ventricle. LV: lateral ventricle. ME: median eminence. ARH: arcuate hypothalamic nucleus 


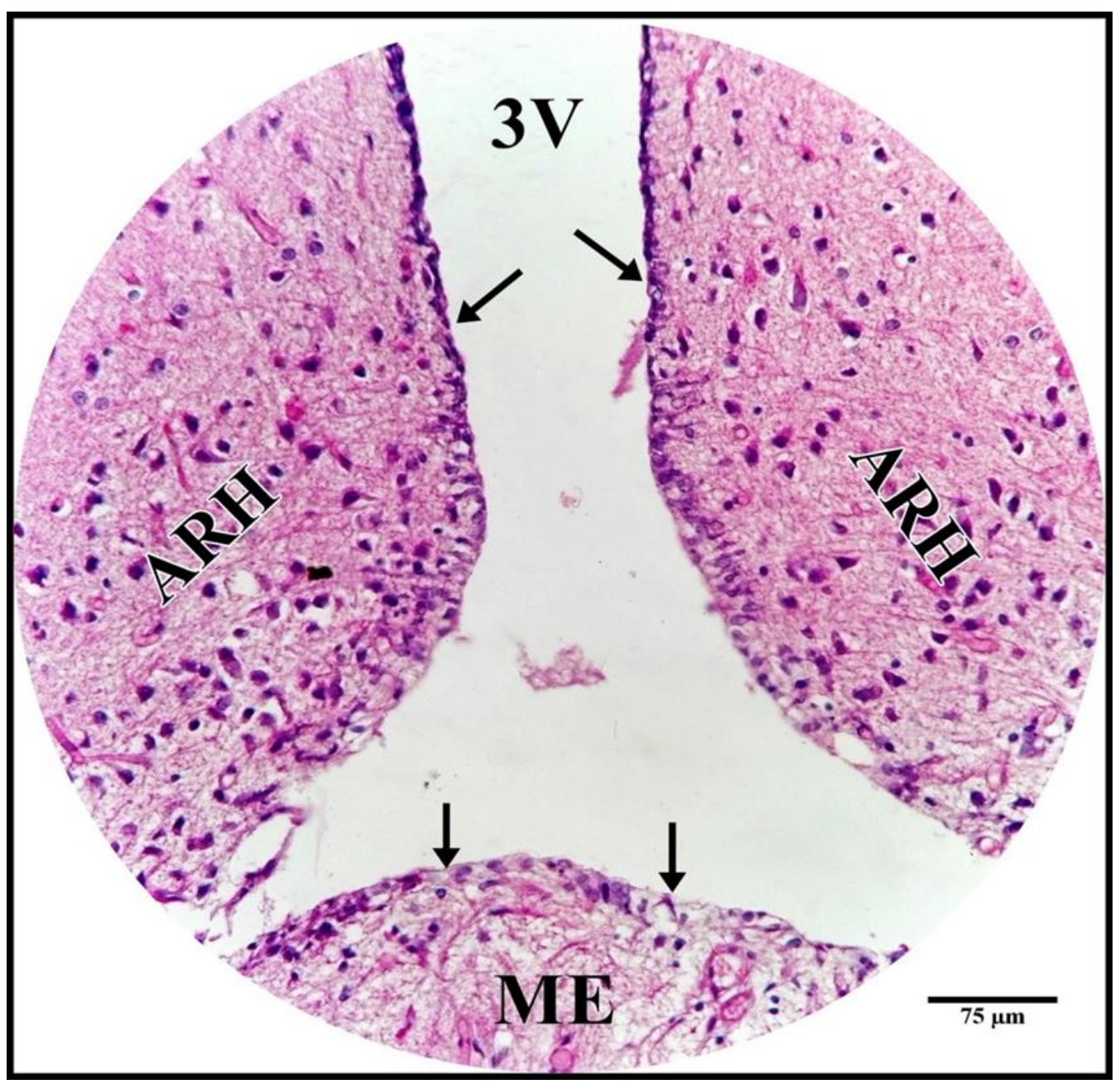

Figure 2. Ependymal lining of the 3rd ventricle walls (arrows). H. \& E. stain. 400X. 3V: $3^{\text {rd }}$ ventricle. ME: median eminence. ARH: arcuate hypothalamic nucleus

\section{Sulcus medianus organum}

The SMO was seen as a median longitudinal cleft in the rostral part of the floor of 4th ventricle. This furrow was lined with a single layer of ECs except at the deepest part of the furrow where a double layer of these cells was observed. Their nuclei stained blue-violate and the cytoplasm stained pink with H. \& E. stain (figures 3-5).

\section{Immunofluorescence labelling} Median eminence

Anti-ZO1 immunolabelling was seen as green fluorescence surrounding tanycytes of the ME.
This labelling of TJs was clearly seen on the apical surface and lateral borders of these tanycytes (figures 6 and 8). An internal negative control is seen in figures 7 and 9 .

\section{Sulcus medianus organum}

Findings of TJs labelling in ECs of the SMO were similar to those seen in tanycytes of the ME. This labelling of TJs was clearly seen on the apical surface and lateral borders of these tanycytes-like cells (figures 10 and 11). An internal negative control is seen in figure 12 . 


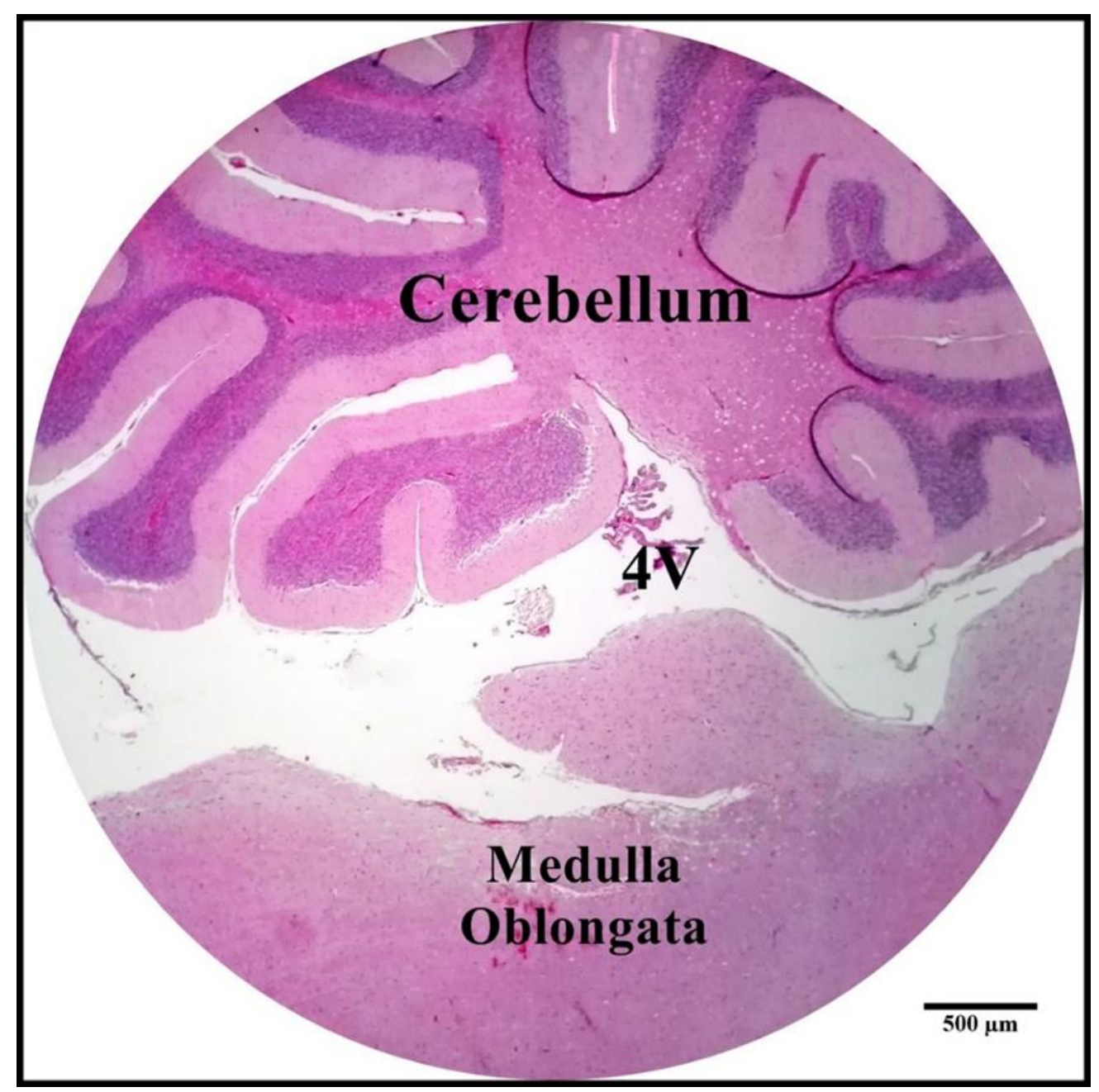

Figure 3. Sagittal section through the $4^{\text {th }}$ ventricle (4V) and SMO (arrows). H. \& E. stain. $40 X$

\section{Controls}

Positive controls for TJs between cells of renal tubules were labelled with ZO1 antibodies (figure 13). Negative controls were prepared by following the same immunohistochemical labelling procedure except for the omission of the primary antibodies (figure 14).

\section{Discussion}

Morphological considerations with H. \& E. stain

\section{Median eminence}

The neurohypophysis is organized into three parts, the ME (infundibulum), the infundibular stem, and the neural lobe (infundibular process). The neurohypophysis contains tanycytes and pituicytes which are specialized glial cells besides nerve terminals and vessels (21).

The ME is considered to be one of the CVOs in the brain that is located in the wall of the $3^{\text {rd }}$ ventricle where tanycytes have been identified and the morphology of these cells has been thoroughly explored by means of photonic observations as well as by TEM and SEM electron microscopy ${ }^{(22)}$.

In this study, examination of sections stained with H. \& E. under light microscope showed cuboidal or irregular cells lining the floor and walls of the $3^{\text {rd }}$ ventricle where cilia were difficult to be identified. Akmayev (23) reported that the floor and ventrolateral walls of the $3^{\text {rd }}$ ventricle were characterized by tanycytic ependymal cells with intimate topographical relationships to hypothalamic neurons and to 
blood vessels of hypothalamus and pituitary. Also, Petrov et al. ${ }^{(24)}$ reported that ependyma at the ME that form the floor of the $3^{\text {rd }}$ ventricle, immediately caudal to the optic chiasm, were irregular in shape (generally flattened) and lack cilia.

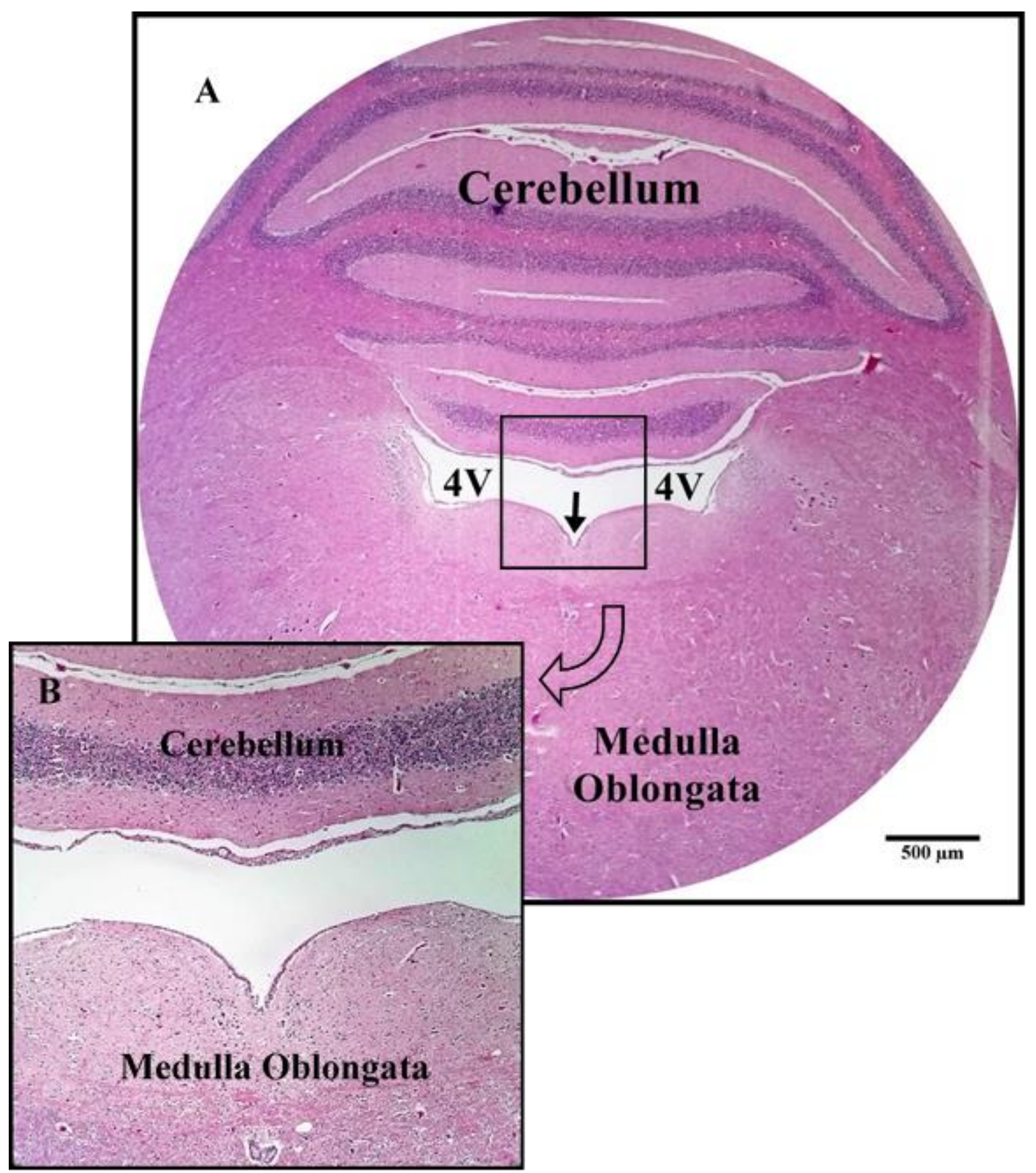

Figure 4. Coronal section of the floor of the 4th ventricle $(4 \mathrm{~V})$ at the region of SMO (arrow). H. \& E. stain. (A) 40X. (B) $100 X$ 


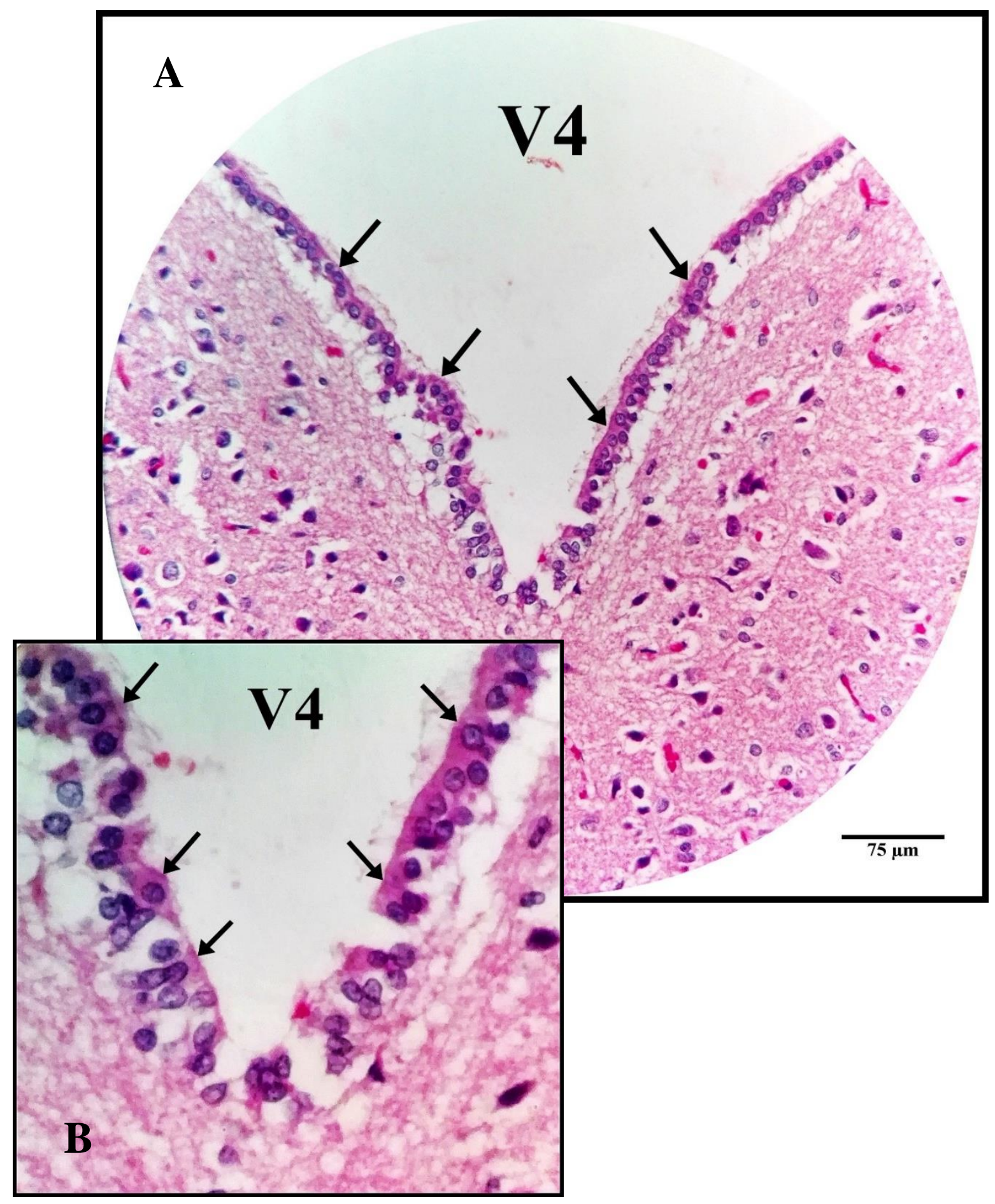

Figure 5. Coronal section of the floor of the $4^{\text {th }}$ ventricle $(4 \mathrm{~V})$ at the region of SMO. Ependymal cells (arrows) line the region of SMO. The median sulcus is lined with a single layer of ependymal cells (arrows). The deepest part of the sulcus shows two layers of cells similar to ependymal cells elsewhere in the walls of the cerebral ventricles. H. \& E. stain. (A) 400X. (B) 1250X SMO: sulcus medianus organum 




Figure 6. Coronal section at the ME showing TJs as green fluorescence around tanycytes (arrows). DAPI nuclear counterstaining appears as blue fluorescence.3V: $3^{\text {rd }}$ ventricle. $400 \mathrm{X}$

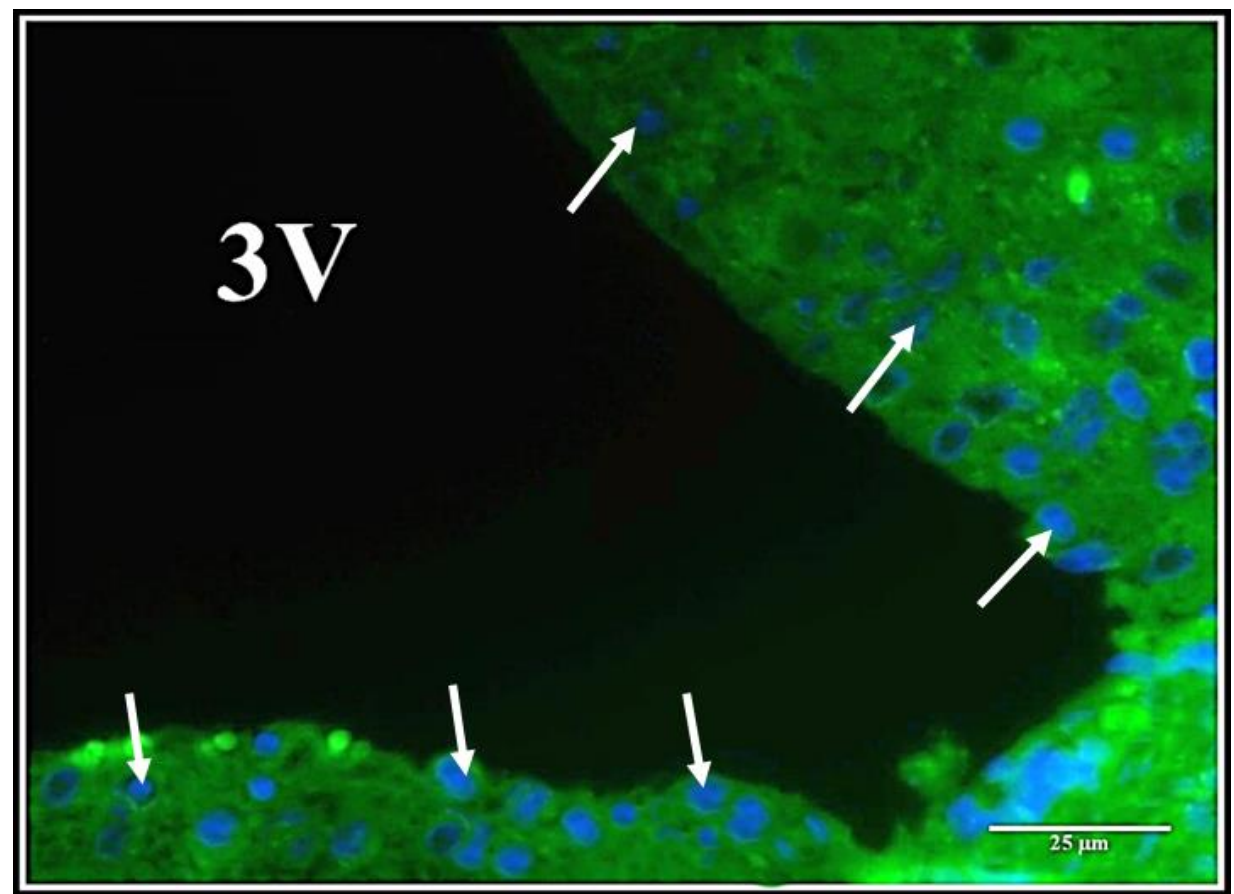

Figure 7. Coronal section at the region of the ME showing ZO1 FITC internal negative control. No labelling is seen along tanycytes of the 3rd ventricle ependymal lining. DAPI nuclear counterstaining is seen as bright blue fluorescence along the nuclei of 3 rd ventricle ependyma (arrows). 3V: $3^{\text {rd }}$ ventricle. 400X 




Figure 8. Coronal section showing TJs as green fluorescence around tanycytes of the ME (arrows). TJs are seen on the apical surface and borders of these cells. DAPI nuclear counterstaining is seen as blue fluorescence. $3 \mathrm{~V}: 3^{\text {rd }}$ ventricle. $400 \mathrm{X}$

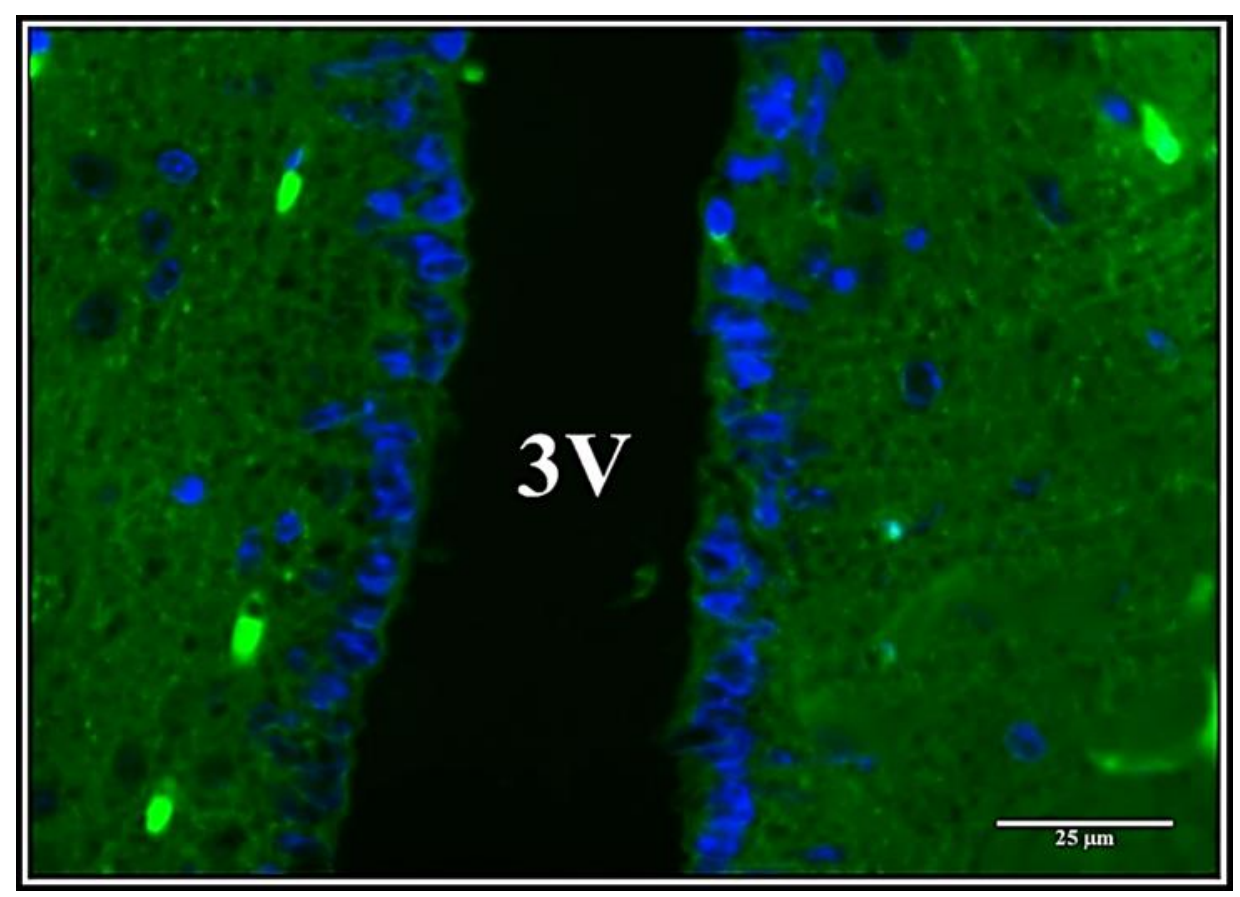

Figure 9. Coronal section at the region of the ME showing ZO1 FITC internal negative control. No labeling is seen along tanycytes of the 3rd ventricle ependymal lining. DAPI nuclear counterstaining is seen as bright blue fluorescence along the nuclei of 3 rd ventricle ependyma (arrows). 3V: $3^{\text {rd }}$ ventricle. $400 \mathrm{X}$ 


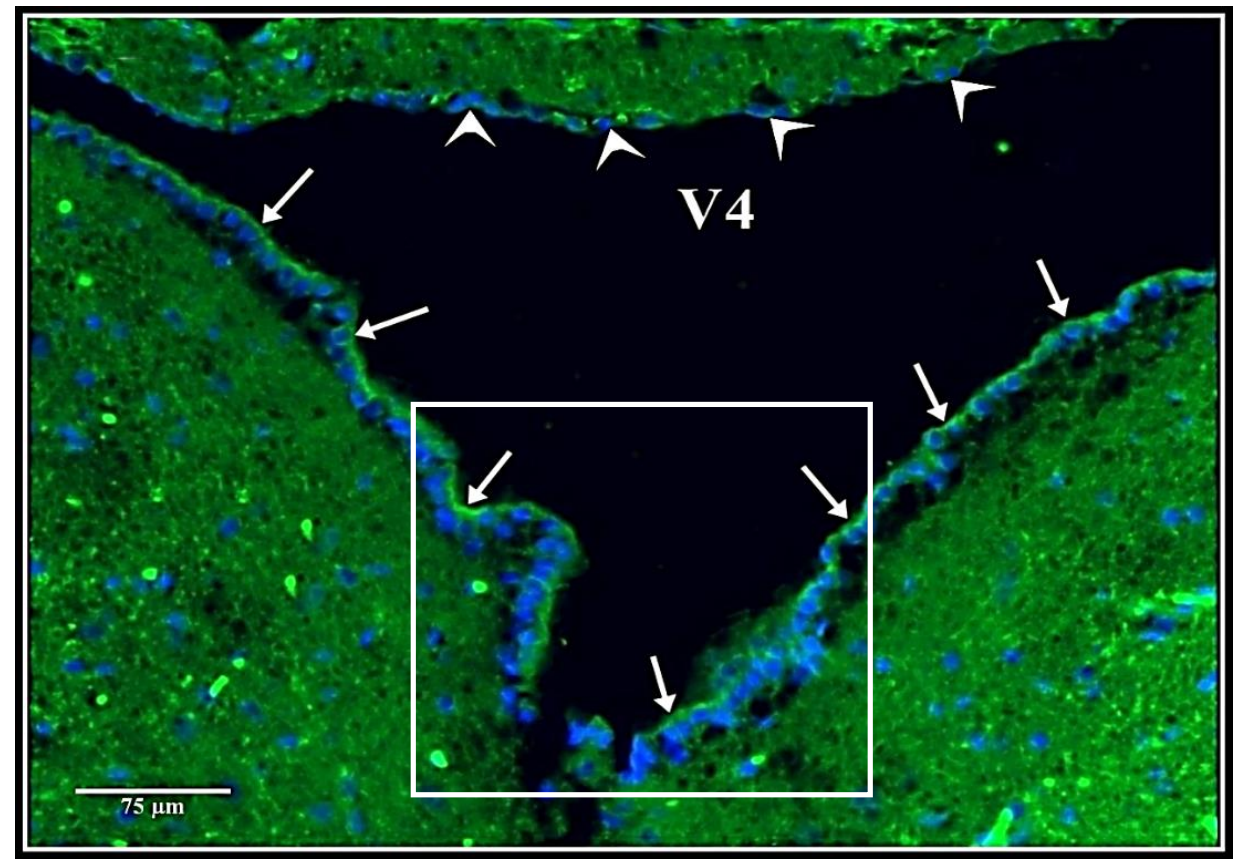

Figure 10. Coronal section showing TJs as green fluorescence around tanycytes of the SMO (arrows). TJs are seen on the apical surface and borders of these cells. DAPI nuclear counterstaining is seen as blue fluorescence. The ependymal cells of roof are negative with ZO1 (head arrows). $4 \mathrm{~V}: 4^{\text {th }}$ ventricle. $400 \mathrm{X}$

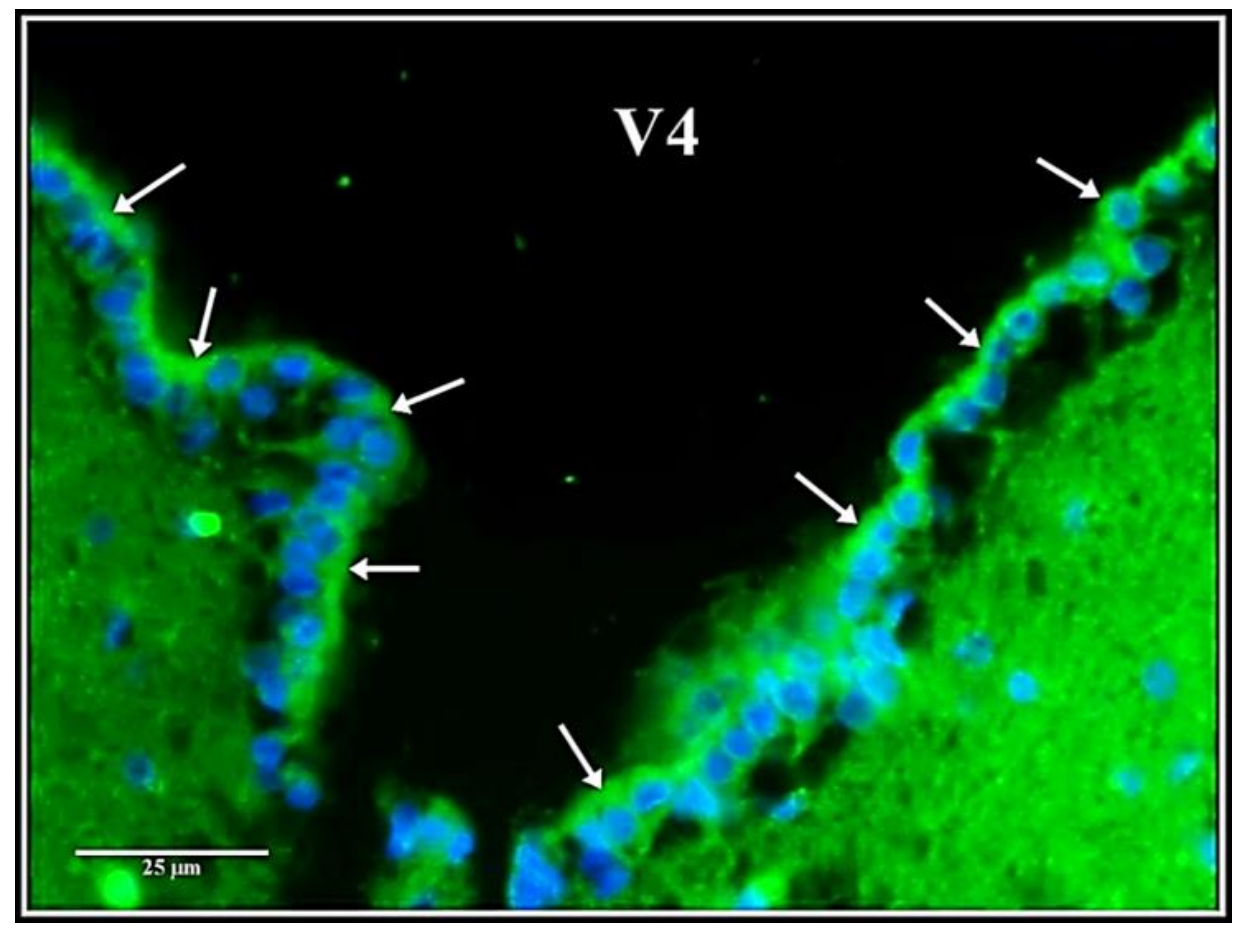

Figure 11. Higher magnification of the inset shown in figure 10. TJs between tanycytes of the SMO are seen as green fluorescence between the cells and on their apical surfaces (arrows). DAPI nuclear counterstaining shows cells nuclei as bright blue fluorescence. $4 \mathrm{~V}: 4^{\text {th }}$ ventricle $630 \mathrm{X}$ 


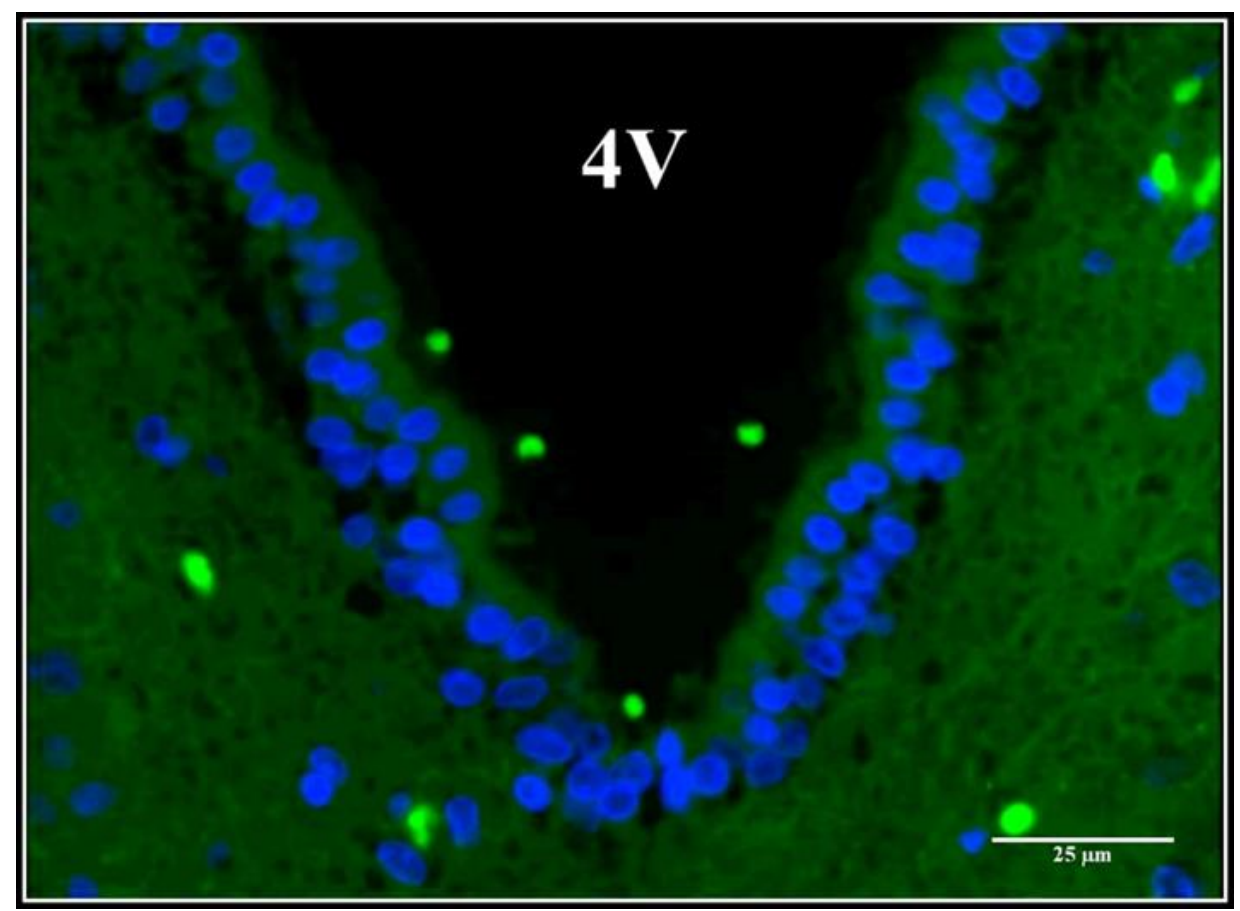

Figure 12. Coronal section at the region of the SMO showing ZO1 FITC internal negative control. No labelling is seen along tanycytes of the 4th ventricle ependymal lining. DAPI nuclear counterstaining is seen as bright blue fluorescence along the nuclei of 4 th ventricle ependyma (arrows). 4V: $4^{\text {th }}$ ventricle. 200X

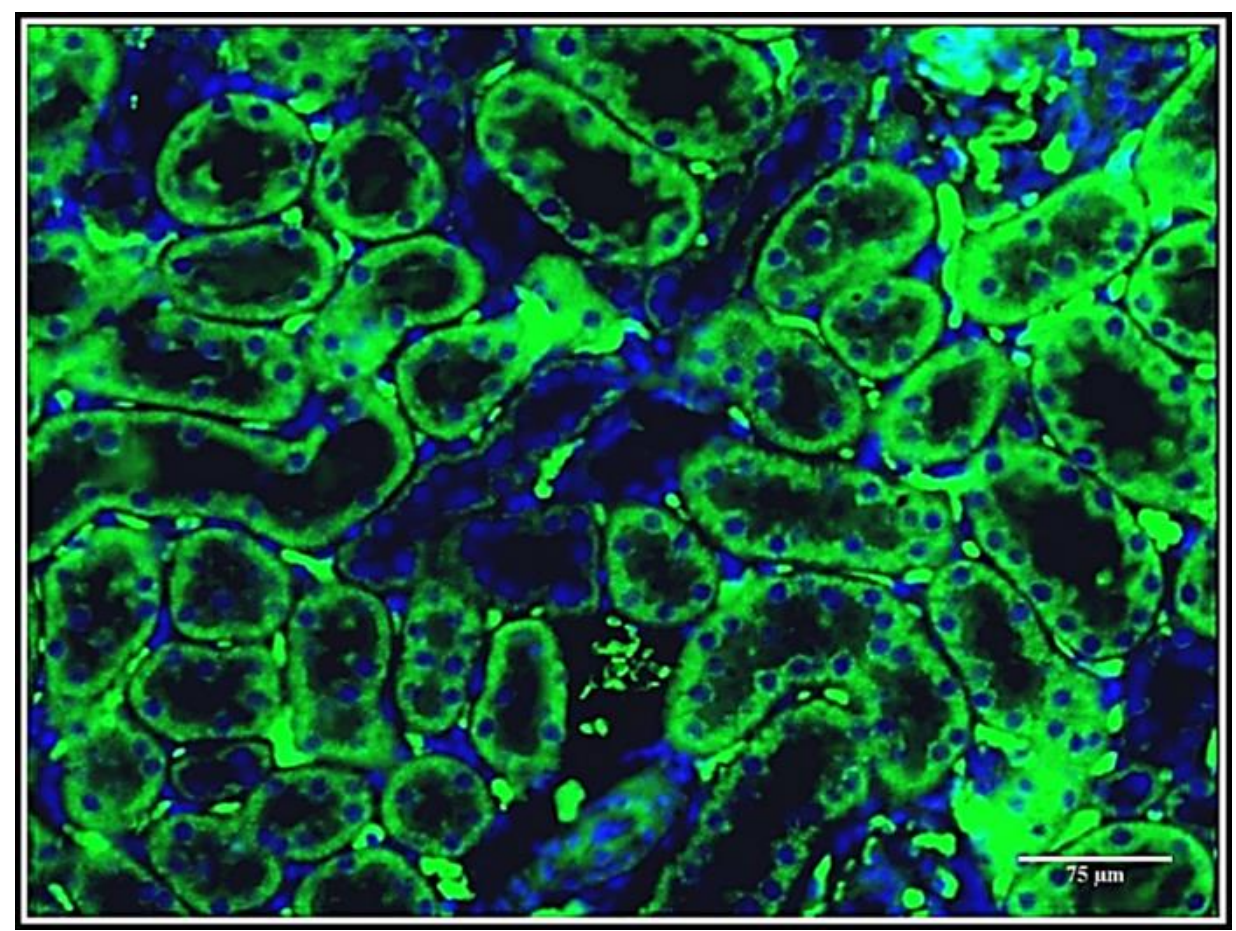

Figure 13. ZO1 positive control in kidney section. Renal tubules show intense green immunofluorescence at TJs between their cells. DAPI nuclear counterstaining is seen as bright blue fluorescence at cell nuclei. 200X 


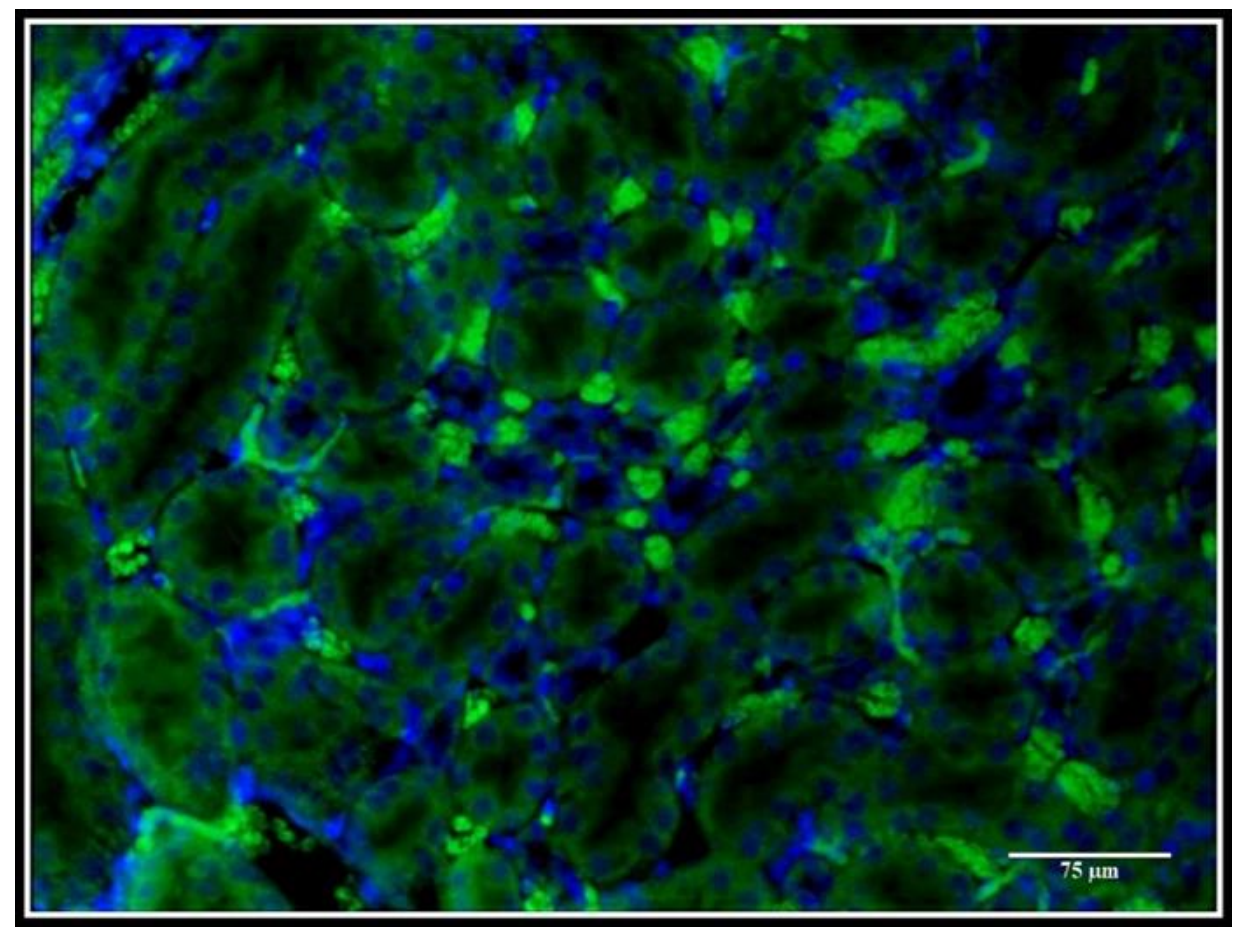

Figure 14. ZO1 negative control in kidney section. Renal tubules do not show TJs immunofluorescent labeling between their cells. DAPI nuclear counterstaining is seen as bright blue fluorescence at cell nuclei. 200X

\section{Sulcus medianus organum}

On light microscopic examination, the epithelium of the SM is pseudostratified with the apical surface of the cells is covered with microvilli; only a few cilia clumps are present (18). Most literatures investigate the caudal part of the SM where the AP is framed by processbearing ECs that connect the ventricular and fenestrated vessels compartments, as portrayed in the ME ${ }^{(25)}$. Researchers, however, did not elaborate on the rostral part of the SM where little attention is paid for the presence of the SMO as one of the CVOs.

Examination with H. \& E. stain showed aligned cuboidal or short columnar cells each with a single round nucleus and no identifiable cilia at their surfaces that line the floor of 4 th ventricle. It is interesting to note that ependymal cells at the depth of the SM in the region of the SMO were seen to be "crowded" in 2-3 layers compared to the single layer ependyma on the MS banks and the floor of the $4^{\text {th }}$ ventricle. This condensation of cells at the SMO may be due to the presence of supraependymal cells on the ventricular aspect of ependyma CVOs ${ }^{(18)}$, or it can be a reflection of the presence of tanycytes or tanycyte-like cells in the region of the SMO.

\section{Immunohistochemical characterization of TJs complexes at tanycytes}

Mullier et al. (6) studied the expression and distribution of important three tight junctional proteins which have essential functional roles in CNS diffusion barriers. These proteins are the ZO1, occludin, and claudin1. ZO1 and occludin immunolabeling was detected at the cells that line the 3rd ventricle and the AP of the $4^{\text {th }}$ ventricle, in other words, those specialized ECs forming the ventricular walls of the CVOs ${ }^{(25)}$.

Since these CVOs lack an endothelial BBB, they serve neurohemal or neurosecretory functions. Capillaries within the CVOs are fenestrated allowing free diffusion of proteins and solutes between the blood and the CVOs. Specialized ECs (tanycytes), which connect by TJs, form a complex network that seal the CNS from the CVOs, creating a distinct BCSFB ${ }^{(26)}$. 
The TJs protein ZO1 is expressed in the special ECs of the CVOs as opposed to the fenestrated endothelial cells suggesting that the barrier has been shifted from the vascular to the ventricular side (27).

\section{Inspection of Immunofluorescence Reaction in the ME}

The ME of the hypothalamus is one such CVO that typically contains a rich capillary plexus with a fenestrated endothelium (28). It also contains tanycytes that constitute the specialized ependyma-glial cellular sheet that lines the floor and the basolateral walls of the third ventricle. A dominant feature of tanycytes is their marked polarization: tanycyte cell bodies are located in the ventral border of the 3rd ventricle, but they also send processes to the vascular walls, where they make contact through "end feet" specializations (29).

In tanycytes located at the ME, previous studies showed that ZO1 immunoreactivity was organized around the cell bodies in a continuous belt, giving rise to a honeycomblike shape. In contrast, tanycytes lining the region of the ventricle adjacent to the arcuate hypothalamic nucleus exhibited a diffuse pattern of ZO1 and occludin immunoreactivity in the apical region of the cells. Similar to tanycytes of the $M E$, an organized pattern of ZO1 and occludin labelling was observed in ECs dorsal to the arcuate hypothalamic nucleus ${ }^{(6)}$. In this study, it could demonstrated that immunofluorescent labelling for TJs and AJs between ECs lining the $3^{\text {rd }}$ ventricle at the region of the ME. This detection of TJs with rabbit anti-ZO1 primary antibodies conjugated with FITC was used as an internal control to validate the results of immunofluorescent labelling of ECs at the region of the SMO. Our results, however, were more in a diffuse rather than a honeycomb pattern, partly because of the fluorescence microscope resolution capacity, and probably because of the type of antibodies used in this study being directly conjugated.

\section{Immunofluorescence labelling of TJs complexes in the region of SMO}

The work of Langlet et al (25), and before that Collins ${ }^{(18)}$ revealed the presence of tanycytelike cells in the floor of $4^{\text {th }}$ ventricle, suggesting that the SMO is another CVO. However, immunohistochemical methods were not used to characterize cell population in that region. In this study, it was aimed to label ECs in the MS with anti-ZO1 antibodies to explore TJs complexes between these cells.

Anti-ZO1 immunolabeling in the SMO region was confined to its cell lining, sparing other cells in the ependymal roof of the $4^{\text {th }}$ ventricle. This finding proved that ECS of the SMO contain TJs, which give them special features of tanycytes or tanycyte-like cells and make them different from the remaining ependyma of the $4^{\text {th }}$ ventricle.

In addition, cells in the depth of the MS at the SMO region showed higher intensity of immunofluorescence to the examining eye. This may support our observation with H. \& E. staining that ECs in the depth of the furrow were arranged in more than one layer, leading to emission of more fluorescence than the single-layered ependyma of the $4^{\text {th }}$ ventricle.

In context of the aforementioned observations, this study suggests that the presence of tanycytes in the region of the SMO could explain the reason beyond the existence of the hypothesized CVO at this location as it can bridge the gap between the $A P$ and the rostrally located CVOs, i.e., on either side of the cerebral aqueduct, where non-neuronal signal transmission may occur through CSFcontacting tanycytes that reach the deeply seated brainstem nuclei.

\section{Acknowledgments}

Thanks to Al-Nahrain University, College of Medicine, and Department of Human Anatomy to provide the facilities and laboratories for the completion of this work.

\section{Author contribution}

Ahmed: collection, assembly and interpretation of data, manuscript writing; Dr. Al-Kaabi: conception and design, interpretation of data, manuscript writing; Dr. Al-Marsoummi: 
interpretation of data; Dr. Al-Aubaidy: manuscript writing. All authors have approved the final article.

\section{Conflict of interest}

Authors declare no conflict of interests.

\section{Funding}

No external funding sources.

\section{References}

1. Korr H. Proliferation of different cell types in the brain. Berlin: Springer-Verlag; 1980. p. 72 p. doi: 10.1007/978-3-642-67577-5.

2. Altman J, Bayer SA. Development of the diencephalon in the rat. III. Ontogeny of the specialized ventricular linings of the hypothalamic third ventricle. J Comp Neurol. 1978; 182(5): 9951015. doi: $10.1002 /$ cne.901820513.

3. Bayer SA. Development of the diencephalon in the rat. I. Autoradiographic study of the time of origin and settling patterns of neurons of the hypothalamus. J Comp Neurol. 1978; 182(5): 945-71. doi: $10.1002 /$ cne.901820511.

4. Horstmann E. The fiber glia of selacean brain. Z Zellforsch Mikrosk Anat. 1954; 39(6): 588-617.

5. Rodriguez EM, Blazquez JL, Pastor $F E$, et al. Hypothalamic tanycytes: a key component of brainendocrine interaction. Int Review Cytol. 2005; 247: 89-164. doi: 10.1016/S0074-7696(05)47003-5.

6. Mullier A, Bouret SG, Prevot V, et al. Differential distribution of tight junction proteins suggests a role for tanycytes in blood-hypothalamus barrier regulation in the adult mouse brain. J Comp Neurol. 2010; 518(7): 943-62. doi: 10.1002/cne.22273.

7. Szathmari A, Jouvet A, Mottolese $C$, et al. Anatomical, molecular and pathological consideration of the circumventricular organs. Neurochirurgie. 2015; 61(2): 90-100. doi: 10.1016/j.neuchi.2013.04.006.

8. Benarroch EE. Circumventricular organs: receptive and homeostatic functions and clinical implications. Neurology. 2011; 77(12): 1198-204. doi: 10.1212/WNL.0b013e31822f04a0.

9. Duvernoy HM, Risold PY. The circumventricular organs: an atlas of comparative anatomy and vascularization. Brain Res Rev. 2007; 56(1): 119-47. doi: 10.1016/j.brainresrev.2007.06.002.

10. Morita S, Miyata S. Different vascular permeability between the sensory and secretory circumventricular organs of adult mouse brain. Cell Tissue Res. 2012; 349(2): 589-603. doi: 10.1007/s00441-012-1421-9.

11. Willis CL, Garwood CJ, Ray DE. A size selective vascular barrier in the rat area postrema formed by perivascular macrophages and the extracellular matrix. Neuroscience. 2007; 150(2): 498-509. doi: 10.1016/j.neuroscience.2007.09.023.

12. Maolood N, Meister B. Protein components of the blood-brain barrier (BBB) in the brainstem area postrema-nucleus tractus solitarius region. J Chem Neuroanat. 2009; 37(3): 182-95. doi: 10.1016/j.jchemneu.2008.12.007.

13. Miyata S. New aspects in fenestrated capillary and tissue dynamics in the sensory circumventricular organs of adult brains. Front Neurosci. 2015; 9: 390. doi: 10.3389/fnins.2015.00390.

14. Abbott NJ. Dynamics of CNS barriers: evolution, differentiation, and modulation. Cell Mol Neurobiol. 2005; 25(1): 5-23. doi: 10.1007/s10571-004-1374-y.

15. Langlet F. Tanycytes: a gateway to the metabolic hypothalamus. J Neuroendocrinol. 2014; 26(11): 75360. doi: 10.1111/jne.12191.

16. Wolburg H, Paulus W. Choroid plexus: biology and pathology. Acta Neuropathol. 2010; 119(1): 75-88. doi: 10.1007/s00401-009-0627-8.

17. Tietz S, Engelhardt B. Brain barriers: Crosstalk between complex tight junctions and adherens junctions. J Cell Biol. 2015 ;209(4): 493-506. doi: 10.1083/jcb.201412147.

18. Collins $P$. The sulcus medianus organ in the fourth cerebral ventricle of the rabbit: a previously undescribed circumventricular organ. J Anat. 1989; 162: 185-93.

19. Suvarna SK, Layton C, Bancroft JD. The Hematoxylins and Eosin. In: Bancroft JD, Layton C. (eds.) Bancroft's Theory and practice of histological techniques. $7^{\text {th }}$ ed. China: Churchill Livingstone; 2013. p. 173-88.

20.Shi SR, Liu C, Taylor CR. Standardization of immunohistochemistry for formalin-fixed, paraffinembedded tissue sections based on the antigenretrieval technique: from experiments to hypothesis. J Histochem Cytochem. 2007; 55(2): 105-9. doi: 10.1369/jhc.6P7080.2006.

21. Paxinos $G$. The rat nervous system. $4^{\text {th }}$ ed. Academic Press; 2014. (eBook ISBN 9780080921372).

22. Joly JS, Osório J, Alunni A, et al. Windows of the brain: towards a developmental biology of circumventricular and other neurohemal organs. Semin Cell Dev Biol. 2007; 18(4): 512-4. doi: 10.1016/j.semcdb.2007.06.001

23. Akmayev IG, Fidelina OV, Kabolova ZA, et al. Morphological aspects of the hypothalamichypophyseal system. IV. Medial basal hypothalamus. An experimental morphological study. Z Zellforsch Mikrosk Anat. 1973; 137(4): 493-512. doi: 10.1007/BF00307226.

24. Petrov $T$, Howarth AG, Krukoff TL, et al. Distribution of the tight junction-associated protein ZO-1 in circumventricular organs of the CNS. Brain Res Mol Brain Res. 1994; 21(3-4): 235-46. doi: 10.1016/0169328X(94)90254-2.

25. Langlet F, Mullier A, Bouret SG, et al. Tanycyte-like cells form a blood-cerebrospinal fluid barrier in the circumventricular organs of the mouse brain. The J Comp Neurol. 2013; 521(15): 3389-405. doi: 10.1002/cne.23355.

26. Engelhardt B, Sorokin L. The blood-brain and the blood-cerebrospinal fluid barriers: function and 
dysfunction. Sem Immunopathol. 2009; 31(4): 497511. doi: 10.1007/s00281-009-0177-0.

27. Vorbrodt AW, Dobrogowska DH. Molecular anatomy of intercellular junctions in brain endothelial and epithelial barriers: electron microscopist's view. Brain Res, Brain Res Rev. 2003; 42(3): 221-42. doi: 10.1016/S0165-0173(03)00177-2.

28. Schulz M, Engelhardt $B$. The circumventricular organs participate in the immunopathogenesis of experimental autoimmune encephalomyelitis. Cerebrospinal Fluid Res. 2005; 2: 8. doi: $10.1186 / 1743-8454-2-8$.
29. Prevot V. Glial-neuronal-endothelial interactions are involved in the control of $\mathrm{GnRH}$ secretion. J Neuroendocrinol. 2002; 14(3): 247-55. doi: 10.1046/j.0007-1331.2001.00772.x.

Correspondence to Dr. Muthanna A. Al-Kaabi E-mail: muthanna.alkaabi@colmedalnahrain.edu.iq Received $10^{\text {th }}$ Nov. 2016 Accepted $12^{\text {th }}$ Jan. 2017 
Published by Al-Nahrain College of Medicine P-ISSN 1681-6579

E-ISSN 2224-4719

Email: iraqijms@colmed-alnahrain.edu.iq http://www.colmed-alnahrain.edu.iq http://www.iraqijms.net

\title{
Isolation, Identification and Determination of Antifungal Sensitivity of Fungi Isolated from A Sample of Patients with Rhinosinusitis in Baghdad City
}

\author{
Israa A. Ali $P h D$ \\ Dept. of Biology, College of Science, Baghdad University, Baghdad, Iraq
}

\begin{abstract}
Background Rhinosinusitis is inflammation of the sinuses, most commonly caused by a viral or bacterial infection or by allergic (or non-allergic; non-allergic could be due to infection). Fungal infections of the sinuses are uncommon and usually occur in individuals who are immunocompromised. However, recently, the occurrence of fungal sinusitis has increased in the immunocompetent population.

Objective Isolation and identification of fungi in Rhinosinusitis with antifungal sensitivity..

Methods The study was carried out on 112 patients who were suffering from rhinosinusitis, and then identification was done for the isolated fungi associated with rhinosinusitis 1-Specimens (Swabs (from nose and sinuses) and Water nasal washing) collection. 2- Direct microscopic exam. 3-Fungal isolation and diagnosis. 4-Anti-Fungal sensitivity test. 5- Patients (112 patient) were diagnosed by specialist Doctors according to the clinical symptoms and CT scan findings and biopsy. attending AlYarmouk Teaching hospital, and Baghdad Medical City. From February to June 2015.

Results The results showed that 38 (33.9\%) patients were suffering from fungal infection in this study. The most common fungi isolated were Aspergillus spp. 18 (47.3\%), followed by Rhizopus spp. 7 (18.4\%), Trichophyton spp. 5 (13.1\%), Penicillium spp. 3 (7.8\%), yeast Candida spp. 2 (5.2\%), Alternaria spp. 1 (2.6\%), Cryptococcus neoformans 1 (2.6\%) and Blastomyces dermatitidis 1 (2.6\%). The antifungal of the most common three fungi isolated, which were (Aspergillus spp., Rhizopus spp., and Trichophyton spp.,) was determined for Amphotericin B, Griseofulvin and Ketoconazole. The result showed that tested fungi were sensitive to Amphotericin B and resistant to Griseofulvin and Ketoconazole.

Conclusion Fungal rhinosinusitis was moderate infection. Aspergillus spp., Rhizopus spp. and Trichophyton spp. were the most commonly fungus iolated from rhinosinusitis. They were sensitive to Amphotericin B and resistant to grisofulvin and ketoconazole.

Keywords Fungal sinusitis, rhinosinusitis, sinusitis, fungal infection in the nose.

Citation Israa A. Ali. Isolation, identification and determination of antifungal sensitivity of fungi isolated from a sample of patients with rhinosinusitis in Baghdad city. Iraqi JMS. 2017; Vol. 15(1): 64-70. doi: 10.22578/IJMS.15.1.8
\end{abstract}

List of abbreviation: $\mathrm{CT}=$ Computerized tomography, $\mathrm{KOH}=$ Potassium hydroxide, SDA = Sabouraud's Dextrose Agar

\section{Introduction}



The sinuses are hollow cavities in the bones around the nose. Sinusitis is one of the most common medical conditions. About 10 to 15 million people each year were suffering from sinusitis (1). Fungal infections of the sinuses are uncommon and usually occur in individuals who are immunocompromised. However, recently, the occurrence of fungal sinusitis has increased in 
the immunocompetent population (2). Many of the causative fungi are opportunists and are not usually pathogenic unless they enter a compromised host. Opportunistic fungal infection is particularly likely to occur in patients with diabetes mellitus, acquired immune deficiency syndrome, tuberculosis, lymphoma, leukemia, or burns. Candidiasis, aspergillosis, mucormycosis, mycetoma, nocardiosis, and cryptococcosis are typical opportunistic infection ${ }^{(1,3)}$.

There are four types of fungal sinus infections: chronic invasive fungal sinusitis, fungal ball, acute invasive fungal sinusitis and allergic fungal sinusitis. Symptoms of chronic invasive fungal sinusitis and acute invasive fungal sinusitis include nasal obstruction, sinus and facial pain and fever. They have tendency to for local invasion. Other symptoms can include runny nose, headache, excessive phlegm buildup and loss of appetite. Fungal ball infections always need to be treated by medication and surgical debridement (4). The diagnosis is based on clinical suspicion, computerized tomography (CT) scan findings and biopsy ${ }^{(5)}$.

Aspergillosis is the group of diseases, which caused by Aspergillus. The most common subtype among paranasal sinus infections associated with aspergillosis is Aspergillus fumigatus ${ }^{(1,6,7)}$. Aspergillus is a very a common indoor mold that can be found on every place $(7,8)$. Mucormycosis is an aggressive, opportunistic infection caused by fungi in the class of Zycomycetes. The genera most commonly responsible for mucormycosis usually are Mucor or Rhizopus $(9,10)$.

The study aim was for isolation, identification and determination of the antifungal activity of fungi isolated from a sample of Iraqi patients with rhinosinusitis.

\section{Methods}

\section{Culture Media}

In this study Sabouraud's Dextrose Agar (SDA) (Himedia/ India) was used as fungal medium. This medium (with antibiotic procaine penicillin and streptomycin) was used for culture purposes ${ }^{(11)}$.

\section{Antifungal drugs}

1) Amfoterisin B (50 mg) from Bristol-Myers Squibb - Turkey.

2) Griseofulvin (500 mg) from Shanghai Pharmaceutical CO., LTD - China.

3) Fluconazole capsules USP $(150 \mathrm{mg})$ from Microlaslimited - India.

\section{Patients}

\section{Patients characters}

This study was carried out on 112 patients who are attended Al-Yarmouk Teaching Hospital and Baghdad Medical City who suffered from sinusitis were diagnosed by specialized doctors according to the clinical symptoms. Swabs were taken from patients from nose, sinuses. The other sample taken from the other group of patients was nasal wash in ear, nose and throat department.

\section{Specimens collection}

1- Swabs: Sterile, clean swabs were used for sample collection, swabs was covered, to prevent contamination of air pollution and retention of the sample without contamination until cultured within a few hours if necessary. Concerning nasal wash, Cotton swabs were wetted with $0.85 \%$ normal saline then used to wipe the nose several times, and then the swabs conducted for direct smear and culture purposes. The fungal infections were detected in laboratory when the samples were grown on (SDA) at $37^{\circ} \mathrm{C}$ for $72 \mathrm{hr}{ }^{(12)}$.

2- Water nasal washing: Sinus wash was put in sterile containers and then was centrifuged. The sedimentation was examined microscopically; 1 to 2 drops were taken from the sediment for culturing on (SDA) medium with antibiotics.

\section{Direct microscopic examination}

Samples have been examined microscopically by taking rubbing the swabs on clean slides then stained with lactophenol cotton blue then 
cover slip was put on and examined (13). Nasal wash was underwent direct examination, by taking a drop of the wash with lactophenol cotton blue the examined microscopically after putting cover slip.

\section{Fungal isolation and diagnosis}

The diagnosis of fungi was depend on the colony morphology and color on petri dishes from both sides, in addition to the shape of sporangium if found, hyphae and spores according to the following references ${ }^{(14,15)}$.

\section{Antifungal sensitivity test}

In this study, $5 \mathrm{mg}$ of anti-fungal (Amphotericin $B$, Griseofulvin and fluconazole) were dissolved in $5 \mathrm{ml} \mathrm{D}$. W., then added as $100 \mu \mathrm{L}, 200 \mu \mathrm{L}$, $300 \mu \mathrm{L}$ respectively ${ }^{(16)}$.

\section{Results}

\section{Patients}

This study was carried out on 112 patients who were suffering from sinusitis, the ages of patients ranged between (3-54) years with mean (28.5) years. In this study, the results revealed that 38 (33.9\%) patients were with fungal growth. The fungal infection was recorded among females as $22(57.8 \%)$ cases, which were higher than males 16 (42.1\%). Identification of fungal infections in this study was based on direct microscopically examination $\mathrm{KOH}$ mount, lacto phenol blue smears, which were showed the fungal elements were in $9(18.7 \%)$ of the total cases (this 9 samples give positive result when cultured on BDA medium) while fungal growth was positive in $48 \%$ of total cases. Concerning sex distribution it has been found that 61 (54.4\%) positive females' cases and 51 (45.5\%) positive cases belong to males.

\section{Characteristics of patients with fungal sinusitis} Patients samples included 102 nasal swab, and 10 samples of nasal wash (Table 1). The ages of patients in this study ranged between $32-48$ years (figure 1 ), the highest rate of fungal infection was between 36-40 years, followed by age group $41-45$ years, the average age of patients with fungal infection (40.4). Fungal isolates were recorded among females 22 (57.8\%) cases, which is higher than males 16 (42.1\%) (figure 2).

The diagnosed isolates were distributed in these patients as follows:

1) Eighteen patients, (47.3\%) were of the genus Aspergillus spp.

2) Seven patients, (18.4\%) were isolated belonging to the genus Rhizopus spp.

3) Five patients, (13.1\%) were belonging to the genus Trichophyton spp.

4) Three of the patients, (7.8\%) were belonging to the genus Penicillium spp.

5) Two patients, (5.2\%) were Candida spp.

6) One patient, (2.6\%) was Alternaria spp.

7) One patient, (2.6\%) was Cryptococcus neoformans.

8) One patient, (2.6\%) was Blastomyces dermatitidis.

As for the genus Aspergillus spp. (Table 2). The highest proportion recorded in $A$. fumigatus (50\%) followed by $A$. niger (27.7\%).

Sensitivity testing of isolated fungi to antifungal agent

The sensitivity of the most frequently isolated fungi (three fungi: Aspergillus fumigatus, Rhizopus spp. and Trichophyton spp.) was tested for the following anti-fungi drug (Amphotericin B, Griseofulvin and Ketoconazole) by all concentrations $100 \mu \mathrm{L}$, $200 \mu \mathrm{L}, 300 \mu \mathrm{L}$ for each antifungal drug and compared them with control (control: fungus cultured on media without anti-fungal). $A$. fumigatus, Rhizopus spp. and Trichophyton spp. were resistance to Griseofulvin and Ketoconazole in three concentration (100 $\mu \mathrm{L}$, $200 \mu \mathrm{L}, 300 \mu \mathrm{L}$ ) and sensitive to Amphotericin $B$ (figures 3, 4, 5 and 6). 
Table 1. Positive sample and percentage

\begin{tabular}{cccc}
\hline Parameter & Nasal swap & Water nasal washing & Grand total \\
\hline The total number of samples & 102 & 10 & 112 \\
Positive samples & 34 & 4 & 38 \\
Percentage $\%$ & 33.3 & 40 & 33.9 \\
\hline
\end{tabular}

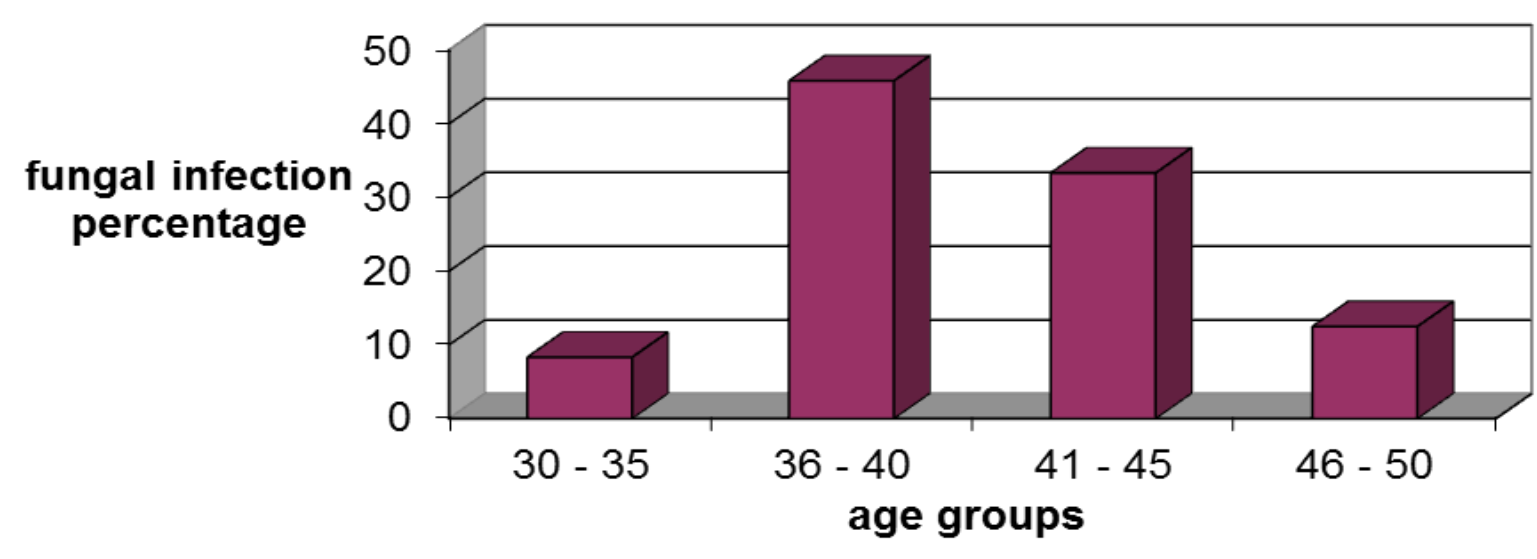

Figure 1. Percentage of age group of patients with fungal infection

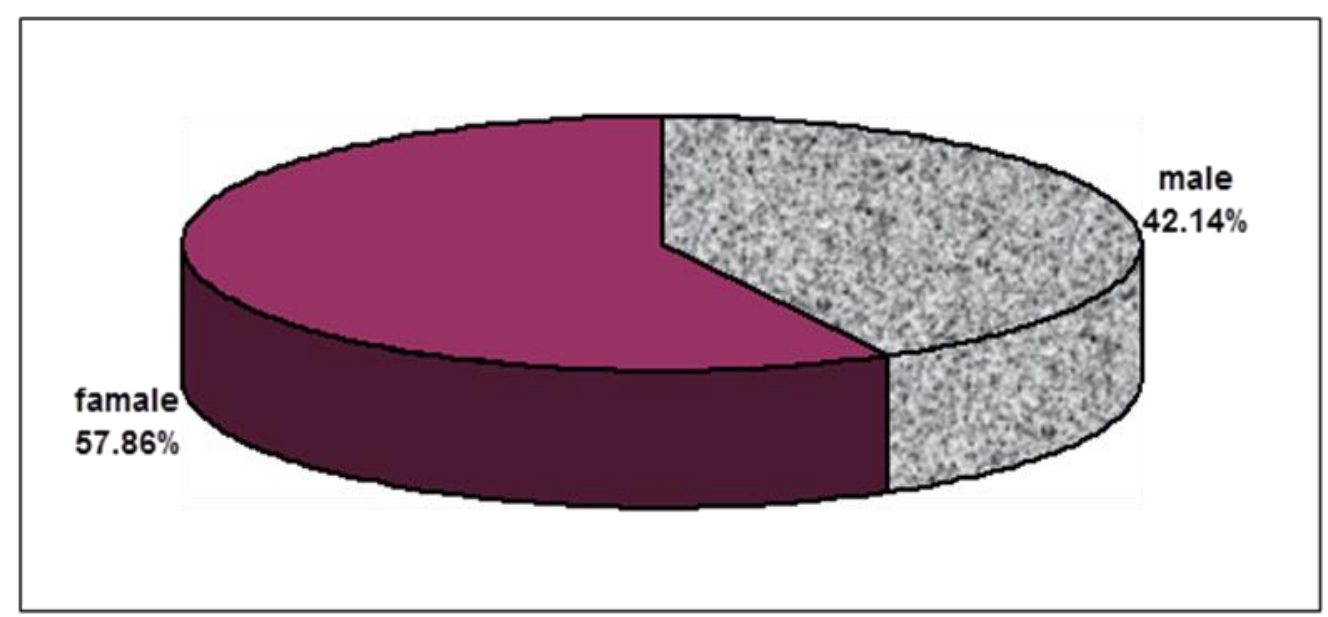

Figure 2. Percentage of sex patients with fungal infection

Table 2. The percentage of Aspergillus spp. was isolated in this study

\begin{tabular}{ccc}
\hline Aspergillus spp. & Number of isolates & Percentage \\
\hline A. fumigatus & 9 & $50 \%$ \\
A. niger & 5 & $27.8 \%$ \\
A. flavus & 4 & $22.2 \%$ \\
\hline Grand total & 18 & $100 \%$ \\
\hline
\end{tabular}




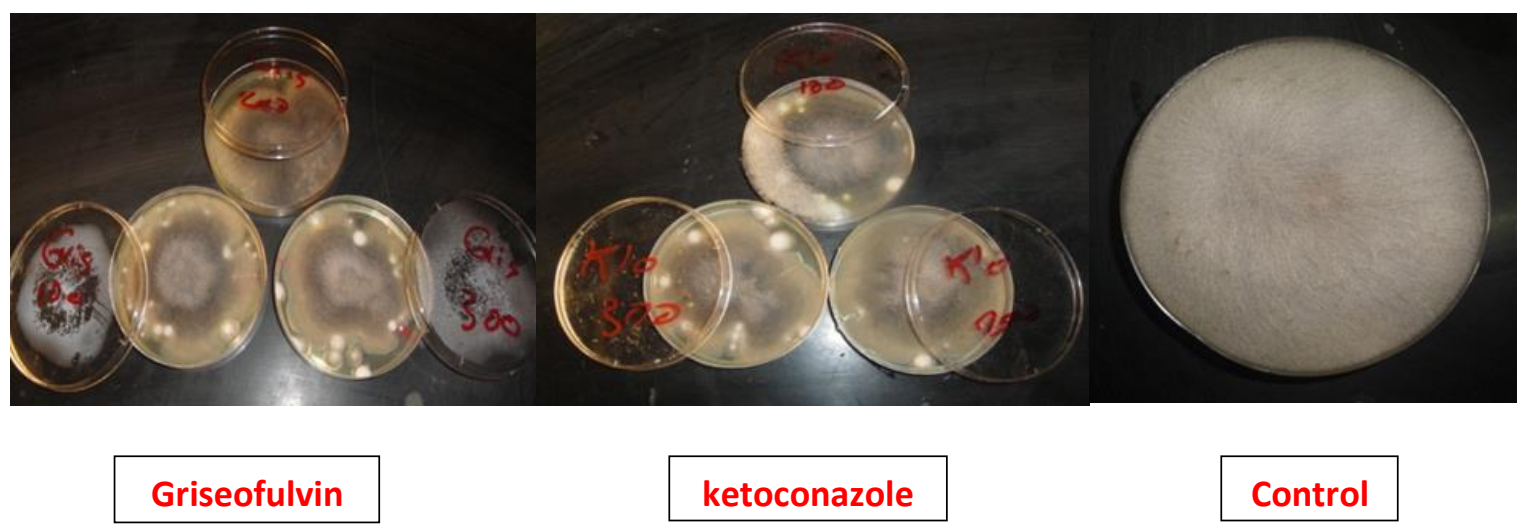

Figure 3. The resistant of Rhizopus spp. to Griseofulvin and Ketoconazole (100 $\mu \mathrm{L}, 200 \mu \mathrm{L}, 300 \mu \mathrm{L})$
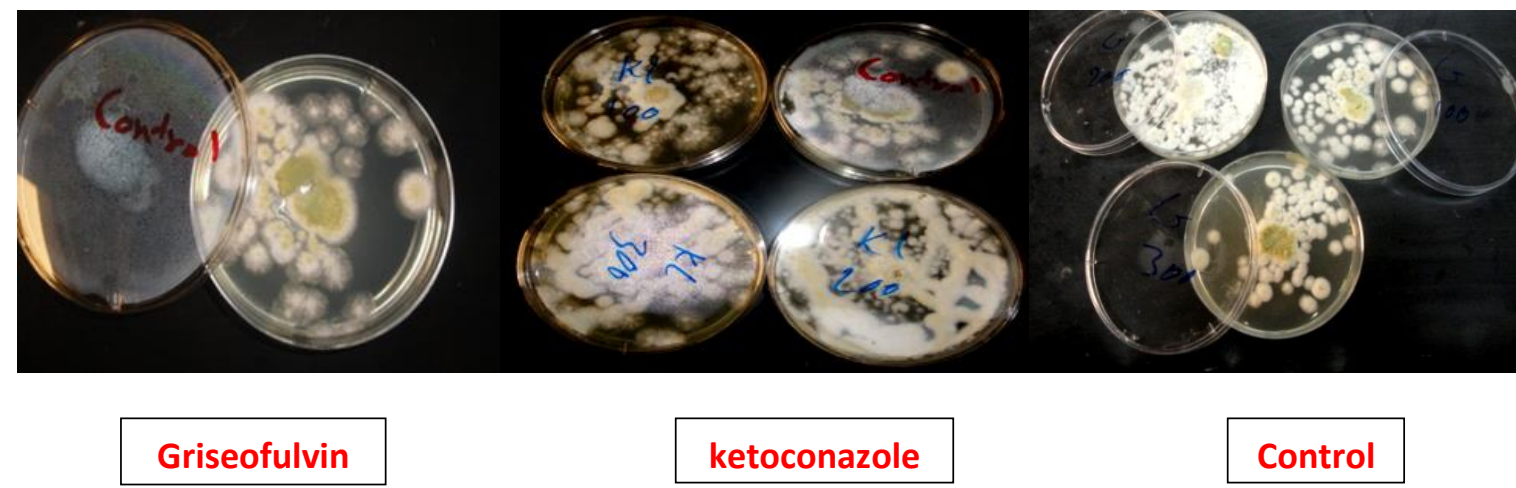

Figure 4. The resistant of Aspergillus fumigatus to Griseofulvin and Ketoconazole (100 $\mu \mathrm{L}, 200$ $\mu \mathrm{L}, 300 \mu \mathrm{L})$

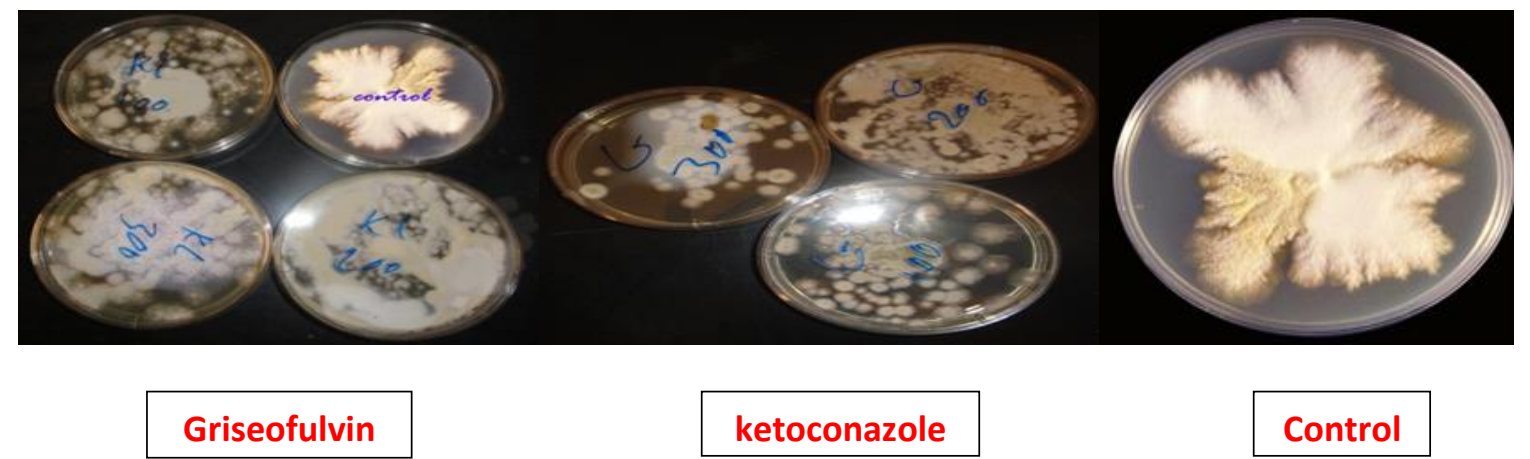

Figure 5. The resistant of Trichophyton spp. to Griseofulvin and Ketoconazole (100 $\mu \mathrm{L}, 200 \mu \mathrm{L}$, $300 \mu \mathrm{L})$ 


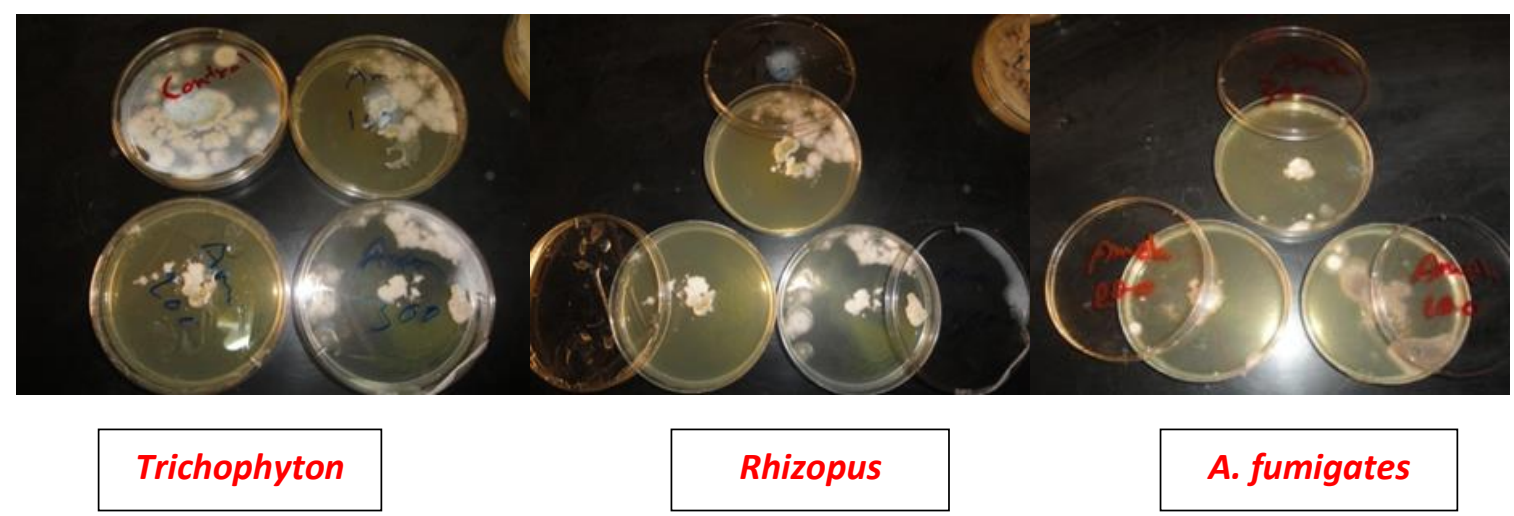

Figure 6. The sensitivity of $A$. fumigates, Rhizopus spp. and Trichophyton spp. to Amphotericin B (100 $\mu \mathrm{L}, 200 \mu \mathrm{L}, 300 \mu \mathrm{L})$

\section{Discussion}

In this study, the ages of patients ranged between (3-54) years with mean (28.5) years. The wide variation in ages indicates clearly the different natural of inflammation of the rhinosinuses and possible infect all ages $(17,18)$. The isolated fungi were few (33.9\%) compared with similar study in Tikirt/Iraq 60\% in (2011) (19); the results in a study in Turkey showed $63.67 \%{ }^{(20)}$ and in USA was $44 \%{ }^{(21)}$.

Fungal organisms are ubiquitous, and our exposure to these organisms occurs on a daily basis. A common location for these organisms to enter the human body is through the sinonasal cavity. Luckily, our immune system helps to prevent infection by these organisms. In those who do develop infection, a benign, noninvasive process usually occurs. However, in some patients, invasive disease does occur. As invasive fungal infections can lead to serious morbidity and mortality; it is important for the clinician to be able to recognize the difference between noninvasive and invasive fungal disease ${ }^{(22)}$.

The study focuses on isolating the fungi from patients in sinus, because most cases of sinus infection are caused by bacteria. As such these types of sinus infection can be effectively treated with antibiotics. Yet fungal sinus infections may not respond to the types of antibiotics most commonly used for sinus infections (23).

Fungal infections are more common in a compromised host or people who already have some chronic disease, which make them all the more susceptible to infections. Many of the causative fungi are opportunists and are not usually pathogenic unless they enter a compromised host ${ }^{(1,2)}$.

Results above were showed the fungal rhinosinusitis in male more than in female perhaps due to the vulnerability of women compared to men or to the short time of the study. Allergic fungal rhinosinusitis was more common in male patients and in patients aged 20-30 years ${ }^{(24)}$. This study showed Aspergillus spp. (47.3\%), formed higher isolation of fungi, this result agrees with many studies such as $(8,25)$, the most common subtype among paranasal sinus infections associated with aspergillosis is Aspergillus fumigatus. The researcher in Jordan (2001) indicated that Pencillium spp. and Aspergillus spp. was the first causative agent and most frequently in chronic sinusitis. While the results from in Tikrit Pencillium spp. give high frequently in sinusitis ${ }^{(19)}$.

The antifungal conventional Amphotericin B (Fungizone) remains the standard therapy for many invasive or life-threatening mycoses, because Amphotericin B acts by binding to ergosterol in the cell membrane integrity and results in osmotic instability ${ }^{(26)}$.

The conclusions of this study were: (1) Fungal rhinosinusitis was moderate infection. (2) The most fungal isolated was Aspergillus spp., Rhizopus spp., Trichophyton spp. (3) The antifungal Amfoterisin $B$ was stronger agent 
against Aspergillus spp., Rhizopus spp., Trichophyton spp.

\section{Acknowledgments}

Great thanks to all participants in this study; patients and all staff in Al-Yarmouk Teaching Hospital and Baghdad Medical City.

\section{Conflict of interest}

None.

\section{Funding}

None.

\section{References}

1. Rosenfeld RM, Piccirillo JF, Chandrasekhar SS, et al. Clinical practice guideline (Update): adult sinusitis. Otolaryngol Head Neck Surg. 2015; 152(2 Suppl): S1S39. doi: $10.1177 / 0194599815572097$.

2. Sganga G. Fungal infections in immunocompromized patients. Mycosis, 2011; 54 Suppl 4(s4): 1-3. doi: 10.1111/j.1439-0507.2011.02134.x .

3. Ramadan $\mathrm{HH}$. Sinusitis, why a new journal dedicated just to sinusitis. Sinusitis. 2016, 1(1): 1-2. doi: 10.3390/sinusitis1010001.

4. Taneja T, Saxena S, Aggarwal $P$, et al. Fungal infections involving maxillary sinus - a difficult diagnostic task. J Clin Exp Dentist. 2011; 3(2): e172e176. doi: 10.4317/jced.3.e172.

5. Bozkurt MK, Ozcelik T, Saydam L. A case of isolated aspergillosis of the maxillary sinus. Kulak Burun Bogaz Ihtis Derg. 2008;18(1):53-5.

6. Marr KA, Schlamm HT, Herbrecht $R$, et al. Combination antifungal therapy for invasive aspergillosis. Ann Intern Med. 2015; 162(2): 81-9. doi: $10.7326 / \mathrm{M} 13-2508$.

7. Machida M, Gomi K. Aspergillus: molecular biology and genomics. Biotechnol J. 2010; 5(3): 336-7. doi: 10.1002/biot.201000025.

8. Eucker J, Sezer O, Graf B, et al. Mucormycoses. Mycoses. 2001. 44: 253-60. doi: 10.1111/j.14390507.2001.00656.x.

9. Guevara JKH. Isolated orbital mucormycosis in an immunocompetent adolescent. Med Stud Res J. 2014; 3: 55-9.

10. Zhu H, Zhang W, Guan J, et al. CT imaging and clinical features of sinus fungus ball with bone erosion. Journal of Nature and Science. 2015; 1(4): e69.

11. Koneman EW, Roberts GD, Wright SE. Practical laboratory mycology, $2^{\text {nd }}$ ed. Baltimor USA: Williams and Wilkins Company; 1978. p. 139-40.
12. Anaissie EJ, Shikhani AH. Rhinocerebral mucormycosis with internal carotid occlusion: Report of two cases and review of the literature. Laryngoscope. 1985; 95: 1107-13. doi: 10.1288/00005537-198509000-00018.

13. McGinnis MR. Laboratary handbook of medical mycology. New York: Academic Press; 1980. p. 80-94.

14. Samson RA, Hoekstar ES, Van Oorschot CA. Introdaction of food - borne fungi. $2^{\text {nd }}$ ed. Baam: Centra Albureavoor Schimmel Cultures. 1984. p. 21125.

15. Chandler FW, Kaplan W, Ajello L. A color atlas and textbook of the histopathology of mycotic disease. Wolf Medical Publications, Ltd; 1989. p. 78-83.

16. Catalano P, Roffman E. Outcome in patients with chronic sinusitis after the minimally invasive sinus technique. Am J Rhinol. 2003; 17(1): 17-22(6).

17. Hamilos DL. Allergic fungal rhinitis and rhinosinusitis. Proc Am Thorac Soc. 2010; 7(3): 245-52. doi: 10.1513/pats.200909-098AL.

18. Chakrabarti A, Das A, Panda NK. Overview of fungal rhinosinusitis. Indian J Otolaryngol Head Neck Surg. 2004; 56(4): 251-8. doi: 10.1007/BF02974381.

19. Majeed HM. Isolation and identification of fungi cause inflammation chronic sinusitis. Tikrit J Pure Sci. 2011; 16(1): 189-92.

20. Karsligil T, mumbu S. Microbiology evaluation for fungal involvement of the paranasal sinuses in Turkey. J Chinese Clin Med. 2008; 10(3): 1-10.

21. Paul B. Chronic sinusitis. J Clin Pract. 2003; 13(4): 1-7.

22. Nam M, Hong $S$, Park J, et al. Extrusion of guttapercha into the nasal cavity causing maxillary fungal sinusitis: a case report. J Rhinol. 2013; 20: 127-9.

23. Castro L, Álvarez MI, Martinez E. Case report of Schizophyllum commune sinusitis in an immunocompetent patient. Colombia Médica. 2010; 41(1): 71-5.

24. Mukherji SK, Figueroa RE, Ginsberg LE, et al. Allergic fungal sinusitis: CT findings. Radiology. 1998; 207: 417-22. doi: 10.1148/radiology.207.2.9577490.

25. Chakrabarti A, Denning DW, Ferguson BJ, et al. Fungal rhinosinusitis: a categorization and definitional schema addressing current controversies. Laryngoscope. 2009. 119(9): 18-24. doi: 10.1002/lary.20520.

26. Dismukes WE. Introduction to antifungal drugs. Department of Medicine, Division of Infectious Clin Infect Dis. 2000. 30(4): 653-7.

\section{E-mail: israaahmed51@yahoo.com Received $18^{\text {th }}$ Aug. 2016 Accepted 2 ${ }^{\text {nd }}$ Jan. 2017}




\title{
Iraqi JMS
}

Published by Al-Nahrain College of Medicine P-ISSN 1681-6579 E-ISSN 2224-4719

Email: iraqijms@colmed-alnahrain.edu.iq http://www.colmed-alnahrain.edu.iq http://www.iraqijms.net

\section{Knowledge, Attitude and Practice of Mothers towards Typhoid Fever Disease}

\author{
Taha N. Sadeq ${ }^{1}$ MSc (Community Medicine), Rasha K. Jabar ${ }^{2}$ BSc (Biology) \\ ${ }^{1}$ Dept. of Public Health, ${ }^{2}$ Dept. of Health Promotion, Al-Kadhimiyia Pediatrics Hospital, Baghdad, Iraq
}

\begin{abstract}
Background Typhoid fever is endemic in Iraq. Hot weather and the frequent interruptions of electricity and water supply during the summer months have resulted in increased incidence. Increased health and disease awareness and improved attitude of residents do indeed reduce the prevalence of typhoid.

Objective To assess the mothers' knowledge, attitude and practice on typhoid fever.

Methods A cross sectional study was conducted at Al-Kadhimiya Pediatrics Hospital. Data collection took place from $10^{\text {th }}$ April 2015 till $20^{\text {th }}$ October 2015. Sample size was (267). Sampling method was based on convenience method. P value $<0.05$ was considered significant. Statistical analysis was done using SPSS software version 20.

Results Sample size was $267(\mathrm{~N}=267)$. Only $1(0.4 \%)$ of the mothers had low score, $54(20.2 \%)$ of the mothers had average score, 147 (55.1\%) of the mothers had good score, 65 (24.3\%) of the mothers had very good score. There was a weak, positive correlation between age of mothers in years and overall knowledge, attitude and practice score, a weak, negative correlation between number of children and overall knowledge, attitude and practice score. Also, there was statistically significant association between mothers' educational levels and their knowledge, attitude and practice category. A statistically significant association between mothers' occupational status and their knowledge, attitude and practice category was found.

Conclusion There are wide spread wrong beliefs about typhoid fever in relation to exposure to sunlight.

Keywords Knowledge, attitude, practice, typhoid fever

Citation Taha N. Sadeq, Rasha K. Jabar. Knowledge, attitude and practice of mothers towards typhoid fever disease. Iraqi JMS. 2017; Vol. 15(1). 71-77. doi: 10.22578/IJMS.15.1.9
\end{abstract}

List of abbreviation: SPSS: statistical package for social science

\section{Introduction}

Dyphoid fever is an acute bacterial infection, characterized by

constitutional symptoms like prolonged pyrexia, prostration and involvement of spleen and lymph nodes. It does not cause life-long or even sufficiently prolonged immunity. Second attack often occurs. The disease is caused by Salmonella typhi. Transmission is by contaminated food, unboiled milk, vegetables or water. Housefly plays a significant role by carrying bacilli from urine or stools of an active sufferer or a carrier to food ${ }^{(1)}$.

In many resource, limited countries, where hygiene and sanitation are poor, typhoid fever is endemic and constitutes a major health problem ${ }^{(2)}$. Typhoid fever is endemic in Iraq. Hot weather and the frequent interruptions of electricity and water supply during the summer months have resulted in increased incidence. As a result, numerous interventions were 
implemented to prevent and control outbreaks. In 2007, 2008, 2009 and 2010, a total of $36,208,58,247,49,113$ and 49,139 suspected cases of typhoid fever were reported, respectively ${ }^{(3)}$.

The typhoid fever has negative socio-economic impact to the majority of the patients who require several weeks to recover, and hence is a major public health concern ${ }^{(4)}$. Incidence of typhoid can be reduced through improved sanitation and hygienic behavior and access to clean water. Increased health and disease awareness and improved attitude of residents do indeed reduce the prevalence of typhoid (4). This study aimed to assess the mothers' knowledge, attitude and practice on typhoid fever at Al-Kadhimiya Pediatrics Hospital in Baghdad, Iraq.

\section{Methods}

A cross sectional study was conducted at AlKadhimiya Pediatrics Hospital. The hospital is a (120) bed, secondary center of referral that serves mainly Al-Kadhimiya region and the north parts of Baghdad. Data collection took place from 10 $10^{\text {th }}$ April 2015 till 20 ${ }^{\text {th }}$ October 2015. Sample size was (267) respondents (mothers) who were accompanying their children either as a consultation visit to the outpatient clinic or staying in the hospital ward as an attendant to their admitted children. Sampling method was based on convenience method.

As long as the accompanying adult agreed to participate, she was included (All included unless refused). Data gathering instrument was done using a questionnaire developed by the researchers based on literatures review. There were 22 questions in all and the questionnaire was administered in Arabic and included sociodemographic variables (4 questions): age of mother in years, number of children, occupational status, educational level. Questions to assess their knowledge level included (10 questions): causative agent of typhoid fever, typhoid fever as a cause for headache, food and water role in transmitting typhoid fever, exposure to sunlight and typhoid fever, contaminated hands transmit typhoid fever, typhoid fever transmission through air droplets, typhoid fever transmission through Kissing from infected person, typhoid fever transmission by shaking hands, subclinical typhoid fever cases and typhoid fever vaccination. Questions regarding mothers' attitude included (4 questions): Knowing the symptoms, typhoid fever will help to see the doctor in time or not, immediate treatment will prevent typhoid fever complications or not, using doctors prescribed medicine is important for the patient to recover from typhoid infection or not, seeking professional medical help immediately in case of typhoid fever infection suspicion. Questions regarding mothers' practice included (4 questions): washing hands during the day, eating food from street food vendors, washing fruits and vegetables with water before eating and heating cold food before consumption.

Overall knowledge, attitude and practice score were ranged from (0-18 score) and categorized as the following: (Less than 9=Low score), (911=Average score), (12-14=Good score), (More than or equal $15=$ Very good score).

Ethical considerations: verbal consent was obtained from all mothers before the questionnaire was administered by personal interview. The questionnaires were anonymized.

\section{Statistical analysis}

Data analysis was done through descriptive and inferential statistics. Descriptive statistics were reported as mean, frequencies and percentages. Age of mothers in years was reported as mean and standard deviations, mothers' occupational status was reported as frequency and percentage, mothers' educational level was reported as frequency and percentage. Each mothers' answer was reported as frequency and percentage and then categorized based on their occupational status and educational level. 
Inferential statistics were as follows: A Pearson product-moment correlation was used to determine the relationship between age of mothers in years, number of children and their overall knowledge, attitude and practice score. Chi-square test was used to determine association between mothers' educational level and their knowledge, attitude and practice category. $P$ value $<0.05$ was considered significant. Statistical analysis was done using SPSS software version 20.

Knowledge, attitude and practices of the mothers was treated as dependent (outcome variable) while sociodemographic characteristics were treated as independent variables.

\section{Results}

Sample size was $267(\mathrm{~N}=267)$, mean age of mothers in years was $(32.31 \pm 11.112)$, mean number of children was (3.68 \pm 2.507$)$. As shown in table $1 ; 235$ (88\%) of them were unemployed, 101 (37.8\%) of them were primary school graduate.

\section{Knowledge answers}

215 (80.1\%) of the mothers answered correctly the question about the causative agent of typhoid fever, 264 (98.9\%) of the mothers answered correctly the question about headache as a sign of typhoid fever, 231 (86.5\%) of the mothers answered correctly the question about typhoid fever transmission through food and water, 218 (81.6\%) of the mothers answered wrongly the question about sunlight role in typhoid fever, $194(72.7 \%)$ of the mothers answered correctly the question about typhoid fever transmission through contaminated hands, 158 (59.2) of the mothers answered correctly the question about typhoid fever transmission through air droplets, $124(46.4 \%)$ of the mothers answered wrongly the question about the role of kissing in typhoid fever transmission, $188(70.4 \%)$ of the mothers answered correctly the question about typhoid fever transmission through shaking hands, $129(48.3 \%)$ of the mothers answered wrongly the question about carrier state of the disease, $163(61 \%)$ of the mothers did not knew that there is a vaccine for typhoid bacteria.

\section{Attitude answers}

262 (98.1\%) of the mothers will see the doctor in time if they Knew the symptoms typhoid fever, 252(94.4\%) of the mothers will seek Immediate treatment to prevent typhoid fever complications, $16(6 \%)$ of the mothers will not use the doctors prescribed medicine to recover from typhoid infection, $12(4.5 \%)$ of the mothers will not seek professional medical help if they suspect of typhoid fever infection.

\section{Practice answers}

Only $3(1.1 \%)$ of the mothers was not wash their hands during the day, $73(27.3 \%)$ of the mothers did eat from street food vendors, only $4(1.5 \%)$ of the mothers were not always wash fruit and vegetables with water before eating, $18(6.7 \%)$ of the mothers did not usually heat cold food before consumption.

\section{Overall knowledge, attitude and practice score}

As shown in Table 1 ; only $1(0.4 \%)$ of the mothers had low score, 54 (20.2\%) of the mothers had average score, 147 (55.1\%) of the mothers had good score, $65(24.3 \%)$ of the mothers had very good score.

As shown in (table 2), there was a weak, positive correlation between age of mothers in years and overall knowledge, attitude and practice score, which was statistically not significant ( $r=0.061, n=267, p=0.319)$.

The test also showed (Table 3 ) that there was a weak, negative correlation between number of children and overall knowledge, attitude and practice score, which was statistically not significant $(r=-0.089, n=267, p=0.148)$.

Chi square test showed (table 4 ) that there was statistically significant association between mothers' educational levels and their knowledge, attitude and practice category ( $X 2=29.816, P=0.039$ ). Chi square test (Table 5) had also showed that there was statistically significant association between mothers' occupational status and their knowledge, attitude and practice category $(X 2=13.458$, $\mathrm{P}=0.004)$. 
Sadeq \& Jaber, Knowledge, Attitude and Practice of Mothers towards Typhoid fever ....

Table 1. Descriptive statistics of the study population

\begin{tabular}{|c|c|c|c|c|}
\hline \multicolumn{2}{|c|}{ Parameter } & Mean & Std. Deviation & $\mathbf{N}$ \\
\hline \multicolumn{2}{|c|}{ Age of mother in years } & 32.31 & 11.112 & 267 \\
\hline \multicolumn{2}{|c|}{ Number of children } & 3.68 & 2.507 & 267 \\
\hline & & Frequency & Percent & Total \\
\hline \multirow{2}{*}{ Occupational status } & Unemployed & 235 & 88.0 & 267 \\
\hline & Employed & 32 & 12.0 & 100 \\
\hline
\end{tabular}

Table 2. Correlation between age of mother in years and overall score of the study population

\begin{tabular}{cccc}
\hline Parameter & Pearson Correlation & Sig. (2-tailed) & $\mathbf{N}$ \\
\hline $\begin{array}{c}\text { Age of mother in years } \\
\text { Overall score }\end{array}$ & 0.061 & 0.319 & 267 \\
\hline
\end{tabular}

Table 3. Correlation between number of children and overall score overall score of the study population

\begin{tabular}{cccc}
\hline Parameter & Pearson Correlation & Sig. (2-tailed) & $\mathbf{N}$ \\
\hline $\begin{array}{c}\text { Number of children } \\
\text { Overall score }\end{array}$ & -0.089 & 0.148 & 267 \\
\hline
\end{tabular}

Table 4. Distribution of the overall score category in relation to the mothers' educational level and its association according to Chi square test

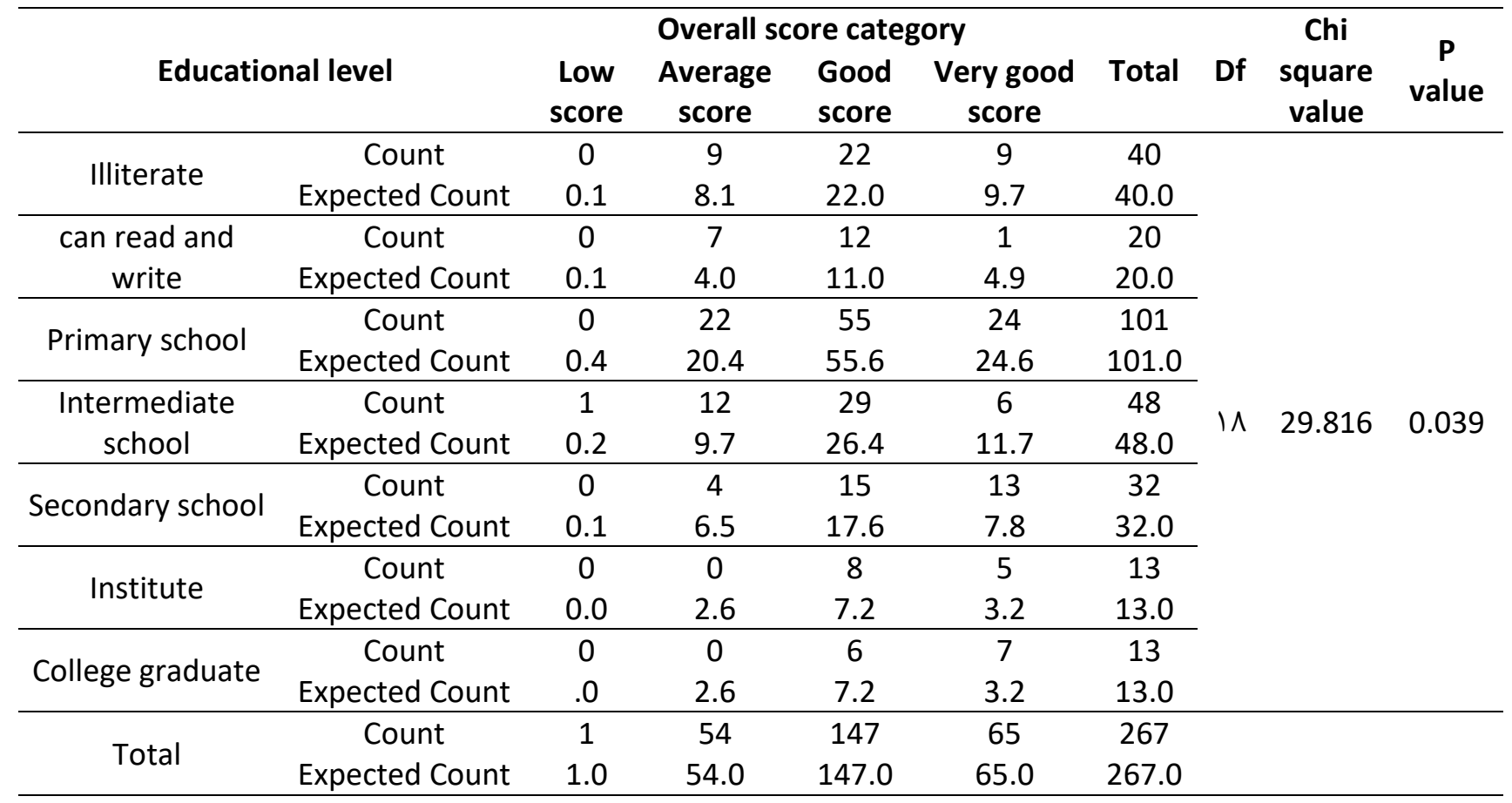


Iraqi JMS 2017; Vol. 15(1)

Table 5. Distribution of the overall score category in relation to the mothers' employment status and its association according to Chi square test

\begin{tabular}{|c|c|c|c|c|c|c|c|c|c|}
\hline \multirow{2}{*}{\multicolumn{2}{|c|}{ Occupational status }} & \multirow{3}{*}{$\begin{array}{c}\begin{array}{c}\text { Low } \\
\text { score }\end{array} \\
1\end{array}$} & \multicolumn{3}{|c|}{ Overall score category } & \multirow{3}{*}{$\begin{array}{l}\text { Total } \\
235\end{array}$} & \multirow{3}{*}{ Df } & \multirow{2}{*}{$\begin{array}{c}\text { Chi } \\
\text { square } \\
\text { value }\end{array}$} & \multirow{2}{*}{$\begin{array}{c}P \\
\text { value }\end{array}$} \\
\hline & & & $\begin{array}{l}\text { Average } \\
\text { score }\end{array}$ & $\begin{array}{l}\text { Good } \\
\text { score }\end{array}$ & $\begin{array}{l}\text { Very good } \\
\text { score }\end{array}$ & & & & \\
\hline \multirow{2}{*}{ Unemployed } & Count & & 51 & 134 & 49 & & & \multirow{4}{*}{13.458} & \multirow{4}{*}{0.004} \\
\hline & Expected Count & 0.9 & 47.5 & 129.4 & 57.2 & 235.0 & & & \\
\hline \multirow{2}{*}{ Employed } & Count & 0 & 3 & 13 & 16 & 32 & & & \\
\hline & Expected Count & 0.1 & 6.5 & 17.6 & 7.8 & 32.0 & & & \\
\hline \multirow{2}{*}{ Total } & Count & 1 & 54 & 147 & 65 & 267 & & & \\
\hline & Expected Count & 1.0 & 54.0 & 147.0 & 65.0 & 267.0 & & & \\
\hline
\end{tabular}

\section{Discussion}

In the current study, (79.4\%) of the mothers achieved above average score, this high score could be explained by the fact that typhoid fever in endemic in Iraq. In 2007, 2008, 2009 and 2010, a total of $36,208,58,247,49,113$ and 49,139 suspected cases of typhoid fever were reported, respectively ${ }^{(3)}$.

The Iraqi Annual Health Reports issued by the Iraqi Ministry of Health reported that there are only $709^{(5)}, 2030^{(6)}$ and $1250{ }^{(7)}$ in the years 2013, 2014 and 2015 respectively. In a sharp decline in case reporting from 2010 and 2009 Annual Health Reports, which reported 49,139 and 49,113 cases of typhoid fever respectively in Iraq ${ }^{(8)}$.

The more typhoid fever cases found in a community the more chance the casual person may acquires knowledge about the disease in through contact with medical services such as health centers, hospitals and private clinics. A previous study in Iraq, which was carried out by reviewing the medical records of 1702 children under 5 years suspected clinically to have typhoid fever during the period from the beginning of January till the end of December 2000, concluded that out of 1702 serum specimens, 546 (32.1\%) proved to be positive for typhoid and paratyphoid fever and indicated that this disease is an important heath problem in this area ${ }^{(9)}$.

Another study from Kirkuk, Iraq during the period 2001-2004 with a sample size of 5055 had concluded that typhoid fever is highly distributed in Kirkuk city (38.57\%) ${ }^{(10)}$.
A study from Nigeria (which was about was about food vendors in primary school) showed that $54.6 \%(\mathrm{~N}=174)$ with good knowledge about typhoid fever among food vendors in primary schools ${ }^{(11)}$.

This study is in agreement with a study from Kenya, which revealed that majority $(88.3 \%$, $\mathrm{N}=350$ ) had knowledge about typhoid ${ }^{(4)}$. In the present study, $231(86.5 \%)$ of the mothers knew that food and water can transmit typhoid fever infection, this is in agreement with a study from Pakistan ${ }^{(12)}$, which concluded that general community $(89 \%, \mathrm{~N}=178)$ was well aware regarding relationship of typhoid fever with unhygienic food and un boiled water. Two hundred and eighteen (81.6\%) of the mothers believed that exposure to sunlight is the cause of typhoid fever infection. This high percentage of this wrong belief could be attributed to the fact that both heat exhaustion and typhoid fever cause increase in body temperature, fatigue and headache ${ }^{(13)}$. Twenty nine percent (29.6\%) of the mothers believed that typhoid fever infection can be transmitted through shaking hands; this wrong belief could be due to their perception that typhoid fever infection transmitted through heat conduction by physical contact with infected person. Sixty one percent $(61 \%)$ of the mothers did not knew that there is a vaccine for typhoid fever. This result could be due to weak promotional campaigns about vaccination against typhoid fever. Two hundred and sixty four $(98.9 \%)$ of the mothers answered by "Yes" to washing hands during the day, in agreement to the 
study from Pakistan which showed that majority (94\%, N=200) of interviewees informed that they and their family members washed hands before eating (12). A study from Kenya had shown that $69.7 \%(\mathrm{~N}=350)$ of the respondents practiced hand washing (4). The same study revealed that those who washed their hands did not suffer from typhoid as much as those who did not.

Another study from Kenya has concluded that 187 (85\%) of the respondents said that it is not true that lack of hand washing practices in the community is the major cause of the spread of typhoid fever while 33 (15\%) of the respondents agreed about this practice ${ }^{(14)}$. A study from India ( $\mathrm{N}=100)$ had concluded that the majority (95\%) of the participants agreed that hand should be washed before and after meals, while only $32 \%$ felt that hand should be washed after defecation. Results showed that $83 \%$ of the participants used Water and soap to clean their hands ${ }^{(15)}$.

In the present study, 73 (27.3\%) of the mothers admitted they eat food from street vendors, the Pakistani study has showed more than half of the sample $(60.5 \%, N=200)$ were routinely eat foods sold on carts by vendors which are unprotected from flies and dust (12).

A study from Kenya had shown that eating food from commercial kiosks was a risk factor for Typhoid fever infection as those who ate from such food outlets suffered from typhoid more than those who did not ${ }^{(4)}$. Another study from Kenya, ( $N=220)$ has concluded 136 (62\%) of the respondents agreed that poor sanitation practices by the public food vendors is a cause of typhoid fever in the community while 84 (38\%) of the respondents said that poor sanitation practices among public food vendors is a cause of typhoid fever in the community (15). Typhoid fever can spread through irrigation of crops using sewage contaminated with Salmonella typhi ${ }^{(16)}$. In this study, 263 (98.5\%) of mothers washed fruit and vegetables with water before eating, this is in agreement with the Pakistani study which has also shown that $(95 \%, N=200)$ of the sample wash fruits before eating. This study concluded that mothers' educational levels was significantly associated with their knowledge, attitude and practice; a study from Kenya had shown that low education level was a risk factor for typhoid fever infection (4).

Another study from Kenya has also concluded that the probability of having a better understanding of typhoid transmission and control was only significantly increased when the respondent's education level went beyond the primary school level ${ }^{(14)}$.

Although the majority of mothers were above average overall knowledge, attitude and practice score about typhoid fever infection; there were still wide spread wrong beliefs in relation to exposure to sunlight, airdroplet, kissing from infected person, shaking hands, carrier state, vaccination, eating from street vendors.

\section{Acknowledgments}

To the hospital manager, Dr. Sana Jawad Abdul Hussein who was very supported and helpful in making this research a success.

\section{Author contributions:}

Dr. Sadeq designed and wrote the research article, Jabar collected the data. Both researchers approved the final research results and conclusion.

\section{Conflict of interest}

There is no conflict of interest.

\section{Funding}

None.

\section{References}

1. Gupte $S$. The short textbook of pediatrics. $11^{\text {th }}$ ed. New Delhi: Jaypee Brothers Medical Publishers (P) Ltd; 2009. p. 276-8.

2. World Health Organization background document. The diagnosis, treatment and prevention of typhoid fever. WHO/V\&B/03.07. Accessed at www.who.int/entity/vaccine-

_research/documents/en/typhoid-diagnosis.pdf on 2/12/2015.

3. Country Cooperation Strategy for WHO and Iraq 2012 - 2017 [Internet]. 1st ed. Regional Office for the Eastern Mediterranean; 2013 [cited 2 December 
2015]. Available

from: http://www.who.int/countryfocus/cooperation_strat egy/ccs_irq_en.pdf.

4. Nguri $\bar{k}$. Risk factors influencing typhoid fever occurrence among the adults in maina slum, nyahururu municipality, kenya. Master of public health thesis. School of Health Sciences of Kenyatta University; 2011.

5. Iraqi Annual Statistical Report. Baghdad: Iraqi Ministry of Health; 2013.

6. Iraqi Annual Statistical Report. Baghdad: Iraqi Ministry of Health; 2014.

7. Iraqi Annual Statistical Report. Baghdad: Iraqi Ministry of Health / Environment; 2015.

8. Iraqi Annual Statistical Report. Baghdad: Iraqi Ministry of Health; 2010.

9. Al-Khushali MN, Al-Khafaji AN, Al-Azzawe ZK. Typhoid and paratyphoid fever in children in Kadhimiya Hospital. Iraqi J Comm Med. 2007; 20(2). 337-41.

10. Ebrahim RM. Seasonal variation of typhoid fever in kirkuk city. Al-Taqani. 2010; 23(5): 94-8.

11. Afolaranmi T, Hassan $Z$, Bello D, et al. Knowledge and practice of food safety and hygiene among food vendors in primary schools in Jos, Plateau State, North Central Nigeria. J Med Res. 2015; 4(2): 16-22.
12. Alam AY, Adil MM, Qureshi AA. Knowledge, attitude and practices survey on hygiene and their impact on health. Rawal Med J. 2008; 33(1): 68-71.

13. Colledge N, Walker B, Ralston S. Davidson's principles and practice of medicine. 21st ed. City???: Elsevier Ltd.; 2010. p. 101.

14. Makhanu E, Onkware $P$, Were D. Impact of cultural factors on the management of typhoid fever in Bungoma County, Kenya. Int J Acad Res Business Social Sci. 2014; 4(5). 491-9. doi: 10.6007/IJARBSS/v4-i5/875.

15. Surapaneni K, Kuberan A, Singh A, et al. Water and sanitation hygiene knowledge, attitude, and practices among household members living in rural setting of India. J Nat Sci, Biol Med. 2015; 6(3): 69. doi: 10.4103/0976-9668.166090.

16. Donald E. Deadly diseases and epidemic typhoid fever. Philadelphia: Chelsea House Publishers; 2004.

\section{Correspondence to Dr. Taha N. Sadeq \\ E-mail: contactdrtaha@yahoo.com \\ Received 24 ${ }^{\text {th }}$ Jan. 2016 \\ Accepted 20 ${ }^{\text {th }}$ Dec. 2016}


Published by Al-Nahrain College of Medicine P-ISSN 1681-6579

E-ISSN 2224-4719

Email: iraqijms@colmed-alnahrain.edu.iq http://www.colmed-alnahrain.edu.iq http://www.iraqijms.net

\title{
The Role of Estrogen and Progesterone on Vaginal Cytology during Proliferative and Secretary Phases of Menstrual Cycle in Women with Polycystic Ovarian Syndrome
}

\author{
Huda R. Kareem ${ }^{1} P h D$, Haider A. Jaafer ${ }^{1} P h D$, Zainab H. Hashim ${ }^{2} P h D$ \\ ${ }^{1}$ Dept. of Human Anatomy, ${ }^{2}$ Dept of Physiology, College of Medicine, Al-Nahrain University, Baghdad, Iraq
}

\section{Abstract \\ Background}

Objective

Methods

Results

Conclusion

Keywords

Citation
In the course of cyclic hormonal fluctuation, cytological changes in the vaginal epithelium can be correlated with the phases of the menstrual cycle, this can be utilized in diagnosis of hormonal status in women with pathological cycles as in polycystic ovarian syndrome (PCOS).

To evaluate the effects of estrogen (E2) and progesterone hormones in PCOS on the vaginal cytology in different phases of menstrual cycle, and its relation to ovulation period.

A non-random sample of one hundred women were enrolled in this study, divided into two groups; 50 women free from PCOS, and 50 were PCOS according to the criteria of Rotterdam 2003. All were underwent hormonal assay including estrogen and progesterone on $2^{\text {nd }}$ and $21^{\text {st }}$ day of the cycle respectively, vaginal smears cytology on the $2^{\text {nd }}$ day, $14^{\text {th }}$ and $21^{\text {st }}$ day of the cycle, stained with $\mathrm{H} \& \mathrm{E}$, the (parabasal, squamous, leukocytes) were identified and counted, ultrasound examination was done on $14^{\text {th }}$ day of the cycle, that divide the sample into ovulatory and an ovulatory subgroups accordingly.

At the $2^{\text {nd }}$ day of the cycle, there was a significant reduction in squamous cell count, highly significant increase in leukocyte, E2 hormone level increased markedly, with a significant negative correlation to leukocytes cells in patients' groups at $P \leq 0.05$. Squamous cells of vaginal smear attained more acidophilic cytoplasm and increase in nuclear pyknosis. At the $14^{\text {th }}$ day of the cycle, a significant increase in squamous cells count at $\mathrm{P} \leq 0.05$, cornified squamous cells predominantly seen associated with low ovulation rates of $44 \%$. Ovulation showed significant reduction in parabasal cells count in patients group at $\mathrm{P} \leq 0.05$. At $21^{\text {st }}$ day of the cycle, progesterone level was reduced with a significant reduction in squamous cells, parabasal cells and leukocytes counts in patients, with no significant correlation between progesterone and vaginal cytology cells, squamous cells consisted of mature cornified cells that seen predominantly in vaginal smear.

Hormonal changes in PCOS presented mainly by the effect of elevated E2 hormone, that associated with increase in squamous cells count and cornification, with reduction in leukocytes and parabasal cells toward mid cycle. Progesterone hormone exert no significant effect on vaginal cytology in PCOS.

PCOS, vaginal cytology, ovulation

Huda R. Kareem, Haider A. Jaafer, Zainab H. Hashim. The role of estrogen and progesterone on vaginal cytology during proliferative and secretary phases of menstrual cycle in women with polycystic ovarian syndrome. Iraqi JMS. 2017; Vol. 15(1): 78-87. doi: 10.22578/IJMS.15.1.10
List of abbreviation: $\mathrm{E2}=$ Estrogen, $\mathrm{H} \& \mathrm{E}=$ Haematoxyline \& Eosin, FSH = Follicular stimulating hormone, $\mathrm{LH}=$ Luteinizing hormone, PCOS $=$ Polycystic ovary syndrome

\section{Introduction}

olycystic ovary syndrome (PCOS) is the
commonest endocrine disturbance
mostly affecting $4-12 \%$ of the women in 
the reproductive age $(1,2)$. This syndrome has the heterogenous collection of the signs and symptoms that gathered together to form a spectrum of disorders with the mild and severe disturbance of reproductive, endocrine and metabolic functions ${ }^{(3)}$.

PCOS is characterized by ovulatory dysfunction, and hyperandrogenism, with complex physiophatology of anovulation (4). However, the Rotterdam European Society of Human Reproduction/American Society for Reproductive Medicine (ESHRE/ASRM)Sponsored PCOS Consensus Workshop Group that convened in 2003 in Rotterdam, required the existence of two of the following three criteria to make the diagnosis of PCOS: oligoovulation or anovulation, clinical or biochemical signs of hyperandrogenism, and polycystic ovaries ${ }^{(5,6)}$.

Because $16-25 \%$ of the normal population has polycystic ovaries appearing on ultrasound (5), the presence of polycystic ovaries was considered to be suggestive but not diagnostic of PCOS. Polycystic ovary appearance at an ultrasound with (ovarian volume $10 \mathrm{ml}$ and/or 12 follicles less than $9 \mathrm{~mm}$ in size) ${ }^{(7)}$.

Accordingly, different patterns of PCOS patients either present as severe phenotype (hyperandrogenism, chronic anovulation, and polycystic ovaries: type I classic PCOS), or patients presenting hyperandrogenism and chronic anovulation but normal ovaries (type II PCOS), the patients with polycystic ovaries had a higher luteinizing hormone/folliclestimulating hormone (LH/FSH) ratio. Ovulation in type II PCOS was relatively common $(28.8 \%$ of patients), and milder clinical and endocrine alterations compared to classic PCOS phenotypes were found. The normal androgenic phenotype was relatively uncommon. These patients had a normal body mass index, insulin sensitivity, and free androgen index, but showed increased levels of $\mathrm{LH}$ and $\mathrm{LH} / \mathrm{FSH}$ ratio ${ }^{(8)}$.

Previously, PCOS was diagnosed on the basis of clinical features of the menstrual dysfunction, obesity, infertility and the direct visualization of the ovaries at the laparotomy ${ }^{(9)}$.

During the reproductive years, PCOS is associated with the important reproductive morbidity, including abnormal bleeding, increased pregnancy loss and complication of pregnancy ${ }^{(10)}$. About $50 \%$ of the women are obese particularly abdominal obesity, imbalance of hormones prevents the ovaries from releasing an egg each month. So, ovulation does not occur and the ovaries produce more immature eggs. These eggs turn into cysts and the ovaries become large and studded with numerous cysts ${ }^{(11)}$.

Nowadays the PCOS are interlinked with many disorders and it is not easy to diagnose the symptoms only with the help of ultrasonography but with some active measures like serum analysis for the detection of the hormonal levels. The easiest way for the detection of the PCOS condition is vaginal smear analysis. The alteration in LH brings out a serious effect in cycle regulation is blocked by the $\mathrm{LH}$ hormone synthesis in excess in the PCOS condition ${ }^{(12,13)}$.

The value of the vaginal smear method for the study of ovarian functions is based upon the response of the vaginal epithelium to the hormones of the ovary. This relationship has been long evident from comparison of the structure of the undeveloped vagina in childhood and the atrophic mucosa of senility with the Histologically normal, fully developed epithelial structure characteristic in sexual maturity; it has more recently also been indicated by the apparent occurrence of rhythmic alterations of the vaginal epithelium during the menstrual cycle (14).

This study aimed to evaluate the effect of ovarian hormones (E2, estrogen) and progesterone in PCOS on:

1. Vaginal epithelium cytology in different days of menstrual cycle including $\left(2^{\text {nd }}\right.$ day, $14^{\text {th }}$ day, $21^{\text {st }}$ day).

2. Correlation of these changes in vaginal epithelial cell counts including (parabasal, squamous, and leukocytes) with ovulation. 


\section{Methods}

A non-random sample of one hundred women were enrolled in this study taken from lum AlBaneen Center for Infertility Therapy and in vitro fertilization (IVF) in Al-Imamein AlKadhimein Medical City, those who were attending the center seeking pregnancy were selected, their phone numbers were taken to follow up them in their subsequent visits within the same menstrual cycle, in the $2^{\text {nd }}, 14^{\text {th }}$, and $21^{\text {st }}$ days to make vaginal smear cytology, with hormonal assay (E2 at $2^{\text {nd }}$ day and progesterone at $21^{\text {st }}$ day), and ultrasound examination at $14^{\text {th }}$ day, they were divided into two groups;

- (Control group): Fifty women free from signs and symptoms of PCOS.

- (Test group): Fifty women with PCOS that fulfill the criteria of Rotterdam $2003^{(6)}$.

For comparative purposes, the cycling profiles of three types of vaginal epithelial cells were assessed throughout the menstrual cycle; these include parabasal cells, squamous cells, and leukocytes.

- Parabasal cells: are small, rounds, slightly oval, with large vesiculated nucleus and small cytoplasm, stained basophilic with H\&E staining.

- Squamous cells: form the largest proportion in vaginal cytology with sharp, flat, angular cytoplasmic borders subdivided into:

- (Precornified) cells: Intermediate stage of their development characterized by basophilic cytoplasm, with intermediate keratohyalin granules, and large vesicular nucleus.

- Superficial squamous cells with acidophilic homogenous cytoplasm and small dark nucleus. (pyknotic).

- Leukocytes: Inflammatory cells that can be normal or abnormal in vaginal cytology appear as dark stained small nuclei with scanty cytoplasm, mainly neutrophil.

\section{Cytological analysis}

The internal vaginal mucosal wall was swabbed with saline-moistened sterile cotton; the swabs were gently rolled onto a clean glass slides. Slide were fixed in 95\% ethyl alcohol for 15 minutes, stained with H\&E stain, as slides pass through descending concentrations of ethyl alcohol; 90\%, 80\%, 70\%, 60\%, dipped in haematoxylin for 2 minutes, then pass under running tab water for 5 minutes, passed to eosin for 1 minute, then pass through ascending concentration of ethyl alcohol 80$100 \%$ (absolute ethyl alcohol), then kept in xylene for 5 minutes, and covered with cover slips (15).

\section{Statistical analysis and level of significance}

Unpaired T-test used to compare between cells count of vaginal cytology (squamous, parabasal, leukocytes) in test and control groups in different days of menstrual cycle, and between ovulatory and an-ovulatory subgroups of control and patient groups in $21^{\text {st }}$ day. Correlation coefficient ( $r$-value) is used to measure the strength of a linear association between two variables (vaginal cytology cells count in relation to hormonal levels E2, progesterone, and ovulation). Fissure exact test used to compare between ovulatory and anovulatory subgroups of patients and control groups. The statistical significance level selected was at $p$-value $\leq 0.05^{(16)}$.

\section{Results}

Distinct cellular changes to the vaginal epithelium were seen at different days of menstrual cycle, these include:

\section{At $2^{\text {nd }}$ day of the cycle}

Significant reduction in the mean number of squamous cells, and highly significant increase in mean number of leukocytes count was found in patients group, while parabasal cells showed no significant changes in patients and control groups (Table 1). With an increase in E2 hormone level in patients group (Table 2), associated with a significant negative correlation to leukocytes cells in patients group (Table 3) at $\mathrm{P} \leq 0.05$. 
Intermediate type of squamous cells predominates in early phase with basophilic cytoplasm that showed keratohyalin granules and vesicular nucleus in control group (Figure
1). In patients group, squamous cells attained more acidophilic cytoplasm and increase in nuclear pyknosis (Figure 2).

Table 1. Mean number of vaginal cells cytology in various days of menstrual cycle in patients and control groups

\begin{tabular}{cccccccc}
\hline $\begin{array}{c}\text { Days of } \\
\text { menstrual } \\
\text { cycle }\end{array}$ & Groups & $\begin{array}{c}\text { Parabasal } \\
\text { cells }\end{array}$ & $\begin{array}{c}\text { P } \\
\text { value }\end{array}$ & $\begin{array}{c}\text { Squamous } \\
\text { cells }\end{array}$ & P value & Leukocytes & P value \\
\hline \multirow{2}{*}{$2^{\text {nd }}$ day } & Patients & $18.52 \pm 5.24$ & 0.08 & $23.52 \pm 5.15$ & $0.002^{*}$ & $5.68 \pm 1.45$ & $<0.001^{*}$ \\
& Control & $16.8 \pm 4.61$ & & $26.4 \pm 3.64$ & & $2.9 \pm 1.11$ & \\
\hline \multirow{2}{*}{$14^{\text {th }}$ day } & Patients & $7.68 \pm 3.32$ & 0.57 & $114.74 \pm 28.2$ & $<0.001^{*}$ & $1.48 \pm 1.35$ & 0.580 \\
& Control & $8.0 \pm 2.32$ & & $79.58 \pm 11.45$ & & $1.32 \pm 1.1$ & \\
\hline \multirow{2}{*}{$21^{\text {st }}$ day } & Patients & $6.42 \pm 3.12$ & $<0.001^{*}$ & $59.82 \pm 10.33$ & $<0.001^{*}$ & $6.42 \pm 3.12$ & $<0.001^{*}$ \\
& Control & $13.72 \pm 4.57$ & & $71.36 \pm 13.9$ & & $13.72 \pm 4.57$ & \\
\hline
\end{tabular}

$*$ Significant $\mathrm{P}$ value $\leq 0.05$

Table 2. Mean values of hormonal assay in patients and control groups

\begin{tabular}{cccc}
\hline & Patients & Control & P value \\
\hline $\begin{array}{c}\text { Estrogen } \\
(\mathrm{ng} / \mathrm{ml})\end{array}$ & $115.8 \pm 32.24$ & $85.9 \pm 25.5$ & $<0.001^{*}$ \\
$\begin{array}{c}\text { Progesterone } \\
(\mathrm{pg} / \mathrm{ml})\end{array}$ & $3.68 \pm 2.37$ & $9.48 \pm 3.98$ & $<0.001^{*}$ \\
\hline
\end{tabular}

$*$ Significant $P$ value $\leq 0.05$

Table 3. Correlation between vaginal cells and E2 level in $2^{\text {nd }}$ day of the cycle

\begin{tabular}{|c|c|c|c|c|}
\hline \multicolumn{2}{|c|}{ Groups } & \multirow{2}{*}{$\begin{array}{c}\text { Squamous cells } \\
-0.201\end{array}$} & \multirow{2}{*}{$\begin{array}{c}\text { Parabasal cells } \\
-0.04\end{array}$} & \multirow{2}{*}{$\begin{array}{c}\text { leukocytes } \\
-0.331\end{array}$} \\
\hline & r value & & & \\
\hline Patients & $P$ value & 0.162 & 0.782 & $0.019 *$ \\
\hline \multirow{2}{*}{ Control } & r value & 0.11 & 0.096 & 0.105 \\
\hline & $P$ value & 0.44 & 0.509 & 0.466 \\
\hline
\end{tabular}

*Significance of $r$ value at $P \leq 0.05$

\section{At $14^{\text {th }}$ day of the cycle}

A significant increase in the mean number of squamous cells count seen in patients group at $\mathrm{P}$-value $\leq 0.05$. Parabasal and leukocytes cells showed no significant changes in patients and control groups (Table 1).
Ovulation rate was higher in control group than in patients group with $44 \%$ in patients group and $82 \%$ in control group (Table 4), with a significant reduction in parabasal cells count in ovulatory sub-group at $\mathrm{P} \leq 0.05$. 
In control group, leukocytes count showed a significant increase in ovulatory sub- groups at $\mathrm{P} \leq 0.05$ (table 5).

Squamous cells are the dominant cell in cytological examination being of intermediate type in control group, with basophilic cytoplasm and vesicular nucleus, changed to cornified squamous cells in patients (Figures $3,4)$.

Table 4. Ovulation documentation by ultrasound on $14^{\text {th }}$ day of the cycle in patients and control groups

\begin{tabular}{cccc}
\hline Groups & Positive & Ovulation & P value \\
& No. (\%) & $\begin{array}{c}\text { Negative } \\
\text { No. (\%) }\end{array}$ & \\
\hline Patients & $22(44)$ & $28(56)$ & $<0.001^{*}$ \\
Control & $41(82)$ & $9(18)$ & \\
\hline
\end{tabular}

* Significant $\mathrm{P}$ value $\leq 0.05$

Table 5. Vaginal cytology cells mean values in relation to ovulation in patients and control groups at $14^{\text {th }}$ day of the cycle

\begin{tabular}{|c|c|c|c|c|}
\hline Groups & Sub-groups & Squamous cells & Parabasal cells & leukocytes \\
\hline \multirow{2}{*}{$\begin{array}{l}\text { Patients } \\
\text { group }\end{array}$} & Ovulatory & $110.41 \pm 26.56$ & $6.64 \pm 2.75$ & $1.5 \pm 1.37$ \\
\hline & anovulatory & $118.14 \pm 29.4$ & $8.5 \pm 3.55$ & $1.46 \pm 1.37$ \\
\hline \multicolumn{2}{|c|}{$P$ value } & 0.335 & $0.042^{*}$ & 0.92 \\
\hline \multirow{2}{*}{ Control group } & Ovulatory & $80.2 \pm 12.05$ & $7.88 \pm 2.29$ & $1.46 \pm 1.61$ \\
\hline & anovulatory & $76.78 \pm 8.12$ & $8.56 \pm 2.51$ & $0.67 \pm 0.28$ \\
\hline \multicolumn{2}{|c|}{$P$ value } & 0.135 & 0.471 & $0.049 *$ \\
\hline
\end{tabular}

* Significant $P$ value $\leq 0.05$.

\section{At $21^{\text {st }}$ day of the cycle}

A significant reduction in the mean number of parabasal cells, squamous cells and leukocytes were found in patients group at $\mathrm{P} \leq 0.05$ (Table 1).

Progesterone level is reduced in patients group that measured at $21^{\text {st }}$ day of the cycle (Table 2). Its effect on vaginal epithelium is seen as mature cornified squamous cells rather than of intermediate squamous epithelial cells in control group (Figures 5,6).
No significant correlation was found between progesterone and vaginal epithelial cells in control and patients' groups at $P \leq 0.05$ (Table $6)$.

\section{Discussion}

Vaginal cytology is an easy and cheap method, with great value in determines the phase of the menstrual cycle in human with normal menstrual cycles. In this study, we need to find if vaginal cytology is applicable in defining the phase of menstrual cycle in PCOS.

Table 6. Correlation between vaginal cells and progesterone level at $21^{\text {st }}$ day of the cycle

\begin{tabular}{ccccc}
\hline Groups & & Squamous cells & Parabasal cells & Leukocytes \\
\hline \multirow{2}{*}{ Patients } & r value & -0.218 & -0.245 & 0.151 \\
& P value & 0.129 & 0.086 & 0.295 \\
\hline \multirow{2}{*}{ Control } & r value & 0.005 & 0.094 & -0.116 \\
& P value & 0.97 & 0.517 & 0.422 \\
\hline
\end{tabular}

* Significant $P$ value $\leq 0.05$. 


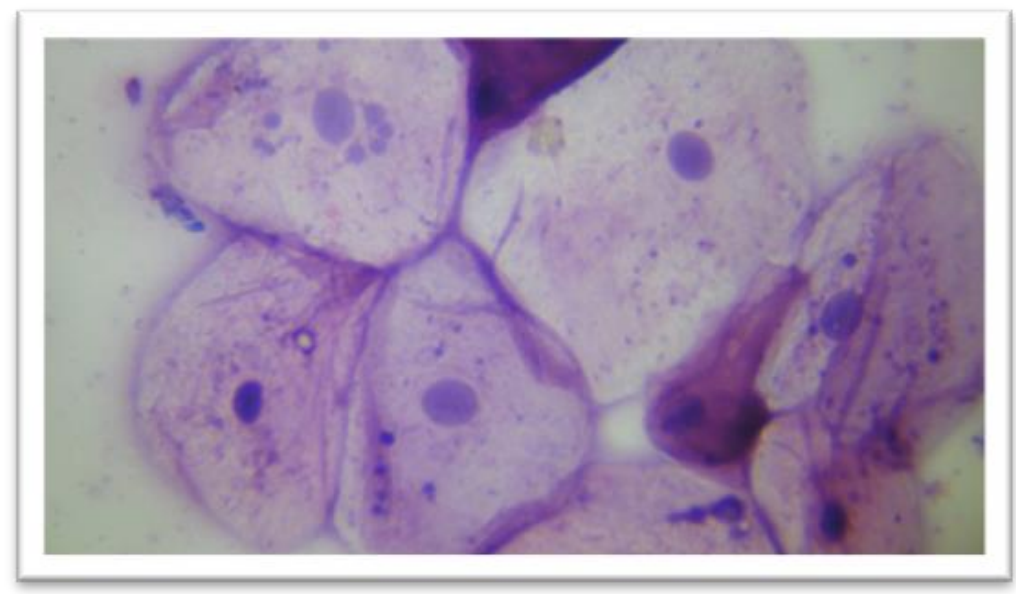

Figure 1. Cells of vaginal cytology in $2^{\text {nd }}$ day of menstrual cycle (control group) showed (precornified) squamous cells, with vesicular nucleus, basophilic cytoplasm and keratohyalin granules. H\&E, 40X

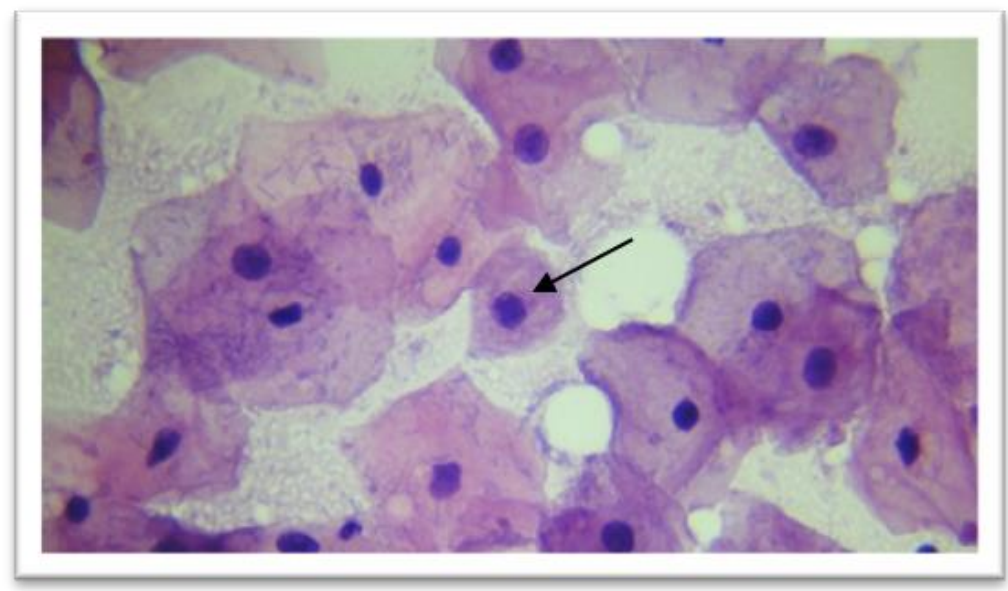

Figure 2. Cells of vaginal cytology at $2^{\text {nd }}$ day of menstrual cycle in (patients group) showed increase in squamous cells acidophila, and pyknosis of their nuclei, keratohyali granules still present, parabasal cell seen (arrow). H\&E, 40X

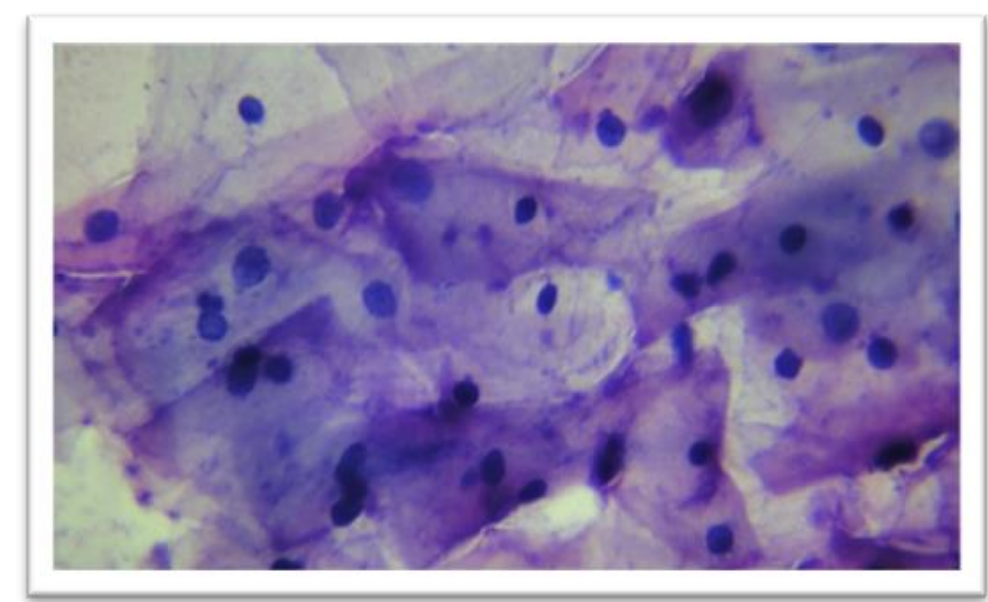

Figure 3. Vaginal cytology in control group at $14^{\text {th }}$ day of the cycle showed predominant squamous cells of pre-cornified type. H\&E, $40 X$ 
Kareem et al, The Role of Estrogen and Progesterone on Vaginal Cytology ....

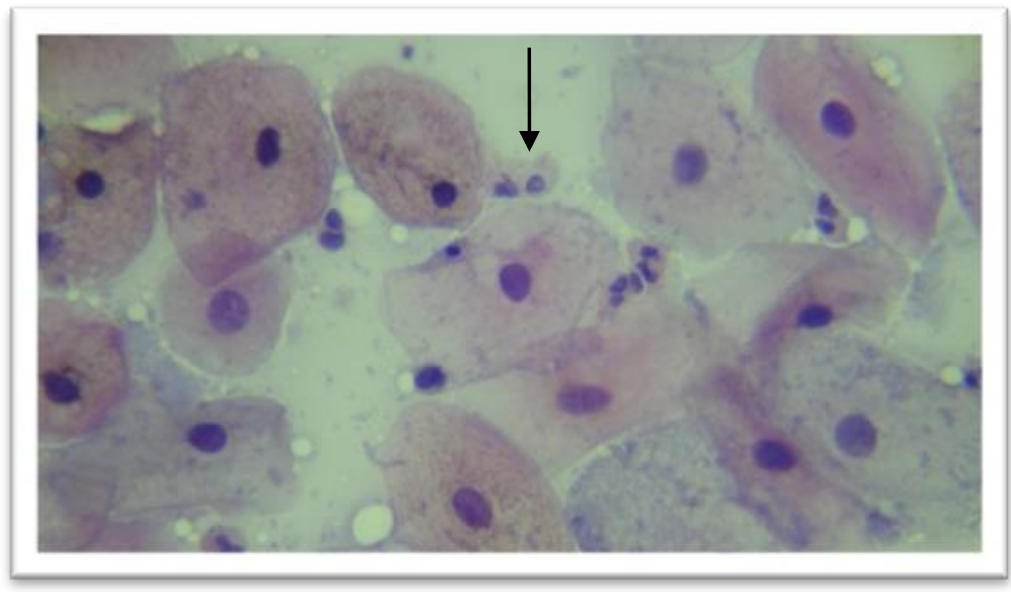

Figure 4. Vaginal cytology in patients group at $14^{\text {th }}$ day of the cycle showed squamous cells of both pre-cornified and cornified types, and leukocytes (arrow). H\&E, 40X

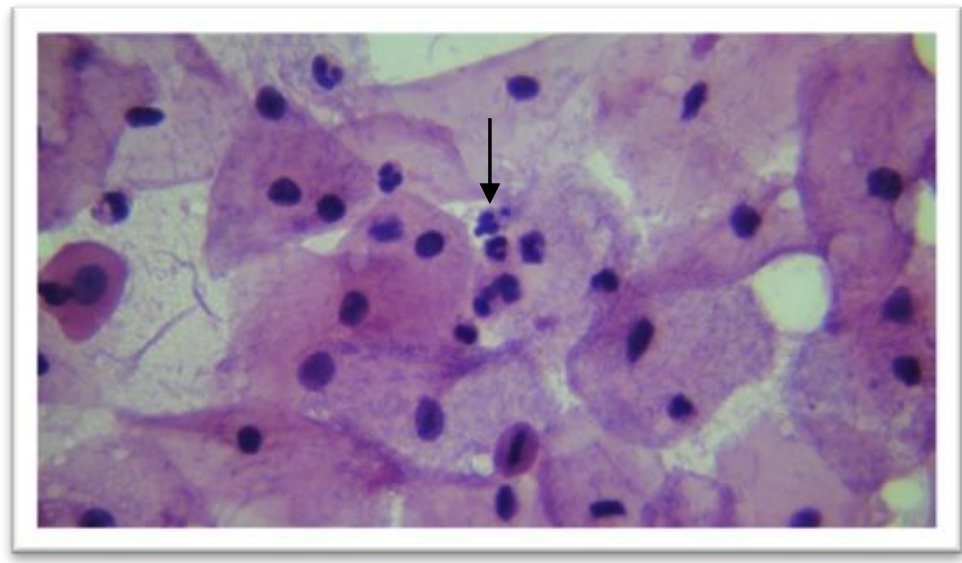

Figure 5. Vaginal cytology in control group at $21^{\text {st }}$ day of the menstrual cycle showed mature squamous cells of cornified types, and leukocytes (arrow). H\&E, 40X

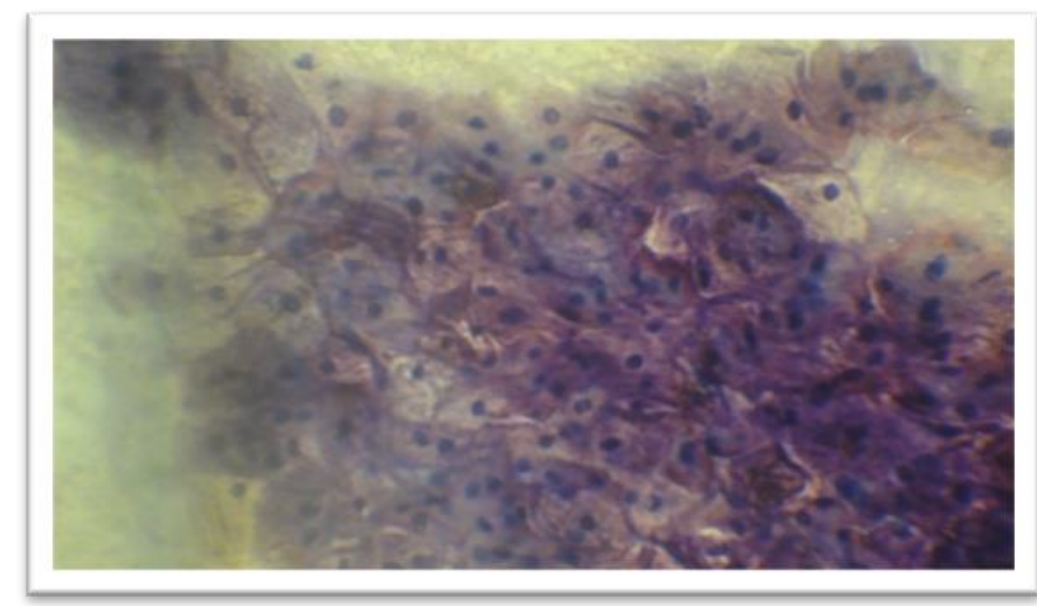

Figure .6. Vaginal cytology in patients group at $21^{\text {st }}$ day of the cycle showed cornified squamous cells. H\&E, $40 X$ 
In patients group, at $2^{\text {nd }}$ and $14^{\text {th }}$ day of the cycle, the increase in mean number and cornification of vaginal squamous cells could be related to elevation in serum E2 level. Thus, estrogens that secreted by maturing follicles can cause thickening of vaginal lining, epithelium moving the cells away from their blood supply, this agreed with (Weiss et al 2004) who mentioned that vaginal cytology provides a useful qualitative measure of cyclic hormonal events that correlates well with endometrial biopsies and urinary estrogen profiles ${ }^{(17)}$.

The significant reduction in leukocytes count in patients group, could be due to hormonal imbalance specifically high E2 level that could act as an immunomodulator. Estrogens act on leukocytes and influence their number and function, through binding to specific estrogen receptors on the leukocytes ${ }^{(18)}$.

The significant negative correlation between E2 level and leukocytes count at $2^{\text {nd }}$ day of the cycle in patients group also related to high E2 level as it acts on the immune system and inflammation, studies have shown that there is clear sex bias in disease presentation, and estrogens have been suggested to be responsible for these differences, these diseases are often associated with defect in leukocyte infiltration and immune dysfunction. Xiang et al. in $2004{ }^{(19)}$ mentioned that E2 inhibits the migration of inflammatory cells, particularly granulocytes, into sites of tissue (20).

The significant increase in parabasal cells count in anovulatory subgroups of patients group could be due to that estrogen effect on parabasal cells (near blood supply), changed into the cornified cells (away from blood supply), their nucleus become smaller, pyknotic. This has been mentioned in the presence of estrogen, epithelial cells mature, creating notable condensation (pyknosis) of the nucleus ${ }^{(21)}$.

The hormonal imbalance that prevents the ovaries from releasing an egg each month, the estrogen hormone continues to increase from the developing follicles that later turned into cysts, this estrogen hormone intern lead to increase in mature superficial nucleated squamous epithelial cells, with predominately pyknotic nuclei ${ }^{(22)}$.

The significant reduction of leukocytes count in an ovulatory subgroups of control group, could be due to failure of ovulation. This explained as continuous rise in E2 level unopposed by $\mathrm{LH}$ regulation, that may lead to continuation action of E2 on vaginal epithelium, as an immunemodulator affect the expression of a number of gene pathways associated with innate immunity, epithelial differentiation, wound healing, and antiviral responses (23).

At $21^{\text {st }}$ day of the cycle squamous cells, leukocytes and parabasl cells reduced in patient group, without any significant correlation to progesterone level that showed reduction in patients group, this could be due to failure of ovulation in patients group as $44 \%$ of them showed documentation of ovulation in ultrasound at $14^{\text {th }}$ day of the cycle.

The presence of precornified and cornified epithelial cells in secretory phase in control group could due to atrophic changes in ovarian follicles that changed to corpus albicans, and lead to reduction in E2 level and this lead to reduction in cornification or keratinization of vaginal epithelium.

Studies correlating variations in vaginal cytology with serum gonadotropins and progesterone and urinary estrogens showed that the karyo-pyknotic index of vaginal cells, which is (average of superficial to basal cells) increases gradually to mid-cycle and peaks on the day after the LH surge. Thereafter, there is a steady decline of the index to the end of the menstrual cycle, when it reaches levels below those in the early proliferative phase. The mean peak of the index is reached 2 days after the total estrogen peak. This lag period is probably required before the vaginal epithelium responds to increased estrogenic stimulation (24).

This study concluded that hormonal changes in PCOS presented mainly by the effect of E2 hormone, that associated with increase in squamous cells count and cornification, with reduction in leukocytes and parabasal cells toward mid cycle. Progesterone hormone exert no significant effect on vaginal cytology in PCOS. 


\section{Acknowledgments}

Authors sincerely thanks all staff of lum AlBaneen Centre for Infertility Therapy and IVF in Al-Imamein Al-Kadhimein Medical City. Also, authors appreciate and thanks Dr. Majid $\mathrm{H}$. Ahmed for his support in statistical analysis.

\section{Author contribution}

Dr. Hashim: Collection of samples, and follow up the patients in subsequent visits for the ultrasound and hormonal essay.at $2^{\text {nd }}, 14^{\text {th }}, 21^{\text {st }}$ day of the cycle. Dr. Kareem: Writing the paper and handling $\mathrm{H} \& \mathrm{E}$ staining of vaginal cytological samples and examination. Dr. Jaafar: Photographing of slides.

\section{Conflict of interest}

Authors declare there is no conflict of interest.

\section{Funding}

Self-funding.

\section{References}

1. Knochenhauer ES, Key TJ, Miller KM, et al. Prevalence of the polycystic ovary syndrome in unselected black and white women of the southeastern United States: a prospective study. J Clin Endocrinol Metab. 1998; 83: 3078-82. doi: 10.1210/jcem.83.9.5090.

2. Farah LH, Lazenby AJ, Boots LR, et al. Prevalence of polycystic ovary syndrome in women seeking treatment from community electrologists. Alabama professional electrology association study group. J Reprod Med. 1999; 44: 870-4.

3. Balen $A H$, Conway GS, Kaltsas G. Polycystic ovary syndrome: the spectrum of the disorder in 1741 patients. Hum Reprod. 1995; 10: 2107-11.

4. Carmina E. PCOS metabolic impact and long-term management. Minerva Ginecol. 2012; 64(6): 501-5.

5. Polson DW, Wadsworth J, Adams J, et al. Polycystic ovaries: A common finding in normal women. Lancet. 1988; 1: 870-2.

6. Rotterdam ESHRE/ASRM-Sponsored PCOS Consensus Workshop Group: Revised 2003 consensus on diagnostic criteria and long-term health risks related to polycystic ovary syndrome. Fertil Steril. 2004; 81: 19-25.

7. Azziz R, Carmina E, Dewailly D, et al. Task force on the phenotype of the polycystic ovary syndrome of the androgen excess and PCOSS Society. The Androgen Excess and PCOS Society criteria for the polycystic ovary syndrome: the complete task force report. Fertil Steril. 2009; 91: 456-88. doi: 10.1016/j.fertnstert.2008.06.035.

8. Guastella E, Longo RA, Carmina E. Clinical and endocrine characteristics of the main polycystic ovary syndrome phenotypes. Fertil Steril. 2010; 94(6): 197201. doi: 10.1016/j.fertnstert.2010.02.014.

9. Zawadzki JK, Dunaif A. Diagnostic criteria for polycystic ovary syndrome: towards a rational approach. In: Dunaif A, Givens JR, Haseltine FP (eds). Polycystic ovary syndrome. Oxford, UK: Blackwell; 1992. p. 59-69.

10. Carmina E. Diagnosing PCOS in women who menstruate regularly. Contemporary OB/GYN. 2003; 1: 53-64.

11. King J. Polycystic ovary syndrome. J Midwifery Women's Health. 2006; 51(6): 415-20. 10.1016/j.jmwh.2006.01.008.

12. Zangeneh FZ, Naghizadeh M, Minaee B, et al. PCOS and Sympathetic outcome: Role of the central and peripheral nervous system in ovarian function of rat. Asian J Pharmaceut Clin Res. 2012; 5(2): 26-32.

13. Chang RA. A practical approach to the diagnosis of the polycystic ovary syndrome. Am J Obstet Gynecol. 2004; 191: 713-7. doi: 10.1016/j.ajog.2004.04.045.

14. Mack HC. Vaginal smear technic: its use in the diagnosis of ovarian failure, as an index to efficacy of endocrine therapy and as a human assay method. J Clin Endocrinol Metab. 1943; 3(3): 169-78. doi: https://doi.org/10.1210/jcem-3-3-169.

15. Nayar R, Wilbur D (eds). The Bethesda system for reporting cervical cytology; definitions, criteria, and explanatory notes. 2nd ed. New York: Springer; 2003.

16. StatSoft, Inc. Electronic Statistics Textbook. Tulsa, OK: StatSoft. Web: http://www.statsoft.com/textbook/, 2013. Accessed at Jul $18^{\text {th }} 2016$.

17. Weiss R V, Clapauch R. Female infertility of endocrine origin. Arq Bras Endocrinol Metab. 2014; 58(2): 14452. http://dx.doi.org/10.1590/0004-2730000003021.

18. Bouman A, Heineman MJ, Faas MM. Sex hormones and the immune response in humans. Hum Reprod Update. 2005; 11(4): 411-23. doi: 10.1093/humupd/dmi008.

19. Cutolo M, Brizzolara R, Atzeni F, et al. (2010) The immunomodulatory effects of estrogens: clinical relevance in immune-mediated rheumatic diseases. Ann N Y Acad Sci. 2010; 1193: 36-42. doi: 10.1111/j.1749-6632.2009.05383.x.

20. Dongqi Xing, Andrew Miller, Lea Novak, et al. Estradiol and progestins differentially modulate leukocyte infiltration after vascular injury. Circulation. 2004; 109(2): 234-41. doi: 10.1161/01.CIR.0000105700.95607.49.

21. Pandit AA, Kalgutkar AK. The value of vaginal cytology in prediction of labour with special reference to eosinophilic and karyopyknotic indices. J Postgrad Med. 1986; 32(4): 210-3.

22. Zondek B, Toaff R, Rozin S. Cyclic changes in the vaginal but not in the uterine mucosa of amenorrheic women induced by a single injection of estrone and progesterone precipitates. Clin Endocrinol. 1950; 10: 615-22. doi: 10.1210/jcem-10-6-615.

23. Ayehunie $S$, Islam $A$, Cannon $C$, et al. Characterization of a hormone-responsive organotypic human vaginal tissue model: morphologic and immunologic effects. 
Iraqi JMS 2017; Vol. 15(1)

Reprod Sci. 2015; 22: 980-90. doi: $10.1177 / 1933719115570906$.

24. Moghissi, K, Puscheck, E, et al. Glob. libr. women's med. 2015. doi: 10.3843/GLOWM.10325. (ISSN: 1756-2228)
Correspondence to Dr. Zainab H. Hashim E-mail: zainab_hashim69@colmedalnahrain.edu.iq

Received 11 ${ }^{\text {th }}$ Aug. 2016

Accepted 4 ${ }^{\text {th }}$ Dec. 2016 


\title{
Iraqi JMS
}

Published by Al-Nahrain College of Medicine P-ISSN 1681-6579

E-ISSN 2224-4719

Email: iraqijms@colmed-alnahrain.edu.iq

http://www.colmed-alnahrain.edu.iq

http://www.iraqijms.net

\section{The Seropositivity of Parvovirus B19 among Kidney Transplant Recipients}

\author{
Zainab A. Hlail ${ }^{1}$ BSC (Biology), Ahmed S. Abdulamir ${ }^{2}$ PhD, Ali J.H. Al-Saedi ${ }^{3}$ FICMS \\ ${ }^{1}$ Dept. of Medical Microbiology, College of Medicine, Al-Nahrain University, Baghdad, Iraq, ${ }^{2}$ Center of Kidney Diseases \\ and Transplantation, Medical City of Baghdad, Iraq
}

\begin{abstract}
Background Parvovirus B19 (PV-B19) is a single strand DNA virus that is responsible for causing several diseases in humans. Parvovirus B19 induced persistent anemia or/and pancytopenia or/and reticulocyteopenia in renal transplant recipients (RTRs).

Objective To find out any association between PV-B19 reactivation / primary infections with abnormal renal function tests, and post-transplantation period in renal transplant patients.

Methods A quality enzyme linked immunosorbent assay technique was applied for detection of anti-human PV-B19 IgM (DRG-Germany) and IgG (DRG- Germany) in sera of 50 renal transplant recipients followed up for three successive months and 50 normal were collected from the Center of Kidney Diseases and Transplantation in the Medical City of Baghdad and Al-Khayal Hospital and other many private laboratories, Iraq, during the period from August 2015 till February 2016. The age was ranged from 11-57 years.

Results This prospective study included fifty renal transplant recipients with fifty subjects as a control group. The mean \pm standard deviation of ages for RTRs was $32.90 \pm 12.76$, which was comparable to that of healthy controls mean $34.02 \pm 14.23$ ranging for both RTRs and control group between 11-57 years old. Thirty five (70\%) RTR aged less than 40 years, and the remaining fifteen (30\%) were above 40 years old, and $38 / 50$ (76\%) of these RTRs were males. Seropositivity rate in control was $2 / 50(4 \%)$ but seropositivity rate in patients was $10 \%$ ( 5 cases) and $10 \%$ ( 5 cases) as turning positive for an individual occurrence of human PV-B19 IgM alone at P value $=0.0299$ and $9 / 50$ (18\%) from control positive for IgG, while $60 \%$ (30 cases) for a similar individual rate of positive human parvovirus $B 19$ IgG at $P$ value $<0.0001$.

Conclusion The human PV-B19 infection rate was significantly higher among renal transplant recipients than normal controls. Infections correlated with abnormal renal functions tests, and which may in turn cause anemia and/or reticulocytopenia.

Keywords Parvovirus-B19, anemia, reticulocytopenia, renal transplant recipients, ELISA

Citation

Zainab A. Hlail, Ahmed S. Abdulamir, Ali J.H. Al-Saedi. The seropositivity of Parvovirus B19 among kidney transplant recipients. Iraqi JMS. 2017; Vol. 15(1): 88-93. doi: 10.22578/IJMS.15.1.11
\end{abstract}

List of abbreviation: $C K D=$ Chronic kidney disease, ESRD $=$ End-stage renal disease, PV-B19 = Parvovirus B19, RTRs = Renal transplant recipients

\section{Introduction}

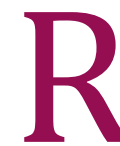

enal transplantation is the treatment of choice for most patients with end-stage renal disease (ESRD). In Iraq, few studies were recently conducted on detecting viral infections or reactivations in Iraqi renal transplant recipients (RTRs) ${ }^{(1,2)}$.

One of the viruses that have been shown to have a role in morbidity and mortality in RTR and post-transplantation immune suppression is Parvovirus B19 (PV-B19). PV-B19 is a 
common human pathogen, causing erythema infectiosum in children, transient aplastic crisis in patients with chronic hemolytic anemia or hydrops fetalis and abortion in pregnant women. Immunosuppressed patients can fail to mount an effective immune response to PVB19, resulting in prolonged or persistent viremia (3).

RTRs can develop symptomatic PV-B19 infections as a result of primary infection acquired via the usual respiratory route or via the transplanted organ, or because of reactivation of latent or persistent viral infection (4). The most common manifestations of PV-B19 infection in immunosuppressed patients are pure red cell aplasia, reticulocytopenia, and erythropoietin-resistant severe anemia (hemoglobin $(\mathrm{Hb})$ less than 11 $\mathrm{mg} / \mathrm{dl}$ in male and $10 \mathrm{mg} / \mathrm{dl}$ in female) and other cytopenias. PV-B19 infects and lysis proerythroblasts, preventing maturation of the erythroid cells causing anemia. This can be detected by testing bone marrow biopsies where giant proeythroblasts with intranucleareosinophilic inclusion body like nucleoli can be seen as diagnostic markers of PV-B19 infection ${ }^{(4,5)}$.

In addition, as a recent discovery and an interesting finding, most frequently detected virus in RTRs is PV-B19 (6). It is noteworthy to mention that among viruses, only the intrarenal persistence of B19 DNA and PV-B19 viremia was directly associated with the development of chronic allograft injury, whereas human cytomegalovirus or EpsteinBarr Virus DNAemia is a risk factor for acute rejection ${ }^{(6,7)}$.

Regarding the diagnosis of PV-B19, it should be considered in transplant recipients with unexplained anemia, erythropoietin-resistant severe anemia and reticulocytopenia, pancytopenia, acute or chronic kidney dysfunction or post-transplantation rejection, collapsing glomerulopathy, and thrombotic microangiopathy (7). Prompt diagnosis of PVB19 infection in RTR requires a high index of suspicion and careful selection of diagnostic tests, which include serology and polymerase chain reaction ${ }^{(8)}$. Most patients benefit from intravenous immunoglobulin therapy IgG and/or alteration or reduction of immunosuppressive therapy. The neutralizing antibodies are able to clear the infection usually by $5^{\text {th }}$ to $10^{\text {th }}$ day of infection. It is proposed that with the rising titers of IgG the virus is cleared and the giant proerythroblasts are replaced by regenerating erythroid cells ${ }^{(9)}$. Moreover, most patients after therapy remain normal until seven months later; thus, IgG therapy of PV-B19 is highly curable and reliable. The only weak point is that anemia and other clinical manifestations caused by PVB19 are underestimated and mostly overlooked by clinicians. Early recognition of the virus and prompt treatment spares the patient unnecessary exposure to blood transfusions, erythropoietin and renal disease caused by the virus.

However, to the best of our knowledge, there is no previous study on PV-B19 in RTRs in Iraq, therefore, this study aimed to prospectively investigate the sero-prevelance of PV-B19 in Iraqi RTRs.

\section{Methods}

This prospective descriptive study was conducted with the approval of the Scientific and Ethical Review Board of Al-Nahrain University/ College of Medicine.

Fifty kidney transplant recipients that's included 38 males and 12 females, who had undergone their first or second kidney transplantation from living donor at from the Center of Kidney Diseases and Transplantation in the Medical City of Baghdad and Al-Khayal Hospital, were included in this study followed for three successive months to detection of viral load. The blood samples collected during the period from August 2015 till February 2016. An informed consent was obtained from each patient prior to participation in the study. Three milliliters of blood were obtained via venipuncture for the serological methods. These three milliliters of samples were 
centrifuged by gel tube and serum were separated without delay. The sera were stored at $-20{ }^{\circ} \mathrm{C}$ and tested for anti-Parvovirus B19 IgG and IgM by enzyme linked immunosorbent assay (ELISA; DRG/ Germany). The $\mathrm{Hb}$ and mean corpuscular volume (MCV) levels were measured on the cell counter (Sysmex K-1000, TOA Medical Electronics Co. Ltd., Kobe, Japan).

\section{Results}

In this study, 27/50 patients were anemic (hemolytic anemia and 23/50 patients were non-anemic). The mean serum creatinine value for patients was $1.66 \pm 1.17$ ranging between 0.54 and $7.10 \mathrm{mg} / \mathrm{dl}$, but in normal population was $0.81 \pm 0.118$. Sixteen out of fifty $(32 \%)$ of the patients had impaired renal function; (serum creatinine value more than $1.2 \mathrm{mg} / \mathrm{dl}$ ). The mean for glomerular filtration rate (GFR) that estimated by the Modification of Diet in Renal Disease study equation GFR (MDRD); its value was $67.69 \pm 30.38$ ranging between 12.75 to $150.9 \mathrm{ml} / \mathrm{min} / 1.73 \mathrm{~m}^{2}$. The GFR (that calculated by MDRD equation) classified into four groups according to the risk of it, high risky group (GFR <30), moderate risk group (GFR 30-60), low risk group (GFR 61-90), and normal or no risk group (GFR >90). But in normal population, the mean of GFR $\pm S D$ was $110.5 \pm 10.8$.

In this study, the results showed nonsignificant association between seropositivity of PV-B19 and serum creatinine $(P=0.99,0.364)$ for IgG and IgM respectively. Also, the results of IgG for human PV-B19 showed nonsignificant differences with post transplantation period, while the positive IgM for human Parvovirus B19 showed significant differences with infection in the first six months after transplantation because the patients highly immunosuppressant.

The results of this study for IgG showed nonsignificant association low level of $\mathrm{Hb}$ (anemia) for RTR ( $P=0.77)$, (Table 1) while PV-B19 IgM showed significant differences in regard to anemic group (0.021), (Table 2 ).

Table 1. Association between anemic status and human Parvovirus B19 IgG

\begin{tabular}{ccccccccc}
\hline \multirow{2}{*}{ IgG } & \multicolumn{2}{c}{ Negative } & \multicolumn{2}{c}{ Positive } & \multicolumn{2}{c}{ Turing positive } & \multicolumn{2}{c}{ Total } \\
& Count & $\%$ & Count & $\%$ & Count & \% & Count & $\%$ \\
\hline${ }^{*}$ Anemic & $10 / 50$ & 20 & $17 / 50$ & 34 & $0 / 50$ & 0 & $27 / 50$ & 54 \\
Not Anemic & $10 / 50$ & 20 & $13 / 50$ & 26 & $0 / 50$ & 0 & $23 / 50$ & 46 \\
\hline Total & $20 / 50$ & 40 & $30 / 50$ & 60 & $0 / 50$ & 0 & $50 / 50$ & 100 \\
\hline \multicolumn{8}{c}{ P value $=\mathbf{0 . 7 7 3}$} \\
\hline
\end{tabular}

*Anemic: Hb less than $11 \mathrm{mg} / \mathrm{dl}$ in male and $10 \mathrm{mg} / \mathrm{dl}$ in female

Table 2. Association between anemic status and human Parvovirus B19 IgM

\begin{tabular}{ccccccccc}
\hline \multirow{2}{*}{ IgM } & \multicolumn{2}{c}{ Negative } & \multicolumn{2}{c}{ Positive } & \multicolumn{2}{c}{ Turing positive } & \multicolumn{2}{c}{ Total } \\
& Count & $\%$ & Count & $\%$ & Count & $\%$ & Count & $\%$ \\
\hline${ }^{*}$ Anemic & $23 / 50$ & 46 & $0 / 50$ & 0 & $4 / 50$ & 8 & $27 / 50$ & 54 \\
Not Anemic & $17 / 50$ & 34 & $5 / 50$ & 10 & $1 / 50$ & 2 & $23 / 50$ & 46 \\
\hline Total & $40 / 50$ & 80 & $5 / 50$ & 10 & $5 / 50$ & 10 & $50 / 50$ & 100 \\
\hline \multicolumn{8}{c}{ P value $=\mathbf{0 . 0 2 1}$} \\
\hline
\end{tabular}

*Anemic: Hb less than $11 \mathrm{mg} / \mathrm{dl}$ in male and $10 \mathrm{mg} / \mathrm{dl}$ in female 


\section{Discussion}

The use of more aggressive immunosuppressive regimens for preventing/reducing rates of acute kidney rejection in RTRs, has adversely led to emergence of viral infections as an important cause of allograft loss ${ }^{(10)}$. Parvovirus B19 is one of these emerging viral infections after transplantation; PV-B19 causes several different clinical diseases and serious complications especially in renal transplant recipients ${ }^{(11)}$.

Infection with human PV-B19 presents with several clinical manifestations. The most common manifestations of PV-B19 infection in immunosuppressed patients are anemia and other cytopenias (12). Thus, this diagnosis should be considered in transplant recipients with unexplained anemia and reticulocytopenia or pancytopenia. Anemia is a common problem after renal transplantation and affects more than $40 \%$ of recipients ${ }^{(13)}$. In this study, $54 \%$ cases had anemia according to the criteria of the American Society of Transplantation $(\mathrm{Hb}$ $\leq 11 \mathrm{mg} / \mathrm{dl}$ in male and $\leq 10 \mathrm{mg} / \mathrm{dl}$ in female). The available reports have mentioned the prevalence of patients with severe anemia (defined as $\mathrm{Hb} \leq 11$ and $\leq 10$, respectively, in male and female patients) ${ }^{(14)}$.

Seropositivity of human PV-B19 in renal transplant recipients includes:

A) IgG serostatus: The true incidence of PV-B19 infection in renal transplant patients may be underestimated, because PV-B19 serology may not be routinely searched in transplanted patients. Moreover, serological tests may fail to detect PV-B19 infection in immunosuppressed patients ${ }^{(11)}$.

Furthermore, easy and rapid mode of spread through respiratory route may play an important role in the increased prevalence of this virus in our community ${ }^{(15)}$.

In the control group of this study, the seroprevalence of PV-B19 IgG was 18\%; these IgG-positive healthy persons might be at the end of resolving their B19 viremia or that some of these controls may had very-low-titer PVB19 DNA that persisted for longer than predicted by the standard natural history model ${ }^{(16)}$. On the other hand, in this study, the rate of PV-B19 IgG was $60 \%$ in RTRs. Compared to control group, this ratio was too high, because all of the patients involved in this study were a high-risk population, namely immunocompromised.

In a study by Khameneh et al in Iran, the seroprevalence of PV-B19 IgG was $69.2 \%$ of renal transplant recipients ${ }^{(14)}$. In a study by Soliman et al in Egypt, the sensitivity, specificity and accuracy of anti PV-B19 IgG in a sample population of pediatric oncology patients were indicated to be $81.2 \%, 53.4 \%$ and $61 \%$, respectively. This was explained that cancer patients exhibited weak immune response, like transplant recipients ${ }^{(17)}$.

B) IgM serostatus: Total prevalence of IgM antibodies to human PV-B19 in control group was $4 \%$ ( 2 samples were positive out of total 50 tested), but during follow-up of RTR, $10 \%$ were IgM-positive, $10 \%$ were IgM-Turing positive and $80 \%$ were IgM-Negative of PV-B19 at P value $=0.02$.

This seropositivity of PV-B19 IgM refers to acute infection. It is known that the PV-B19 infection is either due to reactivation of a latent infection in a general immunosuppression situation (18) or it is the result of a prolonged primary infection in an immunocompromised individual ${ }^{(19,20)}$.

These findings are attributed mainly to reduced RTR immunity by the use of immunosuppressive regimen leading to human PV-B19 reactivation and rapid replication causing the infection in patients. And as a response to infection, the remaining immune system in RTRs secretes antibodies type IgM in an attempt to combat or curb the infection of human PV-B19. According to the results of the current study, estimating serum level of anti PV-B19 IgM in RTR sounds a good test reflecting first, the immune suppression status of RTR and second evaluating the presence of emerged viral infection of PV-B19. 
Both PV-B19 IgG and IgM may be present at or soon after onset of illness and reach peak titers within 30 days ${ }^{(14,21)}$. Because IgG antibody may persist for years, diagnosis of acute infection is made mainly by the detection of IgM antibodies.

This study concluded that the seroprevalence of PV-B19 was relatively high in kidney transplant recipients in Iraq. The incidence of PV-B19 infection might be underestimated in the renal transplant population. Patients are not routinely tested for this virus because the diagnosis is not often considered and because selection of diagnostic tests can be confusing. Blood film and reticulocyte counting should be recommended as a routine screening programmatic least every two months, and PVB19 viral load measurement is recommended for those who had reticulocytopenia. This study recommends Iraqi transplant centers to include serological tests for the detection of PV-B19 infection in kidney donors and recipients.

\section{Acknowledgments}

The authors would like to acknowledge the Center of Kidney Diseases and Transplantation in The Medical City of Baghdad and Al-Nahrain College of medicine, for their cooperation in accomplishing this study.

\section{Author contributions:}

Hlail: Sample collection, serology and hematology working and manuscript writing. Dr. Abdulamir: study design, statistics, and final revision of manuscript. Dr. Al-Saedi: Consultant nephrologist helped in selection of patients.

\section{Conflict of interest}

The authors have no conflicts of interest.

\section{Funding}

Self-funding.

\section{References}

1. Al-Obaidi $A B, A b d K H, K a d h i m ~ H S$, et al. $B K$ polyomavirus and Cytomegalovirus Co-infections in renal transplant recipients: a single center study. Int J Adv Res. 2015; 3: 856-64.

2. Shams-Aldein $S A$, Abdlameer $A S, A l-O b a i d i A B$, et al. Detection of Epstein Barr virus in renal transplant recipients: two centers study. Iraqi J Med Sci. 2015; 13(2): 191-9.

3. Barzon L, Murer L, Pacenti $M$, et al. Investigation of intrarenal viral infections in kidney transplant recipients unveils an association between parvovirus B19 and chronic allograft injury. J Infect Dis. 2009; 199(3): 372-80. doi: https://doi.org/10.1086/596053.

4. Capenko S, Kozireva S, Folkmane I, et al. Anemia as a complication of parvovirus b19 infection in renal transplant recipients. Medicina (Kaunas). 2012; 48(6); 299-304.

5. Carraturo A, Catalani V, Ottaviani D, et al. Parvovirus B19 infection and severe anemia in renal transplant recipients. ScientificWorldJournal. 2012; 2012: 102829. doi: 10.1100/2012/102829.

6. Krishnan P, Ramadas P, Rajendran PP, et al. Effects of Parvovirus B19 Infection in renal transplant recipients: a retrospective review of three cases. Int J Angiol. 2015; 24(2): 87-92. doi: 10.1055/s-00341371759.

7. Kurukulasuriya A, Hamed AA, Al-Muslahi M, et al. Acquired pure red cell aplasia caused by parvovirus B19 infection following a renal transplant. Sultan Qaboos Univ Med J. 2011; 11(2): 280-3.

8. Porignaux $R$, Vuiblet $V$, Barbe $C$, et al. Frequent occurrence of parvovirus B19 DNAemia in the first year after kidney transplantation. J Med Virol. 2013; 85(6): 1115-21. doi: 10.1002/jmv.23557.

9. Waldman M, Kopp JB. Parvovirus-B19-associated complications in renal transplant recipients. Nat Clin Pract Nephrol. 2007; 3(10): 540-50. doi: 10.1038/ncpneph0609.

10. Parsyan A, Candotti D. Human erythrovirus B19 and blood transfusion - an update. Transfus Med. 2007; 17(4): 263-78. doi: 10.1111/j.13653148.2007.00765.x.

11. Alves MT, Vilaca SS, Carvalho $M$, et al. Human parvovirus B19 infection in a renal transplant recipient: a case report. BMC Res Notes. 2013; 6: 28. doi: 10.1186/1756-0500-6-28.

12. Waldman M, Kopp JB. Parvovirus B19 and the kidney. Clin J Am Soc Nephrol. 2007; 2 Suppl 1: S47-56. doi: 10.2215/CJN.01060307.

13. Zilinska Z, Chrastina M, Breza J, et al. Parvovirus B19 infection--the cause of severe anaemia after renal transplantation. Vnitr Lek. 2010; 56(7): 774-8.

14. Khameneh ZR, Sepehrvand N, Sohrabi V, et al. The seroprevalence of Parvovirus B19 among kidney transplant recipients: a single-center study. Saudi J Kidney Dis Transpl. 2014; 25(1): 16-21.

15. Yaegashi N. Pathogenesis of nonimmune hydrops fetalis caused by intrauterine B19 infection. The Tohoku J Exp Med. 2000; 190(2): 65-82.

16. Ekman A, Hokynar K, Kakkola L, et al. Biological and immunological relations among human parvovirus B19 genotypes 1 to 3. J Virol. 2007; 81(13): 6927-35. doi: 10.1128/JVI.02713-06.

17. Soliman Oel-S, Abd El-AalHegaziHasan M, El-Ashry R, et al. Parvovirus B19 infection in pediatric oncology patients: diagnostic value of clinical and serologic 
parameters compared with nested PCR. J Pediatr Hematol Oncol. 2009; 31(3): 173-6. doi: 10.1097/MPH.0b013e3181983b2d.

18. Plentz $A$, Wurdinger $M$, Kudlich $M$, et al. Low-level DNAemia of parvovirus B19 (genotypes 1-3) in adult transplant recipients is not associated with anaemia. J Clin Virol. 2013; 58(2): 443-8. doi: 10.1016/j.jcv.2013.07.007.

19. Us T, Ozune L, Kasifoglu N, et al. The investigation of parvovirus B19 infection in patients with haematological disorders by using PCR and ELISA techniques. Braz J Infect Dis. 2007;11(3):327-30.

20. Heegaard ED, Petersen BL, Heilmann CJ, et al. Prevalence of parvovirus B19 and parvovirus V9 DNA and antibodies in paired bone marrow and serum samples from healthy individuals. J Clin Microbiol. 2002; 40(3): 933-6.

21. Wildig J, Michon $P$, Siba $P$, et al. Parvovirus $B 19$ infection contributes to severe anemia in young children in Papua New Guinea. J Infect Dis. 2006; 194(2): 146-53.

Correspondence to Zainab A. Hlail

E-mail: zainab.ali9213@yahoo.com Received $16^{\text {th }}$ Oct. 2016 Accepted 6 ${ }^{\text {th }}$ Dec. 2016 
Published by Al-Nahrain College of Medicine P-ISSN 1681-6579

E-ISSN 2224-4719

Email: iraqijms@colmed-alnahrain.edu.iq http://www.colmed-alnahrain.edu.iq http://www.iraqijms.net

\title{
Frequency of Human Cytomegalovirus and Human Herpesvirus-1 Antigens in Product of Conceptus Tissues of Pregnant Women with Spontaneous Abortion
}

\author{
Areej A. Hussein ${ }^{1}$ PhD, Post Doc, Sawsan T. Salman² FICMS, CABOG, Basim M. Khashman ${ }^{3}$ MSC \\ ${ }^{1}$ Dept. of Microbiology, ${ }^{2}$ Dept. of Obstetrics and Gynecology, College of Medicine, University of Diyala, Baqubah, Iraq, \\ ${ }^{3}$ Iraqi National Cancer Research Center, University of Baghdad, Iraq.
}

\begin{abstract}
Background Viral infections in pregnancy are major causes of maternal and fetal morbidity and mortality. Infections develop in the neonate transplacentally, perinatally or postnatally.

Objective To determine the frequency of cytomegalovirus and human herpesvirus-1antigens in product of conceptus tissues of pregnant women with spontaneous abortion and to study the association of the various socio-demographic and antenatal factors.

Methods Fifty (50) product of conceptus tissues samples were collected during the period from September 2013 till April 2014 from pregnant women with spontaneous abortion attended at Al-Batool Teaching Hospital for Maternity and Children in Baqubah city. All sociodemographic and antenatal characteristics such as age, education level, economic level, occupation, residence, gestational age, history of abortion and gravity were recorded. Human cytomegalovirus and human herpes virus-1 antigens were detected by immunohistochemistry technique in Department of Microbiology, College of Medicine, University of Diyala.

Results Among 50 formalin-fixed, paraffin embedded product of conceptus tissues blocks, the results showed that positivity frequency of human cytomegalovirus and human herpesvirus-1 antigens were $36 \%$ (18 out of 50 ) for each one. Patients age varied from (15-45) years with mean of 29.48 years. The highest rate of viral infection was diagnosed in the age 26-35 years. Multiple variables regarding frequencies of cytomegalovirus and human herpesvirus-1antigens simultaneously, was evaluated, and none of the variables had significant difference.

Conclusion Human cytomegalovirus and human herpesvirus-1 seems to play a significant role in first trimester pregnancy loss and its infection rate is comparable with that in the other countries, also pregnant women in Baqubah city may have the risk for acquiring viral infection during pregnancy and consequently adverse pregnancy outcomes.

Keywords Abortion, cytomegalovirus, human herpes virus, immunohistochemistry, pregnant women Citation Areej A. Hussein, Sawsan T. Salman, Basim M. Khashman. Frequency of human cytomegalovirus and human herpesvirus-1 antigens in product of conceptus tissues of pregnant women with spontaneous abortion. Iraqi JMS. 2017; Vol. 15(1): 94-102. doi: 10.22578/IJMS.15.1.12
\end{abstract}

List of abbreviation: $\mathrm{B} 19 \mathrm{~V}=$ Human parvovirus $\mathrm{B} 19, \mathrm{HCMV}=$ Human cytomegalovirus, HHSV-1/2 = Human herpes simplex virus, PBS $=$ Phosphate buffers saline

\section{Introduction}

pontaneous abortion or pregnancy loss is the natural death of an embryo or fetus before it is able to survive independently

(1). The cutoff of 20 weeks of gestation after 
which, fetal death is known as a stillbirth (2). There are several factors related to spontaneous abortion, such as genetic abnormalities and infections (3). Many studies showed virus such as human cytomegalovirus (HCMV), human herpes simplex virus (HHSV1/2), human parvovirus B19 (B19V), enterovirus, adenovirus, and varicella-zoster virus are causative agents of spontaneous abortion (4-6).

Herpesviruses comprise the largest family of viruses with oral manifestations. Eight types of herpesvirus are known to be pathogenic in human (7).

Human cytomegalovirus is the most common congenital infection, occurring in $0.3-1 \%$ of all live births worldwide. It may lead to permanent disabilities in the unborn child, such as deafness, blindness and mental impairments (8). Primary HCMV infection results in life-long latent infection, and although congenital infection after reactivation and re-infection with a different HCMV strain may occur, the risk of congenital infection is highest for seronegative women ${ }^{(9,10)}$.

Another virus that could be implicated in recurrent abortion is herpes simplex. Genital herpes is the result of infection by human herpes simplex virus type 2 (HHSV-2) and to a lesser extent human herpesvirus type 1 (HHSV1). There has been a rise in the prevalence of genital human herpesvirus infections in both industrialized and developing countries. The main factors attributed to the spread of human herpesvirus include asymptomatic virus shedding and under recognition and underdiagnoses of the disease. At the level of the individual patient, genital herpes is associated with significant psychological morbidity and complications such as neonatal herpes, the result of transmission of HHSV from mother to baby ${ }^{(11,12)}$. The incidence of asymptomatic cervical HHSV-2 infections was considerably higher in patients with a history of spontaneous abortion with a possible etiologic connection between human herpesvirus and spontaneous abortion (13).
Serologic assays were not very useful for the elucidation of the role of human herpesvirus in inducing spontaneous abortions, although they indicate that the state of pregnancy predisposes to human herpesvirus reactivation (14).

So, this study aims to determine the frequency of HCMV and HHSV-1 antigens in product of conceptus tissues of pregnant women with spontaneous abortion and study the possible association of the various socio-demographic and antenatal factors.

\section{Methods}

\section{Study design}

This cross-sectional study was done during the period from September 2013 to April 2014 in Al-Batool Teaching Hospital for Maternity and Children, pregnant women with spontaneous abortion were enrolled in the study. The age of women ranged from (15-45) years. Product of conceptus tissues samples were collected from all participants after the abortion and all sociodemographic and antenatal characteristics such as age, education level, economic level, occupation, residence, gestational age, history of abortion and gravidity were recorded.

\section{Ethical approval}

The proposal was reviewed and approved by College of Medicine; University of Diyala, permission to conduct this study was obtained from Al-Batool Teaching Hospital for Maternity and Children administrator in Baqubah city, Diyala, Iraq. Participants were also informed that they have full right to discontinue or refuse to participate in this study.

\section{Sampling and processing}

From each participating woman, data were obtained and product of conceptus tissues sample were collected in a clean container with $10 \%$ formaldehyde and used to prepared formalin fixed paraffin embedded tissues block, then immunohistochemistry used for the detection of anti-cytomegalovirus ppm 
antibody or late Ag (CMV- Cat. No. ab 49214. Cambridge Science Park - England) and specific human herpes virus type 1 envelop antigen (HHV-1 - Cat. No. ab9533. Cambridge Science Park - England).

According to manufacturer's protocol. The slides were deparaffinized and rehydrated by xylene and serially graded alcohol for 5 minutes each and then distill water. Endogenous peroxidase activity was blocked by $3 \%$ hydrogen peroxide for 10 minutes. Slides were washed in phosphate-buffered saline. Then treated with protein block, incubated at $37{ }^{\circ} \mathrm{C}$ for 5 minutes and washed with phosphate buffers saline (PBS). Primary antibody was applied to cover slides and incubated for 1 hours in humidity chamber at $37{ }^{\circ} \mathrm{C}$ (Primary Antibody was prepared at dilution 1:100). Slides were rinsed gently in PBS. The secondary antibody was added for 10 minutes at room temperature, followed by the addition of Streptavidine-HRP antibodies for 10 minutes at $37{ }^{\circ} \mathrm{C}$. After washing, samples were stained with diluted liquid DAB for 15-45 minutes at room temperature. Slides were counterstained with hematoxylin for 30 second and washed well in running tap water, then dehydrated and mounting with permanentmounting medium (DPX), examined under light microscope was finally done.

\section{Statistical analysis}

Chi-square test were used to analyzed the data of present study and P-values $<0.05$ were considered statistically significant.

\section{Results}

This study comprised of 50 pregnant women with spontaneous abortion among these women minimum age was 15 years and maximum 45 years. Mean age of the aborted women was 29.48 years; majority of pregnant women with spontaneous abortion were among the age group 15-35 years. According to education level most participants had primary school education 28 (56\%), regarding occupation and economic level, high percentages were recorded within housewives and intermediate level and they are accounted $86 \%$ and $78 \%$ respectively. There were highly significant differences $(P<0.05)$ noticed between pregnant women with spontaneous abortion and different parameters while nonsignificant correlation noticed only among age groups as shows in table (1).

The number of pregnant women with spontaneous abortion in the first trimester was 41 cases (82\%) while in the second trimester were 9 cases (18\%). There was highly significant differences $(\mathrm{P}<0.05)$ noticed as shows in table (2). Second time abortion was very high 23 (46\%) compared with other, multiparty in was higher among aborted women and they were accounted 31 (62\%), but the difference was not significant.

Immunohistochemistry results have demonstrated that 18 out of 50 (36\%) in product of conceptus tissues of aborted women cases were positive for HCMV and HHV-1, but statistical analysis showed insignificant difference at $\mathrm{P}>0.05$ as shown in table (3) and figure (1).

Table (4) and (5) demonstrate the correlation between expression of HCMV and HHV-1 with different variables. The results of present study showed that there were no significant differences between immunohistochemistry expression of both HCMV and HHV-1 with age, education level, economic level, occupation, residence, gestational age, last history of abortion and gravidity. Based on Chi-square test of analysis and Fischer exact test. 
Table 1. Socio-demographic characteristics of subjects

\begin{tabular}{ccccc}
\hline \multicolumn{2}{c}{ Variable } & Number & Percentage & $\begin{array}{c}\text { Comparison of } \\
\text { Significance } \\
\text { P-value }\end{array}$ \\
\hline \multirow{2}{*}{ Age stratum } & $15-25$ years & 19 & $38 \%$ & \\
& $26-35$ years & 19 & $38 \%$ & 0.375 \\
& $36-45$ years & 12 & $24 \%$ & \\
Education level & Illiterate & 8 & $16 \%$ & 0.000 \\
& Primary School & 28 & $56 \%$ & \\
& Secondary School & 6 & $12 \%$ & 0.000 \\
Occupation & Tertiary level & 8 & $16 \%$ & 0.000 \\
& Working & 7 & $14 \%$ & \\
\hline \multirow{2}{*}{ Economic level } & Housewives & 43 & $86 \%$ & 0.002 \\
& Low & 8 & $16 \%$ & \\
\hline \multirow{2}{*}{ Residence } & Intermediate & 39 & $78 \%$ & \\
\hline Total & High & 3 & $6 \%$ & $72 \%$ \\
\hline
\end{tabular}

Table 2. Antenatal characteristics of subjects

\begin{tabular}{ccccc}
\hline & Variable & Number & Percentage & $\begin{array}{c}\text { Comparison of } \\
\text { Significance } \\
\text { P-value }\end{array}$ \\
\hline Duration of & $1^{\text {st }}$ trimester & 41 & $82 \%$ & 0.000 \\
pregnancy & $2^{\text {nd }}$ trimester & 9 & $18 \%$ & \\
& $3^{\text {rd }}$ trimester & 0 & 0 & 0.000 \\
Number of & First time & 6 & $12 \%$ & \\
abortion & Second time & 23 & $46 \%$ & \\
& Third time & 19 & $38 \%$ & 0.000 \\
\hline Parity & Fourth time & 2 & $4 \%$ & \\
& Nulliparaous & 5 & $10 \%$ & \\
& Primiparaous & 11 & $22 \%$ & \\
& Multiparaous & 31 & $62 \%$ & \\
\hline
\end{tabular}

Table 3. Positive and negative results for CMV and HHV-1 among studied group

\begin{tabular}{cccc}
\hline IHC results & $\begin{array}{c}\text { Positive } \\
\text { No. (\%) }\end{array}$ & $\begin{array}{c}\text { Negative } \\
\text { No. (\%) }\end{array}$ & $\begin{array}{c}\text { Comparison of Significance } \\
\text { P-value }\end{array}$ \\
\hline CMV & $18(36 \%)$ & $32(64 \%)$ & 1.000 \\
HHV-1 & $18(36 \%)$ & $32(64 \%)$ & \\
\hline
\end{tabular}




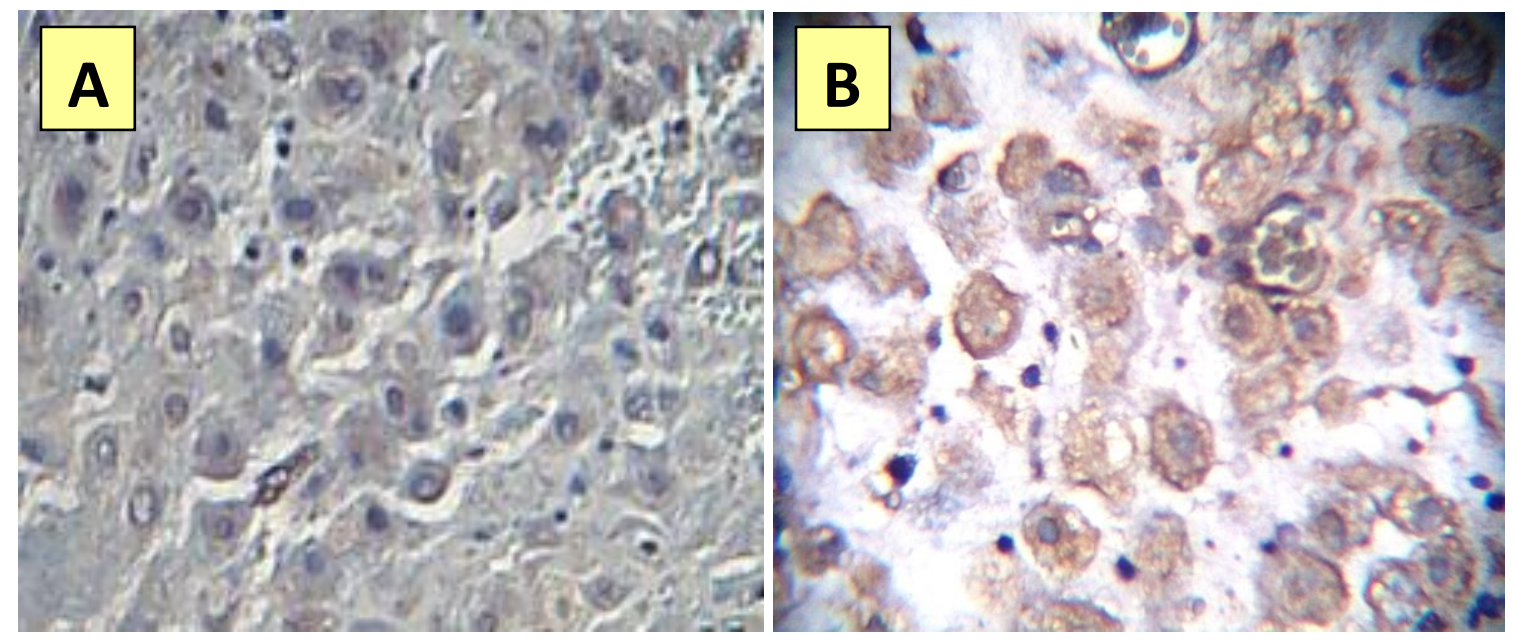

Figure 1. Immunohistochemistry for HCMV and HHV-1 in product of conceptus tissues of pregnant women with spontaneous abortion section, stained by DAB chromogen and counter stained with heamatoxylin is shown as radish brown in positive cases (magnification power, 400). A-HCMV positive expression, B- HHV-1 positive expression.

\section{Discussion}

Viral infections are more likely to occur at certain times in life such as childhood, adolescence and pregnancy. Pregnant women are at greatest risk of viral infection, due to the fact that they have defect in immune response. We chose in this study this segment of females for focus with a view two reasons the extent of the problem in our society. The idea was to investigate the viral infection rate among pregnant women with spontaneous abortion. Human cytomegalovirus is linked to late abortions and to stillbirth and reactivation of chronic HCMV infection in the course of pregnancy might result in fetal infection with spontaneous abortion (15-17). The current study had demonstrated that HCMV infection in pregnant women with spontaneous abortion was $36 \%$, this result is comparable with result of a study done in Erbil city, which found that the seropositivity was $30.05 \%{ }^{(18)}$. However, other studies showed higher rate than result of present study, which reported a detection rates ranged between $62.3 \%$ and $81.1 \%(19,20)$. When compare to studies conducted in Arabic countries such as Tunisia, where a $96.3 \%$ seroprevalence of HCMV antibody was reported among 404 Tunisian pregnant women (21). High frequency rate could therefore be related to a higher risk of infection, but it may also be related to use less sensitive diagnostic methods such as virus culture in certain areas compare with other technique. While the rate was lower in study done by el-Sayed and Goda that achieved $12 \%{ }^{(22)}$.

There is a $2 \%$ incidence of HHSV-1 or HHSV-2 infections among women during pregnancy ${ }^{(23) .}$ Herpes virus 1 accounts to about one-third to a half of cases of neonatal herpes ${ }^{(24,25)}$.

The result demonstrated that the frequency of HHV-1 was $36 \%$ in product of conceptus tissues of pregnant women with portentous abortion. Similar study carried out by Frenkel, et al., 1993 (26), who reported that HSV was detected by serology in $36 \%$ in pregnant women with no history of genital herpes. Also, this result was in agreement with the findings el-Sayed and Goda (2007) who reported that 40\% women with recurrent abortion have HSV IgM (22). Increased risk of spontaneous abortion, stillbirth, and congenital anomalies have always been associated with herpes virus ${ }^{(27)}$. 
Iraqi JMS 2017; Vol. 15(1)

Table 4. Distribution of positive and negative HCMV-IHC results according to socio-demographic and antenatal characteristics of study

\begin{tabular}{|c|c|c|c|c|}
\hline \multicolumn{2}{|c|}{ Variable } & \multirow{2}{*}{$\begin{array}{c}\begin{array}{c}\text { Positive } \\
\text { No. (\%) }\end{array} \\
6(33.33 \%)\end{array}$} & \multirow{2}{*}{$\begin{array}{c}\begin{array}{c}\text { Negative } \\
\text { No. (\%) }\end{array} \\
13(40.62 \%)\end{array}$} & \multirow{2}{*}{$\begin{array}{c}\text { Comparison of } \\
\text { Significance } \\
\text { P-value }\end{array}$} \\
\hline & $15-25$ & & & \\
\hline Age (year) & $26-35$ & $10(55.55 \%)$ & $9(28.12 \%)$ & 0.111 \\
\hline & $36-45$ & $2(11.11 \%)$ & $10(31.25 \%)$ & \\
\hline \multirow{4}{*}{ Education level } & Illiterate & $1(5.55 \%)$ & 7 (21.87\%) & \multirow{4}{*}{0.294} \\
\hline & Primary School & $13(72.22 \%)$ & 15 (46.87\%) & \\
\hline & Secondary School & 2 (11.11\%) & $4(12.50 \%)$ & \\
\hline & Tertiary level & 2 (11.11\%) & $6(18.75 \%)$ & \\
\hline \multirow{2}{*}{ Occupation } & Working & $2(11.11 \%)$ & $5(15.62 \%)$ & \multirow{2}{*}{0.659} \\
\hline & Housewives & $16(88.88 \%)$ & $27(84.37 \%)$ & \\
\hline \multirow{3}{*}{ Economic level } & Low & $3(16.66 \%)$ & $5(15.62 \%)$ & \multirow{3}{*}{0.508} \\
\hline & Intermediate & $13(72.22 \%)$ & $26(81.25 \%)$ & \\
\hline & High & $2(11.11 \%)$ & $1(3.12 \%)$ & \\
\hline \multirow{2}{*}{ Residence } & Urban & $15(83.33 \%)$ & $21(65.62 \%)$ & \multirow{2}{*}{0.181} \\
\hline & Rural & $3(16.66 \%)$ & $11(34.37 \%)$ & \\
\hline \multirow{3}{*}{$\begin{array}{l}\text { Duration of } \\
\text { pregnancy }\end{array}$} & $1^{\mathrm{St}}$ & $15(83.33 \%)$ & $26(81.25 \%)$ & \multirow{3}{*}{0.854} \\
\hline & $2^{\text {nd }}$ & $3(16.66 \%)$ & $6(18.75 \%)$ & \\
\hline & $3^{\text {rd }}$ & 0 & 0 & \\
\hline \multirow{4}{*}{$\begin{array}{l}\text { Number of } \\
\text { abortion }\end{array}$} & First time & $2(11.11 \%)$ & $4(12.5 \%)$ & \multirow{4}{*}{0.217} \\
\hline & Second time & $9(50 \%)$ & $14(43.74 \%)$ & \\
\hline & Third time & $5(27.77 \%)$ & $14(43.75 \%)$ & \\
\hline & Fourth time & $2(11.11 \%)$ & 0 & \\
\hline \multirow{4}{*}{ Parity } & Nulliparaous & $1(5.55 \%)$ & $4(12.5 \%)$ & \multirow{4}{*}{0.705} \\
\hline & primiparaous & $3(16.66 \%)$ & $8(25.0 \%)$ & \\
\hline & Multiparaous & $13(72.22 \%)$ & $18(56.25 \%)$ & \\
\hline & Gravid & $1(5.55 \%)$ & $2(6.25 \%)$ & \\
\hline
\end{tabular}

The results of current study showed the highest HCMV and HHV-1 infection rate among those enrolled cases at age interval between 15-35 years, cases of HSV-1 infections are seen worldwide and do not discriminate by age (28). Comparison of HCMV and HHV-1 positive results according to occupation and economical level, most positive cases occur within non-worker women and with intermediate economic level but no significant correlation occur among them. Human cytomegalovirus is found universally throughout all geographic locations and in all socioeconomic groups (19). Also, this result agrees with Pechaham et al. $2001^{(29)}$.

Although the present study revealed that the HCMV and HHV-1were highest in the first trimester, this result was consistent with those reported by other who found that the highest infection rate of HCMV and HHV-1 among aborted women ${ }^{(6,30)}$. Also, HHV found in the second trimester (27). While other study done 
by Skoczyński et al, (2015) who did not confirm the prenatal transmission of HPV and HSV during the investigation in 138 samples of amniotic fluid from pregnant women during the second trimester of gestation ${ }^{(31)}$. However, the damage is still more sever in infections occurring during the first half of pregnancy, while infections in the second half would result in reduced mortality ${ }^{(32)}$.

Table (5): Distribution of positive and negative human herpesvirus 1-IHC results according to socio-demographic and antenatal characteristics of study group

\begin{tabular}{|c|c|c|c|c|}
\hline \multicolumn{2}{|c|}{ Variable } & \multirow{2}{*}{$\begin{array}{c}\begin{array}{c}\text { Positive } \\
\text { No. (\%) }\end{array} \\
7 \text { (38.88\%) }\end{array}$} & \multirow{2}{*}{$\begin{array}{c}\begin{array}{c}\text { Negative } \\
\text { No. (\%) }\end{array} \\
12(37.5 \%)\end{array}$} & \multirow[t]{2}{*}{$\begin{array}{c}\text { Comparison of } \\
\text { Significance } \\
\text { P-value }\end{array}$} \\
\hline \multirow{3}{*}{ Age (year) } & $15-25$ & & & \\
\hline & $26-35$ & 7 (38.88\%) & 12 (37.5\%) & \multirow[t]{2}{*}{0.976} \\
\hline & $36-45$ & $4(22.22 \%)$ & $8(25.0 \%)$ & \\
\hline \multirow{4}{*}{ Education level } & Illiterate & $4(22.22 \%)$ & $4(12.5 \%)$ & \multirow{4}{*}{0.203} \\
\hline & Primary School & 7 (38.88\%) & 21 (65.6\%) & \\
\hline & Secondary School & $4(22.22 \%)$ & $2(6.25 \%)$ & \\
\hline & Tertiary level & $3(16.66 \%)$ & $5(15.62 \%)$ & \\
\hline \multirow{2}{*}{ Occupation } & Working & $2(11.11 \%)$ & $5(15.62 \%)$ & \multirow{2}{*}{0.956} \\
\hline & Housewives & $16(88.88 \%)$ & $27(84.37 \%)$ & \\
\hline \multirow{3}{*}{ Economic level } & Low & $4(22.22 \%)$ & $4(12.5 \%)$ & \multirow{3}{*}{0.667} \\
\hline & Intermediate & $13(72.22 \%)$ & $26(81.25 \%)$ & \\
\hline & High & $1(5.55 \%)$ & $2(6.25 \%)$ & \\
\hline \multirow{2}{*}{ Residence } & Urban & $14(77.77 \%)$ & $22(68.75 \%)$ & \multirow{2}{*}{0.495} \\
\hline & Rural & $4(22.22 \%)$ & $10(25.0 \%)$ & \\
\hline \multirow{3}{*}{$\begin{array}{l}\text { Duration of } \\
\text { pregnancy }\end{array}$} & $1^{\mathrm{St}}$ & $16(88.88 \%)$ & $25(78.12 \%)$ & \multirow{3}{*}{0.459} \\
\hline & $2^{\text {nd }}$ & $2(11.11 \%)$ & 7 (21.87\%) & \\
\hline & $3^{\text {rd }}$ & 0 & 0 & \\
\hline \multirow{4}{*}{$\begin{array}{l}\text { Number of } \\
\text { abortion }\end{array}$} & First time & $2(11.11 \%)$ & $4(12.5 \%)$ & \multirow{4}{*}{0.848} \\
\hline & Second time & 7 (38.88\%) & 16 (50.0\%) & \\
\hline & Third time & $8(44.44 \%)$ & 11 (34.37\%) & \\
\hline & Fourth time & $1(5.55 \%)$ & $1(3.12 \%)$ & \\
\hline \multirow{4}{*}{ Parity } & Nulliparaous & $2(11.11 \%)$ & $3(9.37 \%)$ & \multirow{4}{*}{0.694} \\
\hline & primiparaous & $4(22.22 \%)$ & 7 (21.87\%) & \\
\hline & Multiparaous & $10(55.55 \%)$ & $21(65.62 \%)$ & \\
\hline & Gravid & $2(11.11 \%)$ & $1(3.12 \%)$ & \\
\hline
\end{tabular}

In the current study, there is no significant correlation between the HCMV and HHV-1 infection in aborted pregnant women with age, education level, occupation, economic level, residence, gestational age, history of abortions and parity; so, these cannot be considered as risk factors for infection.
The differences between the results of the previously mentioned studies and even with the results of present study could be related to many factors, like the methodology in the current study used molecular technique while other study may use serological methods, sample size, studied population different from one area to another, the duration of incubation 
if samples collect in acute infection the result will different from chronic infection, individual's immune status, demographic and geographical variations season and etc.

The current study concludes that viral infections with HCMV and HHV-1 might play a role in recurrent abortions. A cytomegalovirus and human herpesvirus-1 antigen is comparable with that in the other countries, and pregnant women in Baqubah city may have the risk for acquiring viral infection during pregnancy and consequently adverse pregnancy outcomes. Careful investigation for such conditions must involve detecting the presence of these viruses. Further investigation is needed with large sample size to clarify this issue and studying the role of other viruses in the pregnant women such as parvovirus.

\section{Acknowledgments:}

Authors like to express their thanks to all patients were included in this study.

\section{Author contributions:}

Authors participate in drafting the article and revising it critically for important intellectual content.

\section{Conflict of interest:}

The authors report no conflicts of interest.

\section{Funding:}

Self-funding.

\section{References}

1. Hurt KJ, Guile MW, Bienstock JL, et al. The Johns Hopkins manual of gynecology and obstetrics. $4^{\text {th }}$ ed. Lippincott Williams and Wilkins. 2012. p. 438-9.

2. http://www.nichd.nih.gov/.What is pregnancy loss/miscarriage. Retrieved 14 March 2015.

3. Atik RB, Hepworth-Jones BE, Doyle PA. Risk factors for miscarriage. In: Farquharson RG, Stephenson MD (eds). Early Pregnancy. Cambridge, UK: Cambridge University Press; 2010. p. 9-18.

4. Chow $S$, Craig $M$, Jacques $C$. Correlates of placental infection with cytomegalovirus, parvovirus B19 or human herpes virus 7. J Med Virol 2006; 78: 747-56. doi: 10.1002/jmv.20618.

5. Kim ID, Chang HS, Hwang KJ. Herpes simplex virus 2 infection rate and necessity of screening during pregnancy: A clinical and seroepidemiologic study.
Yonsei Med J. 2012; 53(2): 401-7. doi: 10.3349/ymj.2012.53.2.401.

6. Zhou, Ya, Guohui B, Qiongxiu Z, et al. Detection of cytomegalovirus, human parvovirus B19, and herpes simplex virus-1/2 in women with first-trim ester spontaneous abortions. J Med Virol. 2015; 87(10): 1749-53. doi: 10.1002/jmv.24218.

7. Lynch DP. Oral manifestation of viral diseases. In: Tyring SK (ed). Mucosal immunology and virology. London: Springer; 2006. p. 99-105.

8. Dollard SC, Grosse SD, Ross DS. New estimates of the prevalence of neurological and sensory sequelae and mortality associated with congenital cytomegalovirus infection. Rev Med Virol. 2007; 17: 355-63. doi: 10.1002/rmv.544.

9. Fowler KB, Stagno S, Pass RF. Maternal immunity and prevention of congenital cytomegalovirus infection. JAMA. 2003; 289: 1008-11.

10. Wang $C$, Zhang $X$, Bialek $S$, et al. Attribution of congenital cytomegalovirus infection to primary versus non-primary maternal infection. Clin Infect Dis. 2011; 52: e11-e13. doi: 10.1093/cid/ciq085.

11. Cusini, M, Ghislanzoni M. The importance of diagnosing genital herpes. J Antimicrob Chemother. 2001; 47 Suppl T1: 9-16.

12. Straface G, Selmin A, Zanardo V, et al. Herpes simplex virus infection in pregnancy. Infect Dis Obstet Gynecol. 2012; 2012: 385697. doi: 10.1155/2012/385697.

13. Bujko, M, Sulovic V, Zivanovic V. Herpes simplex virus infection in women with previous spontaneous abortion. J Perinat Med. 1988; 16(3): 193-6.

14. Sifakis, S, Koumantakis E, Koffa M. Detection of herpes simplex virus (HSV) in aborted material using the polymerase chain reaction technique. Gynaecol Obstet Invest. 1998. 45: 109-15.

15. Clewley JP. Polymerase chain reaction assay of parvovirus B19 DNA in clinical specimens. J Clin Microbiol. 1989; 27(12): 2647-51.

16. Szkaradkiewicz A, Pieta P, Tulecka T. The diagnostic value of anti-CMV and anti HPV, B19 antiviral antibodies in studies on causes of recurrent abortions. Ginekol Pol. 1997; 68 (4): 181-6.

17. Kenneson A, Cannon MJ. Review and meta-analysis of the epidemiology of congenital cytomegalovirus (CMV) infection. Rev Med Virol. 2007; 17: 253-76. doi: 10.1002/rmv.535.

18. Ali SA, Sharef TY. Serological study of cytomegalovirus (CMV) in spontaneous abortion. Zanco J Med Sci. 2007; 11(1): 31-6.

19. Munro SC, Hall B, Whybin LR, et al. Diagnosis of and screening for cytomegalovirus infection in pregnant women J Clin Microbiol. 2005; 43(9): 4713-8. doi: 10.1128/JCM.43.9.4713-4718.2005.

20. Odland J $\varnothing$, Sergejeva IV, Ivaneev MD. Seropositivity of cytomegalovirus, parvovirus and rubella in pregnant women and recurrent aborters in Leningrad country, Russia. Acta Obstetricia Gynecol Scand. 2001; 80: 1025-30. 
21. Hannachi N, Marzouk M, Harrabi I, et al. Seroprevalence of rubella virus, varicella zoster virus, cytomegalovirus and parvovirus B19 among pregnant women in the Sousse region, Tunisia. Bull Soc Pathol Exot. 2011; 104(1): 62-7. doi: 10.1007/s13149-0100119-z.

22. el-Sayed ZM, Goda H. Relevance of parvovirus B19, herpes simplex virus 2, and cytomegalovirus virologic markers in maternal serum for diagnosis of unexplained recurrent abortions. Arch Pathol Lab Med. 2007, 131(6): 956-60. doi: 10.1043/15432165(2007)131[956:ROPBHS]2.0.CO;2.

23. Brown ZA, Selke S, Zeh J, et al. The acquisition of herpes simplex virus during pregnancy. $N$ Engl J Med 1997; 337: 509-15. doi: 10.1056/NEJM199708213370801.

24. Brown ZA, Wald A, Morrow RA, et al. Effect of serologic status and cesarean delivery on transmission rates of herpes simplex virus from mother to infant. JAMA. 2003; 289: 203-9.

25. Whitley R, Arvin A, Prober C, et al. Infectious diseases collaborative antiviral study group. A controlled trial comparing vidarabine with acyclovir in neonatal herpes simplex virus infection. N Engl J Med. 1991; 324(7): 444-9. doi: 10.1056/NEJM199102143240703.

26. Frenkel, L M, Garratty EM, Shen JP. Clinical reactivation of herpes simplex virus type 2 infection in seropositive pregnant women with no history of genital herpes. Ann Intern Med. 1993; 118: 414-8.
27. Money D, Steben M, Infectious Diseases Committee, Society of Obstetricians and Gynecologists of Canada. Guidelines for the management of herpes simplex virus in pregnancy. J Obstet Gynaecol Can. 2008; 30(6): 514-26.

28. Malm G. Neonatal herpes simplex virus infection. Semin Fetal Neonatal Med. 2009; 14(4): 204-8. doi: 10.1016/j.siny.2009.01.005.

29. Pechaham C, Tookey P, Logan S, et al. Screening options for prevention congenital cytomegalovirus infection. J Med Screen. 2001; 8: 119-24. doi: 10.1136/jms.8.3.119.

30. Kapranos NC, Kotronias DC. Detection of herpes simplex virus in first trimester pregnancy loss using molecular techniques. In Vivo. 2009; 23(5): 839-42.

31. Skoczyński M, Krzyżanowski AR, Goździcka-Józefiak A, et al. Prevalence of human papillomavirus and herpes simplex virus in amniotic fluid from pregnant women of Eastern Poland. Postepy Hig Med Dosw (Online). 2015; 69: 1349-52.

32. Sinclair J, Sissons P. Latency and reactivation of human cytomegalovirus. J Gen Virol. 2006; 87(Pt 7): 1763-79. doi: 10.1099/vir.0.81891-0.

Correspondence to Dr. Areej A. Hussein
E-mail: areej.2002@yahoo.com
Received 11 $1^{\text {th }}$ Aug. 2016
Accepted 20
th Dec. 2016




\title{
Iraqi JMS
}

Published by AI-Nahrain College of Medicine
P-ISSN 1681-6579
E-ISSN 2224-4719
Email: iraqijms@colmed-alnahrain.edu.iq
http://www.colmed-alnahrain.edu.iq
http://www.iraqijms.net

\section{Successful Trial of Labor After Primary and Repeated Cesarean Sections: A Case Report}

\author{
Yosra T. Jarjees FIBMS (Obs Gyn) \\ Dept. of Obstetrics and Gynecology, Ninevah College of Medicine, University of Ninevah, Iraq
}

\begin{abstract}
This is a case report of a patient who achieved a successful vaginal birth for five times attended by a traditional birth attendant twice after two cesarean sections and thrice after three cesarean sections.
\end{abstract}

Keywords Vaginal birth after cesarean delivery, VBAC, VBAC delivery, trial of labor after cesarean delivery, prior cesarean delivery, risks for uterine rupture, vaginal delivery

Citation Yosra T. Jarjees. Successful trial of labor after primary and repeated cesarean sections: A case report. Iraqi JMS. 2017; Vol. 15(1): 119-121. doi: 10.22578/IJMS.15.1.13

Introduction

$\mathrm{P}$ olicies of routine repeat cesarean section for all women with scarred uterus were never widely practiced now in the world ${ }^{(1)}$. A trial of labor after previous cesarean delivery has been accepted as a way to lower the overall cesarean delivery rate ${ }^{(2)}$. Planned vaginal birth after cesarean section is a clinically safe choice for the majority women with a single previous lower segment cesarean delivery (3). The proportion of women with previous cesarean section who are allowed a trial of labor varies from country to country and from center to center ${ }^{(4)}$. The decision to undergo a trial of labor is an individual one and should be based on careful patient counseling (5). Most published series indicate that approximately $72-75 \%$ of trials of labor after a previous cesarean delivery result in successful vaginal births ${ }^{(6)}$.

The most important complications of attempted vaginal birth for women with single previous low transverse cesarean section are uterine scars dehiscence and rupture. The risk of uterine rupture increases with the number of previous uterine incisions ${ }^{(7)}$. Because of the risks associated with trial of labor after cesarean and complications, the American College of Obstetricians and Gynecologists recommends that the trial of labor be undertaken in facilities with staff immediately available to provide emergency care ${ }^{(8)}$.

The aim of presenting this case is to show the probability of safety of conducting a trial of labor repeatedly in the same patient after one, two and three lower segment cesarean sections.

\section{The case}

Mrs. Sabha was 35 years old, she was 38 week pregnant, gravida 10 para 9 all are alive, term and of normal weights. She presented requesting cesarean delivery and bilateral tubal ligation. According to her past obstetric history; her $1^{\text {st }}$ pregnancy has been ended by uncomplicated emergency cesarean section for a breech presentation at term. She delivered the $2^{\text {nd }}$ baby by normal vaginal delivery. The $3^{\text {rd }}$ 
pregnancy delivered by emergency cesarean section for prelabor rupture of membranes. The $4^{\text {th }}$ and $5^{\text {th }}$ pregnancies delivered vaginally successfully by a traditional birth attendant. In the $6^{\text {th }}$ pregnancy the patient chose to deliver her baby in the hospital, so she was delivered by cesarean section because she had 2 previous cesarean sections. Then the patient delivered her $7^{\text {th }}, 8^{\text {th }}$, and $9^{\text {th }}$ pregnancies by normal vaginal delivery also by a traditional birth attendant although she had three previous cesarean sections. The patient had no records of the previous operations. The interpregnancy intervals in all these pregnancies were between 1 and 2 years without any contraception and the neonatal weights were within average. The outcomes were successful following all deliveries and there were no maternal or neonatal complications. All these operations were not complicated by infection or postpartum hemorrhage and no history of blood transfusion. The patient had no medical diseases. On examination, the vital signs were normal and she was of normal body mass index and obstetric examination was of term uterus, longitudinal lie, of vertex presentation with audible fetal heart. For her last pregnancy (the 10th), the patient had requested cesarean and bilateral tubal ligation.

The operation was done in Albatool Maternity Teaching Hospital in Mosul at 2009. The indication was three previous cesarean sections. During the operation, the lower uterine segment seemed not affected by her repeated pregnancies and birth and there were no adhesions to the abdominal wall and or intraabdominally. The postoperative period passed smoothly.

\section{Discussion}

The concept of vaginal birth after cesarean section is interesting; although it is not safe as originally thought ${ }^{(9)}$. There are no randomized controlled trials comparing planned vaginal birth after cesarean with planned repeated cesarean section and the evidence for these interventions is obtained mainly from nonrandomized cohort studies ${ }^{(10)}$.

We tried in this case report to show that vaginal delivery after cesarean section can be achieved successfully after one, two, and three cesarean sections. The surgeon should provide the patient information about the state of the lower segment during each operation, so the doctor and the patient can take an idea about the risk of the trial of labor in the next pregnancy. Although obtaining an old record is useful, its absence probably should not interdict a trial of labor in a patient who desires to attempt vaginal delivery ${ }^{(11)}$. This patient has deficiency in her previous records but the decision to deliver vaginally was taken by the patient and the midwife based on ignorance and lack of adequate information about the risk and benefit of planed vaginal birth after cesarean section. Nevertheless, her decision has positively affected her plans for future pregnancies.

Some authors said that trial of labor following two previous cesarean sections is acceptable in the majority of cases and result in good maternal and neonatal outcomes (12). In this case, the repeated success is due to the success in the first attempt. Previous vaginal birth especially after one cesarean section is the best predictor for successful vaginal birth after more than one cesarean section (13).

An important factor that helped in the successful outcome in this lady was that the indication of first cesarean section was not a recurrent cause (breech presentation, unless the breech recurred), also the patient was young and of normal body mass index. Body mass index greater than 30 is a predictor of unsuccessful outcome (14). Advanced maternal age is associated with decreased likelihood of planned vaginal birth after cesarean success (15). The gestational age of the previous pregnancies in this lady were all at term and also the babies' weights were normal. Both preterm and postterm pregnancies and birth weight greater than $4000 \mathrm{~g}$ can affect the success rate of vaginal birth after cesarean 
section. Preterm cesarean section is a predisposing factor for rupture uterus in the subsequent pregnancy ${ }^{(16)}$.

We see that in this patient the short interpregnancy interval did not affect the outcome. Some studies reported that the success of the trial is related to period in between pregnancies. An interdelivery interval of $\leq 24$ months of gestation was associated with a 2- to 3-fold increase in the risk of uterine rupture compared with an interval of $>24$ months of gestation ${ }^{(17)}$.

There is limited evidence on whether maternal or neonatal outcomes are significantly influenced by the number and type of prior uterine scar ${ }^{(18)}$.

This case report presents an evidence to facilitate the antenatal counseling in women with prior cesarean birth who want to undergo planned vaginal birth after cesarean section.

\section{References}

1. Scott JR. Vaginal birth after cesarean delivery. A common-sense approach. Obstet Gynecol. 2011; 118: 342-50. doi: 10.1097/AOG.0b013e3182245b39.

2. Queenan JT. How to stop the relentless rise in cesarean deliveries. Obstet Gynecol. 2011; 118: 199200. doi: 10.1097/AOG.0b013e3182266682.

3. National Institute for Health and Clinical Excellence. Cesarean section. NICE clinical guideline 132. Manchester. NICE; 2011.

4. Landon MB, Grobman WA. Vaginal birth after previous cesarean. In: Gabbe SG, Neibyl JR, Simpson $\mathrm{JL}$, et al (eds). Obstetrics: normal and problem pregnancies. 7th ed. City???: Elsevier; 2012. P.???

5. Studsgaard A, Skorstengaard M, Glavind J, et al. Trial of labor compared to repeat cesarean section in women with no other risk factors other than a prior cesarean delivery. Acta Obstet Gynecol Scand. 2013; 92(11): 1256-63. doi: 10.1111/aogs.12240.

6. Royal College of Obstetricians and Gynecologists. Birth after previous cesarean birth. Green-top Guideline No. 45, Oct. 2015.

7. Fitzpatrick KE, Kurinczuk JJ, Alfirevic Z, et al. Uterine rupture by intended mode of delivery in the UK: a national case-control study. PLoS Med. 2012; 9: e1001184. doi: 10.1371/journal.pmed.1001184.

8. American College of Obstetricians and Gynecologists. ACOG practice bulletin no. 115: vaginal birth after previous cesarean delivery. Obstet Gynecol. 2010;
116(2 Pt 1): 450-63. doi: 10.1097/AOG.0b013e3181eeb251.

9. Dodd JM, Crowther CA. Elective repeat caesarean section versus induction of labour for women with a previous caesarean birth. Cochrane Database Syst Rev. 2012; 5: CD004906.

10. Dodd JM, Crowther CA, Huertas E, et al. Planned elective repeat caesarean section versus planned vaginal birth for women with a previous caesarean birth. Cochrane Database Syst Rev. 2013; 12: CD004224. doi: 10.1002/14651858.CD004224.pub3.

11. Balachandran L, Vaswani PR, Mogotlane R. Pregnancy outcome in women with previous one cesarean section. J Clin Diagn Res. 2014; 8: 99-102. doi: 10.7860/JCDR/2014/7774.4019.

12. Ugwu GO, lyoke CA, Onah $\mathrm{HE}$, et al. Maternal and perinatal outcomes of delivery after a previous cesarean section in Enugu, Southeast Nigeria: a prospective observational study. Int J Womens Health. 2014; 13(6): 301-5. doi: 10.2147/IJWH.S56147.

13. Sentilhes L, Vayssière C, Beucher G, et al. Delivery for women with a previous cesarean: guidelines for clinical practice from the French College of Gynecologists and Obstetricians (CNGOF). Eur J Obstet Gynecol Reprod Biol 2013; 170: 25-32. doi: 10.1016/j.ejogrb.2013.05.015.

14. Awan S, Bibi S, Makhdoom A, et al. Adverse fetomaternal outcome among pregnant overweight women. Pak J Med Sci. 2015; 31(2): 383-7. doi: 10.12669/pjms.312.6530.

15. Abou El-Ardat M, Izetbegovic S, Mehmedbasic E, et al. Frequency of vaginal birth after cesarean section at clinic of gynecology and obstetrics in Sarajevo. Med Arch. 2013; 67(6): 435-7. doi: 10.5455/medarh.2013.67.435-437.

16. Lannon SM, Guthrie KA, Vanderhoven JP, et al. Uterine rupture risk after periviable cesarean delivery. Obstet Gynecol. 2015; 125(5): 1095-100. doi: 10. 1097/AOG.0000000000000832.

17. Conde-Agudelo A, Rosas-Bermudez A, Castano F, et al. Effects of birth spacing on maternal, perinatal, infant, and child health: a systematic review of causal mechanisms. Stud Fam Plann. 2012; 43: 93-114.

18. Turqut A, Ozler A, Siddik EM, et al. Uterine rupture revisited: Predisposing factors, clinical features, management and outcomes from a tertiary care center in Turkey. Pak J Med Sci. 2013; 29(3): 753-7.

\section{E-mail: yjarjees@yahoo.co.uk Received $9^{\text {th }}$ Dec. 2016 Accepted $8^{\text {th }}$ Jan. 2017}




\section{المجلة العراقية للعلوم الطبية}

$$
\text { المشرف العام }
$$

الأستاذ الاكتور علاء غني حسين

$$
\text { رئيس هيئة التحرير }
$$

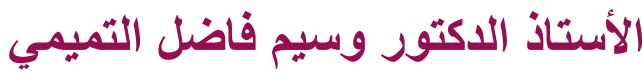

$$
\text { المدرس الدكتور ماجد تير التحرير احمد }
$$

هيئة التحرير التنفيذية

$$
\begin{aligned}
& \text { حسن عزيز الحمداني } \\
& \text { حيدر صباح كاظم } \\
& \text { عبد الكريم محمد علي } \\
& \text { حيدر جواد مبارك } \\
& \text { ريا سليمان بابان } \\
& \text { وسن إسماعيل السعدي } \\
& \text { أحمد رحمة ابو رغيف إعيل } \\
& \text { أثثير جواد عبد الأمير } \\
& \text { تقي سعدون عطية } \\
& \text { أحمد صاحب عبد الأمير } \\
& \text { علي فؤاد الهاشمي } \\
& \text { بان جمعة قاسم } \\
& \text { الأستاذ الاكتور } \\
& \text { الأستاذ الدكتور } \\
& \text { الأستاذ الدكتور } \\
& \text { الأستاذ الاكتور } \\
& \text { الأستاذ الاكتورة } \\
& \text { الأستاذ الاكتورة } \\
& \text { الأستاذ الاكتور الأدناذ الاكتور } \\
& \text { الأستاذ المساعد الدكتورة } \\
& \text { الأستاذ المساعد الدكتور } \\
& \text { الأستاذ المساعد الدكتور } \\
& \text { الأستاذ المساعد الدكتور } \\
& \text { الأستاذ المساعد الدكتورة } \\
& \text { المحرر اللغوي } \\
& \text { المحرر المنضد المغد } \\
& \text { إسراء سامي ناجي } \\
& \text { زينب علي حمودي } \\
& \text { سكرتارية المجلة }
\end{aligned}
$$

عنوان المراسلات إلى المجلة العراقية للعلوم الطبية، صندوق بريد 70044 بغداد، العراق. تلفون (964+)ـ. رقم الإيداع في دار الكتب والوثائق ببغداد 709 لسنة 2000 


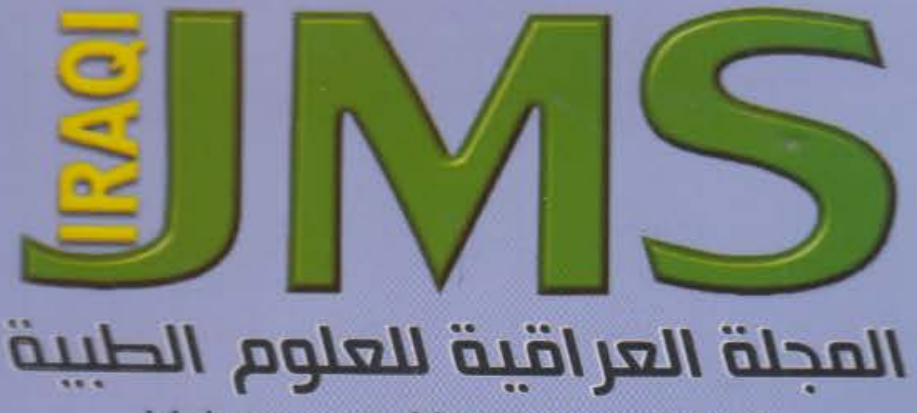

Volume 15, Number 1, 2017 January-March

P. ISSN 1681-6579

E- ISSN 2224-4719

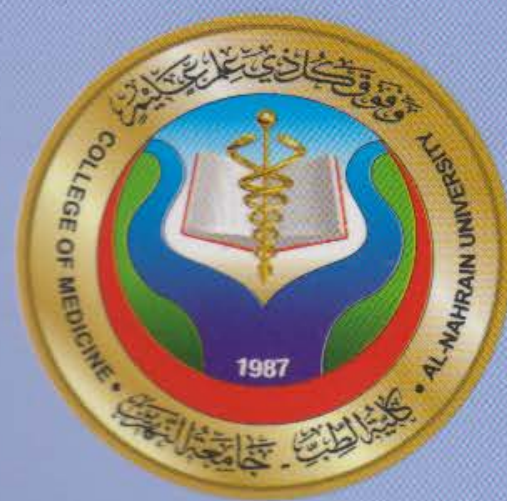

\section{Contents}

\section{Editorial}

1. CERVICAL CANCER SCREENING IN DEVELOPING COUNTRIES

Ban J. Qasim

ARTICLES

2.TECHNICAL ERRORS IN USING INHALERS AMONG PATIENTS WITH ASTHMA OR COPD IN IRAQ

Hasanain G. Khudhair, Haidar A.N. Abood, Ali M. Al-Mousawi, Sajjad J. Al-Hatab, Ibrahim A. Al-Obaidi, Ali A.K. Abutiheen

3.IMMUNOHISTOCHEMICAL MALONDIALDEHYDE ANTIBODIES CHANGES OF THE ADULT MICE TESTES AFFECTED BY PRENATAL MANGANESE CHLORIDE EXPOSURE

Hayder J. Mubarak, Nameer F. Gaeab, Hussein A. Jarullah

4.DUCTECTASIA OF THE BREAST; AN EXPERIENCE WITH HADFIELD OPERATION (RADICAL EXCISION OF THE SUBAREOLAR DUCT SYSTEM)

Taqi S. Atiyah

5. COMPARISON OF TWO VIRUS CONCENTRATION METHODS FOR ENTERIC VIRUSES DETECTION IN MOROCCAN WASTEWATER AND TREATED EFFLUENT

Hasna A. Amdiouni, Leena Maunula, Arwa M. Al-Shuwaikh, Jalal Nourlil ...................

6.ASSESSMENT OF SERUM ZINC LEVEL IN PATIENTS WITH POLYCYSTIC OVARY SYNDROME

lqbal G. Farhood

7.LOCALIZATION OF TIGHT JUNCTIONS BETWEEN TANYCYTE-LIKE CELLS OF THE SULCUS MEDIANUS ORGANUM IN RAT BRAIN

Fadhil H. Ahmed, Muthanna A. Al-Kaabi, Sarmad E. Al-Marsoummi, Hayder A. AlAubaidy

8.ISOLATION, IDENTIFICATION AND DETERMINATION OF ANTIFUNGAL SENSITIVITY OF FUNGI ISOLATED FROM A SAMPLE OF PATIENTS WITH RHINOSINUSITIS IN BAGHDAD CITY

Israa A. Ali

9.KNOWLEDGE, ATTITUDE AND PRACTICE OF MOTHERS TOWARDS TYPHOID FEVER DISEASE

Taha N. Sadeq, Rasha K. Jabar

10.THE ROLE OF ESTROGEN AND PROGESTERONE ON VAGINAL CYTOLOGY DURING PROLIFERATIVE AND SECRETARY PHASES OF MENSTRUAL CYCLE IN WOMEN WITH POLYCYSTIC OVARIAN SYNDROME

Huda R. Kareem, Haider A. Jaafer, Zainab H. Hashim

11.THE SEROPOSITIVITY OF PARVOVIRUS B19 AMONG KIDNEY TRANSPLANT RECIPIENTS

Zainab A. Hlail, Ahmed S. Abdulamir, Ali J.H. Al-Saedi

12. FREQUENCY OF HUMAN CYTOMEGALOVIRUS AND HUMAN HERPESVIRUS-1 ANTIGENS IN PRODUCT OF CONCEPTUS TISSUES OF PREGNANT WOMEN WITH SPONTANEOUS ABORTION

Areej A. Hussein, Sawsan T. Salman, Basim M. Khashman

13.SUCCESSFUL TRIAL OF LABOR AFTER PRIMARY AND REPEATED CESAREAN SECTIONS: A CASE REPORT

Yosra T. Jarjees 